\title{
Artwork as Practical Social Action: An Ethnomethodological Study and the New Sociology of Art
}

\author{
Maximilon Baddeley
}

A thesis

submitted to the Victoria University of Wellington in fulfilment of the requirements for the degree of Doctor of Philosophy 


\begin{abstract}
Few studies in the sociology of art observe artists in their work. Of the few, little investigate the phenomenon of social order, and when they do, they research artists at a distance. Hence, there is room to contribute studies and descriptions of the observable actions artists conduct when they find themselves in the midst of doing their work; that work is argued here as a sociological accomplishment, topic of interest, and evidence of the actual and not imagined practical management of social reality. An emergent literature, the new Sociology of Art, has started to pay close attention toward observing artists' situated and sequential actions as they occur naturally and in real time. Yet neglected in these often overly conceptual studies are detailed descriptions of artists finding ad hoc solutions to their practical workplace problems. In my motivation to observe artists in their work, I ask how artworks are organised in and as practical social action. With video camera in hand and in aid by the sociological attitudes of ethnomethodology and its research praxis, I aim to explicate social phenomena of order, specifically observable within sites consisting of a street corner, an artist's studio, an urban café, and river terrain. This thesis presents data first collected and then taken from the large video data corpus to form four single-cases. I recognise in this thesis the effort evident within ethnomethodology's recent scholarship to acknowledge Aron Gurwitsch's gestalt concept functional significance as partially influencing Harold Garfinkel's study of endogenous order. I saw functional significance as an opportunity to explore, rather experimentally, how one artistic action relates to another, and how that interdependence was locally managed by the artists themselves during their artistic processes. This thesis contributes written descriptions of artistic action as social action, findings from which the new Sociology of Art may benefit.
\end{abstract}




\section{Acknowledgements}

I would like to thank the participants of this study. Entering into the close proximity of ordinary working settings is unusual at best. I consider having someone filming you during that ordinary work is invasive under normal circumstances: Thank you for offering your time, commitment, and emotional energy to this research. These studies would be nothing without your generous involvement within them and compassion toward unusual scholarly pursuits such as this one.

I have made the more personal acknowledgements in private. 


\section{Prologue}

My first encounter with ethnomethodology resulted in excitement, challenge, then confusion. Garfinkel's writings managed to make sense of the social world whilst not making much sense in relation to sociology. Garfinkel's advice was to read his writings alternatively, to treat ethnomethodology more like recommendations - instructions to go out into everyday life and attempt to see how the social world is assembled, in actual settings, by actual people, as they may take for granted their publicly accountable actions as a feature of that order.

In studying how ordinary people organise their common daily interactions with themselves, other people, and the dynamic world around them, I realised through Garfinkel's work that social life is more contingent and ad hoc than what I had commonly appreciated, discussed and taken as a serious scholarly topic. The success of a person's reifying methods, ones used to structure and adapt local contingencies into orderly scenes, formal rules, structures, definitions, explanations, and the rest, is part of what makes the ethnomethodological domain so difficult to study. ${ }^{1}$

I must make special note in this prologue of the phrase "the substitution of objective for indexical expressions" (see Garfinkel, 1967), as this is what I found was what I was looking for within classic ethnomethodology. This so-called substitution problem really troubles truth theories of correspondence: It seems as though determining a social fact is quite a troublesome operation for a sociologist, or in fact any other person to deal with.

Here is the finer point to the thesis: Later ethnomethodology suggests that the study of endogenous orders make up a large part of how social orders are organised where indexical expressions were perhaps best thought of as constitutive parts of a gestalt

\footnotetext{
${ }^{1}$ These properties are also features that are in the environments of doing the activity of sociological thinking, like organising scribbles, interpretations of others ideas, ordering sentences, relating data to theory and the rest of ordinary office work and its many daily practices that make it distinctively what it is: the organisation of practical action.
} 
contexture. This thesis thus focuses on the interconnected and relational properties between actions that people ordinarily perform on any occasion, in any setting, within everyday life.

Before laying down my personal acknowledgements, I want to express my core motivations for conducting the following study about artistic practice. In reality, the subject matter could have been anything. Ethnomethodological writings cover a vast range of topics, from yachting to legal proceedings, from changing a car tyre to friendly military fire. An exhaustive list of topics would cover several more pages. People in society do things with their bodies and voices to make themselves seen and heard. What interests the ethnomethodologist, and became an interest for me, is not just what people do, but how they artfully do the things they do.

Coming into this dissertation I had read all the ethnomethodology I could get my hands on. Yet there was more to be discovered, not in the texts, but in doing the actual empirical work itself.

The ethnomethods that surround real time artistic practice in ethnomethodology had yet to be discussed in any strong way which surprised me because of the way that artistic practice itself is highly creative, ad hoc, ambiguous, constitutive, and generally appreciative of unorthodoxy, and unconventional approaches to normalised rules and systems, et cetera. Further, the body plays such a central role in artistic practice. For example, the human eye as it visualises the world around it has been somewhat modelled in theories and artistic methods of drawing such as linear perspective and light logics. How are these models used in practice to organise a creative session was the first query to be asked. This, alongside the motivation to understand more of how people organise their living conduct in ordinary ways, was enough to adapt my earlier proposal, and move towards a ethnographic study instead, one treating artistic practice as a socially organised practice. Eager to learn more of Garfinkel's own treatment of the correspondence theory and the misreading of key theoretical figures, I 
wrote the following thesis as an account of my growth as a scholar attempting to live as a student of social life. I tried my best to push toward the praxeological attitudes found within ethnomethodological research. The following is an example of that attempt to get as close as possible to the action. 


\section{Table of Contents}

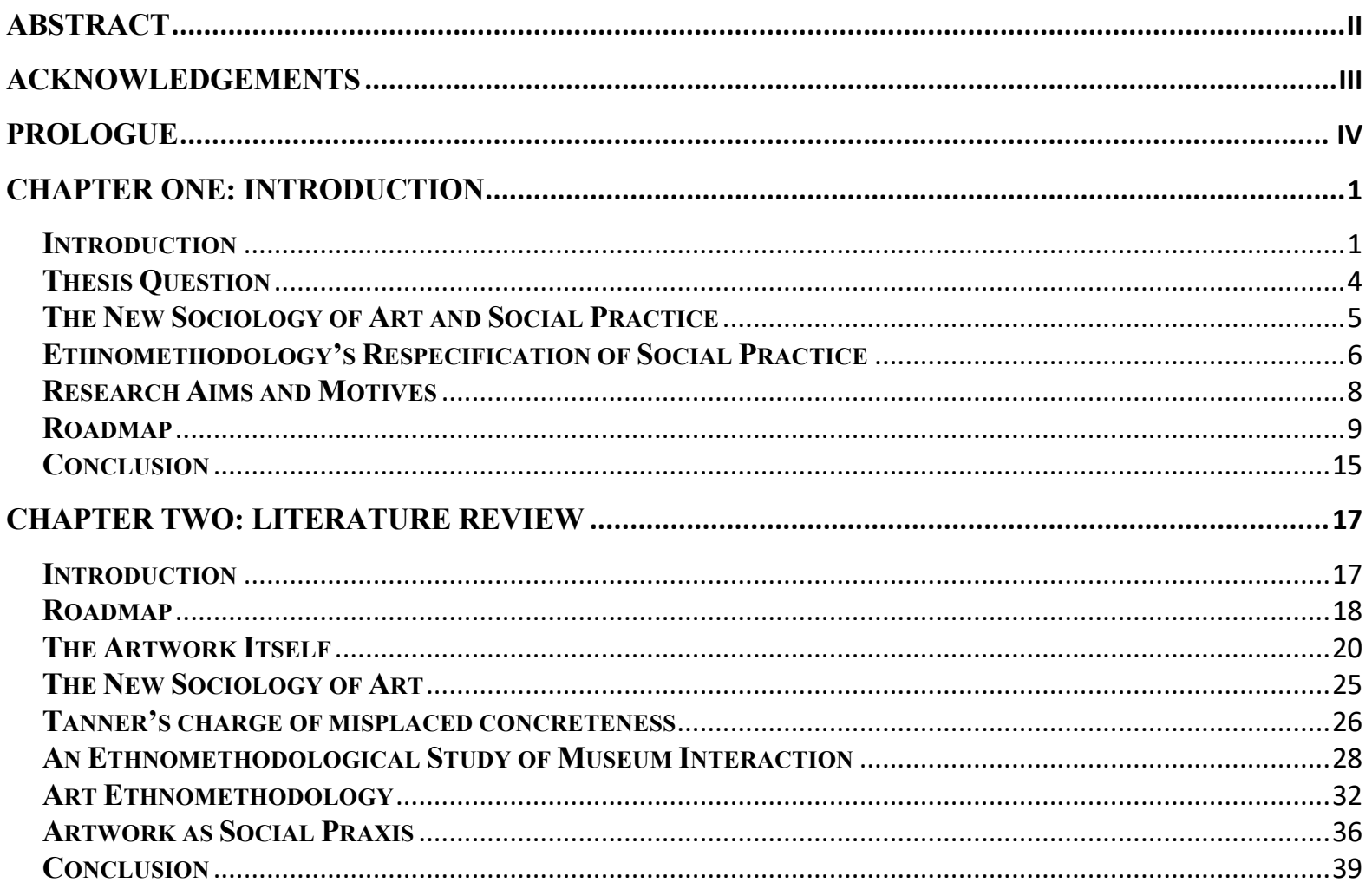

CHAPTER THREE: A METHODOLOGICAL ATTITUDE AND ITS THEORETICAL

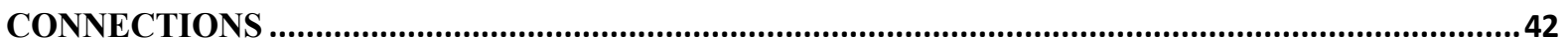

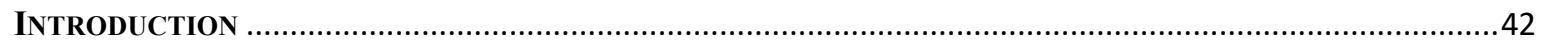

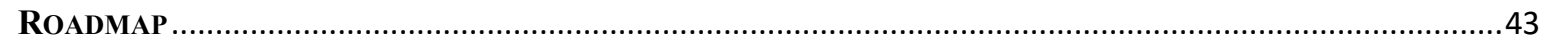

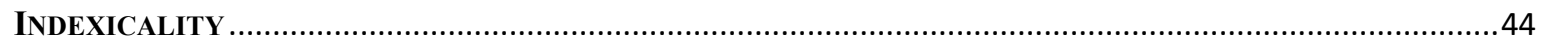

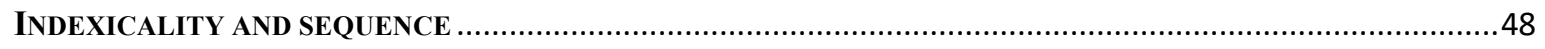

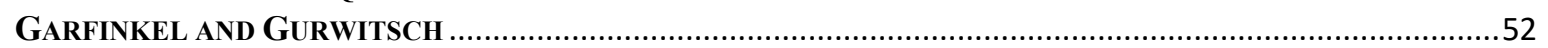

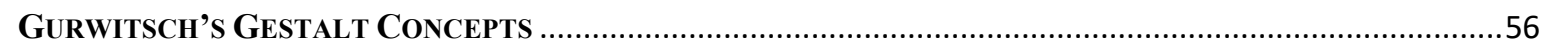

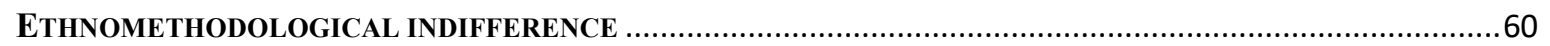

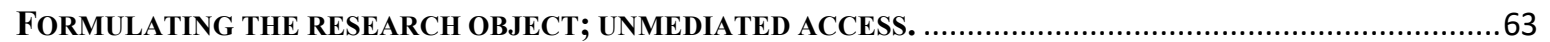

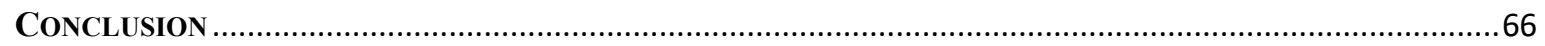

CHAPTER FOUR: NAVIGATING A LANDSCAPE IN SEARCH OF A PAINTING SUBJECT ...........70

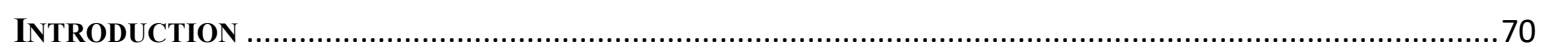

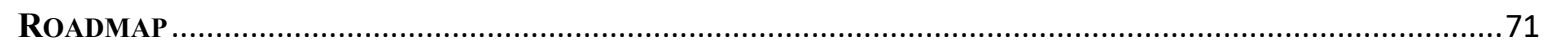

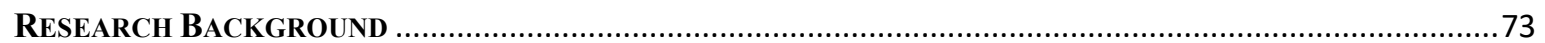

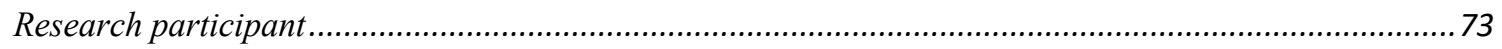

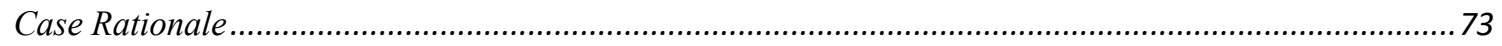

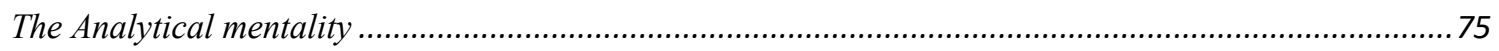

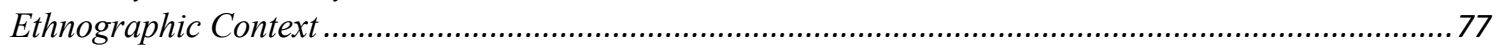

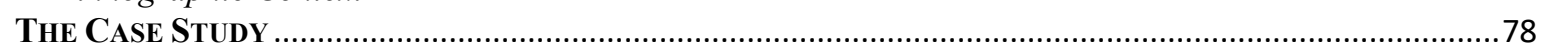

Narrowing down Nature into a painting subject ................................................................................. 78

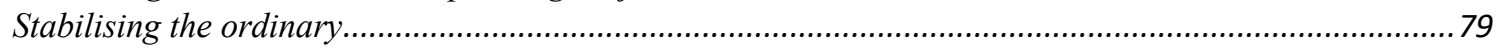

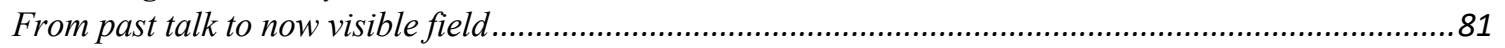

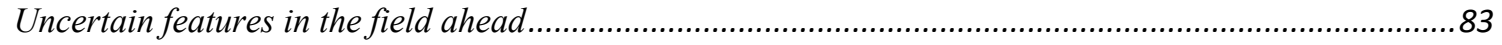

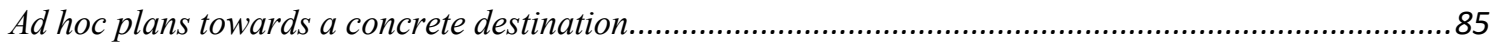

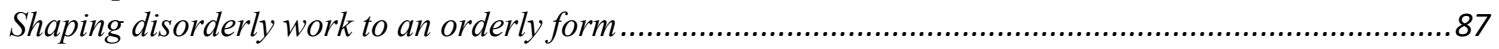

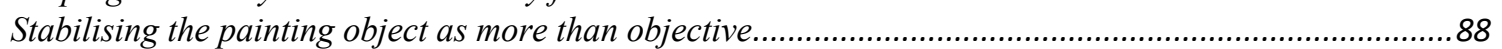

Finding out what we were doing all along.........................................................................................90

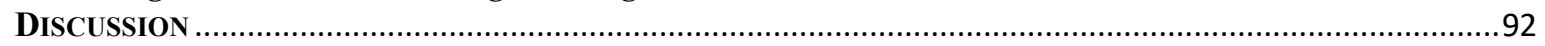


CHAPTER FIVE: EXCAVATING FOR LIGHT BEHIND CLOSED STUDIO DOORS. EXPLORING THE PRACTICAL ACTION OF PAINTING THROUGH A GURWITSCHIAN FRAME ......................95

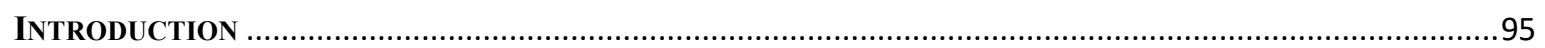

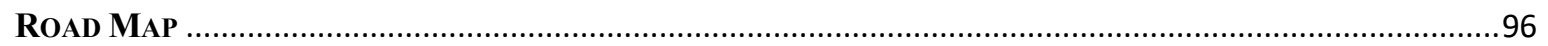

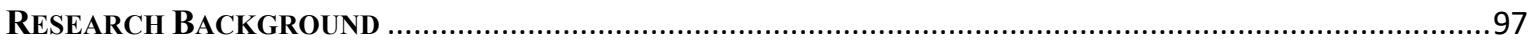

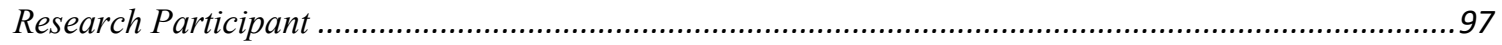

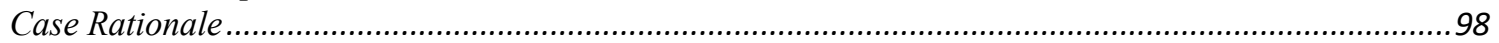

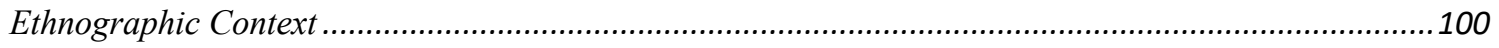

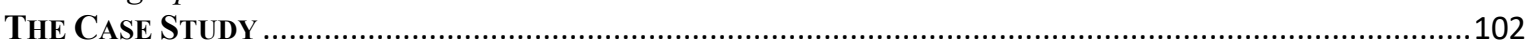

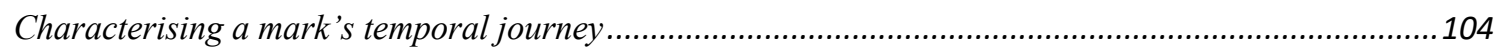

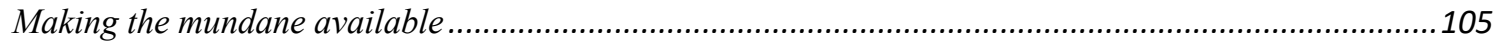

Ad hoc work is a significant part of the final artwork..........................................................................107

Layering marks by accidental means .........................................................................................110

Collecting another type of brush................................................................................................114

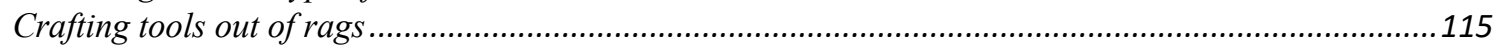

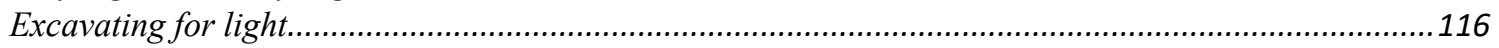

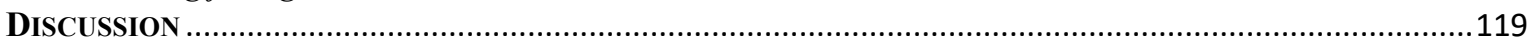

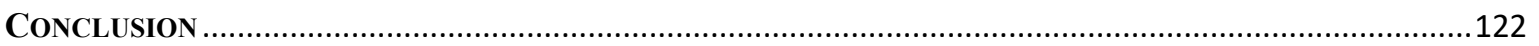

CHAPTER SIX: AD HOCCING AN APPROXIMATION. THE LOCAL WORK OF DOING URBAN

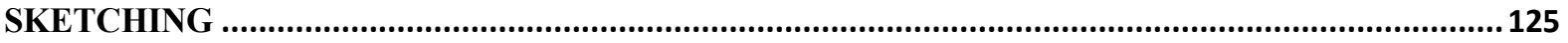

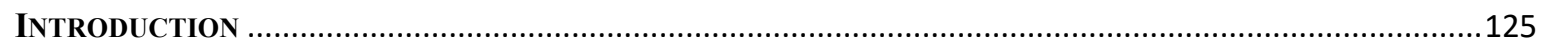

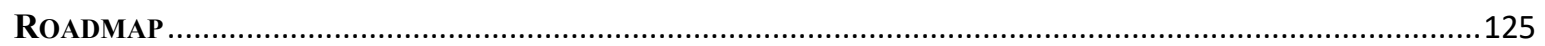

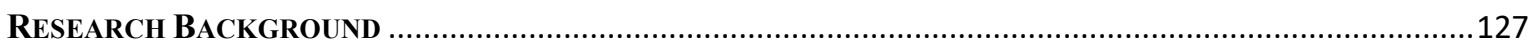

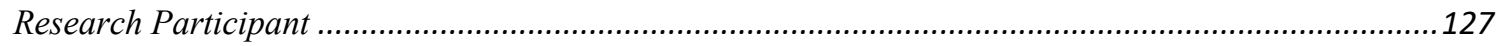

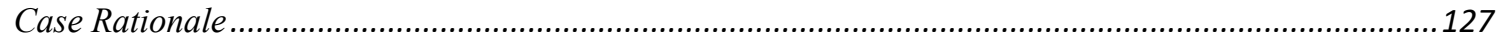

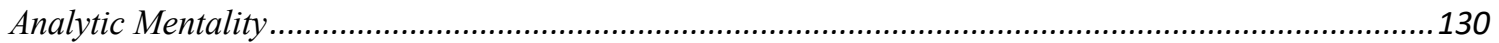

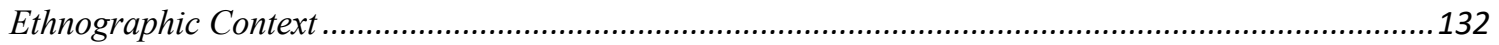

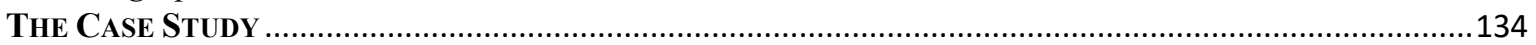

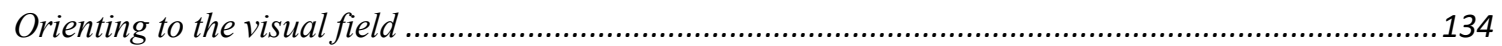

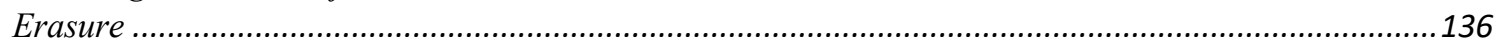

Finding a candidate unit of vertical measurement ………................................................................137

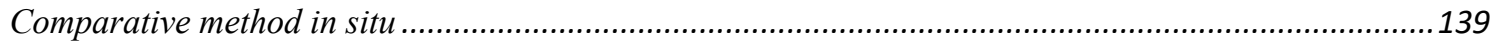

Translating the modified landscape to the domain of rendering field....................................................141

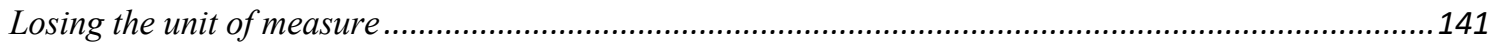

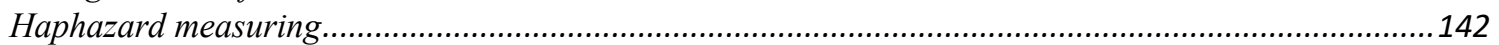

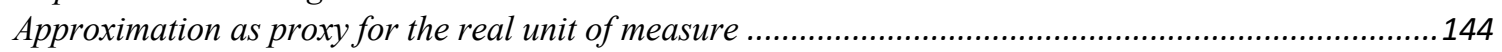

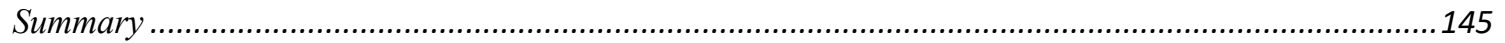

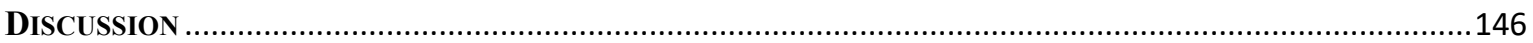

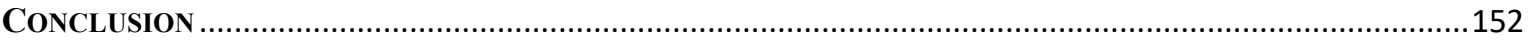

CHAPTER SEVEN: ARTWORK-A TALKING GROUP'S PRACTICAL SITUATED

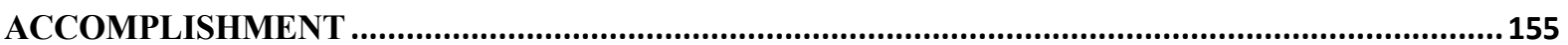

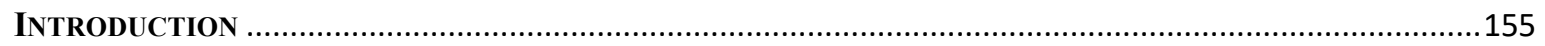

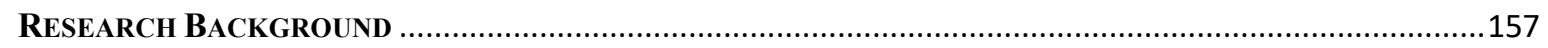

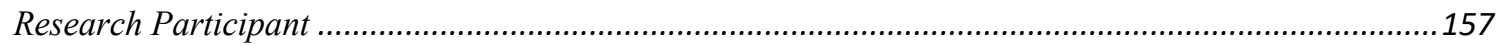

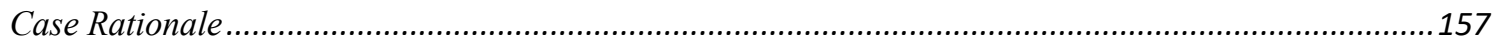

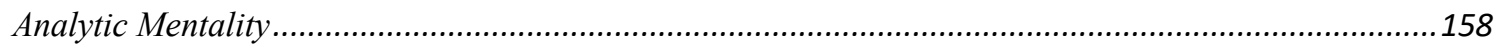

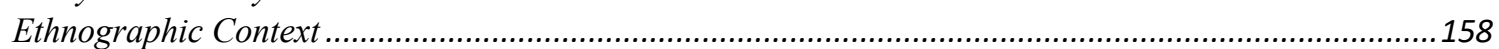

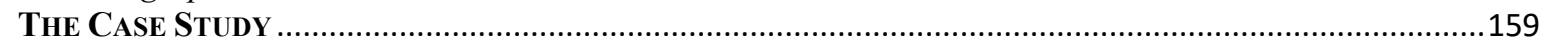

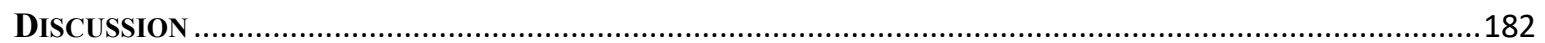

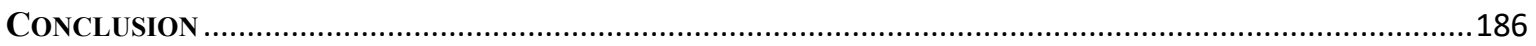

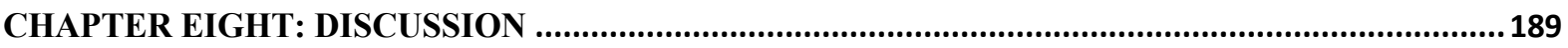

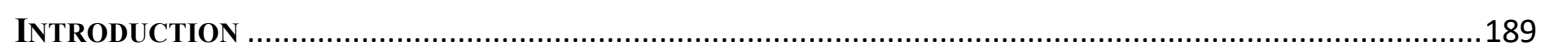




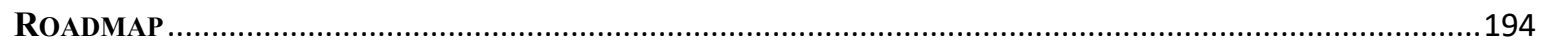

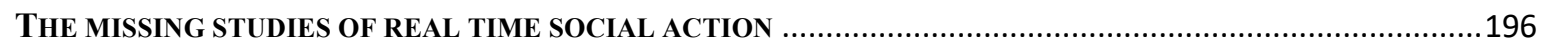

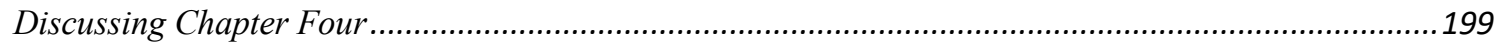

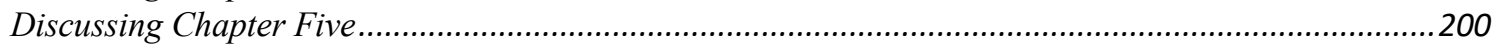

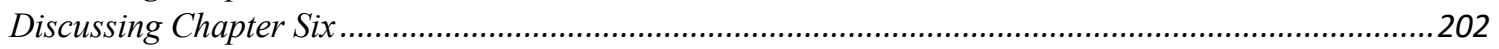

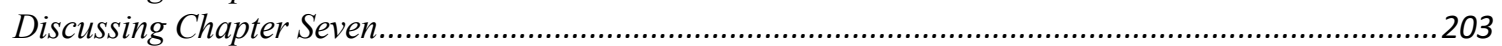

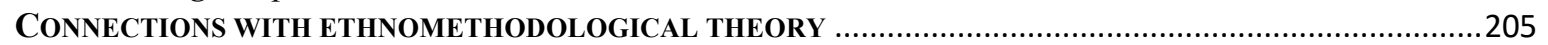

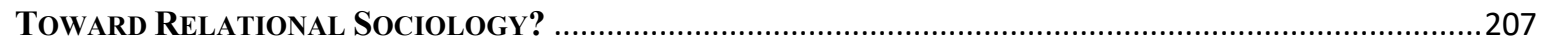

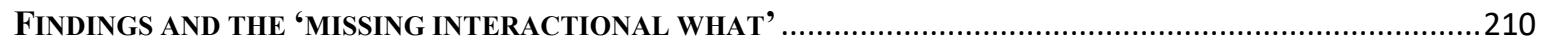

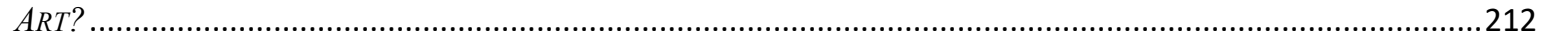

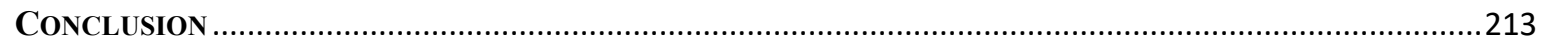

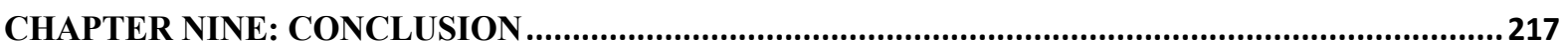

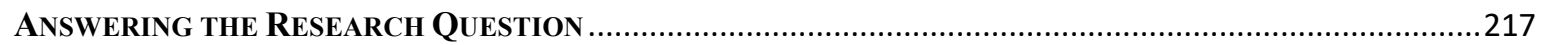

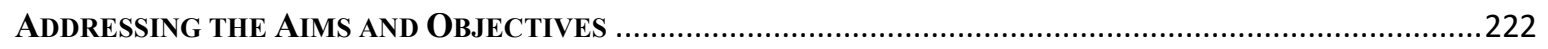

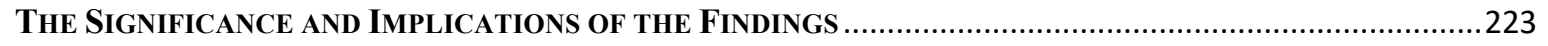

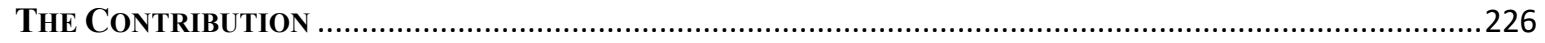

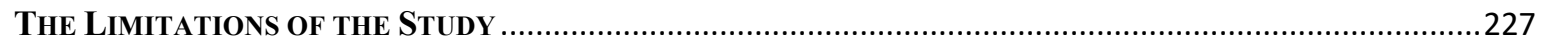

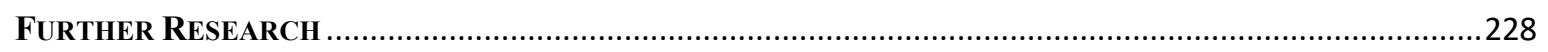

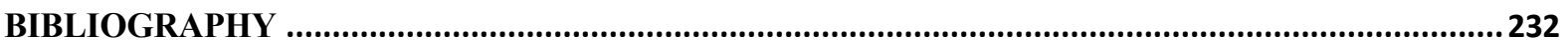

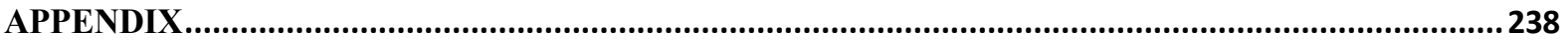

General Ethics: Signed Consent, ANONYMisation, AND DATA MANAGEMENT .....................................238

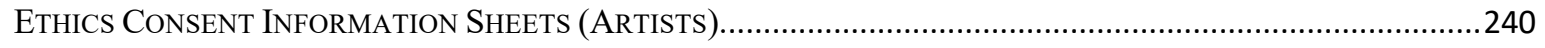

ETHICS CONSENT INFORMATION SHEETS (SKETCHERS). .............................................................242 



\section{Chapter One: Introduction}

While in one sense you might want to say that the signed object is a start on producing a general mode, ethnomethodology wants you to go the other way to the event's accountability at source (Garfinkel, 2007, p. 19).

\section{Introduction}

This dissertation presents four ethnographic case studies; qualitative research designed to record and interpret the moment-by-moment interactions of artists during their creative episodes at work. I rely on these video recordings of artistic practice to describe how formations of actions are organised during the creation of artwork. My aims in conducting this study is to understand, specifically, how the relations between actions constitute social order. Many of the research techniques and ways of presenting and writing about the collected data stem from this objective to understand social order. I ask how a person's practical actions contribute to how an artwork may gain (and retain) meaning in those very actions.

Ethnomethodology, a specialised sub field within sociology designed to extensively study this subject matter, suggests that students of social life should "focus upon how, in a given setting, structures of action are produced and managed" (Hester \& Francis, 2007, p. 4). Following this suggestion, the following empirical case studies focus on artists in their natural settings: a painter's studio, a natural landscape, an urban street, and an urban café. These studies describe how people as artists produce and manage their activities: a painter's brush movements, a plein air artist's subject selection, an urban sketcher's measuring, and a group of artists orientating themselves towards the evaluation of their drawings during an ordinary café conversation. All four empirical chapters present video data as visual figures, 
together with verbal transcriptions, to showcase how people organise their real-time, situated, practical actions into context-renewing social resources.

It may be of interest to know early that I enrolled in two local art schools and learned basic and introductory artistic principles, techniques, and ways of seeing like an artist in preparation for these four ethnographies. This artistic pedagogy involved still life drawing, sketching, painting; life drawing and painting of naked human bodies; urban sketching and perspective straightedge drawing. I undertook these lessons to gain a beginner's understanding of how artistic practice is approached as artistic practice. Although none of the many autoethnographic notes written during these experiences of skill acquisition feature here in this dissertation, it may be of additional importance to recognise how I took seriously the ethnomethodological idea of gaining a member's competence (see Garfinkel \& Wieder, 1992, p. 182). I ultimately abandoned pursuing it further not only because of its demand, but due to the skill of the artists studied, and ultimately, the question of what is relevant research for the current sociology of art literature ${ }^{2}$. In any case, the following study of artistic practice does not examine artistic practice from the position of an art historian, nor art practitioner, but rather from a sociologist working with ethnomethodological approaches of seeing professional practices as socially founded.

For sociology it is not a typical concern to research the technical practice of how an abstract artist uses brushes to produce a painting nor how an urban sketcher measures objects in the visual field. I offer no dominant definition of sociology—nor art—within this dissertation; however, I do claim underwritten inspiration from both the idea of co-operative sociality of the type featured in Goffman's interaction order (Goffman, 1983; see Goodwin \&

\footnotetext{
${ }^{2}$ In any case these materials may be used in subsequent papers outside of the confines and scope of the current dissertation: how the relations between artists and their materials co-constitute an artwork in interactive social settings from a first person perspective, similarly building on the foundational work of Sudnow's "Ways of the Hand" (1978) to explicate being in the world to produce art.
} 
Cekaite, 2018, p. 33-53), and specifically, of ethnomethodological respecification of social action and order. Human action is considered herein as social action. Consequently, although sociality is richly observable in intersubjective settings, for ethnomethodology, sociality is found in all accountable activities, including non-intersubjective settings. This is due to the indexicality of actions, and the fact that people belong as members of a common language community regardless of whether they are alone or together.

Relevantly, although I intend to study, and therefore produce descriptions of an artist's technical work to focus on endogenous social order, a trouble may be pre-empted. The new sociology of art did not pose any particular focus on artistic technical praxis. Furthermore, and consequently, studies of artistic practices as practical social action may not directly contribute to art sociology literatures due to one main reason: ethnomethodology is incommensurable with, and alternate to, formal sociology (Garfinkel, 1991; 2002). In many ways, for ethnomethodological studies to find a home in a foreign literature, respecification may need to receive paradigmatic acceptance in such hospitable sociologies if it is to avoid an inherent contradiction - studies can be done but only if agreement is made on what exactly is meant by a member's constitutive actions stabilising and producing objective facts.

Situating myself in the living conduct of what it may really be like to put on hiking boots and traverse river terrain with art equipment, interviewing an artist at work in his studio and then being sent a self-made video of him working in solitude, drawing an urban object, and congregating with an urban sketching group to discuss recently created images, established the background context for the research within the following dissertation. These single episodes further require the recognition that comparing one setting with another is fruitless under the deliberate approaches taken herein due to the single-act nature of meaning I am attempting to explore. Regardless of whether an artist is working in solitude behind closed studio doors, or whether artists are collectively working in groups, people act. These 
actions are therefore observable and reportable, and provide domains for sociological inquiry: to see more of the way living persons organise their environments to get on with their current moments. The empirical studies within this dissertation aim to contribute to the new sociology of art by turning the topic of social order into an explicit object of empirical inquiry; one pursued in this dissertation under the explicit influence of ethnomethodological theory and its approaches towards the study of everyday social life.

\section{Thesis Question}

How are artworks organised in and as practical social action?

The following chapter first provides a brief overview of the dissertation's key sections, then maps the structure of the entire document. In the sections to follow, the above thesis question is situated within the sociology of art literature. The methodological attitude used to answer this question is drawn from the notion of ethnomethodological respecification, a way to think alternatively about how social order is constituted. The aims and motives of using this attitude (to create empirical studies for the sociology of art) is then discussed. One main motivation in choosing ethnomethodology as the primary analytical mentality was to identify, interpret, experiment with, and expand upon the idea of one distinct concept: Functional Significance. Organising a thesis question, situating it within the literature, and elaborating on a methodological attitude to engage with an empirical study required ethics approval, data collection, and its management; topics that are established in this introduction and then referred to throughout the empirical chapters. Lastly, whether all human action is social, and whether ethnomethodological respecification retains the social in sites of human praxis remains an open question to be answered within the following dissertation. 


\section{The New Sociology of Art and Social Practice}

Placing the thesis question within a current and lively literature is possible, as asking how artworks are made intelligible and formed in and as practical social actions during social interaction is suitable to at least one program of research in art sociology: The New Sociology of Art (De La Fuente, 2007; 2011). Here, scholars are interested in how artworks are made via social practices, where they know about social institutions and structures, but little of the empirical studies of the artwork itself (see Becker et al, 2006) — or, relatedly, they ask where are studies of the artful social practices of art in action (see Acord \& DeNora, 2008). I make the argument that ethnomethodological studies of everyday life are compatible with that of the new sociology of art's similar research direction toward understanding how artworks are constituted in local and real time artful social action (see DeNora, 2014; see also the full literature review presented in Chapter 2). Moreover, Tanner (2004) argues the work of Baxandall is foundational to modern art sociology. I assess here how ethnomethodology's approach differs from Tanner's argument, consequently rejecting a need for any foundational theory to deduce findings for art sociology.

Art sociologists use ethnomethodological ideas (see Hennion, 2004; Rubio, 2012), but little of this empirical work gets close to the topic of the mundane detail of the local orderliness of practical action and reasoning that ethnomethodologists professionally research (Livingston, 1987). These art studies focus on practices (Fox, 2013; Gerber \& Klett, 2014; Zembylas, 2014), but not on practices as mundane social orders. More could thus be gained by appropriating ethnomethodological thinking into art studies (see Armour, 2000; Kreplak, $2018 \mathrm{~b}$ for such examples). I realised that describing how artworks are formed in and as constitutive social practice was something which De La Fuente (2019) and new art scholarship has left unaddressed at the turn of the current decade. I thus aim to contribute to 
that discussion several descriptive studies of the work people do to organise the mundane social orders that surround an artworks production.

\section{Ethnomethodology's Respecification of Social Practice}

One aim of this dissertation is to address how, by analytically describing the formation of artworks in and as constitutive social practices, mundane orders are discoverable by using the technique of 'ethnomethodological respecification'. Button states:

Ethnomethodology is an alternate sociology in terms of its respecification of order 'inand-as-of-the-workings-of-ordinary-society'...An ethnomethodological respecification is, consequently, a respecification of action and order-in-and-as-ofthe-workings-of-ordinary-society. In respecifying these matters, ethnomethodology respecifies action and order as specified in the human sciences, and in so doing has constituted an alternate sociology (p. 8).

This dissertation experiments with, and explicates how, artists do a range of activities in single episodes of their ordinary practices as organised social accomplishments rather than approach them from an exogenous position to then be searched for fitting to a priori models.

I elaborate on the idea that all human action is social action; that studying social action, including language and technical practices, reveals the highly contextual nature of how people act in situ. Under this view, there is no prior meaning nor intelligibility external to actions, and to study endogenous order phenomena requires this assumption of language to hold: All action is indexical (Chapter 3).

Focusing on how an artist paints behind closed studio doors, of how tools were used, colours mixed, and strokes were made, may raise suspicious questions of consequence, or importance as scholarly discoveries into constitutive social order. In preview of one of the 
chapters to come (Chapter 5), I noticed the way an artist, for example, was unable to add a large brush into a small pot of paint and subsequently produced a momentary pause whereby his solution of retrieving a smaller brush led to the obvious consequence of painting differently that he had intended. These small, microscopic practical features of studio practice are prevalent in the site-specific context of a practitioner's work for the day. Frequently, however, these mundane issues hold significant consequences for how the artwork was produced, as for example, due to haphazard and ad hoc action, whether involuntary or not, the artist had made available the possibility to use two brushes at the same time and decided to do so during a later period of that day's work, impacting the final result of the painting.

An artist having trouble with finding the right size brush is not a trivial topic of discussion. When member's act in the world, they organise their action into meaningful local structures which future actions relate to. The relating of actions to one another is often not something we as persons stop and think about. But when we do it is hard to escape the fact that when we act, we act in accordance to our tasks at hand. How the artist managed his actions with his equipment at and in hand is the concern of this chapter. It offers an idiosyncratic view of societal action yet it closely scrutinizes the naturally occurring conduct that an artist performed behind closed studio doors.

Many of his acts are unplanned, discovered, and taken for granted, and such things were difficult to recognise unless the data was carefully considered during the descriptive analytical process.

Video cameras help: "Video cameras are to the ethnomethodologist as microscopes are to the biologist" (Liberman, 2013, p. 241). By watching and rewatching video data, an artist's observable practical actions are seen to organise painting activity in and through the accountable actions and their local consequences for further action. Paying attention to the 
ways persons work to produce the orderliness of their settings is entirely sociological; for what else do people do but first act in the world? $?^{3}$

\section{Research Aims and Motives}

Analysing practical action in such a careful manner is done not without issues. One key research motive is therefore a methodological one. I specifically aim to progress one of the foundational theoretical insights given by the writings of gestalt phenomenologist, Aron Gurwitsch, received by Harold Garfinkel during his doctoral studies (Chapter 3). In earlier forms of ethnomethodological development, Gurwitsch's ideas had been relatively underused compared to the field's later writings in the so-called ethnomethodological studies of work (Garfinkel, 2007; see also Eisenmann \& Lynch, forthcoming; Garfinkel, 2012).

Gestalt concepts may help adapt the analytical attitude of all ethnomethodological, including conversation analytical approaches, by way of engaging with a renovation of methods (see Watson, 2008; 2016a; 2016b). This omission of gestalt concepts from earlier ethnomethodological writings (Garfinkel, 1967) thus further fuels the narrative of the dissertation project at large: Each empirical case study and its ethnographic design is to revolve around the exclusive exploration of gestalt contextures, functional significance, and gestalt coherence (see Gurwitsch, 1964, p., 367; Fele, 2008). ${ }^{4}$ I aim to learn at various key stages throughout the doctoral journey of how to approach the theoretical attitude of Gurwitsch's ideas as they apply to real-world sites of detail. Garfinkel took Gurwitsch from perceptual chimera to everyday life (see Maynard, 2014), and this notion is prevalent in the way the following research may unfold.

\footnotetext{
${ }^{3}$ Ethnomethodology connects these studies of technical organisation with hybrid studies of work (see Lynch, 2012; 2015).

${ }^{4}$ I revisit these ideas in full within Chapter 3, 'Key Concepts'.
} 
Ethnomethodological thinking may project an inherent anxiety about what constitutes social order $^{5}$ for mainstream sociology. Studies of practical action and reasoning are in fact studies of the social (because for them, all human action is language bound and embodied and part of a language community, and thus social) and therefore I am motivated to further investigate how these practical properties of social action presumably, and in part, may lead one to descriptively assemble what is social about an artist working in solitude. As Button's above quote envisioned, utilising ethnomethodological respecifications of social order may provide an alternate newfound domain of constitutive social order as member's practical accomplishments, an alternate human science. Worked up descriptions of such phenomenon may furnish the new sociology of art with empirical materials for fruitful discussion regarding how artworks gain their social intelligibility. The topics of investigation are the mundane methods people use to naturally organise their actions into accountable forms for themselves, or for one another. It is reasonable to ask what these ethnomethods would look like when artworks are being discussed and or created. I stress the reluctance to discuss these theories in favour of getting to the heart of the empirical details; however, without such theoretical and conceptual framings, the dissertation as qualification for evidence of sociological contribution may appear to some as overtly descriptive in nature. From an ethnomethodological point of view there is great value in such detailed description. The directions I take in this thesis are done so to advance the research of understanding of the phenomenon of practical social order, and not the theoretical attitudes that may guide it toward description.

\section{Roadmap}

\footnotetext{
${ }^{5}$ Garfinkel's later writings, especially his work on "hybrid studies" (Garfinkel, 2007; see also Garfinkel \& Liberman, 2007) represent this.
} 
The dissertation produces eight chapters. The second chapter, the literature review, is comprised of five main sections. First it assesses Art from Start to Finish (Becker, et al., 2006). Second, it recognises that Acord and DeNora argued independently of Becker et al. (2006) that the orthodoxies of art sociology did not take seriously how artworks gain, or afford, their meanings through situated social actions and their surrounding social activities. Third, however, it describes how Jeremy Tanner resists these sensibilities (Tanner, 2010) and argues in favour of establishing Baxandall's (1974) art analyses as the foundational approach for new art scholarship. Fourth, it argues against Tanner. Ethnomethodology's unique perspective on a priori and a posteriori epistemics seeks to determine how meaning is made by observing how persons interact with the social world. Fifth, by reviewing the policy of the missing interactional what (Garfinkel, 2002), I argue Yaël Kreplak’s emergent work on praxeological objects is connected to art sociology (Kreplak, 2015; 2017; 2018a; 2018b), and therefore by grasping and orientating to the question of how are artworks formed by artful social practices (DeNora, 2014; Kreplak, 2018b), the following dissertation aims to advance the intellectual influence of an ethnomethodological attitude in art sociology.

The third chapter, the key concepts, is comprised of five main sections. It introduces the concept of indexicality, a key concept and theoretical rephrasing from within ethnomethodological literature. Due to indexicality's ability to articulate a version of social order as being a highly contextual one, it was necessary to elaborate the sequential properties of indexical expressions. No action exists in isolation, and the sequential properties of indexical expressions further elaborate on how ethnomethodologists understand social intelligibility as a real-time, practical event and accomplishment. The chapter then introduces Garfinkel's intellectual relationship with Gurwitsch, including the importance for ethnomethodologists to return to the work of Aron Gurwitsch as an intellectual rival. In which subsequently, Gurwitsch's theory of functional significance and gestalt contextures is 
reviewed. This concept is a central theme that runs throughout the entirety of this dissertation's empirical case studies as one of its unique features. Lastly, connecting with the concept of ethnomethodological indifference, the analyst ought to orient towards how participants act in real-time situated activity, rather than seek out a proof for a sociological definition, model, theory, or representation. The study is ordinarily describing what and how people do things in the world.

The chapters that follow are empirical case studies. The fourth chapter, which describes the navigational work artists may do when plein air painting, is structured in five main sections. It connects with the new sociology of art's discussion on the contextually indeterminate production of meaningful art objects and then it introduces the research site, the research participants, the ethics concerns, the data and methods, and justifies how the case was selected. Third, Garfinkel's misreading of Gurwitsch's gestalt contexture comprises the analytical mentality of the chapter's analysis where Rod Watson's recent work and articulation of a "kaleidoscopic metaphor" (see Watson, 2008, p. 232) is drawn as the primary mentality for describing practical actions witnessable on the video tape. Fourth, the verbal and graphic transcripts are presented. They display records of the organisational talk and gesture between two artists and a social researcher. These details were extracted from video-recorded data that was obtained during a one-day field trip. The analytical focus orients toward describing how a painting subject was selected and formed in the sequential embodied conduct. This section makes up the main empirical focus of the chapter. Consequently, this case study focused on how participants (an interacting party of three) worked at determining what was to become constitutively relevant to their task-at-hand: How a natural landscape was organised into a subject to be painted though interconnected social actions. 
The next empirical case study of an abstract studio artist painting behind closed studio doors, Chapter 5, is structured in five main sections. It first defines gestalt contextures, justifying why and when the research was conducted, identifies the research participant, and lastly, presents the analytical mentality. The artist is then seen grounding, characterising a mark's temporal journey, making the mundane relevant to his painting action, working ad hoc, accidentally layering marks, getting lost in a process of discovery related to the artwork, collecting brushes, crafting rags, excavating for light, and lastly the drawing; all of which comprised the creation of an artwork. The results of the case analysis are then discussed.

Chapter 6, an artist measuring the dimensions of a building with his pencil during an urban sketching session, is structured by five main sections. Aided by Garfinkel's analytic recommendations, the raw video data was translated into presentable transcripts where the once lived order was glossed at. These visual transcripts present the sequential activity of the comparative measuring method in action; a technical method an artist may use to translate accurate proportions of the visual field onto the rendering fields such as paper or canvas. By describing how an artist organised his conduct to obtain a unit of measure from the visual field, and then abandon that unit by substituting it for a new unit of measure taken from the sketching pad, the case study gains its focus. Between the time of these two measurements, a series of contingent, mundane, and messy actions occurred. This chapter draws upon the ethnomethodological attitude of respecification, raising a question of how the analysis of data may be treated as a corrigible claim. Subsequently, the sociology of art ought to consider adopting the attitude to aid researchers in noticing how artful social practices often conceal themselves as embodied living effacements (see Livingston, 1987).

Chapter 7, a group of artists talking about their recently completed drawings as they use their sketching books as prompts, is structured by five main sections. The case study used 
materials gathered during the urban sketching ethnography (Chapter 6). Wellington Rose Garden Café is where the action took place, with participants meeting there to discuss their recently completed drawings. I had arrived in the café that day, having just spent two hours sketching to find three artists, seated and talking amongst themselves. This case study draws upon both the writings of Aron Gurwitsch and his theory of functional significance (see Chapter 3), and Garfinkel's development of these ideas. The natural discussions surrounding the members' talk of their artworks became the phenomenon of concern (see Heath \& Luff, 2007) as this roughly collected data remained useful for transcription. This case showed detailed graphic and written transcriptions detailing how several artists interact with one another in real time. The group's natural conversational activities used to organise how artworks gained social meaning in a group talk setting were the key focus of the study. This chapter demonstrates how artists' talk could be examined in real-world settings to describe those intersubjective practices as contributing factors for an artwork's social existence.

Chapter 8 , the discussion, is structured by six main sections. I argue that an art sociology that enables the social researcher the freedom to visit social settings where artworks are obvious features, and to observe and record how people interact with those objects, or interact with themselves whilst art objects feature in their intersubjective talk and conduct, would provide us with adequate conditions to gain access to social phenomena in the making. I then discuss how Gurwitsch's gestalt theories inspire ethnomethodologists to show how one action cannot be removed from its setting without altering that setting's formation. This is important because meaning is not seen as an individual unit or singular act that stands alone, rather meaning is produced as a constitutive relationship between an entire temporal assembly of practical actions. To discover the meaning of an artwork is then to describe how these practical social actions organise a setting to be meaningful and accountable. 
I then briefly connect with Crossley's position suggesting relational sociology must endeavour to tackle the problem of individualism - it must endeavour to capture the action in interaction. Here, Crossley suggests relational sociology must endeavour to capture and analyse the social world in interaction, analysing what happens between social actions. I take issue with this. In the findings, I claim to have found from this dissertation's empirical descriptions that artworks are formed by person's situated endogenous actions in a myriad of social and non-social ways. This thesis argues the relations between two actions are meaningful when they are interdependent in both person-to-person and person-to-object interaction, as described as an assembly, and organisation in and as practical social action. Importantly, because these accounts cannot be found in advance, they require a presentation that demonstrates how accounts were organised in observable settings; that is, the meaning is discussed in the descriptive work, and not in the findings themselves.

In the ninth and last chapter, the conclusion, I move to answer the research question, raising the notion that little of the art sociology literature demonstrates how constitutive actions are freely formed by the members involved in their creation without first corresponding that formation to a sociological theory, principle, model, or concept external to the member's local work itself. Additionally, studies of practice between ethnomethodology and the sociology of art are compatible with one another. This thesis argues the relations between two actions are social when they are interdependent in both person-to-person and person-to-object interaction. I then address the aims and objectives, the significance and implications of the findings, the contribution to the literature, and the limitations of the study. I end the conclusion by suggesting future research, the state of ethnomethodological theory, and the new sociology of art in the foreseeable future. 


\section{Conclusion}

This dissertation's research focus remains less on the artwork, or art object, and more on the structures of practical action an embodied person, one situated in the living world, uses to organise how an artwork (or an art object) is relevant (or not) to their practical activities at hand. Analytically describing the relations between one observable practical action and the next is where this thesis may gain its surface subject matter. ${ }^{6}$

I recognised an ethnomethodological take on human praxis as social action due to a person's membership to society, as Hester and Francis (2004) suggest:

Using the term 'individual' to refer to activities done by a single person acting alone does not mean that such activities are somehow less social than others done by persons acting together. Even if an activity is being done by an individual acting entirely alone, it is none the less a social activity in the sense that we intend here. (p. 2)

The sense they intend allows the reader to accept that every human action is social because our societal membership is inescapable. Human actions are thus social and thus inevitably relatable to the actions of other societal members as persons belong to a society of others. Under this view, to study how people do things in isolation may provide an explication of the social from within non co-present situations. This attitude is prevalent within most ethnomethodological versions of the social, and it is one that I employ throughout the following dissertation: "If anything is axiomatic to ethnomethodology, then, it would be that 'there are' social practices available for the seeing, and that wherever one finds them, social order will be right there (Hilbert, 2007, p. 8)".

\footnotetext{
${ }^{6}$ Itself subject to the fine-grained analysis and rigour expected from ethnomethodological studies (see Liberman, 2007).
} 


\section{Chapter Two: Literature Review}

Art from start to Finish could serve as the model for a twenty-first century sociology of art (De La Fuente, 2007).

Artworks in and as a variety of practices should, it is hoped, provide a program of research that could fruitfully be taken up by researchers, artists, and art professionals (Kreplak, 2018b).

\section{Introduction}

This chapter presents, evaluates, and identifies several key epistemological developments within the sociology of art. From this, we can contextualise the relevance of ethnomethodology as it has the important aim of explicating social order in and as practical social action. This review is guided by the emergence of a question seldom seen, but often requested within art sociology: How are artworks formed by artful social practices? (DeNora, 2014; Kreplak, 2018b). The aim of this review is to state my thesis question: How do practical social actions organise the intelligibility of artworks? The review also seeks to justify its value to the standing sociology of art literature and its detailed studies of social action in and as artistic practice.

The review begins by examining an edited-collection of seminar papers, compiled together as a text: Art from Start to Finish: Jazz, Writing, Painting, and Other Improvisations (Becker, et al., 2006). This was an important, and timely piece of work for the sociology of art. It sought to softly resist the field's macro-orientated orthodoxies of the period (Inglis \& Hughson, 2005). Namely, the objectivist frameworks (Bourdieu, 1984), critical analyses (Adorno, 1976; Hauser, 1982), and social-structural theories (Becker, 1982) that commanded 
the direction of art sociology during the last century (Hennion \& Grennier, 1999; Zolberg, 1990). When the authors of the text collectively explored how artworks themselves come to be finished, they met an epistemological challenge: How can an artwork's meaning be sociologically determined? (Becker, 2006).

The problem did not go unnoticed, and this New Sociology of Art (De La Fuente, $2007 ; 2011)$, generated a few studies with varying success. Findings such as the non-human materiality of creative assemblages (Fox, 2015), noise artists using indeterminacy as a social resource (Gerber \& Klett, 2014), and the cultural production of socio-material engagements (Rubio, 2012) tested the collegiality of the now somewhat slowing movement.

This review traces the epistemological developments within the new sociology of art movement and aims to evaluate the suitability of ethnomethodology's program (Garfinkel, 2002) to these contemporary positions. I end by advocating for an ethnomethodological approach; one that looks to provide a series of empirical works, richly described empirical studies into the microspheres of art in everyday life (DeNora, 2000). These studies will describe how a realist landscape painter, an abstract studio painter, and a group of urban sketchers create artworks.

\section{Roadmap}

This chapter is comprised of five main sections. First, I will assess Art from Start to Finish: Jazz, Writing, Painting, and Other Improvisations (Becker, et al. 2006). Three of the text's early paradigmatic provisions led to a guiding principle: The fundamental indeterminacy of the artwork itself (Becker, 2006), where, debatably, an artwork's meaning is indeterminate without the shared use of social conventions. This subsection argues that Becker's principle is fundamentally misaligned with its own program, resulting in an inherent 
epistemological contradiction: The program projects the study of the a posteriori workings of how an artwork gains its meaning, yet it does so from an a priori vantage point.

Second, Acord and DeNora (independently of Becker et al. above) argue the orthodoxies of art sociology did not take seriously how artworks gain, or afford, their meanings through situated social actions and their surrounding social activities. This subsection traces the development of their art in action approach. They softly connect with ethnomethodological principles and advocate, unlike Becker et al., for a research method with a posteriori sensibilities towards the pursuit of understanding the fluidity of artwork formation.

Third, Jeremy Tanner resists these sensibilities (Tanner, 2011). He argues in favour of establishing Baxandall's (1974) art analyses as the foundational approach for new art scholarship. By doing so, he addresses what he calls the fallacies of misplaced concreteness. Tanner helpfully and impressively examines these by engaging with an ethnomethodological study of a museum interaction (Heath \& vom Lehn, 2004). Tanner's critical, yet constructive, argument highlights the extensive range of sociological approaches available; however, he takes issue with indexicality, an ethnomethodological maxim which radicalises the study of how artworks are provided their meaning. For Tanner, meaning is partially independent, and therefore he recommends studying artwork from an a priori foundation.

Fourth, ethnomethodology's unique perspective on a priori and a posteriori epistemics seeks to determine how meaning is made by observing how persons interact with the social world. By reviewing the policy of the missing interactional what (Garfinkel, 2002), this section addresses a common trope, the Howard Becker Phenomena (see Lynch, 2015). Garfinkel reminds us that although we learn about several features of Jazz from the study of their artworlds (Becker, 1978), we do not see musicians work together to produce music in real time, and in their lived and observable social occasions_-details which 
ethnomethodologists claim are central for studies of the phenomena of constitutive social order (Button, 2003; Garfinkel, 1986). In this section I argue the consequences of applying this missing what attitude may offer an alternate and renewed way to freshly examine the routine, constitutive, and relevant interactional practices of artist's everyday artistic practices.

Fifth, Yaël Kreplak's emergent work on praxeological objects is connected to art sociology (Kreplak, 2015; 2017; 2018a; 2018b). Her work is the final location of the review. Concerned with describing how persons form the meaning of an art-object, she provides examples of how artworks have a plurality of relevant versions which depend upon where, including how, persons manage their affairs in lived situations to either include (or exclude) art objects. Her thesis centres on the argument that ethnomethodological descriptions of the ordinary interactive practices can advance knowledge and understanding in art sociology. She shows how artworks are made objective in and by the real-time management and production of social actions (Kreplak, 2018b).

Lastly, and in conclusion, I come to suggest the new sociology of art ought to monitor the adoption of how analyses of single-case a posteriori sensibilities focusing on the situated activity of real-time social action may provide interesting and original viewpoints to appreciate the social work persons do when they interact with art works. By grasping and orientating to the question of how are artworks formed by artful social practices (DeNora, 2014; Kreplak, 2018b), I situate the dissertation and advocate for the intellectual influence of an ethnomethodological attitude in art sociology. How people constitute the meaning of their social worlds, and by extension the intelligibility of artwork, is the primary empirical focus waiting herein.

\section{The Artwork Itself}


Ok, now we know all about artistic institutions. We know about their relations to their environment societies. We know how their making and reception are affected by class and all those other things. But what about - you know - what about the artwork itself? (Becker et al., 2006).

Worried that social science was at risk of overlooking the role the artwork itself plays within a variety of underlying sociological perspectives, several scholars congregated at a special conference and focused on, and discussed, an ideal research object: How do artworks come to be finished? This conference produced an edited collection of papers that formed and organised its work efforts around ways to examine how artworks still are social behind studio doors (Becker et al, 2006). There are three main avenues of investigation. The first provision highlights artworlds - society contributes various meanings to a work of art; the second provision, an artworks agency — artworks exist as material objects; and the third and final provision, an artworks temporality—social interaction is understood as a sequentially unfolding process of events. These three provisions (artworlds, agency, and process) may contribute to problematising how artworks gain their meaning for some art sociologists. If, for example, social interactions are unpredictable then there is no clear path for noninteractional studies to determine an artwork's meaning.

This is a social interactionist perspective. These scholars further sought working though this problem by developing "The Principle of the Fundamental Indeterminacy of the Artwork itself' (Becker, 2006, p. 23). Becker (2006) presents:

I mean only to indicate the empirical reality that lies behind what we could call the Principle of the Fundamental Indeterminacy of the Artwork. That is, it is impossible, in principle, for sociologists or anyone else to speak of the "work itself" because there is no such thing. There are only the many occasions on which a work appears or is 
performed or read or viewed, each of which can be different from all the others ( $p$ 23).

And,

A work takes many forms and that the "work itself" is isolated only by virtue of a collective act of definition. This means that what the work is, while in no way arbitrary, is subject to great variation and can never be settled definitively in some way that is dictated by its physical nature. This is the full meaning of the Principle of the Fundamental Indeterminacy of the Artwork that I announced above (Becker, 2006, p. 24).

Howard Becker assesses here an assumption shared amongst critical sociological theories in that persons interact with artworks under social constraints. I interpret his assessment to suggest an artwork's epistemological status is evaluated under, for example, the classic epistemological dualism: An object's meaning is either a priori (independent of), or a posteriori (dependent upon) social interaction. Understanding how actors provide meaning to artwork will require the artwork itself program to adopt an a posteriori epistemological stance due to this great variation of collective, fluid social definitions of artworks and objects.

According to De La Fuente (2007), the new art sociology glimpsed this stance, and increasingly drew attraction to its outward facing presentation, of how it may repossess cultural objects from a view from nowhere and situate them within social settings themselves (see Acord \& DeNora, 2008; see also Zembylas, 2014). The adoption of Becker's principle enabled the further development of a criticism towards a priori paradigms. It was argued that they cheapened context-dependent studies of art, relying on sui generis sociological 
explanations (Hennion, 2004; see also Zolberg, 2015, p. 901). ${ }^{7}$ The new art sociology gained much needed traction as a result.

Given these epistemological positionings however, the literature shows little of Becker's principle. It has never been used in original research beyond discussing the chapters of the edited book (Becker, et al., 2006). One reason for this may be that the principle suggests one thing but delivers another. The program does not provide any description of how people manifest the local assemblages of how social actions may constitute the meaning of an artwork, in real time and in situ. ${ }^{8}$ This is surprising for if the program had shown how an artwork's meaning does in fact depend upon contingent, sequential, and agent-based processes performed within social interactions, then studies of these social interactions would undoubtedly remain the empirical priority of the program. ${ }^{9}$ Under the principle, artworks are theoretically understood on the unique, indeterminate, and varied occasions in which they present themselves: They have no meaning outside of these settings, so given this, where are the studies which display this central common object of research? Becker provides a reason why such studies may not yet exist:

That is not what sociologists do. And, to be truthful, it is not what we want to do. We almost never attempt to explain a single instance of some kind of behaviour. No, we look for an explanation of a kind of behaviour that happens repeatedly, to which we give the name "social structure" or something similar, which connotes regularity, durability, and predictability. And we do not customarily consider it worthwhile to gather the kind of highly detailed accounts of the genesis of particular works that are what specialists in the fields routinely collect. We would rather learn a little about

\footnotetext{
${ }^{7}$ (DeNora, 2000) had earlier placed and advocated for a similar position.

${ }^{8}$ This is an ethnomethodological position, entirely, through and through (see Heritage, 1984).

${ }^{9}$ It is reasonable to suggest such studies would be, or lend themselves toward, single-case analyses due to the dynamic situated-bound-contingencies of social actions.
} 
many instances of something or, at least, much less about any particular work and more about many of them (Becker, 2006, p. 29).

Under this insight, an artwork's meaning is thus not determined by situated action but by collective social behaviours and definitions. A person's materialisation of conventions as defining how an artwork gains its meaning is the theoretical result.

Here, social conventions of one setting are unable to determine the unique future meaning of an artwork placed in another-artworks are fundamentally indeterminate themselves and not to be considered a priori. Becker's invocation of social conventions subsequently renders the opposite clear: If a collective definition is used to define varying artworks, then these definitions could be researched, found, and then used to offer statements of how persons not only define artworks, but how they may uniquely determine further definitions in other activities.

The turn to the work itself (Becker et al, 2006) oriented sociology to focus in on, and discuss a common research object: How persons in local situations use social conventions to work out a collective definition of an artwork. Yet, given the variety of these collective definitions the program has yet to deliver such empirical examples as observable in situated action. The principle is an irony: Becker shows the professional sociologist's technique is one of reducing how people see, create, and define art-work in terms of a social constraint existing outside of the local interactional work itself (a collective definition capable of producing external social structure). The sociology of art may not need such an approach to the study of social structure. Rather, students of social life ought to orient toward the analysis of single case, a posteriori social interactive orientation of artworks in their settings. 


\section{The New Sociology of Art}

Shortly after the publication of Art From Start to Finish: Jazz, Writing, Painting, and Other Improvisations (Becker et al, 2006), Tia DeNora and Sophia Acord independently issued a paper discussing many comparable topics. Like Becker et al., (2006), theyfound art sociology's overtly structural perspectives (see Zolberg, 1992) claimed external social conventions'(Becker, 1982) and social class structures (Bourdieu, 1984) as driving how an artwork gains its meaning. Acord and DeNora (2008) shift away from these types of socialstructural explanations and move towards the emergent local-interactional work that persons do in natural social settings. For them, describing such interactional operation of the arts would be a significant scholarly accomplishment for art sociology. Their text is relevant for the current review because rather than relying on a priori constructs (like Becker's social conventions), Acord and DeNora advocate an approach which sociologically examines "how specific features of artistic forms emerge as meaningful and consequential within interactions" (Acord \& DeNora, 2008, p. 226) and avoid the risk of epistemic contradiction.

The sociologies Acord and DeNora review differ in the level of emphasis put upon situated activity. They, like Becker et al., suggest the sociology of art should increase studies that investigate the processes of meaning-making by turning to the work itself and by introducing the idea of affordances (DeNora, 2000; 2014), where people are treated as embodied, creative agents. ${ }^{10}$ The sociologist ought to resist corresponding predefined categories to these material engagements. Consider the following two opinions: "Culture is not a set of a priori categories that act on people and determine their cognitive processing in given situations"; and that: "Real time events may play a leading role in determining how, and even if, culture is integrated into action trajectories" (Acord \& DeNora, 2008, p. 234).

\footnotetext{
${ }^{10}$ Affordances in this context is not the same as emphasizing the agency of an object. It is more to do with how music or other artistic objects afford actors with the possibility of generating cultural meaning.
} 
These insights connect with Garfinkel's notion of the cultural dope (Garfinkel, 1967).

Garfinkel suggest that how people interact with artworks in sequentially unfolding situations, may have no relationship with some of sociology's structural-theoretical deductions - people can, and do, make sense of their social worlds without the use of applying sociological knowledge to do so because such knowledge is already known to them as society's members (see Lynch, 2012).

Acord and DeNora draw from this ethnomethodological sensibility to further develop their argument. These ideas feature at length within their earlier publications: Writings of a curator's practical lived-work on contemporary art (Acord, 2006; Acord, 2010), music in everyday life (DeNora, 2002), and in DeNora's more recent epistemological interpretations of culture, reality and everyday life (DeNora, 2014). Yet, recognising Hennion's ethnomethodological notion of reflexivity (Hennion, 2007a, see Watson, 2005), where the idea of how social action arrives before an artwork's meaning, is where an issue develops: "Art forms have consequences for action, but at the same time, their affordances are fluid" (Acord \& DeNora, 2008, p. 232). A person's situated activity may be influenced by an artwork, but when and how that influence arises is not a determinate phenomenon. In short, persons acting in natural settings may organise that setting in and around artwork, and at times, that artwork may organise how that action predisposes the social setting itself.

This ethnomethodology-influenced new sociology of art adopts a strong version of a priori epistemological footing, yet before progression may be made, it is a stance that Jeremy Tanner challenges below and therefore requires review.

\section{Tanner's charge of misplaced concreteness}

Jeremy Tanner (2010) challenges the new sociology of art (De La Fuente, 2007). He rejects their a posteriori epistemological stance for losing sight of the external social world. 
Tanner suggests Baxandall's socio-historical analytical approaches anticipated "the commingling of the social and the artistic" (Tanner, 2010, pp. 244-246) to form a powerful theoretical framework which accepts a priori structures. According to Tanner, the new sociology of art developed two fallacies of misplaced concreteness. The first fallacy introduces contingency:

The concept of 'contingency' only makes sense in relation to a complementary conception of duration... without a reference to frames of duration (structures), an invocation of 'change' and 'contingency' has more rhetorical than analytical value (Tanner, 2010, p. 246).

We see Tanner conceptualising 'contingency', and thereby creating the second (and relationally dependent) fallacy:

It is equally a fallacy of misplaced concreteness to see 'structure' (whether cultural or social) as constraining in contrast to local and 'contingent' interactions as the site of choice and free agency (Tanner, 2010, p. 246).

Tanner dismisses the value of an approach that claims social structure constrains an individual's free-will because local-interactional settings are also constraining. Furthermore, if micro and macro sociological approaches are constraining, then solving social constraint is unavoidable for both approaches. Consequently, Tanner's charge of misplaced concreteness allows sociology to capitalise on conceptual analysis, whilst automatically protecting itself from arguments against social constraint.

Tanner productively pre-empts the resistance to his fallacies of misplaced concreteness and turns to review ethnomethodology's indexicality maxim - "that persons engaging with an art object 'index' it under those circumstances" (Acord \& DeNora, 2008, p. 234). Indexicality is important for Tanner's argument because it is a concept which 
radicalises context by seeing all action (and therefore for ethnomethodologists meaning, see Chapter 2), as context-dependent (Lynch, 1993). As Tanner challenges however, if contingency is a property available in both interaction and wider structural placements, then indexicality is a mistaken concept.

Tanner defends this view by employing Schutz's (1967) notion of social typifications: "Typifications necessarily pre-exist the specific object they typify or the particular situation they define" (Tanner, 2010. p, 246). Without discussing Schutz's concepts here, it is clear the epistemic question Tanner asks is open-ended: Is contemporary art sociology to research social meaning from an a priori or a posteriori position? As examined in this review, the new sociology of art favours the latter, and rather than leave it at a literary level, Tanner moves to defend his argument through reviewing an empirical example of an ethnomethodological analysis.

\section{An Ethnomethodological Study of Museum Interaction}

Tanner takes interest in a video-study showing how ordinary museum visitors view art (Heath \& vom Lehn. 2004). A father and son interacted with one another at a small Caravaggio exhibition, which took place in the Musèe des Beaux Arts in Rouen. The information provided by Heath and vom Lehn below is pertinent to the forthcoming discussion:

The exhibition notes, contained on a portable A4 card, describe how Caravaggio incised the canvass with his palette knife to provide an outline of the main compositional structure of the picture before the painting. In this painting it is the outline of the figures that is of particular significance (Heath \& vom Lehn, 2004, p. 49). 
With the A4 card in hand, the boy, turns to his father and states: "Put yourself underneath, see there with the mouth" - to which the father replies: "Ah yes, yes yes yes" (Heath \& vom Lehn, 2004, p. 51). The boy instructs his father several times. Heath and vom Lehn understand these instructions shape the father's viewing of the picture, discovering for him incisions which may have remained unseen if the father were to follow the A4 card alone. Under this description, the participants' embodied interaction groups the intelligibility of the artwork together.

Tanner takes issue with the epistemic status of the portable A4 card. For him, the card exists as a partially independent entity, which belongs to the design of the institutional structure. When visitors engage with the A4 card, it manifests Caravaggio's artistic genius:

The choice of the boy to focus on the incisions is itself cued by exhibition notes on an A4 card, themselves just one index of the larger institutional setting in which the family encounter the painting (Tanner, 2010, p. 247).

For Tanner, embodied actions of the viewer determines the painting's meaning. However, only if the A4 card is to be characterised as an external entity to such embodied actions, will the correct reality of the resource be determined - a reality understandable only through structural-contingency; a reality which ethnomethodology and the new sociology of art misplace. ${ }^{11}$

\footnotetext{
${ }^{11}$ Although Heath and vom Lehn are unlikely to supply a response to Tanner's work directly, I ask of his position: what would happen if the A4 card was not present at the exhibition? The relevance of the card to the instructions of how to see the painting would disappear, gone unfollowed, and therefore, the boy and the father would have never examined the incisions on the canvas. The meaning taken from the interaction would have been entirely different. In this hypothetical scenario, the fact the card makes the action relevant is untrue: if the card was not to exist, actions would still be relevant to the art-object. In fact, many persons may not even read A4 cards when visiting museums in general, thus experiencing the painting differently, my anecdotal self, included.
} 
Reviewing Tanner's argument will show support, in firstly, that the A4 card, gallery notes, and the design of the museum in general, provided participants with typifications before they arrive at the artistic setting. For example, viewers noticing the lines on the canvas is a product of the institutional characteristic of the museum's A4 card. Persons visiting museums may read cards to gain more information on the art exhibition being viewed. In this way, index cards operate as a conventional standard to which shared experiences are elaborated and organised, over time and independently from one person's viewing to the next.

Under these rationalities, Tanner's position is acceptable. The new sociology of art gives too much attention to the local interactional accomplishments of viewers, without appreciating the social-historical instructional devices, such as an A4 card, as having an existence independent of local interactions. However, in his epistemic argumentation, Tanner overlooks the ethnomethodological point which the design of the case study showed: The viewers use the A4 card as a contingent-resource, and not the other way around:

Establishing and creating the sequentially relevant response-to-the-object necessitate a trajectory of action through which the co-participant is positioned to experience the exhibit in a particular way, and through their encounter with the object, to 'naturally' produce the projected, sequentially relevant, reaction (Heath \& vom Lehn, 2004, p. $55)$.

For ethnomethodology, the meaning of the artistic object does not require a historical analysis, an invoking of convention, nor an organising social structure to exist independently of the participant's own interaction. Such structures may be relied on, but such faith needs to be seen in action. What was relied on, however and as shown above, was a concrete 
relevance to an action-sequence, in real time, for the parties to reflexively respond to one another.

Natural in this case is the phenomena in pursuit (rather than have a theory of concreteness dictate what is to be found, it is the parties own ordinary work which dictates their own relevance-structures, social-resources, and accomplished-working of what is meant, by who, and when). All this determines the meaning of an artwork itself, and it is only to be found in the local settings in which it exists. The consequences of this position therefore agree that index cards such as A4 displays found at museums are resources for meaning. However, it is not their existence that is of interest, rather, the work persons do to bring meaning about and make resources relevant in their interactions at hand.

For Tanner, the new sociology of art's focus on momentary interactions and localised constitutive practices, at the expense of institutional analysis and the consideration of large social structures, simply replaces one reductionism with another. Tanner offers a solution and argues Baxandall's sensibilities towards these social structures will enable the new sociology of art to supply a more robust sociological model:

The core concept of art as institution permits Baxandall's analysis to reach from the micro level of specific engagements between the viewers and works of art, to the macro considerations of the relationship between art and the broader social structures within which art is located (Tanner, 2010, p. 253).

Although enticing, I suggest seeing structures-as-resources and meaning-as-accomplishments is not a misplacement of concreteness for the new sociology of art. ${ }^{12}$ In fact, these topics are

\footnotetext{
${ }^{12}$ For ethnomethodologists, the working practice of professional sociologists in substituting "indexical for objective expressions" (Garfinkel, 1967) so that a theory of correspondence can be made and applied back-down
} 
the very things to which the paradigm has been attempting to understand. Consider the following: A focus on [art] 'in action', as a dynamic material of structuration, has yet to be developed” (DeNora, 2000); “There is a significant lack of practice-orientated methods for the analysis of indeterminacy in creative practice" (Klett \& Gerber, 2014); “There has always been a blind spot in the sociology of art: Any discussion of specific artworks" (Becker, et al., 2006, p. 1); "culture is a much more contingent and site-specific phenomenon than sociologists have tended to concede" (Rubio, 2012, p. 156); and lastly, "Practical aesthetics, the conduct, interaction and practice... would seem worthy of a little analytic attention from the social sciences" (Heath \& vom Lehn, 2004, p. 62).

Tanner's charges of misplaced concreteness provided a way to adopt a conceptual analysis of art objects that is in harmony with the new sociology of art by substituting the objective social structures for local relevance (see Liberman, 2007, p. 91). The consequences of doing so may reveal the very subject the new sociology of art is approaching within its studies.

\section{Art Ethnomethodology}

Ethnomethodology's unique perspective on a priori and a posteriori epistemics seeks to burden the persons under observation with the task of determining how meaning is to be formed. Bjelic and Lynch (1991) for example, analysed the epistemic status of prismatic colour. They claimed a person's ability to see colour is inseparable from the embodied work of following Goethe's scientific instruction. A person's discovery work is thus respecified as a constitutive feature of scientific knowledge, one that challenges the non-social existence of

to social structures yet to exist in-action, is the true misplacement. This idea is to be expanded on further in the methodology section. 
scientific objects (Garfinkel, Lynch \& Livingston, 1981; Garfinkel, 2002). These epistemological respecifications consequently aim to place the phenomenon first, and the conceptual second. What is of interest becomes not relating a concept of meaning to the actions of embodied assemblages, or haecceities of activities; rather, it is how persons in those situations manage to assemble those activities for themselves, in meaningful ways. That work remains the object of these ethnomethodological studies of work.

Relatedly, Charles Goodwin $(1994 ; 2000 ; 2013)$ provides an example of how two archaeologists co-ordinated their embodied action to classify the colour of dirt by using a Munsell chart, "a historically structured architecture for perception" (Goodwin, 2018, p. 22). Epistemically, the archaeologists did not create the Munsell chart a priori (Like Tanner's A4 card), yet they are seen to constitute the local intelligibility of the chart by using it as a social resource within their situated professional work, a posteriori (Like Heath \& vom Lehn's A4 Card).

Extending beyond the use of object as social resource, ethnomethodological studies of embodied activities within the wider artworld are concerned with how professional practices constitute an artwork's meaning in more typical artistic settings. How for example, do auctioneers auction (Heath \& Luff, 2007); dancers dance (Bassetti, 2014); operas operate (Anderson, 2004); curators curate (Acord, 2011); and painters paint? (Armour, 2000). Given that the object of ethnomethodological research is to describe how persons do the things they do in real-time and in real-situations to explicate the constitutive social order of mundane practical action, an investigator tasked with choosing a research setting, and in this case one beneficial to the sociology of art, may find guidance in the ethnomethodological attitude of the missing interactional what: "The missing what is nothing other than the practices themselves, as coordinated embodied performances, identical with, carried out through, and constitutive of socially organized activities" (Lynch, 2015, p. 6). 
The ethnomethodological attitude of the missing interactional what (see also Garfinkel, 2002) is a research policy which in part organises the discipline away from sociological theory towards the observable social world as a coherent, and legitimate, field of study.

Consider Sophia Acord and Tia DeNora's (2007, p. 226) suggestion in that inevitably, the sociology of art's avoidance of analysing art in action fails to report the effects of a sequentially unfolding pattern of social action has upon an artwork's meaning. Consider further, a parallel observation of music sociology where "there is a relative paucity of ethnomethodological studies of music making. This seems rather surprising given the centrality of Garfinkel's notion of the missing interactional what"' (Tolmie, et al., 2013, p. 229). Art sociology has the potential to receive and produce ethnomethodological descriptions of sense-making in artistic practices if the attitude of the missing what is adopted, yet risks are involved.

In his auto-ethnography Ways of The Hand (Sudnow, 1978), David Sudnow exemplifies how an ethnomethodological analysis of playing jazz-piano can uncover the constitutive technical details of the local intelligibilities required to play. In contrast, Howard Becker's “Art Worlds” (Becker, 1982) misses such details, not because Becker failed to notice, but because Sudnow was in search of describing something else. As Tolmie et al. (2013) provide a warning about favouring one approach over the other: “Garfinkel's injunction to focus upon embodied practices of music-making as a wholly detachable and free-standing mechanism to produce music poses a risk” (p. 230). They suggest risks are involved with exclusively focusing on the technical details, because in some contexts, music playing involves more than sitting down at an instrument, such as the case of live music where listeners are involved. In this way, Tolmie et al's sociological problem (what makes a group of Irish musicians solve their non-musical concerns) includes understanding how these 
features of a social setting (for instance, how musicians greet each other, order and drink beer, arrive and depart the venue, including other socially relevant pub-activities, and so on) treated just as important and just as interesting to the research as the technical performance the musicians may also provide. Subsequently, For Tolmie et al (2013), sociological descriptions detailing how music is made which focuses on both the social and the technical may provide a more complete description and analysis. All action is relevant to the assemblage of the setting's orderly structure and although Becker may have been occupied more with understanding the movement of art works or art objects from a larger macrooriented perspective, these perspectives are nonetheless important when considering what makes an artwork social, extends beyond the reach of the artist's control. As is often the case we ask: What is the phenomenon in pursuit?

Indeed, a researcher seeing such 'broader' social activities does not compromise the policy of the missing interactional what (Garfinkel, 2002). ${ }^{13}$ We are told that Garfinkel, "While praising Sudnow's effort to engage with and describe the work of professional jazz musicians [he did so] instead of explicating the relevant ensemble practices" (Lynch, 2015, p. 6). Strangely then, Tolmie et al. (2013) in arguing for such ensemble practices to be noticed, their admission of Garfinkel's injunction becomes, from my perspective, somewhat clouded as a judgement to which the missing interactional what is designed to deflect. This is because the phenomenon being investigated is the members' ensemble practices. If that involves a musician in solitude, or a public music session, the ethnomethodologist has work to discover what makes that group, the group that it is. Importantly, however, Tolmie et al. recognise how the missing interactional what may not be exclusive to technical, but rather, beneficial when understanding how the social activities, which surround a social scene, are used in conjunction with technical music playing. In short, both the technical and social can work

\footnotetext{
${ }^{13}$ See Liberman (2007) on the "uncompromising nature of Garfinkel's Rigor".
} 
together to produce descriptive accounts of interactional practices. These are often missed as valuable topics of discussions when sociology is conducted solely in the library.

The sociology of art literature has not addressed the missing interactional what directly. ${ }^{14}$ Constructively, it needs to review how members of the artworld use their surroundings, immediate local resources, in sequential ways, to carry out meaningful interaction with themselves, others, and art objects. I argue, the consequences of applying this attitude will supply a new way to examine the routine, constitutive, and relevant practices of the everyday life which surrounds artistic practices. Garfinkel abandoned the idea that the sociologist can explain to the member more than the members themselves know, namely, a second-order structuring (Garfinkel et al, 1988; Lynch, 2015, p., 8). Practices are therefore seen as a distinctive site, and source, of social order not fully available to sociological analysis (Acord \& DeNora, 2008; Livingston, 2016).

Additionally, if the sociologist agrees that capturing lived social phenomena by literary description alone is impossible, then missing the phenomena is not that radical of a claim. To get as close to this phenomenon as possible, for ethnomethodology, social order exists in the world as a first order (Anderson \& Sharrock, 2016). Subsequently, that order is accountable to the constitutive forms of its production, that is Durkheim's social fact respecified (Garfinkel, 2002). As previously mentioned in the introduction, this dissertation attempts to explore Garfinkel's respecification of order in both technical and social settings, to see whether the social is discoverable, and reportable in sites of human praxis.

\section{Artwork as Social Praxis}

\footnotetext{
${ }^{14}$ Work on understanding art objects at the intersection between sociology of art, aesthetics, and ethnomethodology, does exist, however; for example, see (Ruggerone \& Jenkins, 2015).
} 
Garfinkel's writings have inspired a small number of scholars in art sociology. The potential of his perspectives for new art sociology studies has gone relatively unnoticed by ethnomethodologists themselves, however. Of the few, Yaël Kreplak, for example, connected with the missing interactional what maxim discussed above and explored the benefit of an ethnomethodological approach to art works as material and praxeological objects (Kreplak, 2015). Her research on praxeological objects (Garfinkel \& Wieder, 1988; Lynch, 1988) is suitable for studying a topic that the literature black-boxes, and fails to see: The occupational work that persons do to organise social meanings of art-work (Dominguez, et al., 2013, p. $161)$.

Searching for how persons do artworks in situ, Kreplak video-transcribed the daily interactions amongst museum staff who cleaned and prepared artworks for the Museum's exhibits and installations. She highlights one interaction of an artist instructing a museum staff-member on how an artwork was to be cleaned. Kreplak focused on the mundanity of how the properties of the artwork emerged as part of the instructional work. For example, the spoken properties of, being heavy, being fragile, having marks in some parts, were revealed through Kreplak's analysis as socially achieved (2015):

The usual way to know an artwork is not relevant in the sense that participants do not draw on this knowledge at all to do what they have to do. The title, the date of creation, the description of the different elements, the artist's intention, all the pieces of information we usually refer to when we talk about an artwork are never mentioned in the course of this work. But some other constitutive details are revealed here - they are never mentioned in other contexts. (p. 8)

Kreplak's analysis shows the potential to redefine artworks from a praxeological perspective where this she argues, may provide the work persons do in museums as a 
perspicuous setting- sites that exaggerate how social phenomena (and in this case an artwork) is constituted in social action.

Kreplak's research on praxeological objects furthered an interest in "docile documents" (Lynch, 1985, p. 64; Kreplak, 2017) and "record keeping” (Kreplak, 2018, p. 710). In one of her latest texts, Art in and as Practice (Kreplak, 2018b), she contributes to contemporary debates within the sociology of art, providing an ethnomethodological example of how one may approach the study of artworks and artistic practices from an ethnographic lens focused exclusively on situated interactional practices.

Kreplak argues ethnographies do not fully bridge the gap between artworlds and artworks (Kreplak, 2018b, p. 143). However, if an analyst were to use the missing what attitude they may get closer to understanding how members constitute an artwork themselves: "To identify the constitute practices, which are inevitably missing from versions found in the literature, and which are only to be discovered through a detailed study of the particular deeds that shape these practices" (Kreplak, 2018b, p. 144).

Picking a central topic such as how artworks are situated and carried out as being objective is for her the core task of ethnomethodological analysis. In paying attention to how participants in real-world situations work at determining what is to become constitutive relevant to the practicalities of their ongoing activities, Kreplak describes member's methods of making relevant features of a situation form as an external social fact - an observably real entity, for all practical purposes (Kreplak, 2018b, p. 159-160). Ultimately, in studying a variety of situations where people apprehend an artwork's meaning, Kreplak promises a way to deal with the inherent relativity of perspectives which are all significant contributions to the pursuit of understanding how a work of art gains its sense as a social object. And it is in this way I connect Kreplak's ethnomethodological approach of artwork to the new sociology of art. 


\section{Conclusion}

This chapter evaluated the turn to the work itself (Becker et al, 2006) where sociology seeks to understand how persons in local situations supply meaning to an artwork in real time. However, the principle is an irony: Becker shows the professional sociologist's technique is one of reducing how persons see, create, and define artwork in terms of a social constraint existing outside of the local interactional work itself, rather than focus on the contingent details of social interaction. Furthermore, I argued that if the new sociology of art is to realise the meaning of an artwork, it will need analyses of single case a posteriori sensibility.

Acord and DeNora suggested (by continuing to draw from ethnomethodological sensibilities) that social action arrives before an artwork's meaning: "Art forms have consequences for action, but at the same time, their affordances are fluid" (Acord \& DeNora, 2008, p. 232). This ethnomethodological-based new sociology of art adopted a strong version of a priori epistemological footing which Becker was unable to provide.

Jeremy Tanner challenged this position by asking an open-ended question: Is contemporary art sociology to research social meaning form an a priori, or a posteriori position? As examined in this review, the new sociology of art favoured the latter, and rather than leave it at a literary level, Tanner moved to defend his argument through an empirical example. His charge of misplaced concreteness provided a way to adopt a conceptual analysis of art objects which was in harmony with the sociology of art, but only if the objective relevance is substituted for as local. I argued this substitution work would obliterate what persons do to constitute meaning in and as of local accomplishments under ethnomethodology's indexicality maxim (Liberman, 2007, p. 91).

Given that the object of ethnomethodological research is to describe how persons do the things they do in real time and in real-situations to accomplish a shared sense of stable 
social order, an investigator tasked with the empirical pursuit of a research setting is guided by following the ethnomethodological attitude of the missing interactional what: Abandoning the written word in favour of seeing the phenomenon. This review moved closer to developing criteria for how an ethnomethodological study of art may benefit art sociology.

Furthermore, if the sociologist agrees that capturing social phenomena by literary description alone is impossible, then missing the phenomena is not that radical of a claim. To get as close to this phenomenon as possible, for ethnomethodology, social order exists in the world as a first order (Anderson \& Sharrock, 2017). Consequently, an a priori or a posteriori attitude is irrelevant; we should try to abandon the epistemological debates in favour of getting involved with the social order itself, from the perspectives of the practitioners' sequentially unfolding ways of understanding.

Yaël Kreplak connected with these ideas and paid attention to how participants in real world situations 'work' at supplying what is to become constitutive, relevant to the practicalities of their ongoing activities. She describes members' methods of making relevant features of a situation form as an external social fact — an observably real entity, for all practical purposes (Kreplak, 2018b, p. 159-160). In studying a variety of situations where persons apprehend an artwork's meaning, Kreplak promises a way to deal with the inherent relativity of perspectives, which are all considered significant in the pursuit of understanding how a work of art gains its sense as a social object.

This review presented, evaluated, and advanced, several key epistemological developments within the sociology of art. Namely, the a priori and a posteriori, debate. I have tried to show that ethnomethodology has become increasingly suited to art sociology during the last two decades. In finding the theoretical context of the thesis, I can now place the emergence of a question which is seldomly seen, but subtlety requested within art sociology (DeNora, 2014; Kreplak, 2018b): 
How are artworks organised in and as practical social action?

The remainder of the dissertation is designed to answer the latter question. In the next chapter, I introduce an epistemological position on the way ethnomethodology treats formal sociological reasoning. Furthermore, the concept of ethnomethodological indifference reminds the student of social life to keep constitutive actions in view whilst also being reminded that the phenomenon is altered as soon as they are represented outside of the settings of their production. This further complicates the relationship between how social order exists in the world, and how academics may accurately represent that lived reality given the inherent indexical nature of language. I then discuss this concept of indexicality and then introduce the work of Aron Gurwitsch by way of Garfinkel's later writings on gestalt concepts and then respecified as an empirical project to discover how social reality is constituted and rendered objective. 


\section{Chapter Three: A Methodological Attitude and its Theoretical Connections}

One should be slightly, no very, cautious, about producing headings that would count as a list of "key concepts" in ethnomethodology. A central pursuit in ethnomethodological studies is re-specification of concepts in the light of detailed investigations of particular cases and settings (Laurier, 2009, p. 634).

\section{Introduction}

This chapter discusses several key concepts that I used to aid my thinking throughout twenty-four months of ethnographic fieldwork and video analysis. The four empirical case studies are all comprised of hand-held video data recorded in real time, but perhaps a simple question could be asked on what makes ordinary footage of artists creating art, sociologically interesting. What does video data recorded by the hands of a sociologist have that video data recorded by the hands of another misses? The simple answer is very little, if nothing at all. How ethnomethodologists study meaning is unique however, and to compare their study procedures with other sociological approaches may quickly run a student into trouble.

Garfinkel supposed to describe the constitution of social order. Sociologists ought to discontinue searching for what people say as being other than how they speak, for how they speak tells us what they mean (Garfinkel, 1967). This key intellectual orientation is a first step towards observing social order as a member's practical accomplishment, for what the analyst may search for is found not in pre-defined definitions but rather in a person's methods of acting in everyday life. Included in these methods are social phenomenon that may exist beyond any one individual, a Durkheimian social fact, respecified (Garfinkel, 2002). By turning the topic of how people speak and act into a subject of empirical research inquiry, it 
no longer makes sense to establish the meanings of what people say prior to observing how they actually speak. Social interaction is full of ambiguities, subtle gestures and gazes, and the full range of local contingencies that contribute to the shaping of mutual understanding. As we will see in the following chapter, I attempt to tease out how the social production of meaning has more to do with the immediate relations between actions, other than exclusively found in the actions themselves. To study social order, meaning and intelligibility, an analysis may better be pursued if a set of key research attitudes are available to guide them, not withstanding Laurier's cautionary point in the front quote above.

\section{Roadmap}

Five main sections structure this chapter:

Indexicality: Indexicality is a key concept in ethnomethodology due to its ability to articulate a version of social order as a highly contextual one. Garfinkel's development of indexicality from a philosophical and linguistic issue into a task of sociological inquiry results in the assumption: All action is indexical.

Indexicality and Sequence: Indexical expressions as social action provides all member's actions as context-dependent where no action exists in isolation. Indexical expressions have sequential properties. Observing how actions are sequentially related further elaborates on how ethnomethodologists understand meaning as a real time accomplishment.

Garfinkel and Gurwitsch: This section introduces Garfinkel's intellectual relationship with Gurwitsch, including the importance for ethnomethodologists to return to the work of Aron Gurwitsch as an intellectual 'rival'.

Gurwitsch's Gestalt Concepts: Subsequently, I review here Gurwitsch's theory of functional significance and gestalt contextures, a central theme that runs throughout the entirety of the empirical case studies in this dissertation. 
Ethnomethodological Indifference: This section connects with the concept of ethnomethodological indifference to remind the ethnomethodologist to remain oriented to the practical action and reasoning that a person does in real time situated activity, rather than seek a definition, model, theory or representation of that practical action exogenously.

Formulating the research object; unmediated access: This section questions the participant's taken for granted world. It is possible ethnomethodology undermines the member's own ability to recognise the mundanity of their own activity. For example, members may treat what people say as factual and real. To suggest what they say is understandable only in terms of how it was said, challenges the way persons may approach the meaning of factual accounts. We now turn to the concept of indexicality.

\section{Indexicality}

By way of integrating the writings of the earlier "occasional expressions" (Husserl, 1900) and later, "indexical expressions" (Bar-Hillel, 1954) indexicality gained a unique status in early ethnomethodological scholarship as it drew a line from ordinary language philosophy to sociological inquiry. For ethnomethodologists, indexicality once modified, and then used to notice naturally organised ordinary activities, finds social action irremediably bound to contextual settings (Garfinkel, 1967). Subsequently, ethnomethodology's development of indexicality (see Garfinkel, 1967; Garfinkel \& Sacks, 1970) ${ }^{15}$ into a classic, yet original, sociological program of research is more readily grasped by way of first understanding indexical expressions due to its philosophical origins.

\footnotetext{
${ }^{15}$ Garfinkel and Sacks (1970: 18) refer to 'major philosophers' claiming Charles S. Peirce and Ludwig Wittgenstein, among others; earlier, Garfinkel (1967), cites Husserl, Goodman, and Russell as discussing the problem with reference determination as providing inspiration for his sociological development of them.
} 
Indexical expressions may be classified through a formal linguistic syntax used to parse common speech and conduct, to categorise a word, or a series of words, as being an index (or referent) of a noun or object. Grammatically, for example, indexicals are understood as English pro-nouns ('it', there', 'them', 'they', 'then', 'these', etcetera). Philosopher's may occupy themselves with an issue surrounding indexical expressions: How can one truthfully know the future correspondence between a referent and object? ${ }^{16}$. This problem occurs because the correspondence between an indexical expression and its intended object may vary with the context of its use ${ }^{17}$.

To ask what one of these pro-nouns refers to in advance, as for instance, what does 'that' refer to in the phrase, "can you please pick that up?", is to understand more of the context, situation, place, time, and situated surroundings of how such an utterance was used. The possibility of defining an objective rule, pattern, model or calculus for solving this issue of reference determination thus raises analytical concern for a theory of binary truth as the 'that' in the example above could refer to an infinite number of items. This parallelism between a theory of truth and the way people naturally organise their ordinary activities through indeterminate ambiguities, formed a sociological puzzle left to be further discussed (Coulter 1991, p. 31; Sharrock \& Anderson, 1986, p. 42; see also Suchman, 1987, p. 59). How can what people do be explained? Formal linguistic syntax may be unable to provide a complete objective and determinate model of how meaning operates in real-world settings, as to do so would require one to predict what objects indexical expressions correspond to in advance of their use.

Harold Garfinkel recognised this puzzle as the substitutability of objective for indexical expressions, and it is problematic for formal theory (Kim, 1999; see also Mair \& Sharrock,

\footnotetext{
${ }^{16}$ Later this will be picked up as 'the correspondence theory of truth' which has special status in Garfinkel and thus the development of ethnomethodological approaches towards research and analysis.

${ }^{17}$ Of which without access, an indexicals epistemic status' remains inherently ambiguous and non-determined.
} 
2019). Yet Garfinkel attended to the idea of whether this was a problem for members at all. Given people in everyday life primarily, and successfully, speak and act with ambiguous indexical expressions, what exactly needs replacing for them to produce intelligibility? Garfinkel's insight was not simply an experimental way to avoid the formal problem of truth, he claimed to have discovered an actual, and observable social phenomenon previously unnoticed due to the consequences of his ethnomethodological inquiries (Lynch, 2019). People substituting objective for indexical expressions would alter the way they naturally speak.

Garfinkel asked whether this substitutability is observable as a general property of social interaction (Garfinkel, 1967, p. 6). This classic idea of the substitutability of objective for indexical expressions was held beyond formal remedy because members may themselves work to achieve substitutability (as a social practice) in contextual social settings. Investigating how they do that may be one of ethnomethodology's early provocations for social inquiry.

Although researching substitutability in naturally occurring settings may have provided an early subject for ethnomethodological noticing, Garfinkel, within two significant passages, I believe, completely modified the practice of correspondence theory whilst pressing indexicality into becoming a serious sociological subject:

Although it may at first appear strange to do so, suppose we drop the assumption that in order to describe a usage as a feature of a community of understandings we must at the outset know what the substantive common understandings consist of. With it, drop the assumption's accompanying theory of signs, according to which a "sign" and "referent" are respectively properties of something said and something talked about, and which in this fashion proposes sign and referent to be related as corresponding 
contents. By dropping such a theory of signs we drop as well, thereby, the possibility that an invoked shared agreement on substantive matters explains a usage.

...If these notions are dropped, then what the parties talked about could not be distinguished from how the parties were speaking. An explanation of what the parties were talking about would then consist entirely of describing how the parties had been speaking; of furnishing a method for saying whatever is to be said, like talking synonymously, talking ironically, talking metaphorically, talking cryptically, talking narratively, talking in a questioning or answering way, lying, glossing, double-talking, and the rest (Garfinkel, 1967, p. 28-29).

Garfinkel argues that relating independent social facts to context-dependent activity questions the meaning of the situation. Given this novel and innovative attitude of 'dropping the correspondence theory of truth', substitutability is less of a phenomena to be searched for, and more of a way to see how the indexicality of a situation is rational and managed by the members themselves to produce a sense of stable social order. Objective expressions may or may not be part of that management. Turning from philosophy to study indexicality as a practical social phenomenon:

I use the term 'ethnomethodology' to refer to the investigation of the rational properties of indexical expressions and other practical actions as contingent ongoing accomplishments of organized artful practices of everyday life (Garfinkel, 1967: 11).

If what the parties talk about could not be distinguished from how they were speaking, then investigating how practical actions are constitutively organised, including what methods are used to organise those actions, becomes the ethnomethodological research object for inquiry. 


\section{Indexicality and sequence}

When one does in fact observe how persons naturally act in the world, one may quickly notice people act over time, and in, and for, timely reasons. Maynard and Clayman (1991, p. 397) further comprehended this ordered and socially organised property of indexical expressions. In asking what social activities comprise the temporal orderliness of indexical expressions, they improved two unsatisfactory cases - glossing practices and formulations - from within the now classic ethnomethodological paper, "Formal Structures of Practical Action" (Garfinkel \& Sacks, 1970) and offered up Sack's better concept, "proterms" (see Sacks, 1967). When persons engage in conversational activities, the meaningful relationship between two utterances often depends upon their congruity, and if so, "adjacency pairs" (Schegloff \& Sacks, 1973) may convey the referential and organising properties of conversation. As Maynard and Clayman (1991) continue:

If talk is indexical, as in the use of pro-terms, phrases, and other clauses whose meaning is contextually derived, it is a phenomenon accomplished as participants build utterances in a sequential fashion to make them intelligible and to show understanding in precise ways. In such fashion are the indexical properties of talk ordered (p, 399).

Highlighting the all-inclusive category of indexicality as witnessable in conversational activities, Maynard and Clayman argued the assembly of utterances are sequentially and intersubjectively ordered in temporally relevant ways by the talking members themselves.

Additionally, over the course of a natural conversation, nouns are also used as referential devices. Heritage (1984), for instance, used an example of a young couple in love, where one uttered to the other "that's a nice one" (p. 142). Whether they were window shopping for a wedding ring outside of a jewellery store, or selecting a purchasable vegetable 
at a greengrocer, the adjective "nice" may adopt a radically different meaning, as the contextual environment of the utterance may shape new senses into the words as they are said on each occasion of their specific uses. Subsequently, too much analytical focus upon indexical expressions as individualistic lexical items challenges the exclusive referential feature pronouns may hold. This ethnomethodological noticing expanded, and thus further problematised how referential action may be understood to operate outside of academic vignettes. Ethnomethodologists turned to ordinary everyday discursive settings to uncover the use of social language in real time. ${ }^{18}$

Gestures, gazes and glances, facial expressions, bodily movements, silences, pausesembodied actions - thus modified 'indexical expressions' as a witnessably real "all-inclusive category of practical action" (Livingston, 1987, p. 75). Not only this, but an all-inclusive indexicality of action is just as temporal as the sequentially ordered properties of talk Maynard and Clayman suggested above. Wilson classically highlighted how interactant's embodied interactional actions are related to their immediate previous, current, and future, 'temporal' acts, (Wilson, 1970):

This mutual determination of appearances and underlying pattern is referred to by Garfinkel as indexicality, and a particular appearance is called an indexical particular... Each action in the course of interaction, then, is an indexical particular that is understood by the participants in terms of the place of the action in the context of what has gone before and what they see as the future course of the interaction. (p.

\footnotetext{
${ }^{18}$ Notwithstanding a large amount of relevant scholarship in the philosophy of language (Austin, 1955; Peirce, 1958; see also and Atkinson \& Heritage, 1984, p. 5), the linguistic field of pragmatics (Levinson, 1983), and topics of anaphora specifically (Hanks, 1992; Silverstein, 1976), early ethnomethodology reformed indexical expressions to extend beyond their classical sole property of linguistic action (Vom Lehn, 2014: 95; Schegloff 1984: 68).
} 
68-69).

Wilson treats an indexical particular and an action as sharing synonymity with one another, and here we see how embodied actions are thus indexical (context-specific and contextrenewing). Under these ethnomethodological specifications, reformations, or modifications of indexical expressions, all action (including talk) is contextually determined in (and as) its specific and often sequential, uses (see Liberman, 2013: 263-264 on this liability of the sense of words). Consequently, indexicality seems significantly different from its earlier, philosophical-linguistic indexical expression counterpart. Lynch (1993) succinctly summaries his development within ethnomethodological studies:

For ethnomethodology, indexical expressions and indexical actions constitute an entire field of phenomena to be investigated... unlike Bar-Hillel, Garfinkel and Sacks greatly expand on the relevance of "indexicality" beyond the analysis of specific classes of words... it no longer clarifies anything to say that every possible utterance, statement, or representation is indexical... this is because the distinction in principle between objective and indexical expressions no longer has much value when the topic of study shifts to the "demonstrably rational properties of indexical expressions". At this point, what becomes prominent is not that all expressions are indexical but that members manage to make adequate sense and adequate reference with the linguistic and other devices at hand. The question for ethnomethodology is, how do they do that? Lynch (p. 17-22).

The value of this point lies in the ability of not having to rely on a concept of indexicality to aid the analytical process due to the sentiment of analytical explication itself. It no longer 
made sense to correspond a model of indexicality with how persons observably conduct their affairs in ordinary everyday life, because analytically, the task becomes one of explicating how those affairs are done in that distinct moment in time.

The remaining theme, one which results through working out the theoretical development of indexicality, is one that bounds the analyst to member's local actions. This complicates things in practice. For example, why should the development of indexicality remain interesting when it is ultimately "a ticket into the ethnomethodological theatre that is torn up as soon as one crosses the threshold?” (Lynch, 1993, p. 18). Indexicality pushes us further to the social world as a constitutively produced, and thus an observable, analysable and reportable one. If the resulting option is to either leave indexicality to philosophy or to abandon it during research, then within this dissertation I treat all action as indexical, and see all indexical action as social: Any action is social (see the discussion Chapter 7). Under this premise, indexicality is more of a historical discussion on the pioneering work the early ethnomethodologists accomplished to open up the domain of social order as praxeologically available.

In summary, Garfinkel's development of indexicality raises several empirical motivations and attitudes. First, ethnomethodology is fundamentally a study of constitutive social actions that are used and organised by persons in their settings to structure that setting's local order. Second, writing of how persons do this work is not the same as how that work was done to organise that setting. Third, indexicality suggests that all actions in that setting are local, that there is no worthwhile distinction between objective and indexical expressions outside of what members say or do. The situated temporality of how actions may unfold and correspond to one another in real time as members work may then provide a minimal and fundamental frame for sociological analysis. Subsequently, explicating the 
orderliness in these practical settings, and to then describe the contingencies observable therein is in principal a sociological study of social order.

The next section of this chapter elaborates on the relationship between Gurwitsch and Garfinkel. It aims to introduce an alternative approach to the study of contingent social orders through the Gurwitschian concepts of gestalt contextures and functional significance. Garfinkel's later writings makes public reference to the importance of these concepts for ethnomethodology's program, a discussion to which we now turn.

\section{Garfinkel and Gurwitsch}

Harold Garfinkel teleconferenced in from the comfort of his Californian home to the attending members of the International Institute of Ethnomethodology and Conversation Analysis's $5^{\text {th }}$ conference, held at Manchester Metropolitan University in July 2001, to deliver a keynote lecture on Gestalt Phenomena ${ }^{19}$ (published in 'orders of ordinary action' see Hester \& Francis, 2007). This lecture began with Garfinkel introducing two figures he had extracted from "We, the Navigators: The Ancient Art of Landfinding in the Pacific" (Lewis, 1972) to argue that Western navigational science literatures miss the phenomenal features of sea navigation illustrated within.

Lewis's figures depict first-person representational views of standing on the deck of a Polynesian sea vessel. Garfinkel used this imagery to further encourage the audience members to imagine the embodied work of steering a course by aid of the stars; of how the Polynesians crossed large areas of wild Pacific Ocean to find land. Primarily, Garfinkel argued these features, ones he called the "shop floor constituents of voyaging's work"

\footnotetext{
${ }^{19}$ The mention of gestalt phenomena — 'gestalt coherence, 'functional significance', 'gestalt contexture' - had been only briefly glossed as 'seminal' in his earlier works (Garfinkel \& Wieder, 1992), and not mentioned at all in others (Garfinkel, 1967), although foundational in his earlier, unpublished, thinking (Garfinkel, 1953).
} 
(Garfinkel, 2007, p. 23-26), are often extracted from the lifeworld and academically reified into the known facts of Western models of science ${ }^{20}$. Whereas contrarily, Garfinkel's research position was to remain in constant pursuit of studying how these very constitutive practical actions are themselves organised by living persons prior to, and during, the action of objectivation (Lynch, 2015; Rawls, 2008; see also Liberman, 2007; 2018). Remarkably, the Polynesian sailors demonstrated they were able to meaningfully get to where they needed to go without the reliance of an external scientific model to guide them. An alternative logic was used, one related to the context of the ship's local, and sociologically discoverable, navigational activities.

Although several conference members may have already known this classic and familiar ethnomethodological studies of work argument, whereby formal literatures 'miss the alternative interactional what' (Garfinkel, 1994; see also Garfinkel, Livingston \& Lynch, 1981), not so well known is this distinction having been originally described by Aron Gurwitsch and his contribution to gestalt psychology (see Garfinkel, 2007, p. 23; Garfinkel, 1993; Gurwitsch, 1964). Garfinkel revisited Gurwitsch's theory throughout the remainder of his talk, maintaining Gurwitsch's concepts were fundamental to his own, that early ethnomethodological thinking extended in part from them, and yet that focus upon gestalt diagrams will leave the student of social life unsatiated ${ }^{21}$. The scholarly crux of Garfinkel's talk recommended that Gurwitsch's coherence of objects theory ought to be removed from its philosophic and psychologic conceptual status and placed into a program of contemporary social research.

\footnotetext{
20 This is a classic argument regarding the difference between indexical expressions and objective expressions with the latter unable to fully account for the former (see Garfinkel, 1967; see also Schutz, 1967).

${ }^{21}$ For an elaboration of gestalt constituents upon indexical expressions see (Wieder 1974, p. 161-164).
} 
Garfinkel's “Ethnomethodology’s Program” (Garfinkel, 2002) (henceforth Program) was published shortly after this conference. Elaborating further upon the centrality of Aron Gurwitsch's gestalt theories in ethnomethodological theory, the editor's introduction clarifies that Garfinkel's personal introduction to Gurwitsch happened during the writing of his master's dissertation at North Carolina between 1939-1943. As Rawls stated: "Gurwitsch provided the idea of gestalts, which, although much modified, became important in Garfinkel's later work, particularly in his focus on the phenomenal field properties of things" (Rawls, 2002, p. 13-15). Additionally, we receive further biographical relevancies as the introduction unfolds. Garfinkel, studying at Harvard toward his doctorate degree, "met with Gurwitsch regularly in his house in Cambridge" and "later, while on the faculty at UCLA, Garfinkel and his students Aaron Cicourel and Egon Bittner would arrange for the first English translation of Gurwitsch's Field of Consciousness" (Rawls, 2002, p. 15). Moreover, Garfinkel's own author's introduction adds serious details to this claim:

That gave both of us [Cicourel] early textual access in English to Gurwitsch's argument on the functional significations and their coherence of figural contexture in its empirical perceptual details. That argument had been a foundational point of departure in all my teaching. It has lasted a long time. It has also been missed as Ethnomethodology's key resource in identifying Ethnomethodology's concerns to specify "the problem of meaning" with a program of certain positive empirical researches and instruction in sociology's identifying "problem of social order" (Garfinkel, 2002, p. 84).

Garfinkel, in linking the first English translation of Gurwitsch's field of consciousness (Gurwitsch, 1964) to the problem of social order (Parsons, 1937; see Garfinkel 1953) had 
provided an awkward mystery to the wider sociological readership of his published works: Why Gurwitsch, and why now?

Unlike "Studies in Ethnomethodology” (Garfinkel, 1967) (henceforth Studies), Program contains multiple references to the importance of Gestalt conceptions: "His demonstrations take on their relevance and consequences as EM rivals... you can't do anything unless you do read his texts" (Garfinkel, 2002, p. 167). One such particular text, rather than an entire philosophical discipline, is helpfully mentioned as a resource after yet another statement demonstrating the seriousness of Gurwitsch's work to Garfinkel's thinking:

The dissertation and subsequent EM studies originated in phenomenologically tutored concerns with description and analysis of the coherence of objects. These were directed to their practical objectivity and practical observability. Carried out by deliberately misreading Gurwitsch's The field of Consciousness, Part Two, Some Principles of Gestalt Theory (Garfinkel, 2002, p. 257-258).

Gurwitsch's book, specifically, section IV thereafter, "Reformulation of the Problem of gestalt (Form) Qualities" (Gurwitsch, 2010, p. 102-135) is full of familiar ethnomethodological examples. Garfinkel's use of strange lingoes, such as endogeneity and autochthony are present in Gurwitsch's writings. Additionally, Gurwitsch reviewed wellknown theoretical arguments such as the problems of formally representing occasional expressions, having originated in Husserl’s “Logical Investigations” (Husserl, 1900).

Garfinkel was undoubtedly influenced by Gurwitsch's writings when producing his own attitudes about social order. His earlier works seemingly omit the centrality of gestalt contextures, causing one to question whether the already published collection of essays which comprise Studies had an underwritten element at play. Although Garfinkel may have 
elaborated on his relationship with Gurwitsch within his later publications, Gurwitsch's earlier texts are still available for review, however. In the next section I turn to look at one of Gurwitsch's key concepts that treat as key to developing an appreciation of how ethnomethodology could have opened the investigation of social order as praxeology.

\section{Gurwitsch's Gestalt Concepts}

Gurwitsch's gestalt theories are highly philosophical and abstract. They seek to provide a general theory of human consciousness, of how the intelligibility of the world is possible. Organisation is central to this theory. A Gestalt is a unitary whole group of things that becomes detached as an organised and closed unit from the surrounding field of other things. These things are termed constitutive parts, and together, the constitutive parts are ordered in such a way to produce wholes.

Gurwitsch's originality stems from his gestalt theory. He posited if a constitutive part was extracted from its whole (Gestalt) then it would be isolated, and thus strip itself not only from its previous phenomenal identity, but consequently both alter the specific relationships it left behind and the subsequent relationships it may yet make. Gurwitsch conceptualises:

By virtue of its absorption into the structure and organization of a Gestalt-contexture, the constituent in question is endowed with a functional significance for that contexture. Each constituent of a Gestalt has a certain function within its structure, for example, being the right members of a pair or the right terminal point of an interval. This function and functional significance, with which a constituent or part exists at its locus within the organizational of its Gestalt, is assigned to it by the specific structure and particular nature of the Gestalt in question (Gurwitsch, 2010, p. 112). 
Crucially, this idea emphasises Gestalt's relational systems (rather than its parts) is what provide the Gestalt its fundamental character. This is important because the priority of parts/wholes shifts due to the phenomenon of relations being temporally organised and situated $^{22}$.

I interpret Gurwitsch's writing here as suggesting gestalt structures are patterns constituted by parts. Each part relates to each other. The relations between parts constitute the gestalt structure. Additionally, these relations may produce functionally significant roles to the overall Gestalt form. If one part is removed from the structure, the relations between that part and surrounding others would be removed also. This would further alter the relationships of the entire structure of the Gestalt, its history and projection. Gurwitsch's thesis states whole gestalt structures gain their very identities from the relationships between the parts rather than the parts or wholes themselves, more precisely, the 'functional significances' produced upon Gestalt assembly, are fundamental to context production:

Gestalt theory replaces the traditional conception of parts and wholes in terms of elements by a functionalistic conception. Parts are defined as constituents or "wholeparts". They are conceived of as essentially determined and qualified by the functional significance which they have with respect to each other and, hence, for the whole of the Gestalt-contexture into which they are integrated. The whole is accordingly considered as the equilibrated and balanced coexistence of its functional parts in their thoroughgoing interdependence...the functionalistic conception of wholes and parts seems to us one of the most valuable contributions of Gestalt theory (Gurwitsch, 2010, p. 114).

\footnotetext{
${ }^{22}$ As we will see later, like indexical expressions, the reference, or relation of a part is unable to be decided in advance, similarly resulting in the empirical motivation Garfinkel has been recommending: turn to see how the relations between actions are organised and managed in the settings by the members themselves.
} 
This "thoroughgoing interdependence and interdetermination of parts" is what Gurwitsch defined as Gestalt Coherence: The "determining and conditioning of the constituents upon each other"..."In thoroughgoing reciprocity, the constituents assign to, and derive from, one another the functional significance which gives to each one its qualification in a concrete case" (Gurwitsch, 2010, p. 131). Not only do we see here the articulation of a thoroughgoing interdependence and interdetermination of parts as relevant to defining functional signification, we are also provided with a system of interlocking, mutually demanding, codependent relationships all reinforcing and supporting each other; an internal unification; a thoroughgoing reciprocity; a Gestalt-Coherence (Gurwitsch, 2010, p. 135). We are left with a sophisticated theory with a small number of key concepts which motivate the analytical and descriptive focus upon the relationships of the parts of a gestalt contexture as defining the functionalistic form of the overall Gestalt in question.

Moreover, if the removal of one constitutive part of a gestalt contexture affects its relational existence, then it follows the invariance of these parts are thus not equal from one case to the next within phenomenal experience. This is because first, both the affected relations may cease to be phenomenally meaningful, and second, any remaining constituents are no longer involved in the co-determination of functional significance to those lost relations between the removed parts. The notion of the functional relationships are bounded to an immediate, sequentiality of unfolding events - meaning — is thus bounded to not only the situation of its occurrence, but to the surrounding 'field' of other actions: All single actions are dependent upon their situated position within or without a group, a gestalt contexture.

In summary, analytically speaking, and in connection to the context of this dissertation, this congruence (as opposed to correspondence) of relationships between 
situated parts means the analyst is always limited to the study of gestalt contextures within single case episodes so that constitutive parts can be described in the fine moment-to-moment detailing within its wider surrounding spatial-temporal phenomenal field. Given the complexity and layers of abstraction within Gurwitsch's ideas, summarising functional significance and gestalt coherence harmonises with Watson as he describes context as having "kaleidoscopic details" (see Watson, 2008, p. 232; 2016, p. 31-39). The descriptive attempt of demonstrating functional significance in action may be enough to get started under this restriction, however. And to that end, Gurwitsch could only take us so far (See Lynch, 1993, p. 126-127) before Garfinkel turned his concepts to the social world.

Having provided a brief review of Gurwitsch's theory and the borrowing of a select few concepts, we can return to Garfinkel's original teleconferenced talk where he asked an illuminating question: "How shall we examine [the phenomenal field] for its demonstrable properties following Gurwitsch's description of those properties that he called the functional significations?" (Garfinkel, 2007, p. 28).

\section{Indexicality and gestalt contextures}

Indexicality is a concept that is so central to ethnomethodological theory that in many ways it could be considered its original breakaway defining feature. Garfinkel's respecification of indexicality retained the way the members speak, act, and organise their action in intelligible and meaningful ways. Paramount to the ethnomethodological worldview, indexicality pushes the social researcher to the world as the issues surrounding meaning become increasingly irrelevant for studies of the social constitution of fact, truth, order and reality as a philosophical problem (Garfinkel, 1967). 
In comparison, gestalt concepts are relatively underutilised in ethnomethodological scholarship beyond insider knowledge, brief published mentions, and short paragraphs or footnotes. There may be evidence of this changing, however, due to a series of key writings which provide Gestalt contextures as a contemporary topic. Further, these writings often discuss indexicality; further still, Rod Watson ${ }^{23}$ has of late claimed a renovation of methods may be appropriate for many of ethnomethodology's classical developments (Watson, 2016a, p. $31-39$; see also 2008; 2016b). If such a renovation of ethnomethodology's classic methods were to occur, then gestalt contextures, ought to be the primary approach taken as "it has become, perhaps, the locus classicus of the concepts of reflexivity and particularly indexicality for later ethnomethodology" (Watson, 2016a, p. 15). Gestalt contextures may “bring into play considerations that change our analytic mentality', that heighten our analytic awareness of the distinctively identifying aspects" (Watson, 2016b, p. 15) ${ }^{24}$. Furthermore, Gurwitsch's writings do not feature in the key foundational paper "formal structures of practical action" (Garfinkel \& Sacks, 1970), nor in Studies (Garfinkel, 1967). They do however feature in Garfinkel's earlier doctoral thesis (1954, see also Rawls, 2008), his later writings (Garfinkel, 1981; 1988; 1993; 2002; 2006; 2012), and particularly, in what came to be known as ethnomethodological studies of work and science (Garfinkel, 1988; see Lynch, 2015). The remainder of this chapter discusses the concept of ethnomethodological indifference.

\section{Ethnomethodological indifference}

\footnotetext{
${ }^{23}$ See Wowk \& Carlin (2004) for a 'provisional examination' of Rod Watson's work and contributions to ethnomethodology, conversation analysis, and membership categorization analysis. No mention in this review of published work is that of Gestalt Contextures, however.

${ }^{24}$ Although Watson was arguing for gestalt contextures to feature in studies of membership categorisation analysis (see Fitzgerald \& Housley, 2016), his argument is adaptable to canonical ethnomethodology as the former builds from the later.
} 
Unlike the concepts of indexicality and gestalt contextures, ethnomethodological indifference talks more of how the representation of contextual actions is possible as a descriptive product, and how this descriptive product attempts to avoid using a formal sociological format, of variables and hypotheses, of a priori methods. The concept may also help bridge the gap between ethnomethodology and the new sociology of art. Caution must be provided however, as the concept of ethnomethodological indifference is itself resistant to synthesis with any other approach due to some of these defining features.

One of the first available classifications of ethnomethodological indifference describes the concept as an analytical mentality, one geared towards "abstaining from judgements about [member's methods] value and importance" (Garfinkel \& Sacks, 1970, p. 163). Three decades later, Garfinkel (2002) declared:

Ethnomethodological indifference is a policy that has been consistently misunderstood. Generally misunderstood as referring to an indifference to aspects of society, such as matters of structure and social order, the policy in fact refers to an indifference to the policies and methods of formal analysis (p. 170).

The policies and methods of formal analysis is a complicated topic in ethnomethodological scholarship. There is no singular definition of what constitutes these. However, the sentiment that ethnomethodological methods are incommensurable with formal analysis may be understood as an inherent tension in the way social orders are lived on the one hand, and how the sociologist, or anyone else, can represent that lived social order on the other.

Ethnomethodologists are thus positioned to claim constitutive social order is not findable through formal analytical approaches external to the settings under study. In this sense, there is a clear understanding that Garfinkel's ethnomethodological indifference 
provides a way for students of constitutive social order to orient towards naturally occurring settings to find in that setting, how the social facts of quotidian life are formed and organised by members practical actions ${ }^{25}$. This may cause tension for a synthesis of ethnomethodological findings with other programmes of research, as for example the new sociology of art as a result.

Garfinkel argues that research into constitutive social orders is only available under the exercise of ethnomethodological indifference, and social orders are "specifically not available to the policies and methods of constructive analysis" (Garfinkel, 1988, p. 107). Granted the radicalness of this statement (social order is only available under indifference!) I ask: Would this cause social orders to be unavailable for other approaches? Garfinkel seems to have positioned ethnomethodological indifference toward two separate paths: (1) to be given special epistemological status as a research technique applied during the pursuit of researching constitutive social order or, (2) has discovered a domain of social phenomenon to which ethnomethodology is directed to investigate.

If Garfinkel claims formal analysis is not very useful for the study of constitutive social order, then the ethnomethodological recommendation may encourage one to bracket the objective status of social facts themselves (Rooke \& Seymour, 2005). Furthermore, if adopted, the attitude may be used to remind the analyst to focus on the lived order of how social actions are organised, rather than test the validity of theoretical concepts themselves (Lindwall \& Lymer, 2005). Consequently, speaking not of the political, but of this

\footnotetext{
${ }^{25}$ This position toward written accounts of living phenomenon may become problematic however when an analyst reflects upon the notion that ethnomethodological indifference is a formal concept itself, and may therefore raise concern with logical ironies - If remaining indifferent to formal academic concepts provides access to research constitutive social order, then what happens if 'ethnomethodological indifference' is treated itself as an example of such an academic formal concept? One response could be to treat the issue in two epistemological levels, first, one which governs the analytical approach, and second, one that identifies formal phenomena through which members practically conceive the world (See, Au-Yeung, 2020 unpublished PhD dissertation).
} 
withdrawal from a calculus of society, Arminen once described, "ethnomethodological indifference [as] the most heavily loaded out of all Garfinkel's many concepts" (Arminen, 2008, p. 232).

I use the concept in this dissertation to provide an orientation to the constitutive work members do to organise their practices, whilst also an appreciation of the indifference to the formal representation of those constitutive practices. Lynch (1997) offers his interpretation, one which defines the version used in my analytical approach:

The policy of 'indifference' should be understood not as a principle that sets up a purified vantage point but as a maxim that encourages a unique way of investigating how social order is consisted. As such, it is a reminder to keep the constitutive order in view. (p. 373).

\section{Formulating the research object; unmediated access.}

Methodologically, organising the data of practical social action in terms of capturing the participant's own endogenous social actions does not come easily. It comes with the need to understand what the participant does not ordinarily notice, as what is expected for them to notice is ethnomethodological: If society is produced in and by local settings, then how do people do the work of producing that sense of structure and make it stable? What artful, contingent ordinary organised ways do members use to retain the formal structures of this setting for this moment? Here, the participant's taken for granted world is brought into question. We face the idealisation in which ethnomethodology may undermine the member's own ability to recognise the mundanity of their own activity - does ethnomethodology explicate that which the member may ordinarily miss? Does the academically trained 
ethnomethodologist have a claim to knowledge about how societies are ordered over and beyond what the member ordinarily knows?

First, a reflection about an issue surrounding the notion of ethnomethodological indifference. I understand Garfinkel's view of social order to be simplified as a request: Turn to the world rather than the word. I reached this idea due to the development of indexicality as expressed above. Located in academic sources, that phrase, however, can only ever be found as a worded request. Ethnomethodology's tension is like coming to master the art of jailbreaking only then to learn the mastery of turning oneself back in. Of course, to never be seen or heard from again is the true sign of a successful escape. The irony is that academics want to be seen and heard - and for good reason: Social research can teach us things about society that actually, and otherwise, do remain unnoticed and require the professional techniques of professional social analysts to uncover. Whether these observations are significant to the participant is another matter entirely.

This basic dualism between the worded texts that 'ethnomethodology as an academic discipline' resides within, and the observable social actions that ethnomethodology seeks to describe is easily understood formally as a double adjective (Sormani, 2014). The lived action that persons in society produce, and worded analytical accounts of that action are both unique and not representative of one another in phenomenal consequences. The realisation that writings are not equal to live action further provides a positive clue to what is required of written social research. How best then, can the words represent that live action? How close can we get to the live action before it becomes words? Ethnomethodology can turn ethnomethodology itself into a study of practical action, of 'doing writing of live action', yet indeed, thinking in this frame of mind may position the researcher into a state of dissatisfaction. It is disappointing that after a considerable volume of energy is spent articulating ordinary live observations, such articulations could never be equal to the live 
activity they seek to describe. Ultimately, this is an ideal standard that can be at first recognised, and secondly mitigated through epistemological strategies to keep the humming of society as the first priority.

Moving towards one of the consequences of utilising ethnomethodological indifference, it could be used to gain access to phenomenon not otherwise available, as (Garfinkel, 1996) stated:

EM is not in the business of interpreting signs. It is not an interpretive enterprise. Enacted local practices are not texts which symbolize "meanings" or events. They are in detail identical with themselves, and not representative of something else. The witnessably recurrent details of ordinary everyday practices constitute their own reality. They are studied in their unmediated details and not as signed enterprises ( $\mathrm{p}$. $8)$.

I interpret Garfinkel as mitigating this issue by suggesting texts are simply not identical to the practices they describe. Yet for Arminen. Garfinkel may be offering a way for analysts to gain "unmediated access" (Arminen, 2008, p. 170),to other's social order phenomenon. Arminen further reminds us social analysts are unable to gain unmediated access to other's lived phenomenon (including ethnomethodologists). Even if analysts utilise the concept of ethnomethodological indifference, they are not saved from the practical tasks of collecting, transcribing, analysing, and describing data into artefacts, i.e., producing publishable social research in the forms of books, journals, manuscripts, theses and monographs. Arminen writes as if ethnomethodologists are unaware of this, as their use of rendering theorems or bracketing exercises is paradoxical: If they are aware, then why attempt to get closer? If they are not aware, then they use devices to get closer. 
In this way, dealing to the inherent irony of the concept, and the claim that social orders are capable of being studied in their unmediated details, ethnomethodological indifference causes a great deal of tension to be resolved before it can be given any security as a worthwhile notion. At the very least, it is convincing as a useful road map, one used to find, apprehend, discover and produce insights into how meaning and social order is produced in the natural social world.

It is my understanding that Garfinkel is not suggesting ethnomethodological indifference gives unmediated access; rather, and this is key, social orders are studied in their unmediated details. The distinction between these words is paramount to understanding how the concept is used as it already brings with it the assumption social orders are lived and not explained ethnomethodologically. The counterargument to be made here is that if we accept Arminen's interpretations then we are setting ourselves up to value our descriptions as explanatory, to stand on behalf of members social order, when in fact, in many ways ethnomethodology is a project of returning to the constitutive actions of the social world. With the tension of doing so to provide a post-hoc descriptive account of what was seen and done and not to capture the phenomenon. Ethnomethodological writings are therefore corrigible and subject to change with another next looking where their privilege is second only to the privilege of acting and existing in the world with and in a community of others.

\section{Conclusion}

This chapter presented the main theoretical context which forms the analytical framing within the following four empirical case studies. Watson suggested gestalt contextures ought to provide an analytical mentality which primarily, treats any, and all, constitutive action as relevant to the formation of meaning and intelligibility, of endogenous human action and structures of practical activity. Key amongst this is the idea and 
vocabularies of the thoroughgoing interdependent and interdeterminate relationship between constitutive parts of a gestalt organisation. One component of this organisation is how the member's natural and free flowing social action may feature in real time activities. Garfinkel recognised the work required to do this in Gurwitsch's gestalt concepts. He took them from their abstract and philosophic formations and moulded them into an research practice, one used to focus the analyst toward what he called the observable orderliness of everyday social life. This dissertation is designed around this recognition and analytical focus.

In the empirical chapters to follow, I utilise gestalt contextures and functional significance in different, perhaps incomplete and competitive ways, and as the chapters develop, my understanding of gestalt contextures as social phenomena increases. The analytic mentality was perhaps in the best state I can offer as a sociological product of this thesis within the last empirical chapter where I learned from earlier cases how gestalt contextures may be further used to frame the empirical focus of locally constituted accomplishments of social order. One consequence of engaging with ethnomethodological analysis, particularly in domains of practical reasoning (Livingston, 2016), was the surprising strength of Garfinkel's use of Gurwitsch's gestalt phenomena due to its general ability to notice an alternate for both social and non-social orders in ordinary life.

This leaves open several questions: What type of ethnography is suitable for art sociology? Are art sociologists interested in the formation of artworks in non-obviously social interactive domains of activity? Are art sociologists interested in the formation of artworks exclusively in social domains of activity; i.e., intersubjective and socially interactional domains of human talk, conduct, gaze, with each other, and with art objects themselves? These concerns provide fodder for the following chapters.

In the following four empirical chapters I turn to describe how a group of artists navigate a river terrain to select a subject to be painted; how an abstract studio painter 
organises his mark-making to produce a work of art; how an urban sketcher measures the angle of a building with his pencil and thumb to subsequently organise his sketching pad; and how a group of urban sketchers discuss their recently completed artworks with one another around a busy café table. These case studies aim to simply showcase through both visual and audio transcribed materials how persons act in small sequences in naturally occurring ways. Guided by the above discussion on indexical and gestalt contextures, explicating the real time, situated, and person's free forming practical action is the aim of the following analyses. 


\section{Chapter Four: Navigating a Landscape in Search of a Painting Subject}

The only way that I understand Garfinkel's work is by finding in the world that which Garfinkel could be talking about. This is the "missing half" of Ethnomethodology's Program (Livingston, 2003, p. 483).

\section{Introduction}

Literature scarcely exists between the juncture of art sociology and art ethnomethodology. Mutual topics within each field orientate around understanding how people organise their conduct in settings which involve interaction with artwork. For example, a musician playing jazz piano (Sudnow, 1978), a painter demonstrating how to mix the colour purple (Armour, 2000), an opera's production staff organising the constitutive actions necessary for putting on a show (Atkinson, 2006), a gallery viewer interacting with an artwork to find evidence of unique mark making (Heath \& vom Lehn, 2004), how art auctions are socially organised through bidding and the sounds of the hammer (Heath \& Luff, 2007), and lastly, how dance rehearsals are treated as organised accomplishments of rhythmic practical actions (Bassetti, 2014). These few ethnomethodological studies of 'art-work interaction' describe how persons do the things they do in real-time, in naturally occurring situations.

This chapter gains its analytical attitude through the ethnomethodological technique of respecifying skilled domains of art practices into ordinary renditions of those self-same practices (see Chapter 3). In other words, analysing how people interact with artworks through an ethnomethodological attitude may hold a unique, yet recurring sentiment which Armour's (2000) polemic expresses: 
Although sociologists of the arts refer to 'artistic practices' treating them as obvious if contested, they fail to appreciate or consider what such practices might actually look like in situ and thus miss the detail of such practices that are the very stuff of art as [social] work (p. 64).

Propositionally then we may ask: What do artists interactively do whilst painting in the world; what impact would an ethnomethodological description of artwork have on the sociology of art? The thesis question asks, how are artworks formed in and as practical social action? In the following case study, I pursue through a fine-detailed video analysis how a landscape artist navigated a river terrain to organise, and then select a 'subject' from Nature during a plein air painting excursion.

I seek to describe several observable social techniques surrounding the interactive work of how this was accomplished, of how a trio of three conduct their searching, navigating and orientating to their surrounding natural landscape as artwork. For example, haphazard pointing, talking and gazing, may consequently display, how common communicative practices are more social than artistic. These may be important for understanding how art objects are accomplished in and as practical social action, hence the new sociology of art can be connected with studies conducted through ethnomethodological attitudes.

\section{Roadmap}

The following chapter is structured in five main sections:

First, I briefly connect with the new sociology of art's discussion on the contextually indeterminate production of meaningful art objects. As the previous literature review chapter has shown, this caused a flurry of researchers to investigate sites where people interact with 
artwork in real time and through social action. Of these studies, few ethnomethodological demonstrations are available. However, identifying and then attempting to answer DeNora's call to research how artworks are formed by artful social accomplishments (DeNora, 2014, p. 7), I suggest ethnomethodology may renew this scholarly interest at the face of the current decade.

Second, I introduce the research site, research participants, ethics concerns, data and methods, and justify how the case was selected.

Third, Garfinkel's misreading of Gurwitsch's gestalt contextures comprises the analytical mentality of the forthcoming analysis (as developed in the previous chapter). In this section, I adopt Rod Watson's recent work and articulation of a 'kaleidoscopic metaphor' (see Watson, 2008, p. 232) as the primary mentality for describing practical actions witnessable on the video tape.

Fourth, I present a series of both verbal and graphic transcripts (Laurier, 2014) that display records of the organisational talk and gesture between two artists and a social researcher. These details were extracted from video-recorded data that was obtained during a one-day field trip. The analytical focus orients toward describing how a painting subject was selected and formed in the sequential embodied conduct. This section makes up the main empirical focus of the chapter.

Fifth and lastly, I conclude by suggesting the sociology of art abandon the pursuit of establishing epistemological foundations, and rather, turn towards analysing how members of living society organise their action in real time. Utilising single-case empirical descriptions of constitutive acts and their organisation of artworks may stoke the fire and ignite a secondgenerational wave of studies for the new sociology of art, inspired exclusively by ethnomethodology's sensitivity toward ordinary society. 
Consequently, the following case focuses on how participants (an interacting party of three) worked at determining what was to become constitutively relevant to their task-athand: How a natural landscape was organised into a subject to be painted though interconnected social actions. I argue these activities can be taken seriously, and the sociological study of artistic practice may be more ordinary, and more social than commonly thought possible.

\section{Research Background}

\section{Research participant}

Freeman White is prolific New Zealand landscape and portrait painter who spent time working in Wellington before relocating his studio to Napier. I travelled from Wellington to Napier to meet with Freeman after receiving an invitation to visit him in his studio after calling him on the phone one week prior. After our brief studio interview, I followed Freeman and his friend Buck to the research site of this study the next morning, the $2^{\text {nd }}$ of August 2018.

\section{Case Rationale}

This case was selected as it was the only footage I had obtained of Freeman painting in real time. The research at large was not originally designed to be a single-case study yet given the participant is a working artist - rather than engage with an ongoing ethnographic research project spanning several sessions - the opportunity to follow Freeman in the wild was a onetime deal too good to pass up. 
The footage obtained clearly shows how the artist navigatea around a river terrain to arrive at a subject to paint. Included in this footage is Freeman, after selecting his subject matter and setting up his equipment, painting. An earlier form of this chapter's data analysis studied how this painterly work was done, of how the brush strokes were used to organise the canvas into an art object.

After having described this artistic action I returned to revisit the earlier navigational footage. Upon another looking I realised the social work that was conducted before the painting activity commenced was just as pertinent to how the artwork was formed, as was the physical and technical painting work itself. The case study then evolved from a study of describing Freeman's artistic praxis - primarily his real time brush and eye work - towards how the interpersonal social relations of the group and their other surrounding actions, like searching, navigating, complaining, following directions, and so on, were used to organise the painting subject as a social object. Many of these organisational behaviours were verbal, gestural and navigational.

As the artists had only an idea of what they wished to paint it was not until they had arrived at the site when the work of organising that site into a series of ad hoc land marks, group navigational instructions, and relevant properties of the site specific social activity of doing painting began. I realised this social work was a good place for the study of self-organising social phenomena. The rationale for this lies mostly in Freeman's technical ability: To describe his masterly painterly action was beyond my natural ability to do it justice. In short, I felt that I did not possess enough adequacy in the skill I was attempting to study. Garfinkel recommends a certain "member's competence" as an attempt to take the looks of things from the perspective of the moment to moment dynamic nature of action. Asking how artworks 
formed in and as practical social action, however, may be provided an answer, one found in the interactional navigational work organised amongst the three artists. This is an area of which I am better able to provide adequacy to the social activity of plein air painting.

\section{The Analytical mentality}

A social analytical style was in mind when describing, viewing and reporting art objects being constituted in and as plein air painting. In my view, ethnomethodology wants to hold no imperative or prohibited set of research procedures or methods so long as the data obtained is adequate to the phenomena under investigation (see Lynch, 2015 on ethnomethodological indifference). Collecting, observing and framing data to design, ask and answer a research question however does require process.

In the following study I draw my analytic mentality from the ideas laid down within the theoretical chapter, but specifically in this chapter, I draw from Watsons recent discussions on ethnomethodology's gestalt contextures (Watson, 2008):

The point about a gestalt contexture is its distinctiveness: each specific phenomenal field is composed of a distinctively-identifying array of phenomenological detail, much in the way that a kaleidoscope furnishes a new, distinctive pattern after each shake. To lift an item of talk-in-interaction from such a distinctively-identifying phenomenal field is to remove it from what Garfinkel and Gurwitsch might term its very specific functional signification (p. 232).

Watson's metaphor of a kaleidoscope is helpful in that it provides two main concepts to help tame the abstract nature of gestalt contextures. A kaleidoscopic image is made up of its small parts to produce a whole pattern, when related to real time social actions - as seen on a videotape for instance - may organise those social actions as an activity made up of smaller 
acts. That is, to observe the acts and their collective organisation as an activity is to see an distinctively-identifying phenomenal field. This metaphor aids the analyst in two ways, first, it suggests the resistance of any approach taken where individual acts are treated apart from the other acts that surround it, and second, when acts are seen as related they relate to one another in a significant way. This relation is significant because it suggests that acts gain their phenomenal meanings from the other acts that immediately relate with them in real time.

Is Waton's decade-long discussion and kaleidoscopic metaphor (Watson, 2008, p. 232) an untapped resource full of unexplored ideas waiting to be picked up at the intersection of art sociology and ethnomethodological thinking? Could his writings be a congregational transformation of ethnomethodology's many classical developments? (see Watson, 2016a, p. 31-39). If a renovation of methods were to occur, then it would place gestalt-contextures as a primary methodological approach: "It has become, perhaps, the locus classicus of the concepts of 'reflexivity' and particularly ‘indexicality' for later ethnomethodology” (Watson, 2016b, p. 15). Gestalt contextures bring "into play considerations that change our 'analytic mentality', that heighten our analytic awareness of the distinctively identifying aspects" (Watson, 2016a, p. 35); moreover, "this sense emerges, develops, and transforms over a texture-specific durée as endogenously appreciated by participants" (Watson, 2008, p. 230). Explicit effort was maintained throughout the analysis to repeatedly return to the video data to draw out the 'salient objects' - a term I used as a place holder for something to be found in such participatory appreciation - as they were woven with, and detached from, their constituted phenomenal fields. This analytical effort to focus on the sequence of individual acts as they chain towards an activity was an early attempt to understand how gestalt contextures could be used to describe the ordinary conduct witnessable on film, not only for the navigational footage found within Freeman's tapes, but of the entire dissertation's video 
corpus as a whole. In this way, the analytical mentality of using gestalt contextures was an alternative way to discuss social acts, action, and activity as endogenously organised.

\section{Ethnographic Context}

In the month of August 2018, I travelled to Napier, a small sea-side city positioned on the East coast of New Zealand's North island to visit Freeman White, a professional landscape and oil painter, in his studio, to discuss his artistic process. He insisted we converse about how painting on location is one of the oldest ways of working in a realist fashion. The French impressionists, Monet, Renoir, and Pissarro popularised the practice and effectively coined the term en plein air (painting in the open air). Freeman explained the difficulty in practicing the craft:

It's really hard because when you're working from nature, everything is constantly in flux, everything's changing, you don't have-you have this multiplicity, and slight variation and change, you know, which is when you're trying to distil something down into a single image, you know_-it's difficult! So, it's a different working method (transcribed audio file):

Distilling something down to a single image gives us an appreciation of the in vivo, the dynamic, the variance, the change, the multiplicity — "the flux of Nature" - that a plein air artist typically pursues: Clouds move, the sun rotates, winds pick up, rain falls, but ideally, yet not in all cases, the point of this activity is to walk away with a small painting known as a study, in principle, a study of nature, of light's effects seen from a single and static viewing point. As our discussion headed to a close, Freeman asked if I would like to see him and his friend capture such "an honest interpretation of a moment in time"-we met the next morning at a small village, Havelock North, which is located a few kilometres south of Napier. After a brief exchange, I followed Freeman and his friend Buck's car along a southbound road. We chased the Tukituki river for thirty-minutes until we came to a rolling stop outside a steel farm gate, beyond which lay a large section of pasture we were to cross 
on foot. At the end of the pasture, another gate, and beyond that, river stones. I brought my small hand-held goPro action camera and without knowing what was to follow, of what Freeman would say or do, or where entirely we were heading, I video-recorded our excursion as it unfolded in real time ${ }^{26}$.

\section{The Case Study}

Narrowing down Nature into a painting subject

We arrived on the scene as a local cohort of three. Freeman led us down a long dirt track and intermittently provided verbal and non-verbal comments. These directed our party's production of a common navigational goal:

(Figure 1, Video 1).
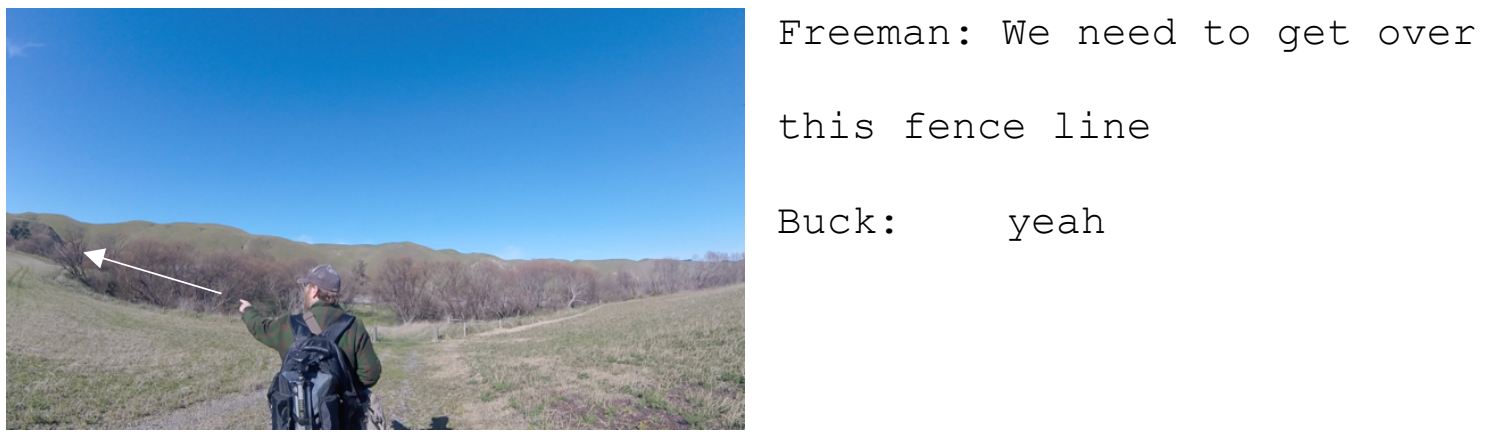

Figure 1.1

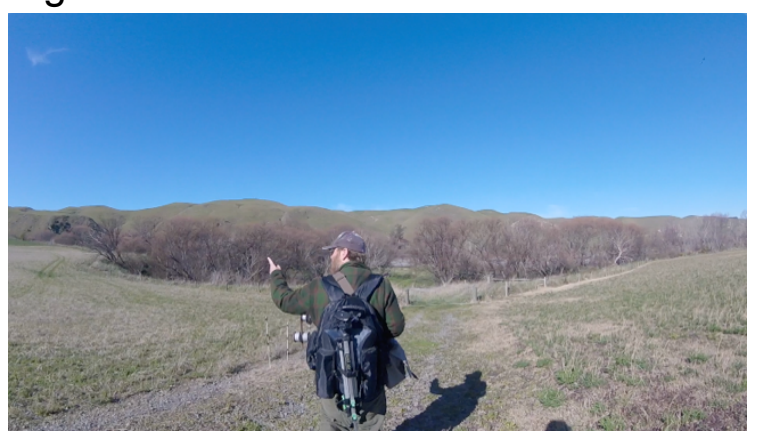

Freeman: And get up here but

Figure 1.2

\footnotetext{
${ }^{26}$ Having this footage available for future looking provides the following description a certain access to knowledge: I knew at the time of writing where I had been, and could thus write about, where we had ended up.
} 


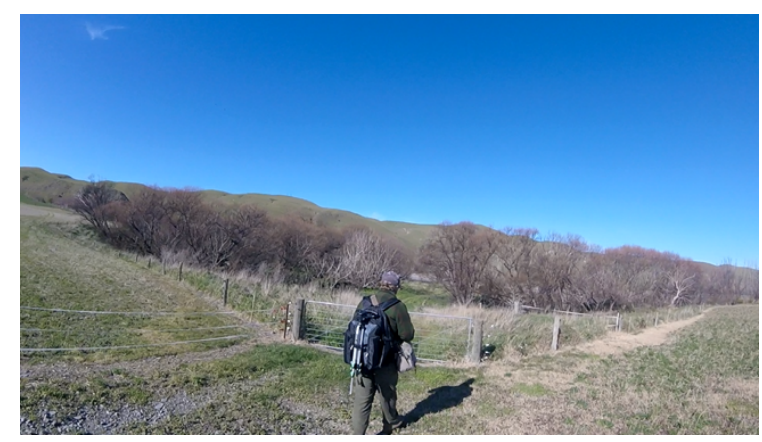

I dunno, we gotta get down,

down the river

Figure 1.3

As illustrated above, Freeman turned his head and raised his hand to form an index-fingered point. Speech accompanied this gesture as he circled the air with his finger: "We need to get over this fence line” (Figure 1.1). Buck confirmed: “yeah”. I remained silent. We walked only but a few steps further as Freeman appended onto his previous doings with another finger-point and utterance: "and get up here, but" (Figure 1.2). These directions immediately circumscribed the likelihood of other spatial orientations featuring within our future trajectory and unfolding field. Because we were heading to a direction Freeman previously indicated, we were to narrow down the surrounding physical space: The landscape's local, spatial, and social contextual field where we found ourselves situated. Yet, our party suspended the sense of these current directional doings until we worked out how to get, find, and search for the as-of-now-non-visible-object of our destination 'waiting beyond the fence line'.

\section{Stabilising the ordinary}

As we walked ahead through thick grass, we passed inconspicuous natural objects as the river appeared upon our party's horizon. We emerged out of this temporary moment and discovered a feature of the landscape worthy of assessment requiring us to make sense of the unfolding situation. Consider figure two below: 
(Figure 2, Video 2).

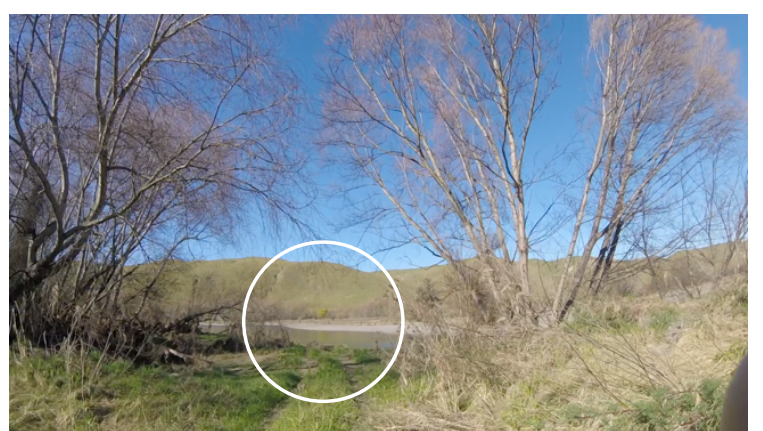

Figure 2.1
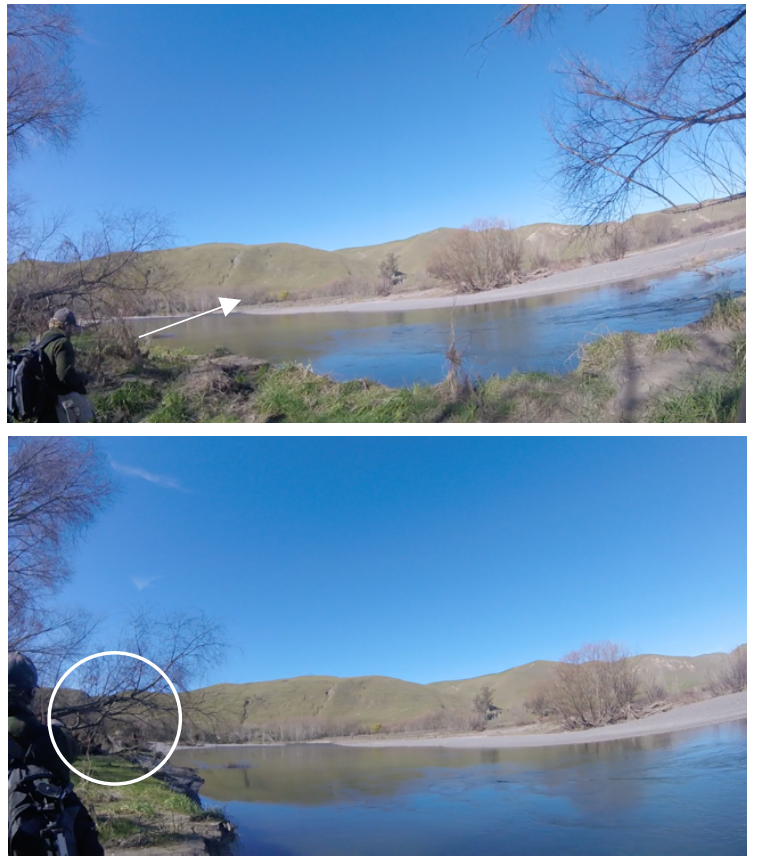

Figure 2.3

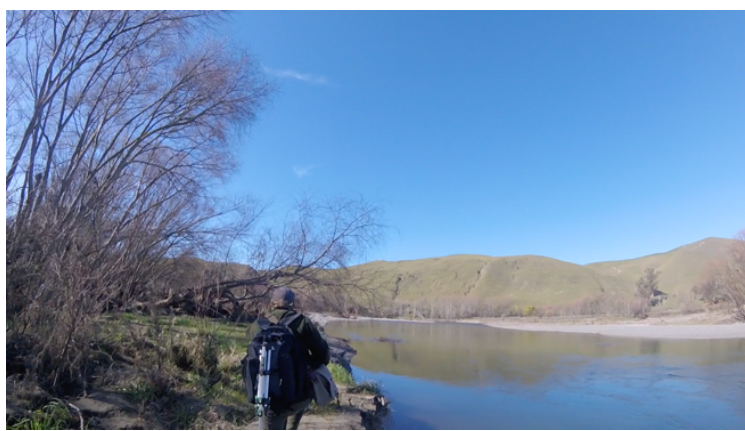

Figure 2.4 [approaching the riverbank]

Freeman: It looks like the river is quite close to the bank now

Buck: Obviously had some floods

Freeman: Wow

Freeman: Yeah, I think we're gonna - right up here sometimes it's way over there Nah that's cool, we can just come along here;

[walking a little]

Freeman: Do you see that?

$$
\text { That's the island }
$$

Researcher: Yep

Freeman: Over in the distance there

Evident in the above figures, Freeman assessed the proximity of the river's water to its bank (Figures $2.1 \& 2.2$ ) then announced to our party a visible pathway "nah that's cool, we can just come along here” (Figure, 2.3). He led the way whilst looking ahead and uttered: “do you see that?" - "that's the island over there" (Figure 2.4). These phrases are social acts 
contributing to the formation of the activity of reconfirmation. Our navigational goal thus avoided potential disruption and remained stable enough for a new addition: The island.

This object appeared to our group for the first time, as evident by my reply "yep". Retrospectively, Freeman's earlier utterance 'over the fence line' confirmed the 'correct direction all along'; and prospectively, 'the island' adapted as a concrete object which was 'meant all along'. That is, our narrowing down of the environmental field - other trees, hills, rocks, etc, became a natural part of plein air painting, as ordinary acts of navigational activity. We pointed, for example, and moved, talked, and thus identified concrete environmental objects and landmarks relative to our group's orientation, as we, as a travelling party, worked together and organised the landscape into relevant features for painting. For the here and now, things were running smoothly and stable enough. Our work continued to fold, adapt, and assemble the painting object out of the seemingly infinite number of potential others amongst their natural surroundings - this tree and not any others, that island and not the one across the river.

\section{From past talk to now visible field}

As we incorporated relevant objects from the entire visual field into our developing phenomenal field, we talked, gestured, and anticipated what the future trajectory of our now previous actions entailed. And as we narrowed down, and entered these objects into our social, endogenous reality, "the island" constituted our first painter's object:

(Figure 3, Video 3). 


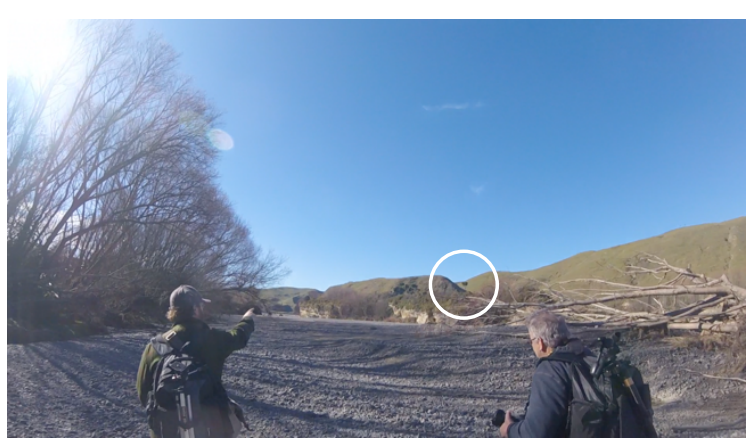

Figure 3.1

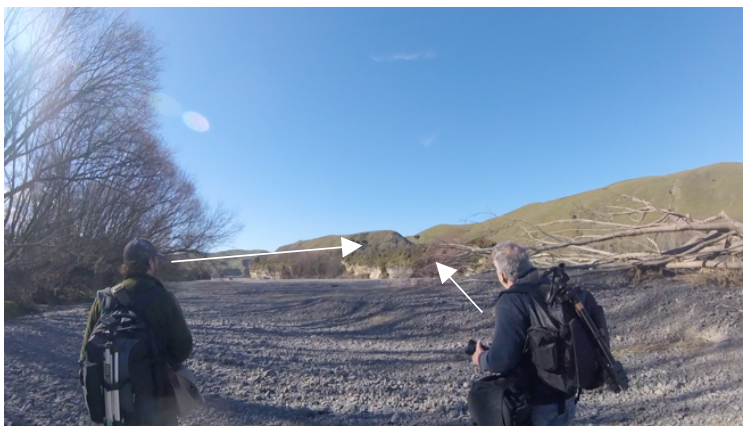

Figure 3.2

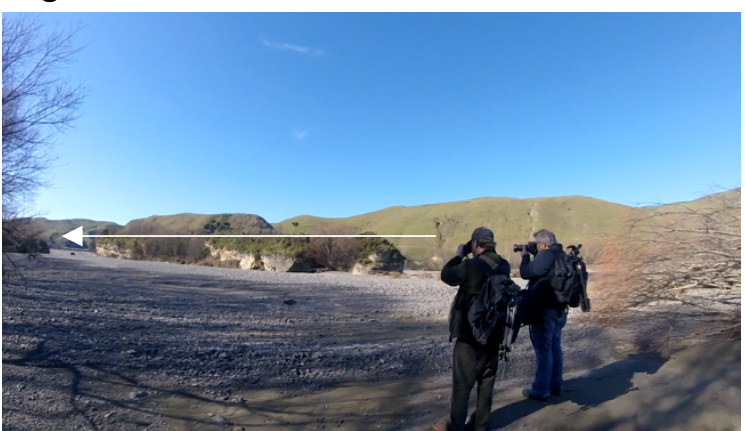

Figure 3.3
Freeman: Its cool ay.

[points to the island].

How it's got the little

cabbage tree on top

Buck: oh yeah

[walking in motion toward the island]

[inaudible concern]

Freeman: yeah we will, we will go up there

As we followed Freeman's instructions, the island appeared within our party's visual field.

Freeman raised his head and uttered, “it's cool ay, how it's got that little cabbage tree on top" (Figure 3.1). We then looked at the island as Buck responded: "oh yeah" (Figure 3.2). The two artists stopped walking once they hit a small sandbank that lay up ahead (Figure 3.3), with this pause they withdrew their cameras as pictures were taken of both the island to the left of our party, and the visual field as it lay upon the horizon. Thus the island appeared upon our visual field for the very first time since arriving on the terrain. It was a found object, one worked out over the previous organisational acts and their glosses: The 'fence line', 'the island', 'the cabbage tree', and lastly, 'we will go up here', are phrases that contributed to the 
ad hoc creation of a plan to be acted out. Consequently, the painter's object awaited further assessment as we continued to navigate the rocky river terrain toward a now fleeting meaningful direction.

\section{Uncertain features in the field ahead}

As the island's salience increased upon our visual horizon the surrounding conditions caused evaluation of the quality of the hitherto unseen painting location. Freeman's desire to lead our travelling party to our destination was called into question as a result. The river may not be high enough, its local state impacted our previous plan: The now encroaching possibility that the river was too difficult to cross appeared as a challenge worth discussion:

(Figure 4, Video 4).

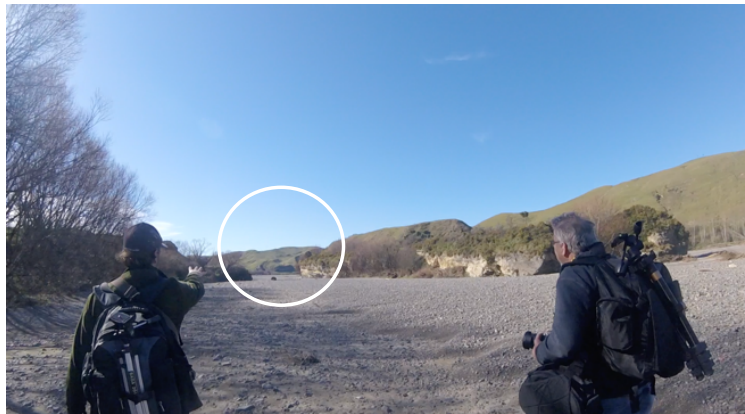

[loud footsteps due to pebble stones]

Freeman: Surely, we would get a nice little painting from that place there yeah

Figure 4.1

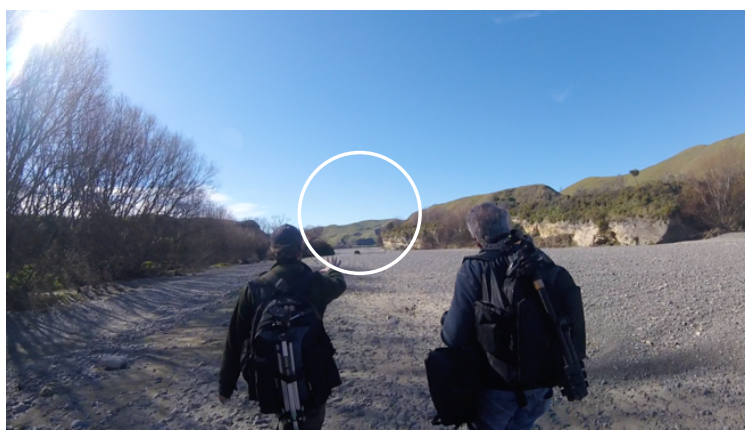

I think this would make a nice little painting This one here

Buck: Coming through now?

Freeman: Well the water is pretty low

Figure 4.2 


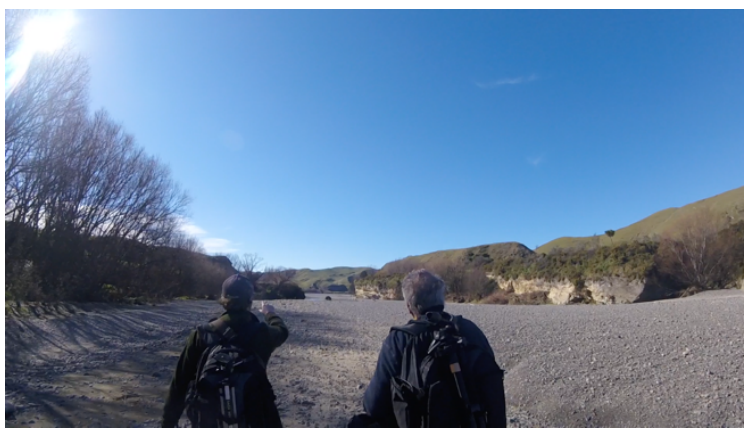

Figure 4.3

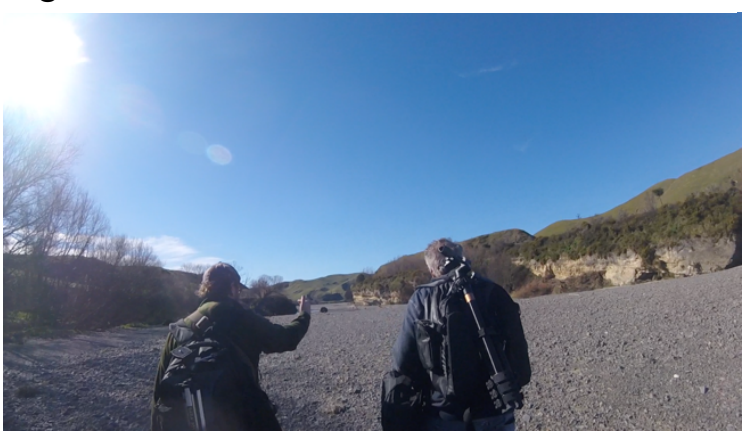

Figure 4.4 [looks to the left at the dry riverbed]

Whereas last time I was here, the river was a lot bigger

\section{Buck: Yep}

Freeman: And you got that reflection

Visible in the figures above, as we walked further towards the island, Freeman uttered whilst he pointed to the visual setting "surely we would get a nice little painting form that place there" (Figure 4.1). As we continued to move forward, he uttered again: "I think this would make a nice little painting, this one here" (Figure 4.2). Buck responded: "coming through now?" As we continued marching towards the river, Freeman assessed the scene. The water was low. He reminded us of how it was much higher when he was here last, which caused a larger reflection of the island upon the river's surface (Figure 4.3; 4.4). Moreover, as we continued to approach the river, we made several assessments, and these I argue, are what may have kept our prior agreement stable enough for the next few moments: Although we had an idea of what to paint, when we arrived at our planned destination, we learnt adjustments were needed — our plan was bound to change. Seemingly insignificant aspects, such as being unable to account for the water level altered our plans. Consequently, as we narrowed down the landscape into relevant painterly features, we were heading toward a major problem to solve. 
Ad hoc plans towards a concrete destination

We met the island at the river's edge, and it agitated the salience of our journey. We were unable to continue any further without walking through the water to reach the other side. Having arrived from our organised path and trajectory's anticipatory location, we shifted our earlier understanding of where we were heading and required deliberation to organise where we were to go next. Remedies were needed, yet Freeman raised a small tension in our group by suggesting we ought to back-track:

(Figure 5, Video 5).

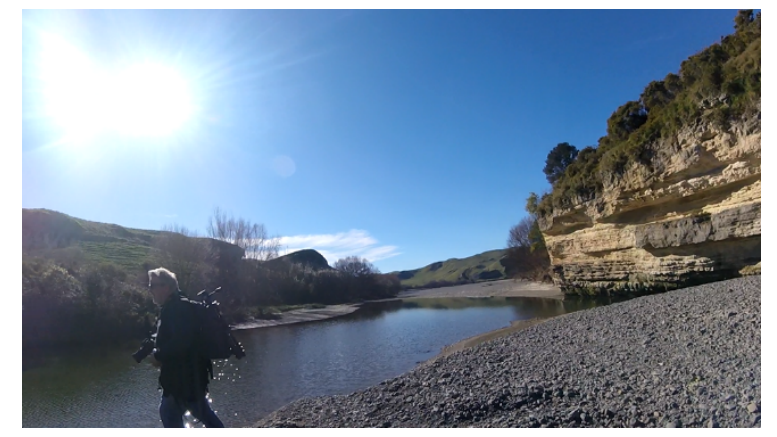

Freeman: Coz I just wanna get some shots of

Figure 5.1

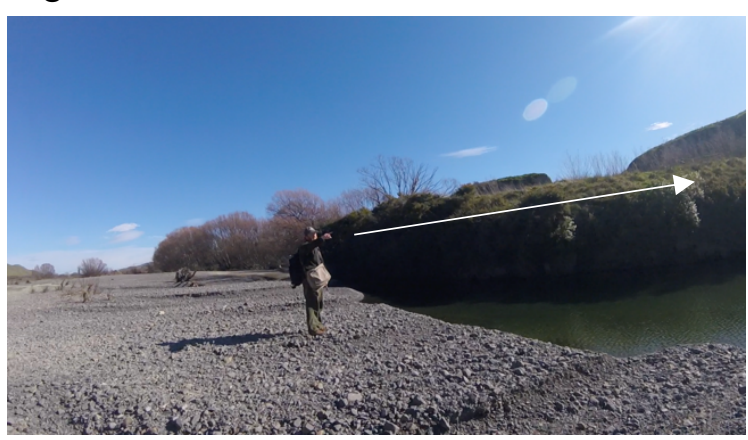

Down this way

Buck: Why don't we go back around the hill?

Figure 5.2

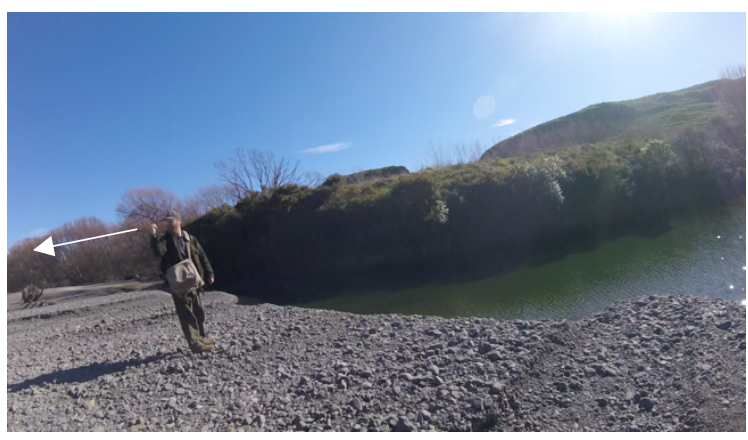

Freeman: No we gotta go back around here and drop

Figure 5.3 


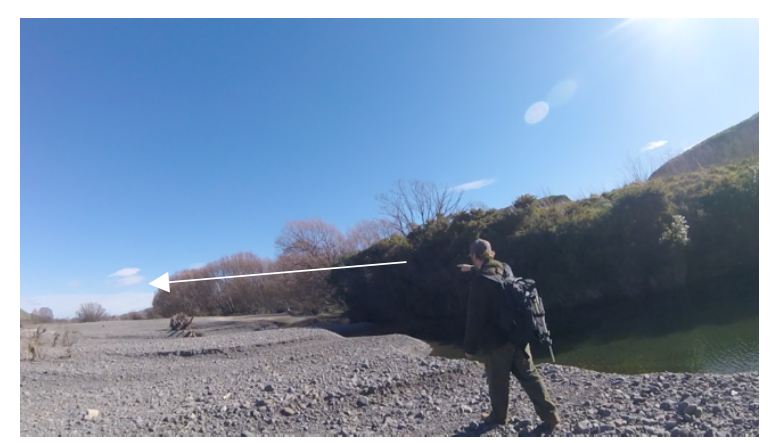

Figure 5.4

In (Figure 5.1) we can see how the water met the riverbank's edges to form a body difficult to cross. Freeman interjected: “Coz I just wanna get some shots of - down this way” (Figure, 5.2). Buck suggested we attempt an alternative route, yet Freeman persisted: "No we gotta go back around here and drop" (Figure 5.3; 5.4). In this last act, Freeman communicated that he wanted a precise viewing angle of the island, one which faced south bound. A new ad hoc plan resulted: We now had a visible concrete destination and thus we shifted our party's task and took stock of both the current destination, and of the view we were to be painting from.

The landscape not only played a role beyond our wayfinding anticipations, but it also affected the entire organisational field that $\mathrm{I}$, as one of the three, thought we had been working towards establishing. That is, the idea of 'reflection' was itself, transformed into the painting subject. This 'analytical discovery' not only distorted the narrative of providing a local plan for our traveling party, it also, in doing so, contorted the entire meaning of what the subject matter could have meant all along. As painters are aware, it was less to do with the physical object, and more to do with relationship between the viewer's body located in space, and how the sun's rays illuminated the object in question. Our painterly activity was now one of organising our group to reach a static viewing station for which the limestone in the waterthe island - would be best painted, it had less to do with the island but of the water that reflected it. 
Shaping disorderly work to an orderly form

It was a curious feature of our work in knowing what, and why, we were walking in the opposite direction of where our original painting subject was located. This increased the value of the reflection-as-painting-subject, however and moreover, it was not any reflection, it was a found reflection, the circumstantial uncertainty of which was unknown: would we make it over the over side? The small details of our phenomenal field had changed as the apprehension of a narrowed landscape continued to develop. The whole social organisation was exhibiting a state of disarray currently being worked out amongst our party.

(Figure 6, Video 6).

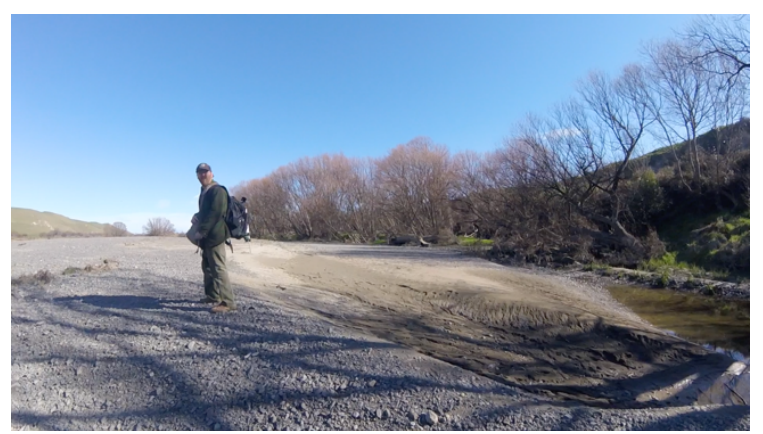

Figure 6.1

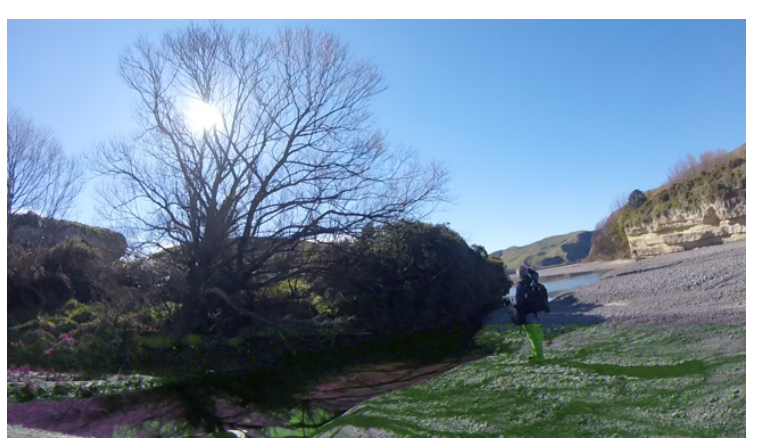

Figure 6.2

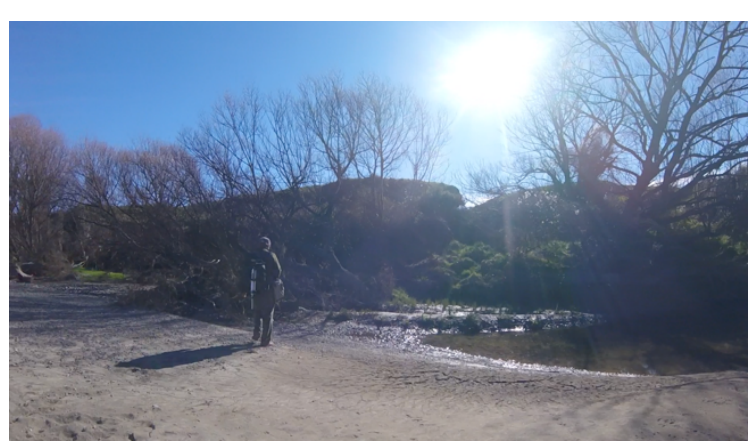

Freeman: Oh. Maybe you're right

Buck: How / can we get up and along there?

Freeman: No, we can get up and along there.

Yep. That's it.

If we can't

Too bad

[Freeman heads towards the hill] 


\section{Figure 6.3}

Above, Freeman had led us a few hundred meters before he paused, turned, and uttered: "Oh, maybe you're right" (Figure 6.1). Buck then interjected: "Could we get up and along there?", Freeman confirmed, then re-confirmed: "Yep, that's it" - "if we can't, too bad" (Figure 6.2), As before, Freeman marched off into a small muddy walkway, determined. Each object within our then immediate surround formed part of our overall painting work and our navigational plans were driving the order's disordered status. Regardless, we managed to arrange our actions into a future that could take shape. The overall goal at large had seemingly detached - the painting activity turned to navigational tasks - to get to the river so as to view the island from a south-bound position so that we were able to paint the reflection of limestone upon the water.

\section{Stabilising the painting object as more than objective}

The island received yet another version as a painter's subject. What lay beyond the hilltop determined whether we would paint the original painting object (as was discovered, the reflection of the limestone upon the river) or, whether another subject was to be painted altogether. There was freedom in the setting, that for example, we may learn there is no easy access to the other side and thus decide to set up our easels on the top of the hill. In any case, I followed Freeman up the bank:

(Figure 7, Video 7). 


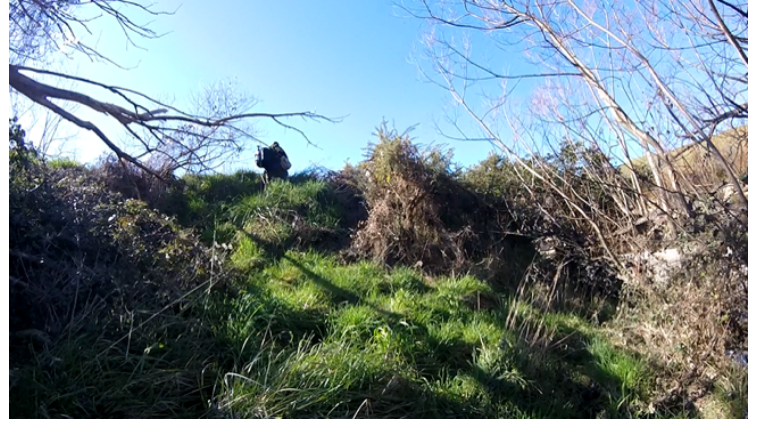

Figure 7.1

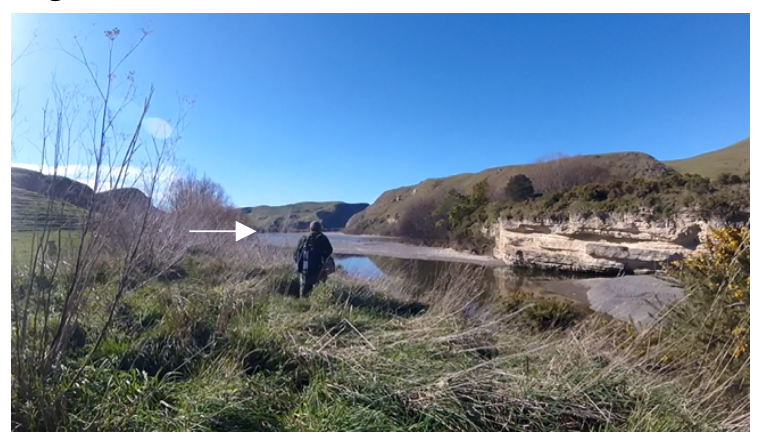

Figure 7.2

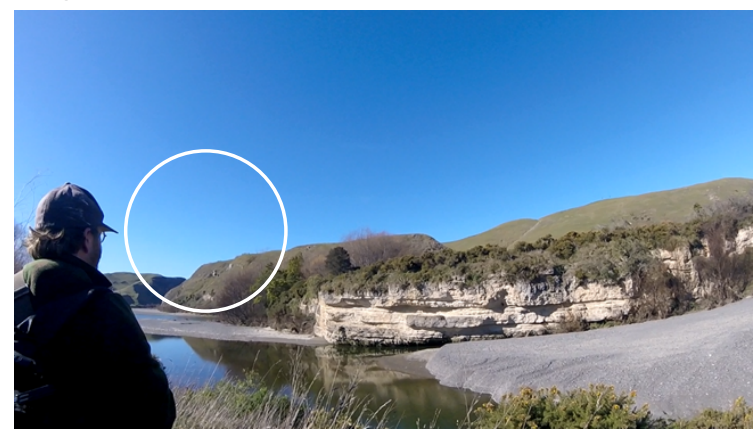

Figure 7.3

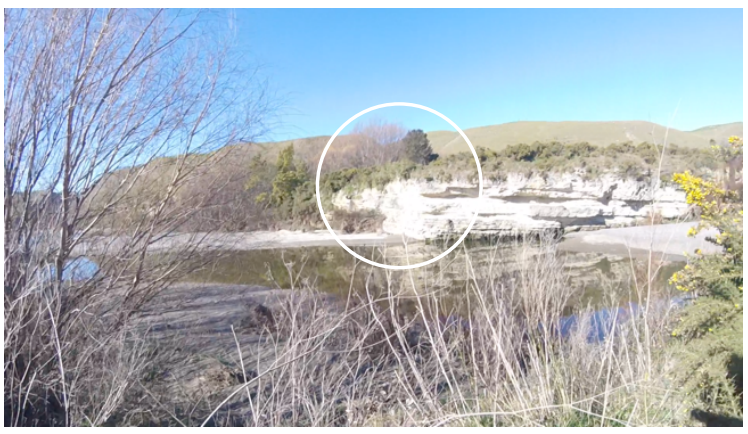

Figure 7.4
[Freeman breaks a path leading up the hill]

Freeman: Oh fuck.

That's pretty nice

[looking at the limestone in silence]

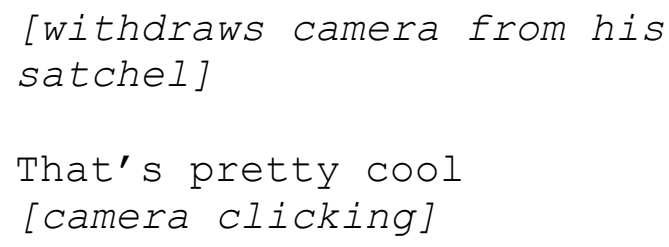

A few moments later trekking through thick mud on the riverside slope, I found Freeman slowly walking whilst peering out towards a natural vista. He then stopped and stated: "Oh fuck - That's pretty nice” (Figure 7.2). We moved on. Dried reeds six-feet tall and thistles 
appeared before us. The grass, mud and shrubbery were thick and difficult to walk through, nevertheless, we pushed forward to a small clearing. Freeman paused, retrieved his digital camera, and started clicking: "That's pretty cool" (Figure 7.4). We slid down the side of the bank to land down on the other side. Freeman had identified the 'reflection of the limestone in the water from two separate angles (Figure 7.3 and 7.4 respectfully). Our initial plan, to walk over the fence line and then through river stones, had rapidly changed from easy wayfinding to difficult and unknown path-breaking. This plan was stabilised against the environment's vistas - the island, the water, the reflection upon the water, and the fact we were closing in on the constituent features of subject selection, encouraged local sensemaking comradery. Consequently, we were stuck in the here-and-now task of organising our interactive work to determine, and produce, a concrete painting subject, of not only limestone in the water but of the possibility of something else.

\section{Finding out what we were doing all along}

As we neared the destination, each previous action, its role within its previous organisational use, and its related meaning, formed as a local historic record of ordinary events. These constitutive parts amounted to, in the arrival of a static viewing point, the final art-object.

Consider (Figure 8) below:

(Figure 8, Video 8).

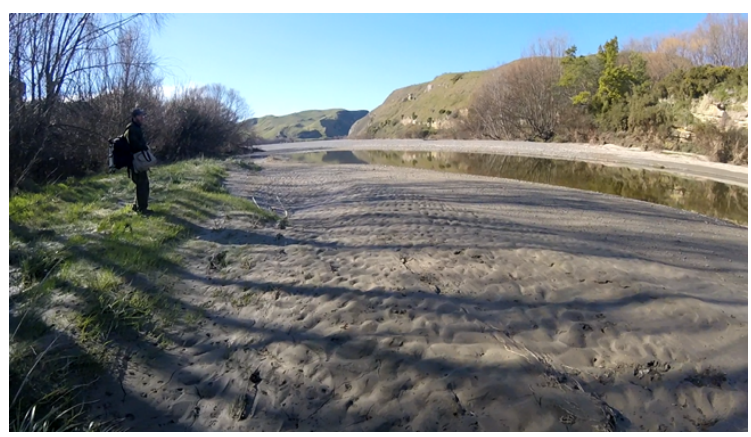

Freeman: Wow, that was worth it I think

Figure 8.1 


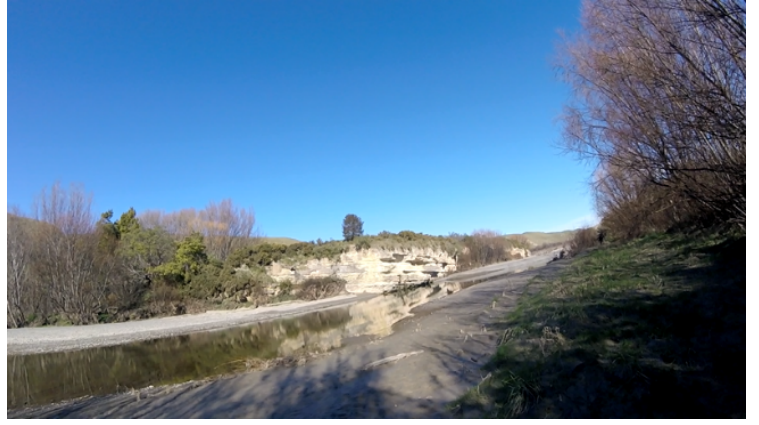

Figure 8.2

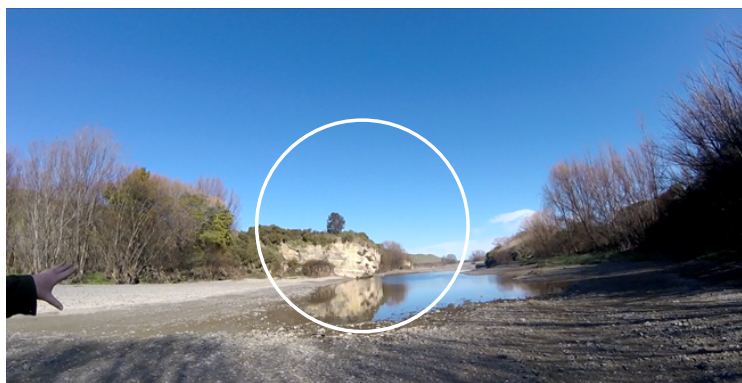

Figure 8.3

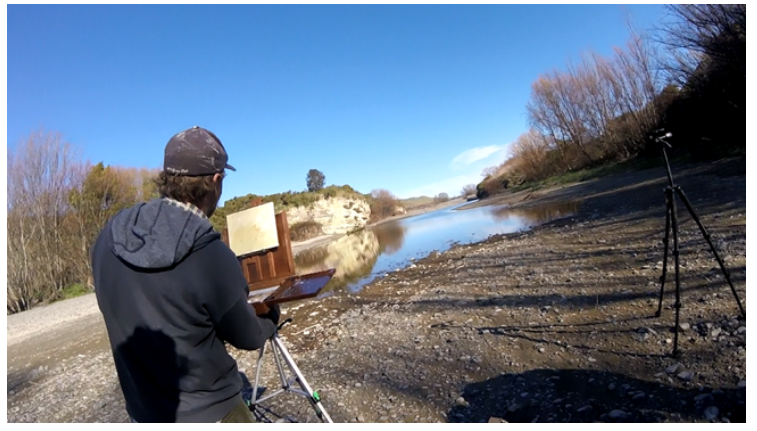

Figure 8.4
Wow .

That's cool.

Researcher: It's lit up isn't it?

Freeman: I love it

Researcher: Direct Sun

Freeman: That. That's lovely. See I think I'll end up painting that.

Look. You've got the reflection of the limestone in the water; got a bit of distance there.

I think that's lovely; I really do.

[whispers] I think that's

what I'll paint

[Freeman starts adding oil colours to his mixing board immediately after setting up his easel]

Freeman assessed the journey as "worth It" (Figure 8.1). I approached him as he took photographs beneath the shade of a nearby cluster of trees. He was in awe of the scene as I said, "it's lit up isn't it? - direct sun" (Figure 8.2). My own understanding of the direct sun upon the island reinforced the contexture I belonged to, had elements separate from Freeman's work. As Freeman and I walked out of the shade and turned to look back at the limestone from the angle he had envisioned from the beginning of our journey 'up over that fence line', He instructed: "I think I'll end up painting that" - "look" - "you've got the refection of the limestone in the water" - "got a bit of distance there" - "I think that's lovely, I really do" - “I think that's what I'll paint" (Figure 8.3). This gestalt shift enabled 
the painting subject to gain salience: The reflection upon the water. Subsequently, we set up our easels (Figure 8.4) and began to paint the subject now known in common. From an ordinary piece of nature to an extraordinary painter's object, how this artwork was constituted was certainly in and as a variety of ordinary social, and navigational practices, typical of mundane organisational activities which surround the practice of painting in the open air.

\section{Discussion}

Subject selection may only comprise one of the activities that are involved with plein air painting, yet I have attempted to show in this chapter how its little social actions integrate in and with their larger painting counterparts. By re-describing the video records with a dedicated focus on the interacting party's navigational organisational accomplishments creating ad hoc plans and managing them over a course of activity - I demonstrated mundane orders were necessary social features of the artist's local painting work. For example, during the searching for the subject-to-be-painted, the cohort-at-work naturally, at a common river setting, required a preliminary inspection of the surrounding landscape. That they were to "head over that fence line". Their ongoing walking continued to produce and maintain this established local plan of action throughout their subsequent journey. The party entertained some objects whilst they increased in relevancy to their task at hand: The scoping and evaluating the painting subject as it appeared within their visual horizon. The work continued, progressed, and their methods of looking were bounded to the local environment. To describe a member's method then was to describe the context of its local arrival, use and departure. My understanding of the direct sun upon the island reinforced a separation from Freeman's own. The group's task “all along” was thus to navigate around the river setting to find the most suitable viewing-angle of the initial painting subject, an aspect of our journey I 
remained non-privy to until the very end. Consequently, this study demonstrated how an interacting painting party individually organised nature into socially meaningful art object(s).

These investigative descriptions of context may raise concern with how the sociology of art treats a priori explanations of meaningful social action beyond the members local work. Moreover, upholding the analytic mentality of Watson's 'kaleidoscopic detail' attributed to each constitutive element observable from the recorded materials as worthy of value - each individual action contributed to the phenomenological field that our party ordinarily sustained.

Displaying how an interacting group observed subject matter for the first time, came to realise a limitation due to the river's water level, re-routed their journey, serendipitously re-viewed the subject, and lastly, became aware of the sun's relationship with the artist's position on foot, all comprised the features of a specific day's work of painting.

Turning towards how members of living society organise their action through singlecase empirical descriptions, including the investigation of a phenomenological field as work, through individual actions and the methods used to sustain and form it, ought to be included in the move from the study of "artwork" (Becker, 2006). Artworks can be seen in the naturally organised, yet spectacular, social actions that surround their formations.

\section{Conclusion}

There is more to learn about the local and meaningful organisation of social context within site-specific detail. The social praxis of art remains in my view, a highly resourceful domain of research for ethnomethodological studies of social order. This chapter drew from an early reading of gestalt contextures and attempted to explicate how social actions are endogenously organised. In retrospect little use comes from using the word 'contexture' or any other word external to the setting, for that matter, as members themselves are focused on organising their 
actions to social accountable entities. The next chapter further explores what that vocabulary may look like and continues to attempt to get as close as possible to the action in its organisational detail. 


\title{
Chapter Five: Excavating for Light Behind Closed Studio Doors. Exploring the Practical Action of Painting Through a Gurwitschian Frame
}

\author{
Ethnomethodologists see practical action and practical reasoning - the work of \\ producing the observed and accountable orderliness of the social world - as social \\ science's fundamental phenomena. What they want to do is make discoveries about \\ this domain. Because that domain is always embodied in its detailed, living \\ effacements, they study settings that provide detailed, technical access to it. \\ (Livingston, 1987, p. 56).
}

\section{Introduction}

This chapter describes one episode of an artist grounding a painting during an ordinary day's work. It uses visual materials obtained from a sixteen week long ethnography into the working studio life of an abstract artist. I argue that the findings of analysing and describing these materials supports Garfinkel's $(1954 ; 2007)$ use of Gurwitsch's concept of functional significance, and therefore attempt to describe how an artist assembles an artwork in and as real-time social action. This reinstating of the original worldly direction of the new sociology of art (De La Fuente, 2007; 2011) is taken to heart in the following chapter.

Throughout the analysis of this chapter's case materials I retain Garfinkel's sociological vision of how individual acts in any setting whatsoever (and in this case an artist painting in isolation) may already contain the means to organise that setting, endogenously. Specifically, I examine in fine-detail how ad hoc tool-exchanges structure the artist's painting activity, and in doing so, attempt to notice how the common sense activity —of the artist attempting to fit a large brush into a small pot of paint — may cause local troubles to be solved as artists work. I expect these moments, and others like them such as the use of 
various tools and equipment, capture several local methods of studio practice. These toolic accounts are essential to the unfolding contexture of studio work, and therefore, to the production of an artwork as cultural object.

Critically, to devalue the role of common sense action to artistic process would also seemingly devalue ethnomethodology's discovery that members' methods organise the primacy of the social world (see Livingston, 2016). Thus, rather than encourage, or worse, contribute to the design of a new turn - a turn away from the action toward the conceptual — as the recent musings of De La Fuente's (2019) later writings may now insinuate, this chapter recommends Garfinkel's "figuration of details" (Garfinkel, 2002, p. 167) as a primary maxim (to be discussed below) capable of renewing the sociology of art's investigation of art in action (Acord and DeNora, 2008; DeNora, 2000), toward observing action in real time.

As the subsequent case analyses develop, I keep the suitability of ethnomethodological studies of work to the new sociology of art at the forefront of analysis. This chapter thus seeks to explicate how an artist organises an abstract painting in real time. There is an inherent tension within the analysis of attempting to see how the social exists behind closed studio doors though the method of ethnomethodological respecification. At this point, the solitary actions of an artist working behind closed studio doors is treated as sociologically meaningful and subject to ethnomethodological analysis as all actions, regardless of dyadic involvement, are practically organised and thus treated as accountable.

\section{Road Map}

Five main sections structure this chapter:

Data and Methods: I briefly define gestalt contextures, justify why, and when I conducted the research; identify the research participant; and lastly, the analytical mentality. 
Case Analysis: I present the case and the rationale for its selection. I then present the analytical materials in the form of ten main sub-sections: Grounding, the characterisation of a mark's temporal journey, how the artist made the mundane relevant to painting action, ad hoc work, the accidental layering of marks, how the artist was lost in a process of discovery, the collection of brushes, crafting of rags, the excavating for light, and lastly the drawing, composing and becoming aware of the painting.

The Discussion and Findings: the results of the case analysis are discussed by identifying the key concepts used in the analysis, the contribution of the findings to the concepts and the topics studied, the effects these findings had on the research problem, the connection of the findings to the research question, and lastly, I discuss how these connections contribute to new knowledge in the field.

\section{Research Background}

\section{Research Participant}

Clive Kelly, born into a creative family, worked in New Zealand as a high-school art teacher for several decades upon graduating as a university fine arts graduate. Throughout his teaching career, he had painted and exhibited his work around the country at various national and local galleries. Clive worked on an entire series of paintings planned for exhibition in early 2020, which we discussed at length, and on film, during a sixteen month long ethnography I conducted between May 2018 and November, 2019. We often met weekly and this research relationship produced a total of 54 hours of film and a range of ethnographic field notes, photographs and audio files regarding Clive's artistic process. This includes his development regarding the working series of exhibition paintings produced throughout the time we spent together talking about his artistic process. 


\section{Case Rationale}

The artist's studio poses challenges for typical sociological description. Due to the nonverbal communication, idiosyncratic mark-making vocabularies, abstract body movements, and absent social interaction, gathering research material for directions in both the new sociology of art (De La Fuente, 2007; 2011) and ethnomethodology's program (Garfinkel, 2002) warrants justification. What is social about painting, why is it worthy of academic attention?

I interviewed Clive about his studio practice to learn about a unique technique he discovered. The weekly ethnographic sessions were recorded with a small and easy to use handheld goPro action camera, filmed from either a hand-held, or a stationary perspective, filming more than fifty hours of footage in total.

Unique to Clive's studio practice is how he begins his paintings with a process he terms 'grounding' ${ }^{27}$. He applies a bitumen mixture (tar and acrylic) to an empty white wooden board so that the Gesso (a white painting medium that aids the brushes motion) can "survive all the way to the end of the painting" (interview notes). This grounding process is guided by two unique painting techniques: Selectively adding and removing bitumen from the board.

I analysed the footage over time and noticed how effectively the artist used toolexchanges to organise his work. The causal relationship between a tool and its subsequent mark-making raised an initial interest which I felt required further inspection. If, for example, a tool's function is pre-determined, then it may be argued the artist could predict how one

\footnotetext{
${ }^{27}$ Typically, grounding is a common painting technique that provides tonal texture to a canvas or painting medium, as most paper, linen, or board is white. Toning or 'grounding' the painting with a mid-tone modifies the white to a darker shade, making it more suitable to impress a scene that more closely resembles natural light (as opposed to white, which may indicate direct light upon an object). In this context however, grounding is an entirely different technique; it is an intricate part of Clive's painting process, as this chapter's case studies will continue to illuminate.
} 
tool would alter his creative product in-the-making. Approaching the data in this way provided an initial analytical frame.

I experimented with the idea of filming both Clive and I discussing this tape in real time; a form of video elicitation. The results were unusable. During this elicitation Clive would gloss and account for his practice, for example, upon inspecting himself pick up a secondary brush so both of his hands were working in tandem he uttered, "see look! I'm painting like a drummer"; Clive then turned to me and uttered: "There is where the music is really important”. These utterances, although useful for ethnographic context, ultimately became unusable due to the way they transformed the study from one that regards the local practical work of him painting in solitude, to one that regards how he accounts for his own painting practices. The outcome of this research exercise provided an opportunity to see that the way Clive accounted for how he was painting, was in fact incommensurable with how he was painting. On the tape, Clive was forming artworks in and as artful social action. He found no interest in pointing this out, however. I expected Clive to notice what I was seeing how one action leads to another to form and assemble a 'painting method'. This was a researcher's presumption, and what in fact I received in return, was an explanation of what Clive saw himself doing. Frustrated, it was not until I went back to my office and looked at the tape when I found a curiosity deserving further, patient inspection.

In the end, the tape used to analyse the data presented within the following case study was selected due to an issue the artist is seen to be solving in real time, during the grounding phase of his painting. I aim to explicate the social in this mundane painterly work in the following presentation of video transcriptions and their written description.

We will see the artist start with a small brush and pot, and as the tape runs, his hands will use different tools at various times throughout the painting activity. Some tool exchanges were deliberate, whilst others were random, contingent, ad hoc, accidental, contextual, and 
the rest. I describe in microscopic detail to emphasise how the artist's tool exchanges played only a small part in an otherwise extensive range of practical action enmeshed within professional artistic activity and capture only a glimpse of the way an artist paints in solitude. My aim is to describe these actions as constitutive of Clive's endogenous practice.

\section{Ethnographic Context}

Clive's studio is situated in a Wellington Suburb, Hataitai, overlooking the water surrounding Evan's Bay ${ }^{28}$. I would often arrive at Clive's house Friday mornings and be greeted with coffee and toast. After our pleasantries, he would lead me down his garden stairs to a studio door. Inside the studio, several paintings remained stacked against one of the walls. Tubes of paints, miscellaneous cans and buckets, tubs and containers, rags, a stool, and a rather awkwardly placed armchair, including other various tables and benches, occupied all four of the studio walls which left just enough room for Clive to move within a small section located in the centre of the studio's carpeted floor.

The studio space was indeed full of old furniture, repurposed. A dresser housed mason jars and tins packed full of brushes of various sizes and lengths. Pinned-up pieces of paper with charcoal marks resembling scenes of nature displayed themselves to the equipment which produced them. On the opposite side of the studio hung coloured photographs. Below them, a darkened heavy desk. Traces of past brushwork—various dribbles and drips of paint accumulated over time on the top of the workbench. Next to this desk, a make-shift bookshelf. Bounded sketching-books lay imbricated in and amongst one of its few shadowed shelves.

\footnotetext{
${ }^{28}$ Artists have a way with words just as they have a way with their eyes and their hands. Clive would often mention his artistic stance as 'an romantic realist'. This emotive stance on Clive's worldview is important for the following study because at times I write in a sense of attempting to speak as Clive may approve: at times I borrow from his words and use them to describe his own action.
} 
Clive often worked with cracked windows openly circulating the pacific breeze as it removed the tar (and the turpentine) which the loud electric fan could not manage to do so on its own during the colder months of the year. Working with bitumen-acrylic mixes caused the unpleasant permeation of chemicals upon the tip of the nostrils all the way to the surface of the tongue, a common experience shared amongst oil painters, and a sensation I became accustomed to over the many months I spent visiting Clive in his studio.

After following Clive down to his studio on one particular morning, I put one foot inside the door. Clive's next utterance attached itself to my next following step: "Yeah, so that was the ground, and it actually became quite formal in the end didn't it?".

I had asked Clive to record himself as he painted the week prior. The following case study analyses that tape and demonstrates how Clive turned an empty white canvas into the beginnings of a work of art in progress, a piece he would continue to work on over the following year. 


\section{The Case Study}

We join the action as the first few seconds of the grounding process (the adding of tar) unfolded. The local organisation of how this or that mark may evolve, how earlier motions, or movements, and those techniques in and as such an ensemble of artistry, constitutes not only their surrounding marks, but the ordinary shape of the day's work. Consider the following visual sequence of actions:

(Figure 1, Video 1).

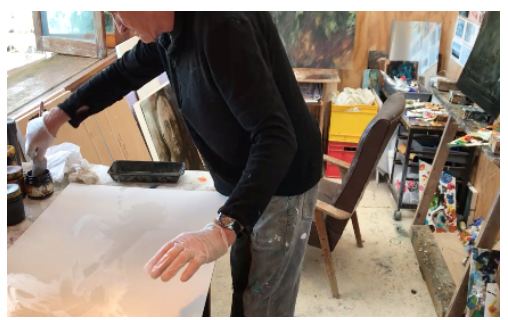

Figure 1.1

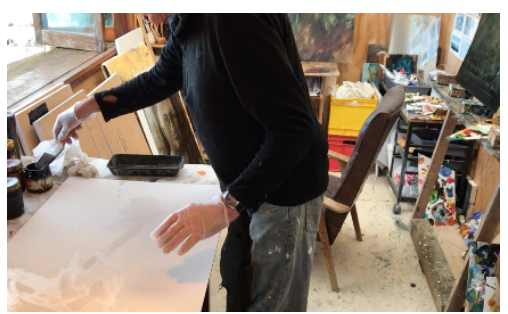

Figure 1.4

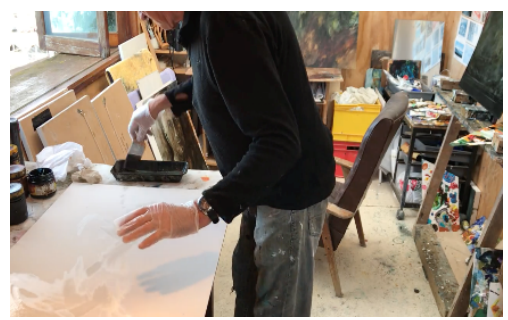

Figure 1.2

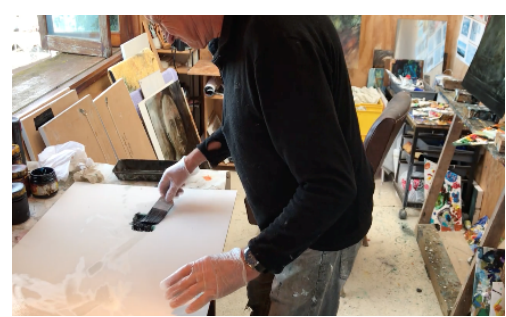

Figure 1.5

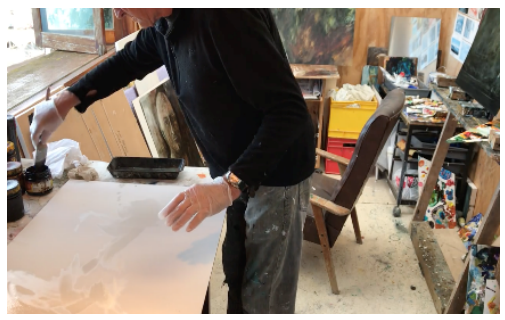

Figure 1.3

Clive stood upright and leaned over his workbench. He held a medium-sized brush in his right hand whilst to guide balance, simultaneously stretched out his left to its side of his body (Figure 1.1). The brush moved from a small open pot of paint mixture, down into a longer and flatter plastic container below that held a comfortable amount of turpentine, and in a quick series of hand movements (Figure 1.2), the now wetted brush returned to the open pot 
of paint (Figure 1.3), collected an adequate amount of tar (bitumen and acrylic oil mixture), and then, in one longer, continuous gesture, he raised the brush out from the pot, catching its bristles against the rim (Figure 1.4) and placed it directly on top of the gesso. A small dark patch appeared after a small circular wrist movement (Figure 1.5).

This patch of tar, in this location, marked an instantaneous contrast of light (the white gesso board) and dark (the bitumen). Additionally, the previous activity of collecting the tar and organising the application of the medium on the board gave rise for future action. The situated and temporal marks and the artist's mark-making accomplishments were part of defining the meaning of this 'patch' of 'tar'. If starting a painting required placing dark tar onto a white board, then this activity would be complete. The artist made many marks over the course of sixteen minutes, however. The initial phase of the painting was accountably not only one of adding bitumen, but specifically, one of 'adding dark'. The marks within this series of mark-making were not only responsive to each other in vivo, but to the previous (and future) in situ developing marks.

The temporal journey of the current unfolding 'figuration of details' (Garfinkel, 2002, p. 167) further characterised the meaningful organisation of this painting. At this specific point in the work, the artist had one opportunity to add areas of dark where he "thought dark should be" (interview notes), in short, meaning was bounded to the brushwork. The next actions provide detail. 
(Figure 2, Video 2).

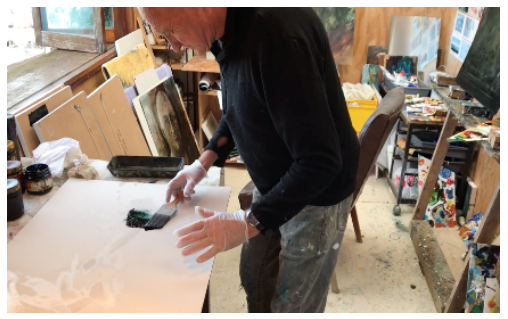

Figure 2.1

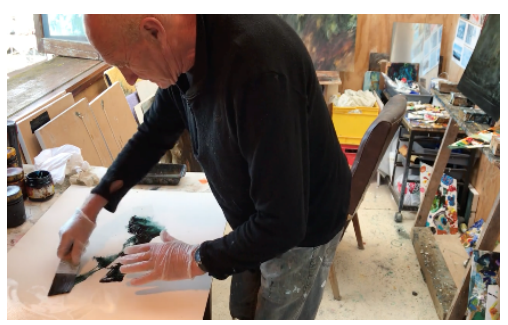

Figure 2.4

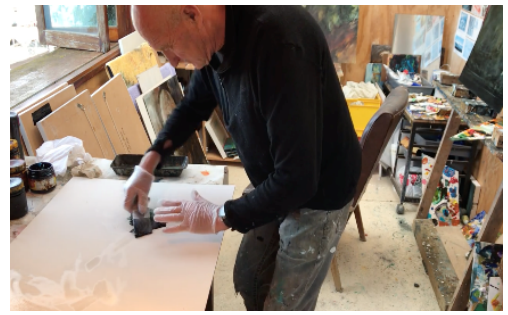

Figure 2.2

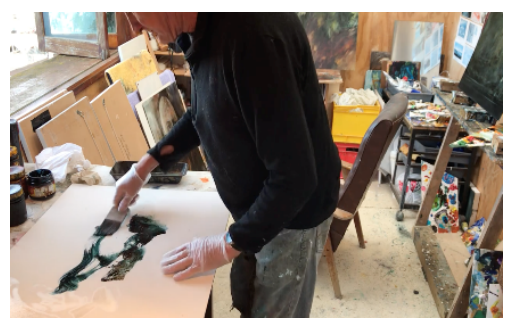

Figure 2.5

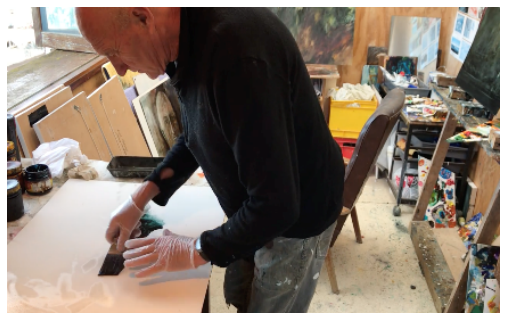

Figure 2.3

Clive paused. He then loosened his grip (Figure 2.1). As the brush lay against the board, he gave one energetic push (Figure 2.2) and with the weight moving through his body onto the brush, it successfully captured medium from the initial patch of tar. He fought to keep the once single-stroked movement propelled, as it continued to pick up other strokes which originated from the shoulder's energy: To the left (Figure 2.3), petering up (Figure 2.4), and then back to the right (Figure 2.5); sharp movements left, down, up, down, up: Some soft, others heavy. The gesso received dark coverings because of these energetic gestures, stances, and hand movements and they were all caught up in the tempo of the artist's body for the next few moments.

There are many ways to hold a brush, to push it around and move it, to give it life. Haphazard, seemingly ad hoc, chaotic, and unorganised - but ordering - action was taking place, with, and under, the brush's bristles. Although impersonation may consist of randomly 
moving a brush with dark paint around a white board, skilled mimicry may consist of more. Rhythmic gestures; the transferring of marks from brush to board with great variance: Some soft, others heavy; weighted balance; and with wrist movements timed for an undisclosed meaning. The artist was displaying skilled action and was in full control of the grounding activity. Clive's painting in action showcases his progressive, reactive, embodied, energetic, quick-to-respond control. The once 'future action' transformed over the course of the markmaking and became a product of the immediate past. The organisational work of the unfolding contexture of the painting continued as each mark seemingly constituted itself against its surrounding others, as each mark waited for its future, for its salience, and therefore its chance to belong to its group, only to then become naturally effaced for the replacement of new figures to come.

Clive continued his mark-making with repeatedly dipping his brush into the pot to collect tar. 'Intention' is not the topic of study, yet such displays of intention were unavoidably strewn throughout this painting activity: One action often signalled another next, and the action-sequence of brush-pot-panel is bounded to the artist's subsequent actions. This makes visible the previous control work: The act of determining the volume of paint upon the brush was visible in that next stroke's trajectory. Clive's mark-making actions supported the fact that embodied action caused the brush to require more paint, and that work is observable.

Making the mundane available

(Figure 3, Video 3). 


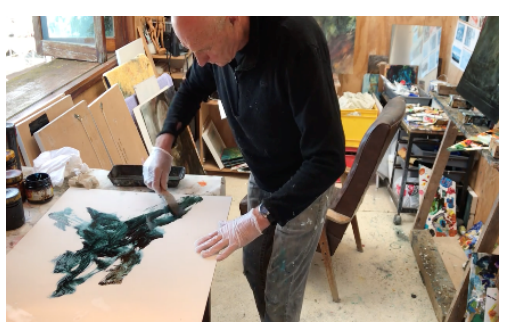

Figure 3.1

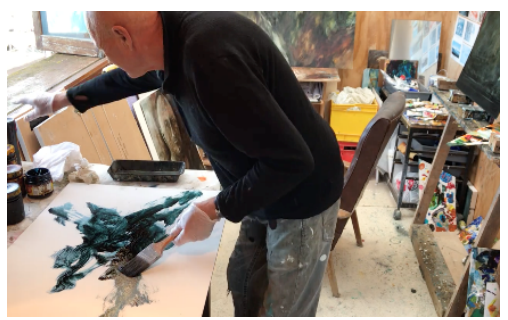

Figure 3.4

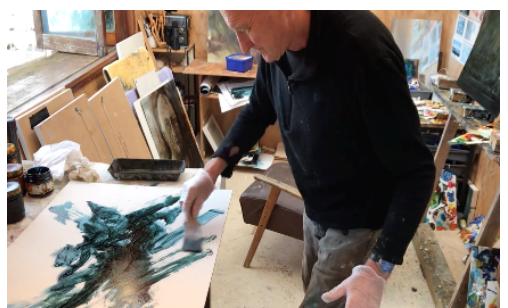

Figure 3.7

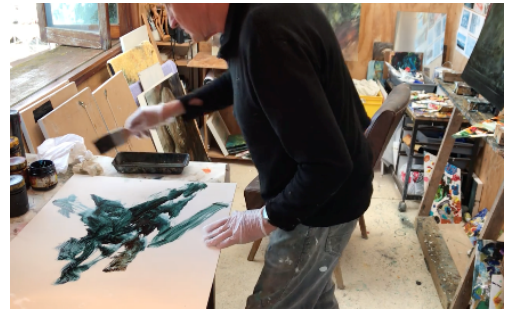

Figure 3.2

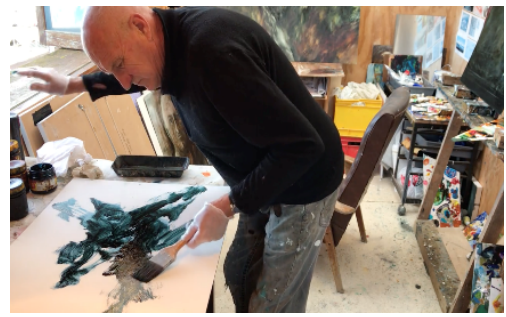

Figure 3.5

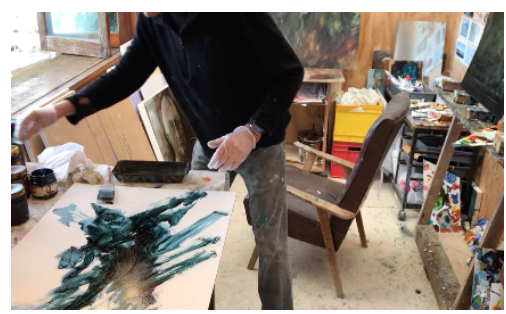

Figure 3.8

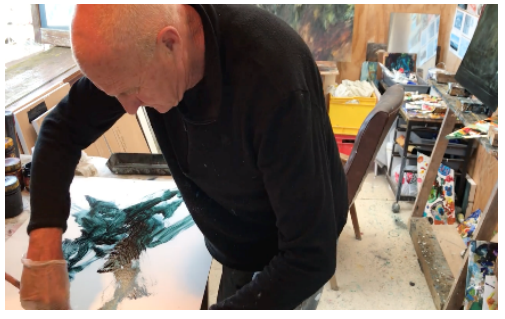

Figure 3.3

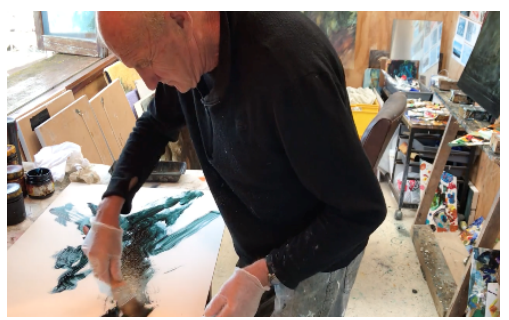

Figure 3.6

With his left-hand applying pressure down onto the board, his right shoulder guided larger strokes that covered greater distances from the work only just performed (Figure 3.1). He stretched his right arm forward into the open pot of paint as he stood back slightly (Figure 3.2). The brush added medium to the original dark patch as it moved to the upper left-edge of the painting (Figure 3.3). Clive suddenly and simultaneously turned his hips and transferred the brush from his right-hand freeing it to reach out and turn the volume up on the speaker (Figure 3.4). During this moment he remained attentive to his left hand's small scratching like movements; the rhythm of which, caused dancing manoeuvres (Figure 3.5). His head remained stable as the brushwork seamlessly continued (Figure 3.6). Clive stood back with one foot after a few more moments of transferring his body's energy into marks and pulled the brush across the top of the board's Gesso (Figure 3.7). Finally, he dragged the brush with him as he stood back with both feet, lifted his head, swivelled around the edge of the table, dropped the brush, and reached for another pot of paint (Figure 3.8). 
Illustrating the transition between mark-making and equipment-exchange demonstrates that Clive's painting work was more than just technical-hand-eye skill displays. There were a range of essential activities that took place within the larger process of markmaking. Tool-exchanges were 'more than' part of the painting practice, they provided the overall activity with ordinary practices, ones just as relevant to the unfolding meaning of the painting as the marks themselves. I argue this domain of skilful painting work imbricated common-place aspects which however insignificant they may be, featured concretely in that setting's structure. Actions, such as collecting paint on a brush were made meaningful because they were organised and accounted for as constitutive features of an otherwise growing contexture of painting activity. Trivialising these features from the painting process would alter the endogeneity of that work. Consider for example, an essentially non-important moment in the artist's next actions seen the case below.

Ad hoc work is a significant part of the final artwork (Figure 4, Video 4). 


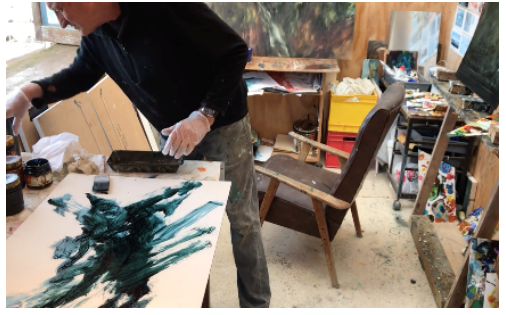

Figure 4.1

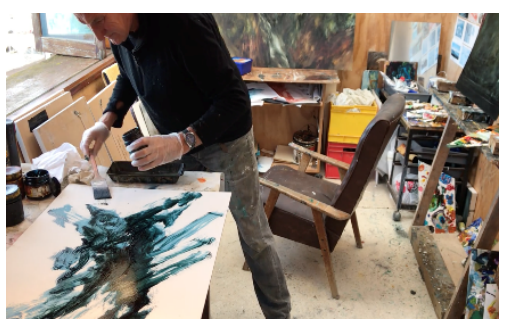

Figure 4.4

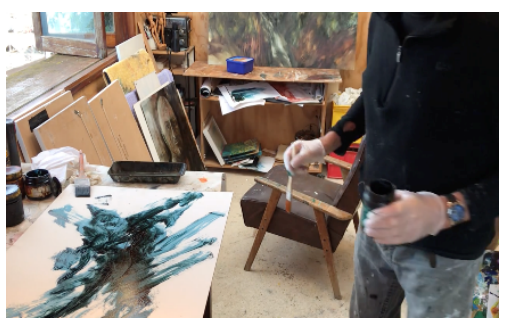

Figure 4.7

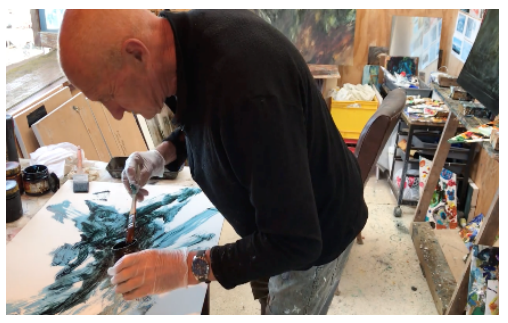

Figure 4.10

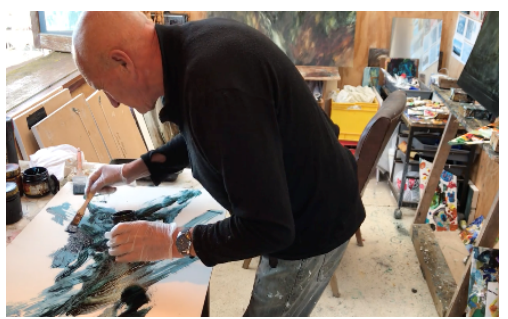

Figure 4.13

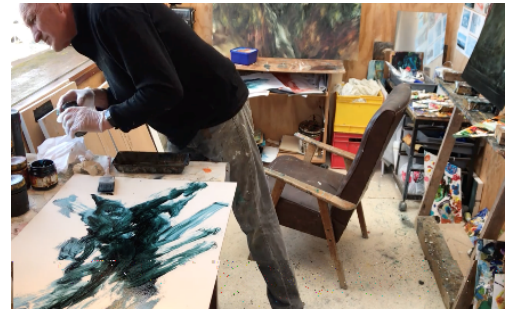

Figure 4.2

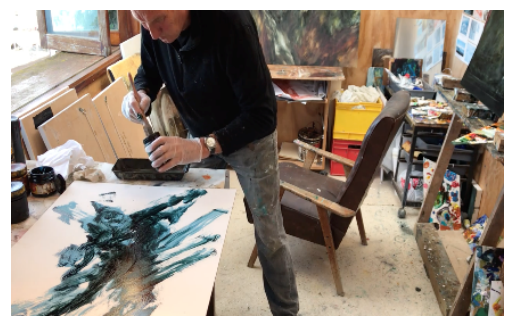

Figure 4.5

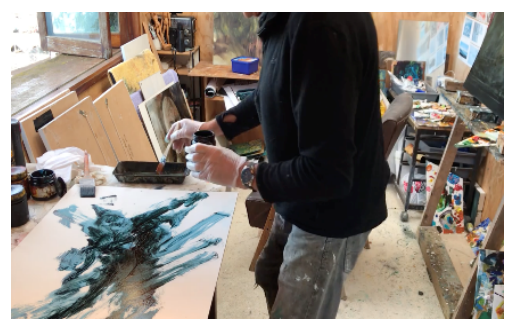

Figure 4.8

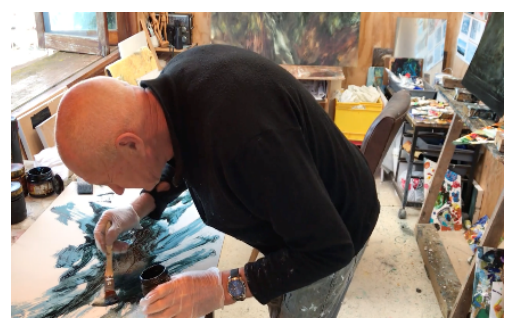

Figure 4.11

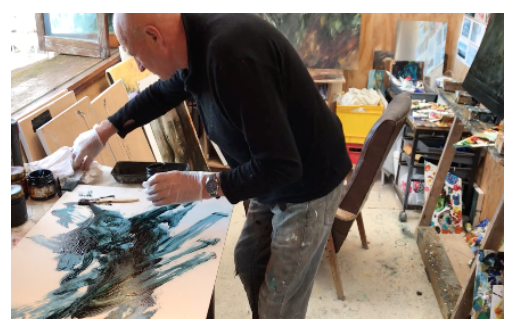

Figure 4.14

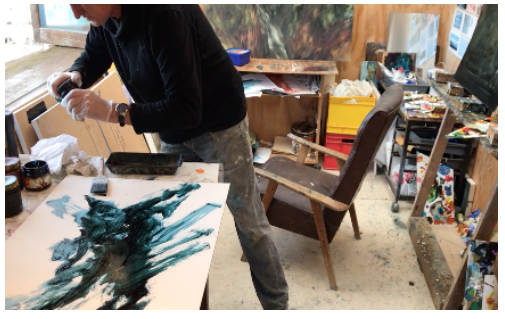

Figure 4.3

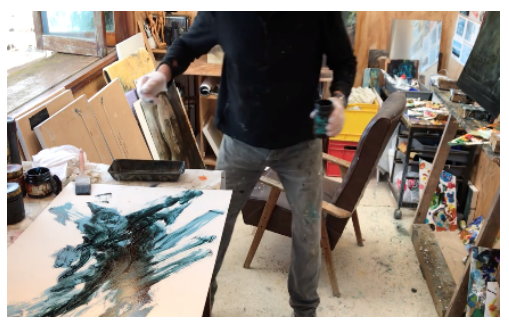

Figure 4.6

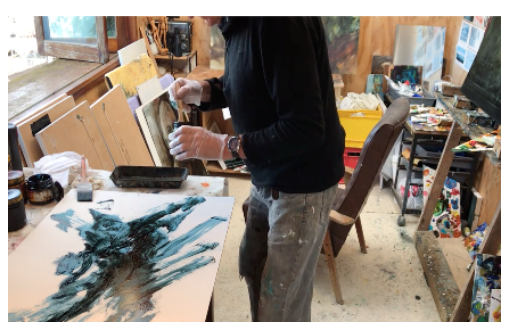

Figure 4.9

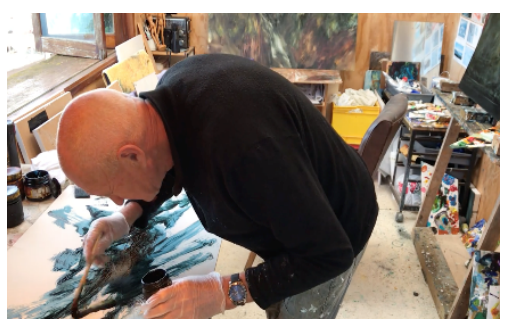

Figure 4.12

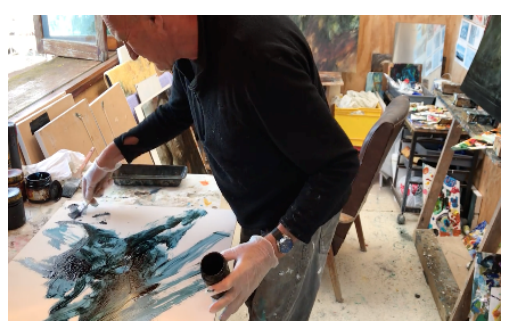

Figure 4.15

The artist, having just laid down a large patch of 'cool phthalo blue mix' onto the board, reached for another jar full of mixture (Figure 4.1). He picked one pot out from the five, swivelled it around, then moved to tap the lid of another mixture altogether. He then reached 
for and picked up another from the group (Figure 4.2). The lid twisted off whilst he looked at the pots left behind. A quick peek inside - 'no' - he quickly tightened the lid back onto the pot and then placed it back down into the group. He picked up another, twisted the lid open, yet, this last jar resisted opening (Figure 4.3). With a stronger turn of the wrist it finally cracked. He picked up the nearest and only brush below to wedge it inside (Figure 4.4). This brush was too large to fit inside the small pot to retrieve paint (Figure 4.5). He placed it down and stepped away off camera (Figure 4.6). The opened pot of paint was still in his left hand when he returned into frame, but he had a new addition in his right: A smaller brush (Figure 4.7). Standing over his artwork in progress, he wet the small brush with turpentine (Figure 4.8), moved it deep into the pot (Figure 4.9), wiped off any remaining excess on the side of the jar's opening and moved his body into a painting position (Figure 4.10). He then applied a small volume of the paint onto the gesso below (Figure 4.11). At this point the artist leaned forward, scrutinized the mark, the colour, the darkness of the new medium: Pure bitumen (a brown tone, darker than the previous blue tone) (Figure 4.12). Retracting his head, he moved upright into a position of gravitational advantage to paint with the small brush. As he started to work from the left of the board to the right, he encountered an ordinary trouble (Figure 4.13). He dropped his small brush and pushed the larger brush off the board to one side (Figure 4.14). He then immediately picked up the smaller brush and used it to shift the entire board to the left with the help of his left hand as the grounding work continued with the smaller brush (Figure 4.15).

The above activity demonstrates the creative ad hoc features of painting work that exist outside of the mark-making practice. This determinate feature of Clive's witnessable painting activity may suggest his creative process was more ordinary than he may have realised in the moment. A simple feature such as not being able to supply the large brush with the intended amount of paint forced the artist to solve his issue, and in this case, it was done 
with the retrieval and use of a smaller brush. What effect would this common sense, completely insightful yet taken-for-granted equipment exchange have upon the unfolding organisation of the painting work? The next few sections are telling.

Just over two-minutes into the activity and layering became an essential painting technique to witness unfolding. Both the spatial and temporal effect of this layering activity altered the point of the painting activity, appending a new phase into the process: Depth. The relevance of the relationship between the two tones (brown and blue) and two brushes (large and small) created not only a spatial layering effect (as the artist can now only ever physically paint on the top layer) but thus consequently, a temporal layer (as the artist is now painting on top of an earlier mark-making exercise). The grounding stands as a living record of immediately prior events.

\section{Layering marks by accidental means}

(Figure 5, Video 5).

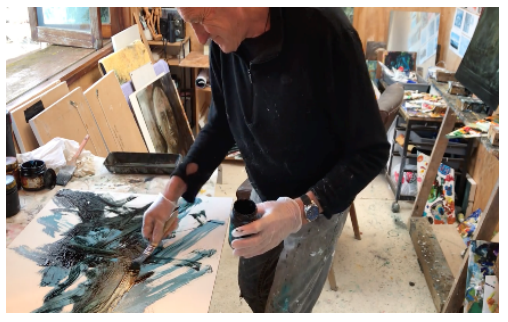

Figure 5.1

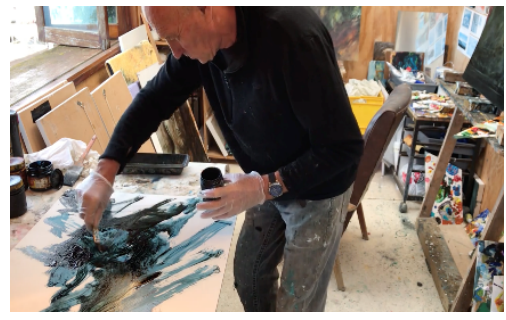

Figure 5.2

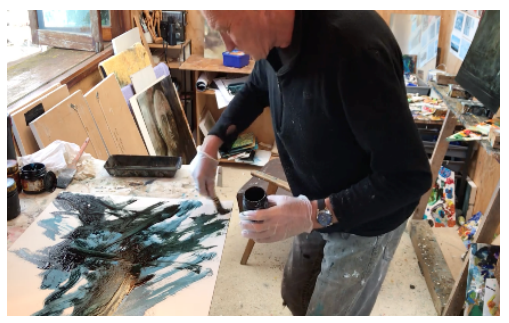

Figure 5.3

The music took over Clive's movements in the legs, hips, and the wrist, and he appeared to be freely painting. He used the smaller brush to vigorously scratch at the board (Figure 5.1), and as it started to visibly run out of medium, it took up a softer stroke as it worked its way back up through the large amount of tar that now sits upon the Gesso (Figure 5.2). The use of the small brush created slight 'scratching' effects where a small amount of medium on the brush, together with the collection of medium on the Gesso, caused some of the medium to 
start removing and exposing a new third layer (the combination of the blue and brown having been scratched off so that the white can appear from behind or underneath) (Figure 5.3).

The small brush undoubtedly affected the way the painting formed as it was only ever part of the painterly action due to its use of solving an unintended issue: Clive did not intend to select the small brush (as evident on tape, he had tried to fit the large brush in the container first) therefore, the painting gained its fundamentally distinctive character and style of layerprogression by depending upon the brush (or tools) used. The larger brush did not remain as the primary tool of use however, and thus the ad hoc nature of the studio work contributed yet again to the local character of the artwork, as it was actively unfolding for, and managed by, the artist in real time.

This phase of adding dark in the grounding process was ending, and the process of discovery — that the artist is "sort of in something, in an environment" (fieldnotes) — began to take over. Although physical actions provided the tools with their use, the tools also provided physical actions with opportunity to modify the work in progress as it moved nearer to completion.

\section{Lost in the process of discovery}

(Figure 6, Video 6). 


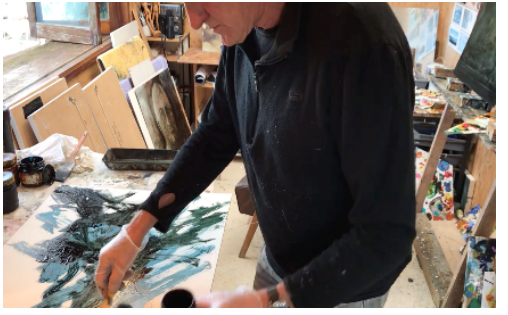

Figure 6.1

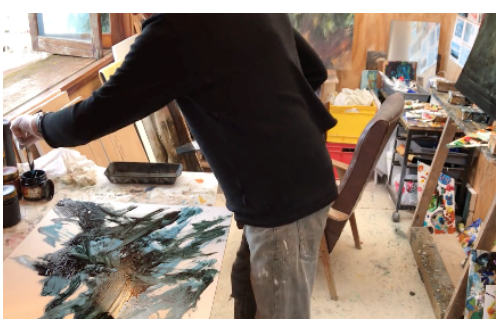

Figure 6.4

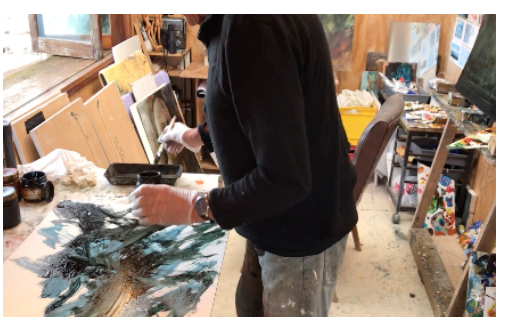

Figure 6.7

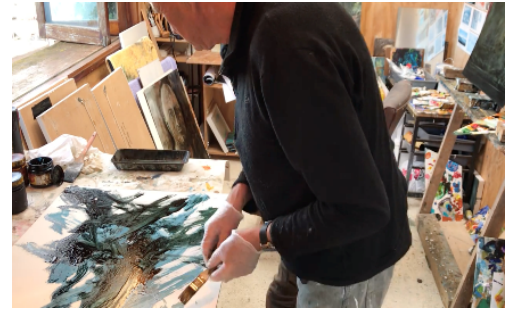

Figure 6.2

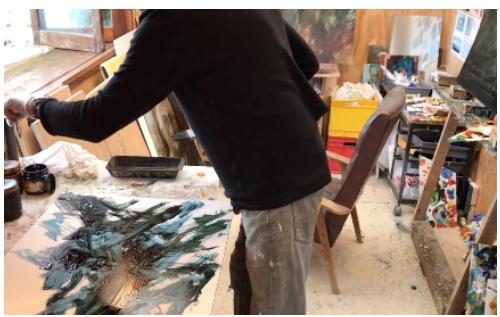

Figure 6.5

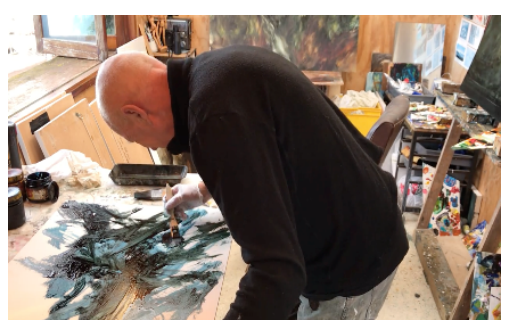

Figure 6.8

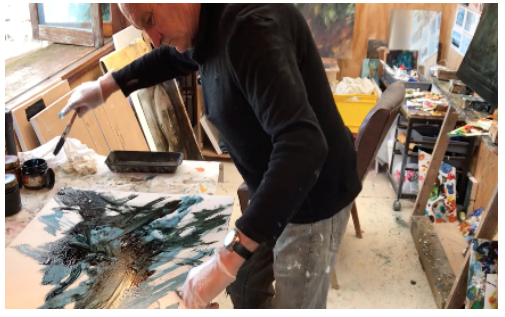

Figure 6.3

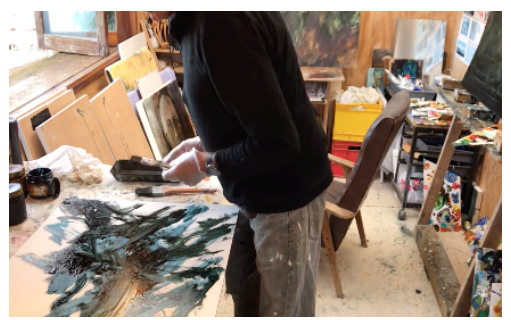

Figure 6.6

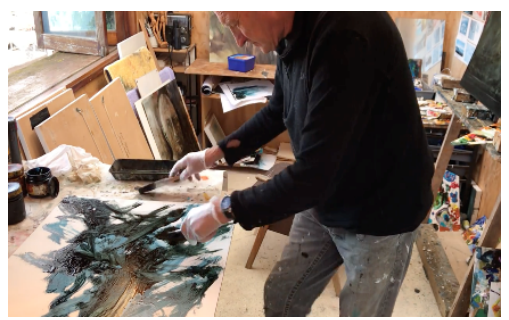

Figure 6.9

Clive placed the pot of paint down whilst he continued to make marks with the small brush

(Figure 6.1). He then moved the small brush to his left hand (Figure 6.2) and reached for the larger brush with his right hand (Figure 6.3). Both brushes, the large and the small, altered his mark-making as they separately worked together. The two-tones of these brushes; the larger brush with its blue medium still on the brush, pushed over the top of the small brush's brown marks and both brushes thus cross-contaminated: The mixing of the two tones via the two brushes variously resulted in a first, second then a third layer appearing simultaneously.

Clive instinctively reached for an open pot visible on the table surface with his left hand and small brush, and just as its tip almost hit the surface (Figure 6.4), the artist then pulled back (Figure 6.5). He dropped the larger brush and transferred the small brush from his left to right hand (Figure 6.6). He picked up the pot of paint with his left hand, and with the brush now in his right hand, he dipped it into the turpentine. His body moved with this action as it brought the pot of paint closer to the brush (Figure 6.7). As he applied the mixture 
down onto the board, he briefly leaned over the desk and scrutinized both the volume and tone of the medium (Figure 6.8). After the placement of pot from his hand to the bench, he moved the small brush back to his left hand and then with his right hand, picked up the larger brush (Figure 6.9). Both brushes, one in each hand, worked together to ground a fourth layer, of increasing definition and the medium started to gain an artistic character - the marks on the board started to take a defining shape with each new layer added.

The value of complex displays of tool-exchange, effortless body movement, organisation of hands, strokes, collections of medium, application of tar, all of which are organised together for the larger task of grounding the painting, is seen in the above series of figures. The artist's forceful intention to use only a very specific medium demonstrated rational, controlled and deliberate painting behaviour. One medium (the blue) was desired. It required the performance of manoeuvres of the hand to avoid collecting another pot's colour. That is, the artist almost collected paint from one pot and then retracted. Furthermore, the artist needed to have available a larger brush to collect from the table, a small brush to use, and a pot of paint misplaced from its group in order to make the above marks. Further still, the activity of adding dark to the board (and the improvised solution of retrieving a small brush) continues to further form the character of the painting. Subsequently, it is reasonable to suggest at this stage of the work the artist looked past his ordinary actions, even though they guided his deliberate mark-making to come.

Nearing the completion of this activity, Clive significantly changed the pace of his process when he began to craft tools out of rags. This dramatic tool-exchange completely altered the setting's temporal structure when after several short moments of brushwork, Clive put down the two brushes into the container of turpentine, initialising a new activity. 
(Figure 7, Video 7).

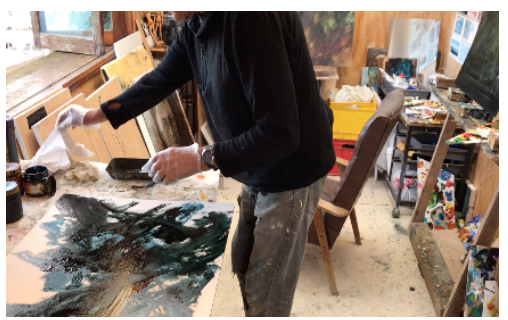

Figure 7.1

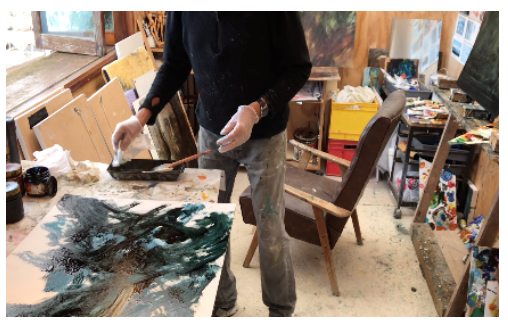

Figure 7.4

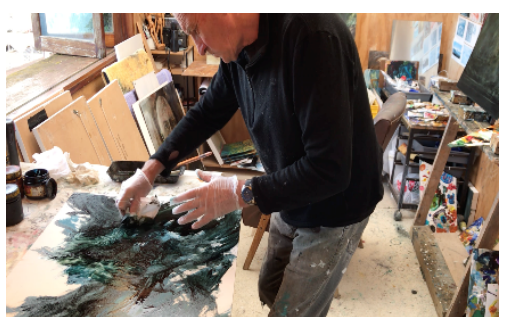

Figure 7.7

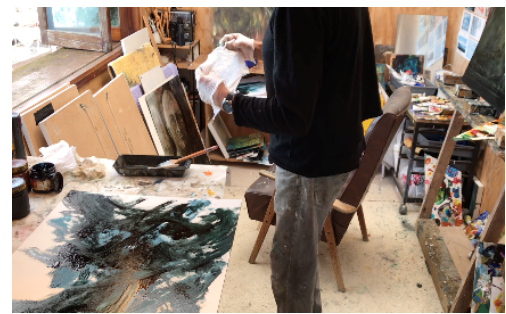

Figure 7.2

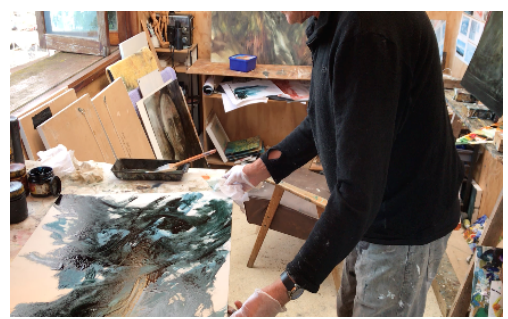

Figure 7.5

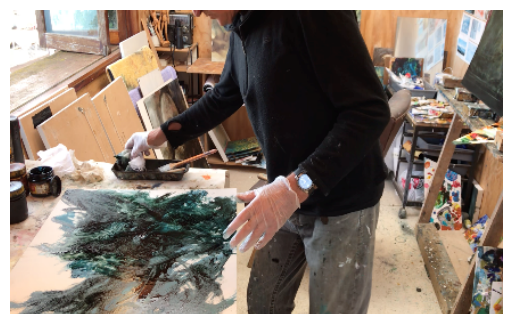

Figure 7.8

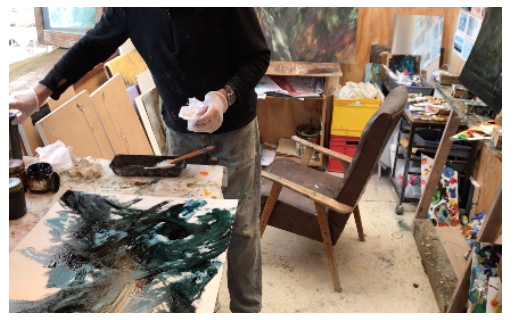

Figure 7.3

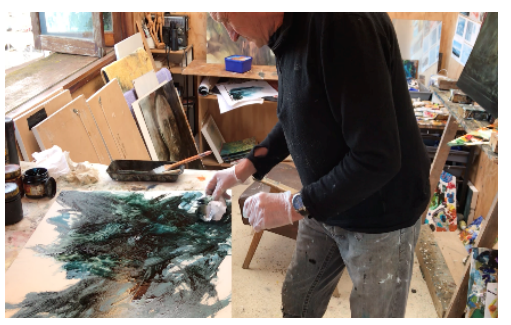

Figure 7.6

A bunched-up scrap of rags commanded attention for sorting. He picked up one (Figure 7.1)

folded the flayed linen once or twice and then he began to physically dance (Figure 7.2).

Encouraged by the rhythm, he turned the volume up on the small speaker sitting at the far end of the workbench (Figure 7.3). With the rag he then collected turpentine (Figure 7.4) and moved his body back around to the front of the workbench which repositioned the board so that Clive was ready to start grounding with the rag (Figure 7.5). Clive pulled the dark brown (almost black) and green-blue tar-medium around the board with wet-rag in right-hand (Figure 7.6). Short dabbing motions, some with raised wrists barely held the rag upon the surface of the board scattered around an area of focus. With a reposition of the foot, Clive used the rag to paint, his mark-making was in the form of compounded pulling followed by light dabbing driven by Clive's large shoulder movements (Figure 7.7). All of his action 
coordinated with his standing body as everything moved together in full force. The rag dipped into the turps once again (Fig 7.8).

The artist is now working in a new phase. There are two phases in this grounding process: Adding dark and removing it to 'add' light. The way he turned the music up, collected a rag from a box at the back end of the studio, and continued to ground, characterised this phase of painting. The consequences of these practices altered the studio setting's time towards nearing the end of a session's work. The artist is a long way from the blank-white Gesso board from which these marks began, and the texture of the rags were developing "movement and feel, drift" (interview notes).

Upon first inspection of the tape, the rag-work shows the artist adding dark to the board. Yet on a second, closer inspection, the turpentine mixed with the already applied tar on the board allowed the rag to move the tar around with a different type of stroke altogether.

\section{Crafting tools out of rags}

(Figure 8, Video 8).

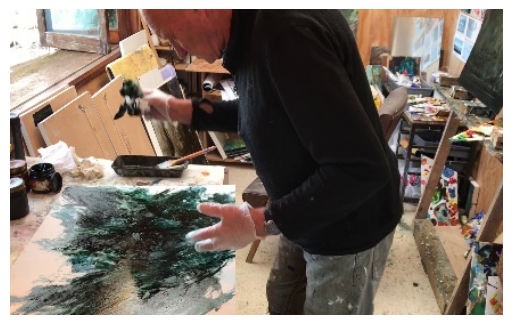

Figure 8.1

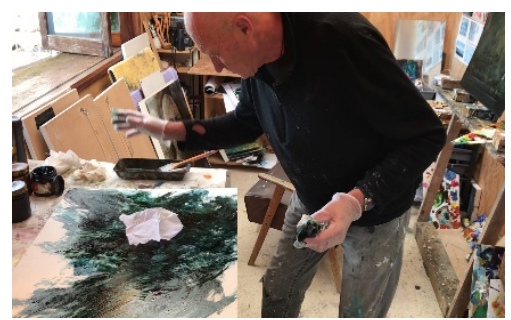

Figure 8.4

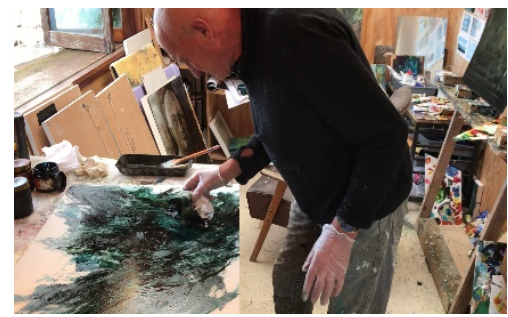

Figure 8.2

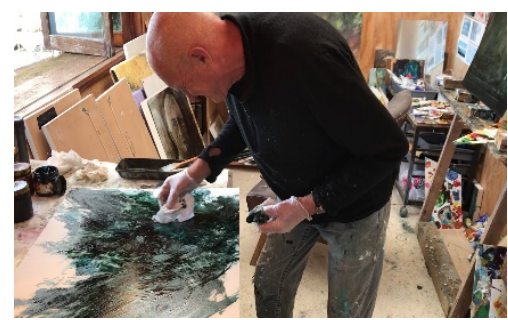

Figure 8.5

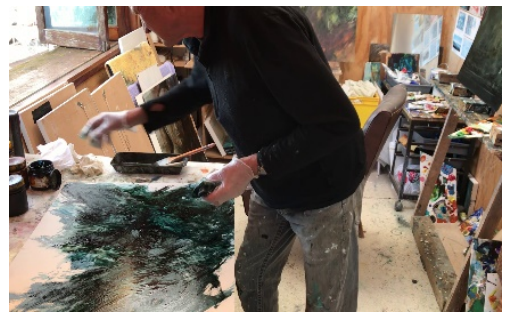

Figure 8.3 
Clive dipped the rag into the container of turpentine, and with one single swoop, lifted the turpentine-soaked-rag high into the air and flicked it down onto the board (Figure 8.1). His petering movements removed tar from the board by gently touching its surface with the tip of the rag (Figure 8.2). And then-with one straightening of the back-Clive leaned in with one foot forward and just as quickly retracted: The rag was now in the left hand with the right reaching for another (Figure 8.3). He picked up a new rag, hovered it over the board and let go of it, where it fell to the surface of the board (Figure 8.4). He pulled this rag towards his body, removing slight amounts of tar from the board, and leaving a textured stroke behind (Figure 8.5). Small adjustments were made to the overall grounding before the rags were placed down on the workbench and the brush. Once an applier of dark, the rag became the applier of light.

\section{Excavating for light}

(Figure 9, Video 9).

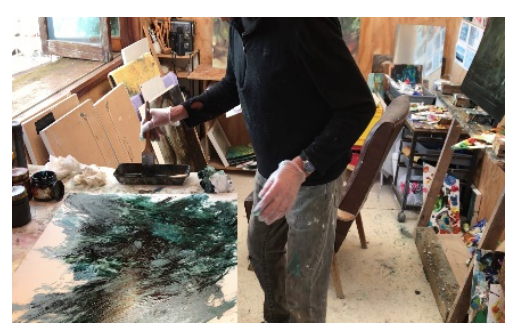

Figure 9.1

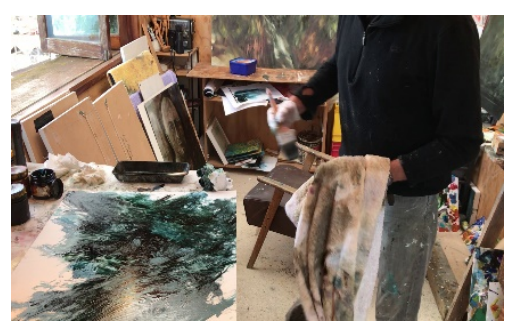

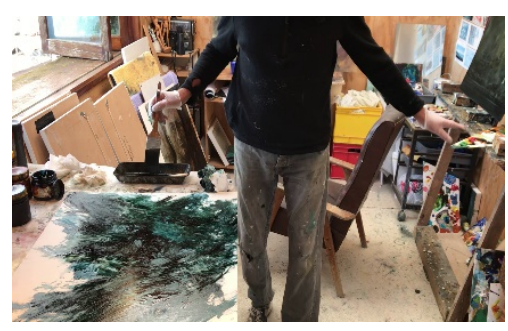

Figure 9.2

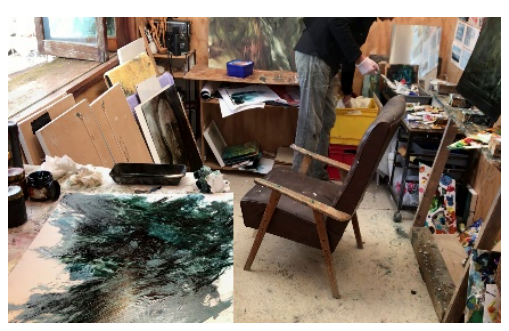

Figure 9.3

Figure 9.4

Clive retrieved the larger brush from the turpentine container with his right hand (Figure 9.1) whilst his left hand reached behind for something, causing his body to pivot just enough for his hand to reach the chair behind him (Figure 9.2). Whilst he pivoted back to the workbench, 
he scanned the room in front of him, then turned, and walked to the back of the studio to examine a box full of towels and rags (Figure 9.3). He returned to the workbench still in search for something and looked under the table to retrieve a towel. He cleaned the brush with it (Figure 9.4). The turpentine-laden brush was then used to remove an area of dark previously applied.

Drawing, composing, and becoming aware of the painting

(Figure 10, Video 10).

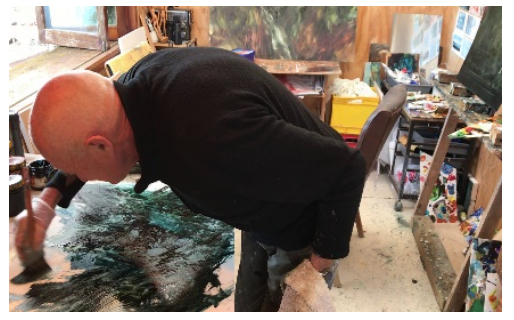

Figure 10.1

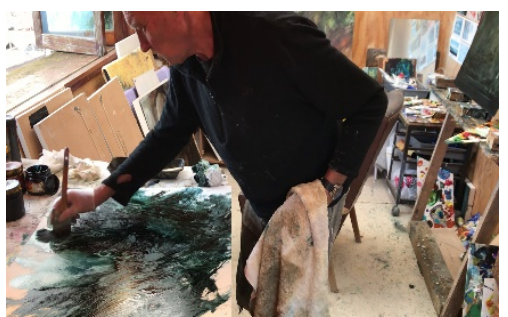

Figure 10.4

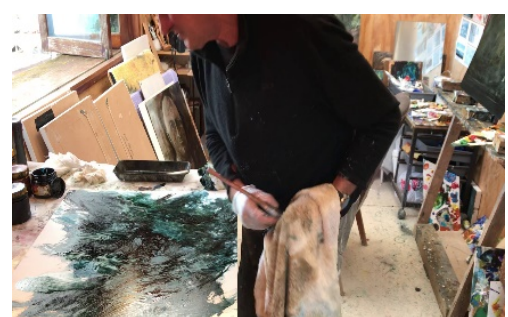

Figure 10.2

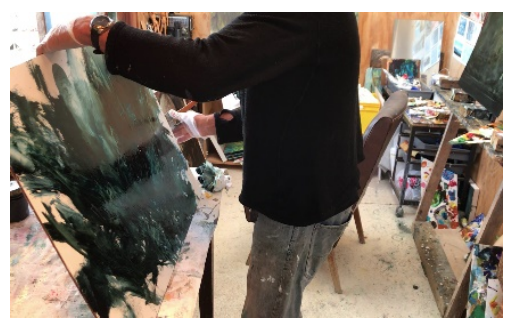

Figure 10.5

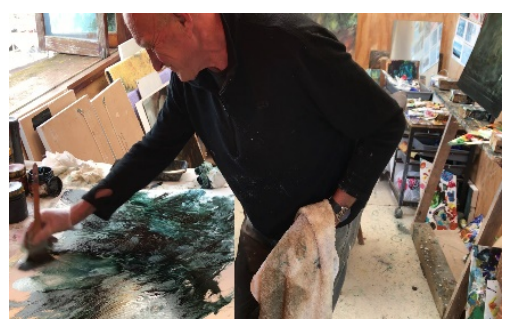

Figure 10.3

Clive confidently dry-brushed the areas of the board where the white Gesso remained (Figure 10.1). His rapid and energetic rubbing motions with a dry brush enabled the board to take on a different texture. He then wiped off the tar on the towel to clean the brush (Figure 10.2) and returned his brush to the same area and continued blending the tar and the gesso together with the dry brush (Figure 10.3). A quick dab into the turpentine, onto the towel, and then the brush immediately returned to the board. The force of the strokes bent the brittles to fan out a larger surface, where vigorous movements continued to blend the tar, lightening the visible tone (Figure 10.4). Clive worked on the top area of the board in this manner, threw the towel to the ground and with his now free hand, lifted the board off the workbench to use gravity as 
a painting tool (Figure 10.5). Once he placed the board back onto the workbench, he returned to the activity of brush-turpentine-towel-rapid-strokes which blended the tar and lightened the top of the painting so that "light can survive all the way through the end of the painting" (post-elicitation notes).

The effect of this whole activity provided the board with a lighter shade of blue at the top of the grounding. Contrasting dark and light, or a tonal range, started to characterise the painting further. The artistic know-how of tones, of dark and light, started to orientate the grounding work to a more formal end. Each action was organised within what we could start to recognise as traditional formal painting, that is, the artist's grounding was at a mid-way point, and for the duration of this activity (another ten minutes of footage) the artist was starting to draw, as opposed to engage with a process of free and emotional response to the marks and their making.

"Yeah, so that was the ground, and it actually became quite formal in the end didn't it?". (Figure 11)

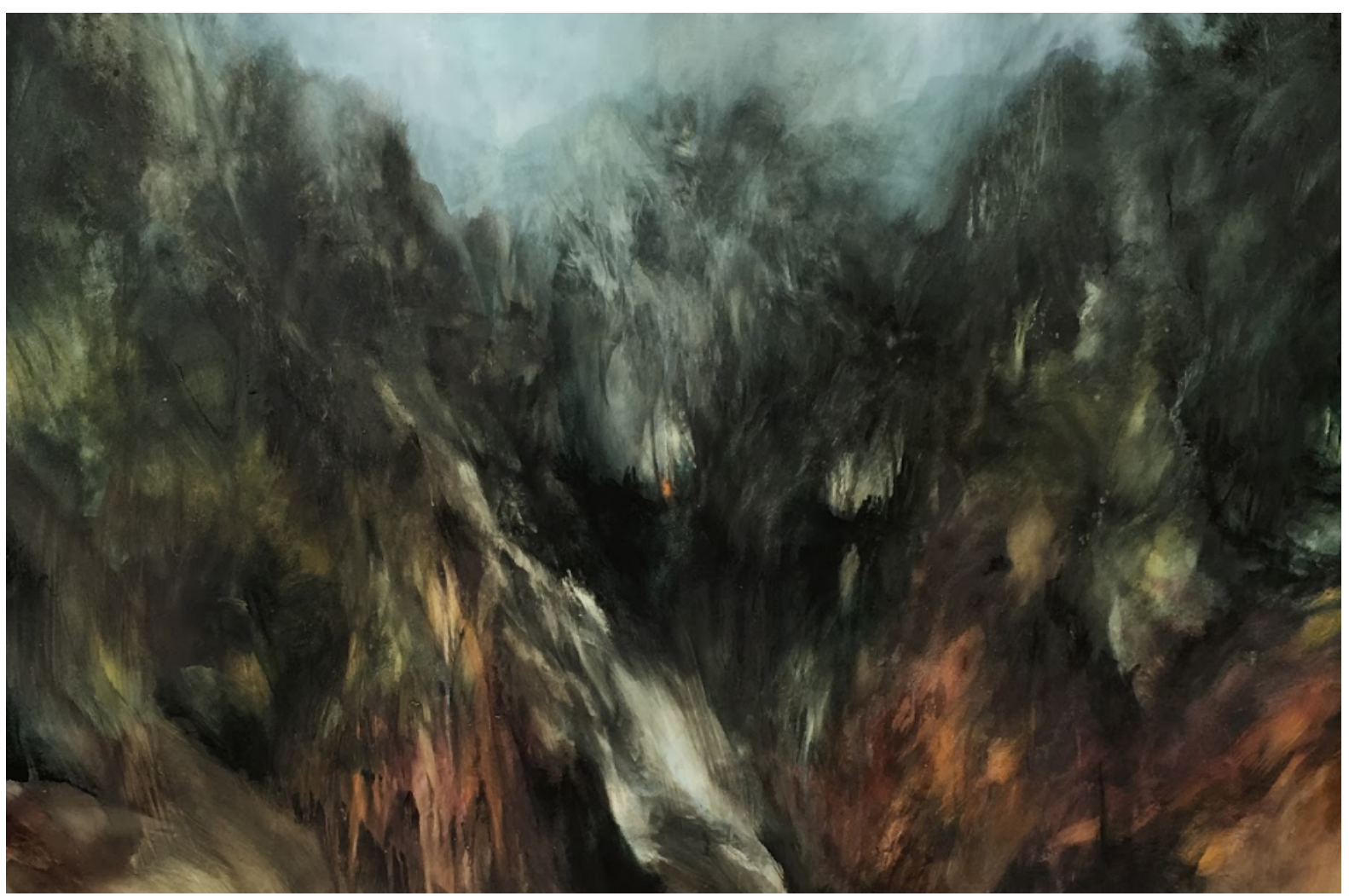




\section{Discussion}

The artist's first marks produced a large patch of bitumen tar, a practical issue to be solved, a contexture for work to follow. The activity of adding dark was thus organised by the subsequent mark-making actions: Pushing tar from the patch around the Gesso board. The placement of each stroke, its trajectory and weight, altered the activity by organising it towards an end through temporally constituent elements. In one instance the brush entered the pot to collect more tar. The action was responsive to a previous stroke's work (similar to how each constituent is related to its gestalt contexture). Naturally however, the ongoing activity of mark-making disrupted itself and shifted to a new organisation throughout the practice of site-specific painting.

In this Chapter I have explored how each action was related to each other, including how each action had its own temporal character and relationship with previous strokes, by remaining analytically orientated to the member's localised actions.

The artist changed brushes during the painting activity. Varying the practice of adding dark, the artist put down both brushes and picked up a new pot of paint. He then had ordinary troubles with locating the correct mixture. His actions imply that he was after a particular pot and therefore he found himself in a self-organising problem as it 'disrupted' itself from the practice of adding dark: How can he get the correct mix onto the board to continue where he had left off? We see the value of applying a notion of "functional significance" 29 in the decidedly simple act of how adding dark came to end (that of adding enough of the first medium) so that a second medium could contribute to the progression of the painting-athand, and the greater activity of adding dark. Accordingly, once the pot was located and dealt

\footnotetext{
${ }^{29}$ Functional significance in this context refers to the deliberate focusing on the relationship between individual acts as providing coherency to the activity. As this chapter is experimenting with this notion, I'm sorry to say, only a vague sense of what that can mean has been established.
} 
to, the artist picked up the large brush to aid this progression, however another issue resulted: The brush was too large to fit into the pot. The artist once again found himself in a selforganising problem as it again disrupted the course of painting, yet this issue required an ordinary ad hoc solution: The retrieval of a new, smaller brush, capable of fitting into the pot of paint. Ultimately, these disruptions are altering, yet also constitutive of the activity. Events may not always run smoothly and contingencies are always present beneath the surface.

Is this act of small-brush-retrieval just as important (if not more so) to the overall painting? In retrieving the small brush, the painting activity continued in a new form. Small brushes make smaller marks, and the relations between these marks are thus different to the ones that were managed prior to their making (Figure 4). These smaller strokes eventually ended, however, and as the artist turned to free up his left hand, transfer the small brush to it, and then pick up the larger brush, both the brushes established a new form: Two brushes make different marks together.

If it were not for the crucial fact that the artist was unable to get the larger brush into the pot, the smaller brush's strokes may have been absent from the artwork in all its forms, as its larger counterpart would have taken its place. ${ }^{30}$ The surface disorganisation of the studio setting contributed to the organisation of the artist's painting behaviour (like needing to get dark medium from a small pot of paint). When the artist picked up the larger brush (and by means of it being there already now established as ad hoc as opposed to socially-determined) whilst placing the smaller brush as to now dual-wield the tools, he did so in and as a series of contextual actions, as they related to, and responded to each other. That is, the only reason

\footnotetext{
${ }^{30}$ There is no guarantee of the latter happening, however. We must go by what the artist had done there and in the tape. I do suspect the chances of Clive using two brushes may have been made eventually. However, I do suspect his use of the brushes, as I have been attempting to explicate, came far sooner than anticipated. I argue this because of the ad hoc nature of how the commonsense awareness of large brushes not fitting into small pots was overlooked by Clive in these moments, resulting in the opportunity for Clive to grab out the tool that was directly Infront of him: the earlier discarded small brush.
} 
why the artist was holding two brushes was because one brush was too large to fit into a small pot of paint.

In more theoretical terms and for the purposes of engaging with this analytical work to begin, the neglected principle of gestalt-contextures was thought a refreshing way to study social action in context. The ethnomethodological use of Gurwitsch's (1964) concept 'gestalt contextures' - "from the coherence of the line drawing to the coherence of social facts" (Garfinkel, 2007, p. 28) is seldom pursued, even in ethnomethodology. According to indexicality (see Chapter Three), if all situated action in the social world, whether in public settings, conversational interactions, or indeed, in isolative settings, regardless of how small or how large, are meaningful, then isolating those actions from their settings would modify their meaning according to functional significance. That is, the studies of individual actions in isolation from their situations and surrounding actions are not suitable for studies of context, rather, how those actions are organised in a sequential series so that how persons act are equal to what they did in the setting. This leaves the analyst with the task of explicating how those actions are endogenously organised from the perspective of the acting member.

In my view, this model of ethnomethodological sense-making derives from the main assumption: Observable human action shows us that society is naturally-organised and ordered through common sense social ordering practices such as the ones Clive displays throughout his work of painting.

I stress here that I used the idea and vocabulary of functional significance not as a search procedure but as a way to stay focused on the artist's actions as they relate to each other. Importantly, removing information regarding the effacing of local action (the uninteresting aspect of such ordinary detachments) may give us false impressions of how artists (and others) really produce artworks. No matter how apparently common sensical, boring, or sheer simplistic some of those actions may be, they are part of the lived reality of 
an artist-in action, and part of the ordering of that artistic world as an entire and allencompassing enterprise.

Keeping sight of how these actions are organised and what persons make locally relevant, on a case-by-case moment-by-moment basis may substantiate claims for understanding of the meaning of such cultural products that are artwork(s).

This chapter is a first attempt at describing, using the vocabulary of gestalt contextures, how an artist working in solitude behind closed doors organised their action to produce and make stable the work of artistic production.

\section{Conclusion}

This chapter began by claiming that Garfinkel's (1954; 2007) use of Gurwitsch's concept functional significance will demonstrate how the artist's constitutive actions are an essential property of worldly action necessary for the creation of his artwork(s). I videorecorded an artist's action over the course of a sixteen-month field ethnography. I repetitively viewed these tapes with analytical focus on the moment to moment actions he displayed on film.

The artist repeatedly found himself in self-organising problems as they disrupted the normal course of painting, yet they required ordinary ad hoc solutions for the painting to progress uninterrupted, and on slightly altered courses. How is that members work done? The effect this practical solution had to the setting and its potential future was realised when the artist picked up both brushes to paint. How would the painting unfold if the large brush was able to fit into the smaller pot of paint to begin with? An analyst can only speculate.

Comparing these findings to the literature is difficult to do because there are few sociological pieces of work that study an artist working in solitude (there are none that study functional significance ethnomethodologically). Connecting with Rod Watson: 
From the inception of ethnomethodology, and especially from 1970 on, Garfinkel has insisted on the centrality to sense-making of members' mastery of the natural language. I think that with a few exceptions such as Garfinkel and Sacks' 'On formal structures of practical actions' (1970) paper and some largely pious comments by Garfinkel on local occupational 'lingoes', this precept of ethnomethodology remains relatively underworked (Watson, 2016b, p. 24).

As mentioned in the discussion, Yaël Kreplak's ethnomethodological, praxeological, and ethnographies of artwork are areas where the underworked nature of this sense-making concept can connect and spur the social analysis of abstract artwork to a wider literature.

One possible line of future research may require stringent orientation to the markmaking activity itself. Because most of the work analysed in this chapter was that of bodily movement, tool-exchange, ordinary troubles, many of the 'meanings of the marks' were missed. Is it sensible to argue that mark-making activity is 'a mastery of the natural language'? (Garfinkel 1967). On the one hand Clive's mark-making activity is meaningful in the sense that his actions produce marks on the canvas. A trouble with analysing these marks is that they do not easily lend themselves towards formal orders: Of instructions, say in contrast of a linear perspective model, or sketching the human anatomy. Not that these are instructional matters, but the written description of these settings may ease that difficulty if artists are more formal in their approach. There is no 'formal method' or plan that Clive follows in his own practices, and for these reasons I can see the merit in researching an artistic setting such as life drawing, to analyse the organisational practice witnessable therein with the help of organising methods such as light logics and perspective models. The difficulty with Clive's working practice is that it is found within the singular marks and their orders. 
The next chapter turns to look at how an urban sketcher organised his sketching activity to produce a sketch. It focuses specifically on the action of measuring an object and translating that measurement onto the sketching page. What does this ordinary sketching work look like? How are artworks organised in and as practical social action? We continue the study. 


\section{Chapter Six: Ad Hoccing an Approximation. The Local Work of Doing Urban Sketching}

Ethnomethodological findings are to be treated as corrigible claims written as sketch accounts (Garfinkel \& Wieder, 1992, p.181).

\section{Introduction}

This empirical chapter continues to draw its attitudes from ethnomethodology. The data collection, the analysis, and the presentation of visual transcripts and the empirical material all focus on displaying how an urban sketcher naturally organises his action during a typical sketching session. The main phenomena I discuss is the sketcher's management of an everyday common practice—-measurement and approximation (Cicourel, 1964)—and describe how the sketcher's 'ethnomethods' ${ }^{31}$ contribute to the formation of a concrete sketch. Placing this focus on sketching ethnomethods contributes descriptive nuances regarding the constitution of artwork to new sociology of art. Sociologists may unintentionally avoid, or deliberately find no interest in explicating these common sense methods. Consequently, I continue to suggest "ethnomethodological respecification" (Garfinkel, 1991) of situated action is suited to the new sociology of art. We will now continue by walking through the urban sketching activity's organisational local details.

\section{Roadmap}

Three main sections structure this chapter:

\footnotetext{
${ }^{31}$ I place the term ethnomethods in scare quotes as it denotes ethnomethods are waiting to be seen and witnessed within the data, by and through the member's actions.
} 
The first section, Data and Methods, was aided by Garfinkel's later writings (Garfinkel, 2002). By taking the raw audio-visual material, I translated it into a presentable format. Epistemologically, I realised the member's actions - their lived order - could never be represented as that lived order. The relationship I thus developed with the data, and the way I wrote of its analysis, was glossed as doing 'analytical descriptions'. Positioning my thinking around the fact 'analytical descriptions' are a sociologist's working procedure, I briefly discuss some ethical issues in relation to the research participant. Within the larger ethnographic project of observing, recording, writing and analysing data, I came to experience the edges of the possibilities regarding representation of social phenomena as sociological knowledge.

The second section is the case study where I guide the reader through the sequential activity of what I call here 'the comparative measuring method in action'. In describing how an artist organised his conduct to obtain a unit of measure from the visual field, and then abandon that unit by substituting it for a new unit of measure taken from the sketching pad, I found that between these two measurements, a series of contingent, mundane, and messy activities occurred. Intrigued, I discovered local order of the most ordinary kind, and this order formed the analytical focus.

In the third section I discuss the research findings as they both relate to the research question and draw upon the ethnomethodological attitude of respecification. In this discussion I raise a question of how analytical data may be treated as what Garfinkel calls corrigible claims. Subsequently, I suggest the sociology of art ought to consider adopting this attitude when engaging with fine-detailed micro analyses of artistic practice, as it may aid researchers in noticing how artful social practices often conceal themselves as "embodied living effacements" (Livingston, 1987), a key aspect of the social organisation of social order, and in this case, of sense-making throughout the activity of urban sketching. 


\section{Research Background}

\section{Research Participant}

Members of the Lower Hutt Art Society's Urban Sketching Group invited me to meet with, and sketch with them, ten times over the course of several months. I accepted their invitation and filmed each weekly session with a hand-held small action camera. We travelled around the wider Wellington Region to sketch and talk about our drawings with one another. Over the several weeks of collected video recordings, of observing how artists find subjects to draw, sketch them, render them, and then present the drawings to each other of - "doing urban sketching" (see Bagnolo, 2018) - I comprised a large video corpus of data to use during the subsequent stages of analysis. I collected all research materials in person to subsequently produce post-ethnographic case analyses. The participants involved in these studies were all filmed, and due to the nature of how the case was selected, only one member, an artist sketching in real time, features in the following analytical materials. Subsequently, the case materials used in this analysis was taken from one single video recording which I collected, among a large corpus of video records, for six months participating as both member and social researcher of a local art collective.

\section{Case Rationale}

I collected this case data in June 2019 when I stood behind an artist and filmed him start to sketch the building in front of us. Just one of many records I had similarly obtained, this real time collection of footage placed the artist's body, sketching pad and subject within the camera's frame as he naturally sketched in, and from the visual field. The collected materials 
were obtained with the explicit intention of later review, analysis, and working up of presentable research transcripts to construct academic value from analytical cases.

The positionality of the camera occupied a unique point in space which subsequently contributed to what was captured beyond what the artist or the researcher could see (see Mcllvenny, 2020, p. 3-4); this epistemological status of having a third eye is marginal ${ }^{32}$.I assumed the difference of the spatial and visual relationship between the artist and researcher could never be 'identically experienced' (see Schutz, 1967 on the fallacy of intersubjectivity). My decision to forgo executing mitigative strategies upon this fallacy came down to the fact that seeing from the true perspective of the artist would have not made the research object any clearer: I was interested in the action of the artist and not the artist's visual perspective. This decision enabled me to find the action (Heath et al, 2010, p. 43). The video records clearly show both the artist's actions and sketching object in the same frame, subsequently reducing the anxiety of missing something out if the perspective of the artist was further considered, such as a head-mounted camera.

Videography as a professional practice is one used to "preserve relevant details and phenomenal field features and reflexively contribute to the configuration of the very interactional order they document” (Mondada, 2006, p. 64). This gave me an appreciation how a video research implicitly modifies the research setting and the studied objects ${ }^{33}$.

Furthermore, I had recalled the artist took a photograph moments before his sketching work commenced (see below photograph) ${ }^{34}$. On inspection of this image, I nevertheless remained unable to see as the artist sees. The photograph was not only digital, but the artist

\footnotetext{
${ }^{32}$ One could mitigate this relationship, for example, by placing a tripod at the height and placement of the artist's eye or providing the artist a head or chest mounted goPro to wear, or even go as far as to attach a small camera to a pair of glasses. Yet, each mitigative strategy would ultimately remain non-identical from the natural vision of 'exactly' what the artist was seeing.

${ }^{33}$ I believe this aided my ability to adjust to what was being seen in the field as a videographer (see Macbeth, 1999).

${ }^{34}$ I requested a copy of this image in a follow up email during analysis.
} 
used a zooming feature to capture the building subject more clearly. Consequently, the photograph thus positions observers to see as if the artist was sitting in the middle of the road, unhelpful for analysis, it however supported a redirection towards managing the recorded videotape; making small versions of the observable activity therein for presentational purposes; and then offering these produced versions as evidence to support claims. The following case analyses video data from a researcher's perspective.

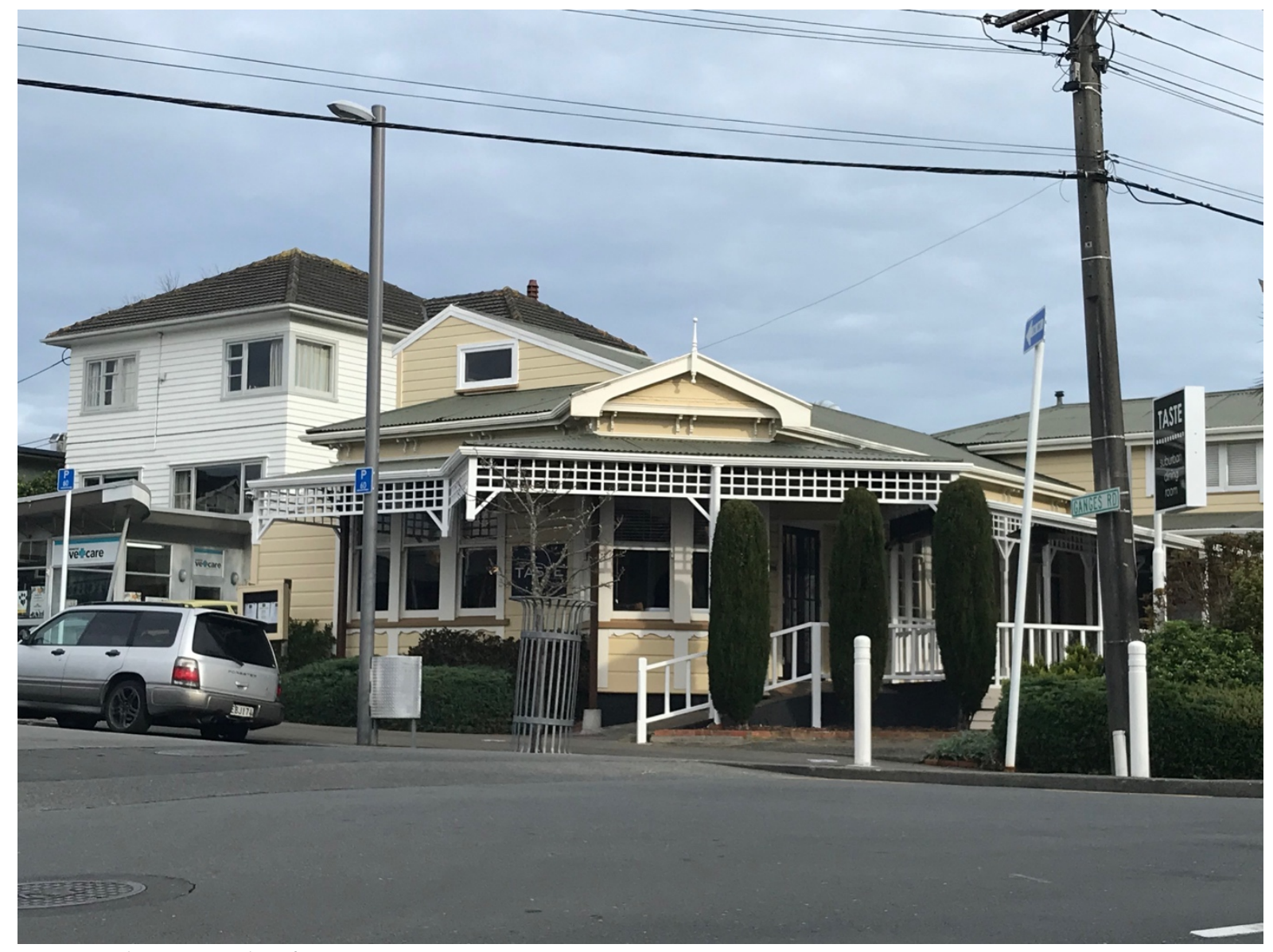

Artist Photograph of position in space.

Lastly, both the positionality of the researcher and the collection of data as a preservation technique further provided the rationale of the case selection. Out of the eight locations I visited with the art group, each tape was viewed, and during this viewing process I was looking for distinct actions involved therein.

The Khandallah tape was unique due to its distinct contents: It showed the act of measuring in action, but not as an achievement, rather the artist can be seen having trouble 
measuring. Analysing this trouble further enabled me to notice how the artist solved this trouble as a contingent and ad hoc achievement. The noticing was the artist lost his measurement to then replace it with another approximation. This feature alone caused the selection of this tape from the others.

\section{Analytic Mentality}

My analytical process was inspired by Goode's articulation of Garfinkel's analytical device (Goode, 1994, p. 127-146) ${ }^{35}$. Ethnomethodologists may understand this device as Garfinkel's "rendering theorem" (Garfinkel 2002; Garfinkel \& Wieder, 1992). This theorem articulates lived order as somehow translatable into an account that stands on behalf of that lived order. For example, I sifted, viewed and revisited the entirety of the corpus of collected video data in search for something analysable. From this corpus, four independent episodes displayed an artist raising and stretching their arm out in front of their body with pencil in hand (the artistic technique known as the comparative method). Reflecting upon seeing this artistic method unfold in real time however, caused a potential candidate from the corpus to arise. Throughout this case selection procedure, I was oriented to the member's actions and gave little concern to what good case selection may entail from consulting with methodological sources. The object of the research was to explicate how a series of contingent practical actions were organised in real time in the context of an urban sketcher sketching.

The act of snipping one raw six-minute video clip into several thirty second episodes initiated the production of such a preliminary analytical object. For each episode I arrived at a name based on the sketching actions displayed therein. For example, the tape labelled from 'start to erasure' showed the artist drawing on page until his action shifted towards haphazard

\footnotetext{
${ }^{35}$ Goode presents a table where its four columns represent the "stages" of the analytical procedure: The lived order, methodical procedure, data/rendering description, and scheme of analysis (see Goode, 2007, p. 15).
} 
erasure work; 'from erasure to pole', 'from pole to wind', 'from wind to lamppost', 'lamppost to end' subsequently follow the names of these clips. These preliminary categories influenced the analytical object as the keywords utilised therein (erasure, pole, wind, lamppost) described objects within both the visual field and the sketching pad. The naming of research materials was thus a product of attempting to simplify what the artist was doing for analytical purposes. In short, the artist's actions were glossed through an analytical lens, and consequently, the research object's formation was henceforth partially constrained by placeholder categories.

Reflexively, these categorising procedures may themselves become versions of the very "apophasis" (Liberman 2007) in pursuit: How may analytical glosses come to stand on behalf of the member's lived order? How can the ethnomethodologist account for another's account in written descriptions? Consider a large passage on this point made by Goode (1994):

The term 'lived order', then, calls our attention to both the contingent and socially structured ways societal members construct/enact/inhabit their everyday world. Ethnomethodologists generally have noted that the lived orders of the everyday world are both relied upon and ignored by societal members... in this sense this everyday orderliness is known. But it is not known in a way that is conscious and reportable... one way to look at ethnomethodology's outlook on the social construction of 'reality' is to understand that ethnomethodology sees a world that is composed exclusively of ongoing, situated, lived orders... [these] orders are the ongoing daily work of societal members, work that is their powerful creation and interpretation of the social structures of everyday action (p. 127-128). 
Getting mediated access to lived order (the artist's local observable work) is possible due to the doubled feature of glosses as accounts - glossing practices are natural features of the social world and can be used as a resource just as much as they could become a topic of study (Garfinkel \& Sacks, 1970; see also Lynch, 2015, p. 193-194). Consequently, the methodic procedure placed the issue of 'methodology' back into the everyday settings it emerged from: We are not looking for definitions to then go out and look for, instead we ask what did the artist ordinarily do during their activity, how can we describe that as organisational?

\section{Ethnographic Context}

The Lower Hutt Urban sketching group congregate each Wednesday and together, travel to sketch various locations around the greater Wellington City region. Upon arrival, the group members would individually disperse and seek out subjects to organise their day's sketch. These sessions were temporally structured, and each artist had two hours, from 1-3pm, to finish their drawings before returning to a pre-organised meeting point: A nearby café or restaurant for a show and tell session (forthcoming chapter). The materials captured, analysed and presented in the following case were built from an afternoon sketch on the $12^{\text {th }}$ June 2019.

Urban sketching is an approach to creating artworks that relies mostly on the real time task of rendering natural objects into pictorial representations. I observed one common style shared among the urban sketching group members. Most begin their drawings with pencil and paper. This 'lay in' process helps to organise the subsequent inking and colouring to follow. During this lay in process, the artist's chosen visual field, and the environmental objects witnessable therein are rendered on the sketching pad. At this stage, if the natural object's dimensional width and height properties are not faithfully transferred to the paper, the subsequent work may be out of proportion, and thus become increasingly difficult to 
address, make any required changes, and so on: It can cause proportional disaster to the final realist image. Once the pencil rendering is at a stage of acceptable progress however, the artist then may continue to correct faint lines before committing to them with permanent ink. At this stage, the drawing may then form a guide for the subsequent colouring work to respond with. In the end, this three-stage process of sketching — pencil lay-in, ink lay-over, and colouring - guides the structure of the artist's artistic activity, which occurs over a twohour window.

After receiving the sketching group's routine Wednesday morning email confirming the time and location of that afternoon's sketching session, I left my University office, caught the train from Wellington central station to the northern suburb of Khandallah, and made my way to Ganges Road, the main village strip on foot. Several artists had already set up their equipment and began drawing by my arrival, however, one artist arrived late, providing an opportunity for his beginning sketching phase to be observed and recorded on film. 


\section{The Case Study}

\section{Orienting to the visual field}

The artist established his orientation to the chosen sketching subject by making the first marks of many to come. These marks began with one, however, and this mark laid down the background the other marks would build upon. This singular line made with $2 \mathrm{~B}$ pencil (Figure 1 below), corresponded with an object in the visual field. Notably, the 'left' of the sketching pad resembled the 'left' of the artist's visual field. Together, the pad and the visual field were linked by this simple act of drawing. Additionally, this mark adapted the setting from a common urban scene into a domain of practical reasoning (Livingston, 2006).

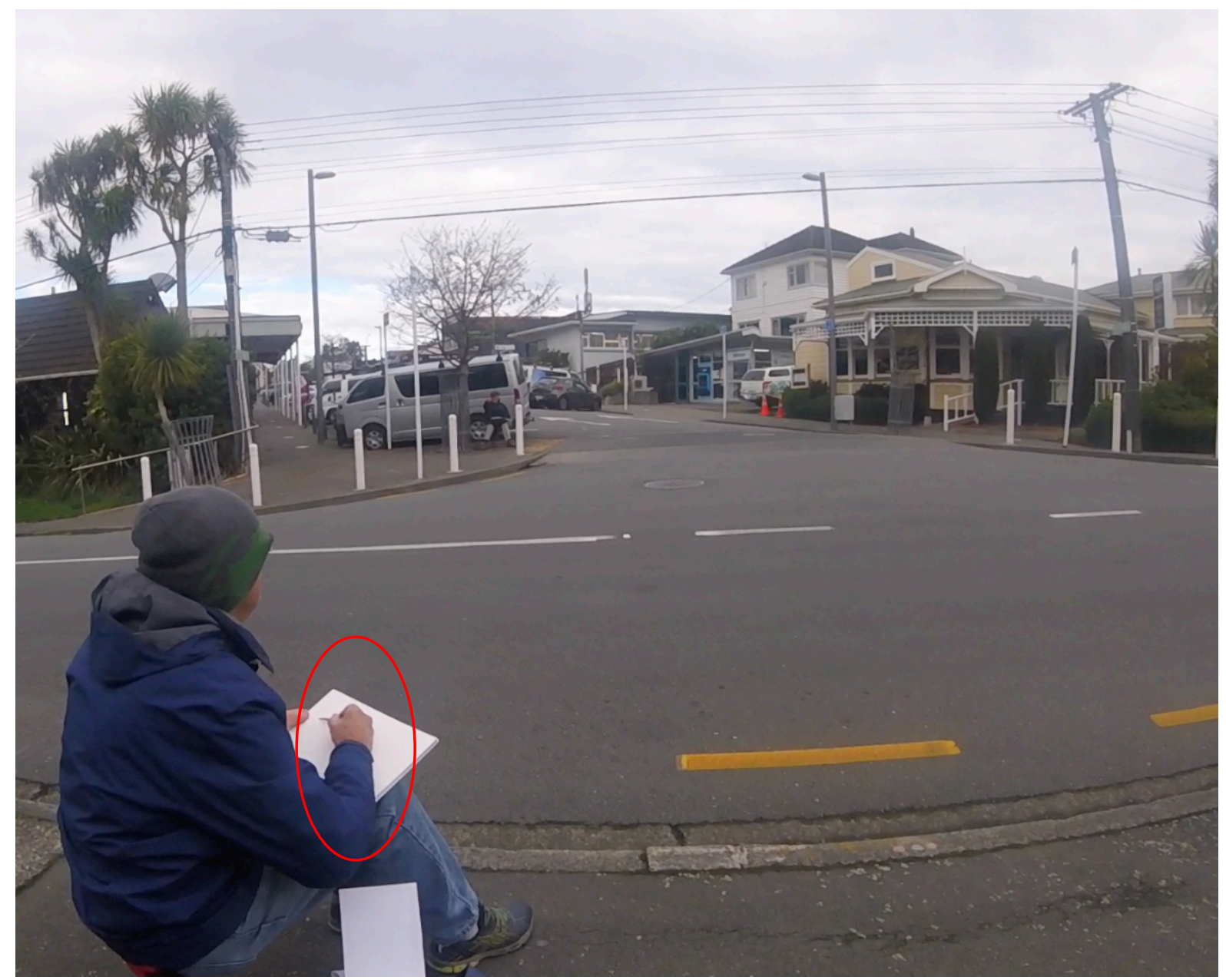


Drawing single lines was done to form a group of marks and the artist continued to orientate to the left of the page over the next ten seconds of this mark-making activity. We see from the nine sequences of action displayed in (Figure 2) below that the artist focused his visual attention between the drawing subject (Figure 2a) and the sketching pad (Figure 2b). He then repeated this action by pulling toward, and pushing away, the pencil from his body (Figures 2e, $2 \mathrm{f}, 2 \mathrm{~g}$ ). The artist looked at the building subject (Figure $2 \mathrm{~h}$ ), checked the placement of the line upon the pad (Figure 2i) and then moved the pencil from his right hand to his left. This act revealed an eraser was hidden beneath his palm.

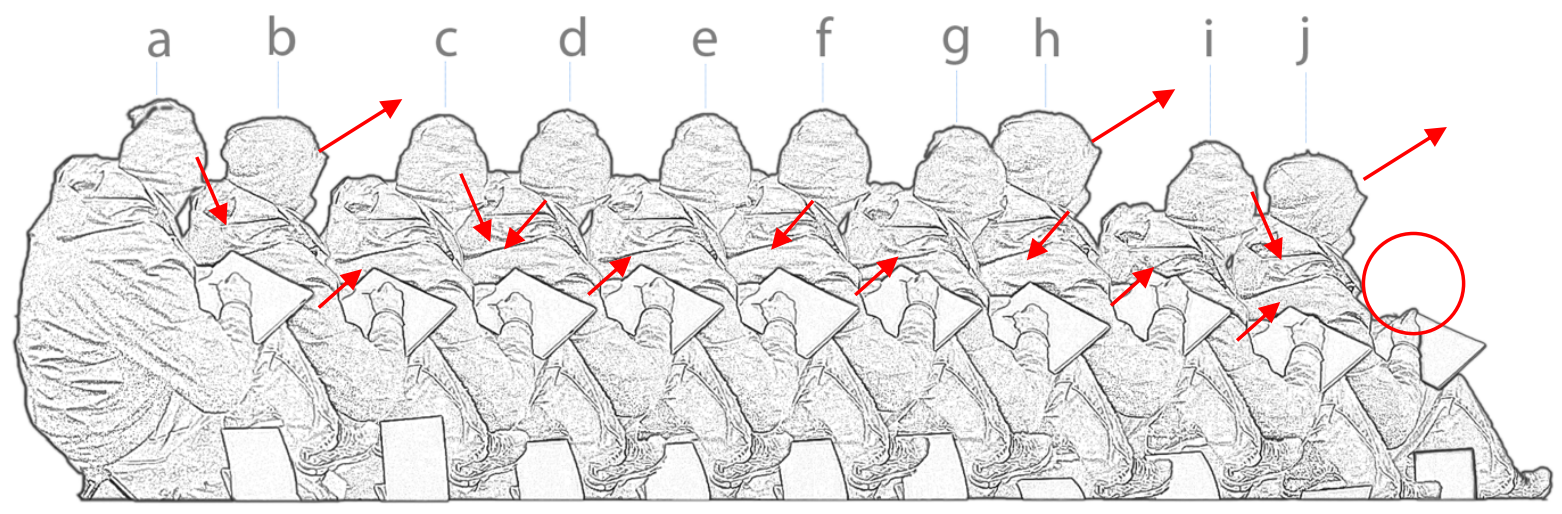

Figure 2

He then gazed at the sketching subject whilst holding the eraser in his right hand (Figure $2 \mathrm{j}$ ).

The pushing and pulling, looking and placing lines on sketching pad constituted the individual drawing acts of a larger drawing contexture. These acts were characterised by their non-measured qualities loosely trusted by the artist's naked eye upon the scene.

Consequently, the orientation to the visual field and transition of equipment (from pencil to eraser) marked a natural end of this current drawing phase. The correspondence between the object and the pad projects the next task at hand. 


\section{Erasure}

The artist controlled the representational accuracy of his drawing through the activity of erasure. During the following sequence of actions, the artist orientated to the pad with eraser in hand (Figure 2a), and for the next few moments, he refrained from lifting his head. He placed the eraser at the top of the pad (Figure 2b) and with one quick downward motion, the light pencil marks, having only just been drawn, were lightened (Figure 2c). The artist returned the eraser to his right palm, freeing up his fingers, as he reclaimed the pencil from his left hand. Continuing, he placed the pencil at the middle of the pad (Figure 2d) and pushed the pencil softly away from his body (Figure 2e), and then as he pulled it towards himself, new lines were superimposed over the old (Figure 2f). He then raised his head, looked out to the building subject, and readjusted his pencil into a non-drawing position

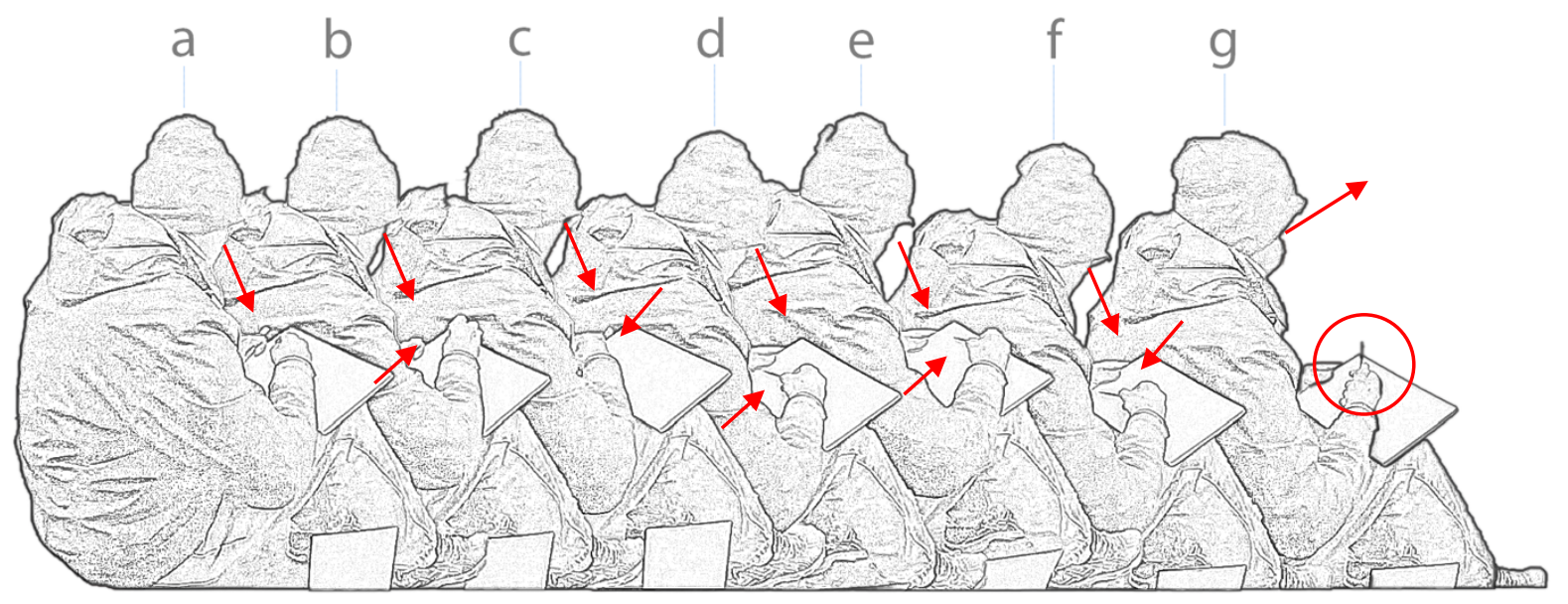

Figure 3

(Figure 2g).

The fact the artist refrained from raising his head during this erasing action reinforced the representational value of the marks as they stood on behalf of the worldly object. If this erasure procedure added such transformative power to the representational qualities of the visual field through a simple line, then the artist had successfully started observational drawing. In this sense, the erasure of the previous marks, including the superimposition of 
one to follow, allowed the artist to focus on how a line ought to look: The urban sketcher did not engage in a 'blind contour' of the artistic field, rather the placement of the lines on the sketching pad were paramount to how this building represented a practically real correspondence between the current visual field, and this now developing 'rendering field'.

These constitutive acts of erasure and replacement established correspondence between the art object and the art subject. This abstraction, and the 'real object', subsequently, were made to stand on behalf of one another, and for all practical purposes came to be treated as identical. The artist had placed the left lamppost on the pad, thus contextualising the production task of drawing the other artistic categories to the urban setting placed before him.

\section{Finding a candidate unit of vertical measurement}

Whilst the artistic practices of erasure and replacement may mitigate representational mishaps during first attempts to capture a line or angle the entire activity of urban sketching is full, perhaps encumbered, with problematic situations to correct and solve. The focus of the next few sections relate to observing how an artist measured an object in the visual field. Its representational qualities may add additional certainty to the correspondence between marks and the artist's point in space. One mark can be used as a measure to which all other marks relate.

Below, Figure 4 illustrates how the artist made his visual field match his rendering field as it unfolded in real time by utilising a semi-formal art technique. The artist raised his right hand from the pad (Figure 4a) and moved to hold the base of the pencil perpendicular to the floor (Figure $4 b$ ). He then stretched his arm out in front of his body and aligned the pencil to meet his right eye (Figure 4c). The pencil was held steadily at the left lamppost for a few moments (Figure 4d) then moved to the right lamppost (Figure 4e) before it returned to the initial left position. The pencil moved far off to the right (Figure 4f) and then the artist 
immediately lowered both his head and arms and focused on the pad resting upon his knees.

He retained the location of his thumb on the pencil (Figure 4g).

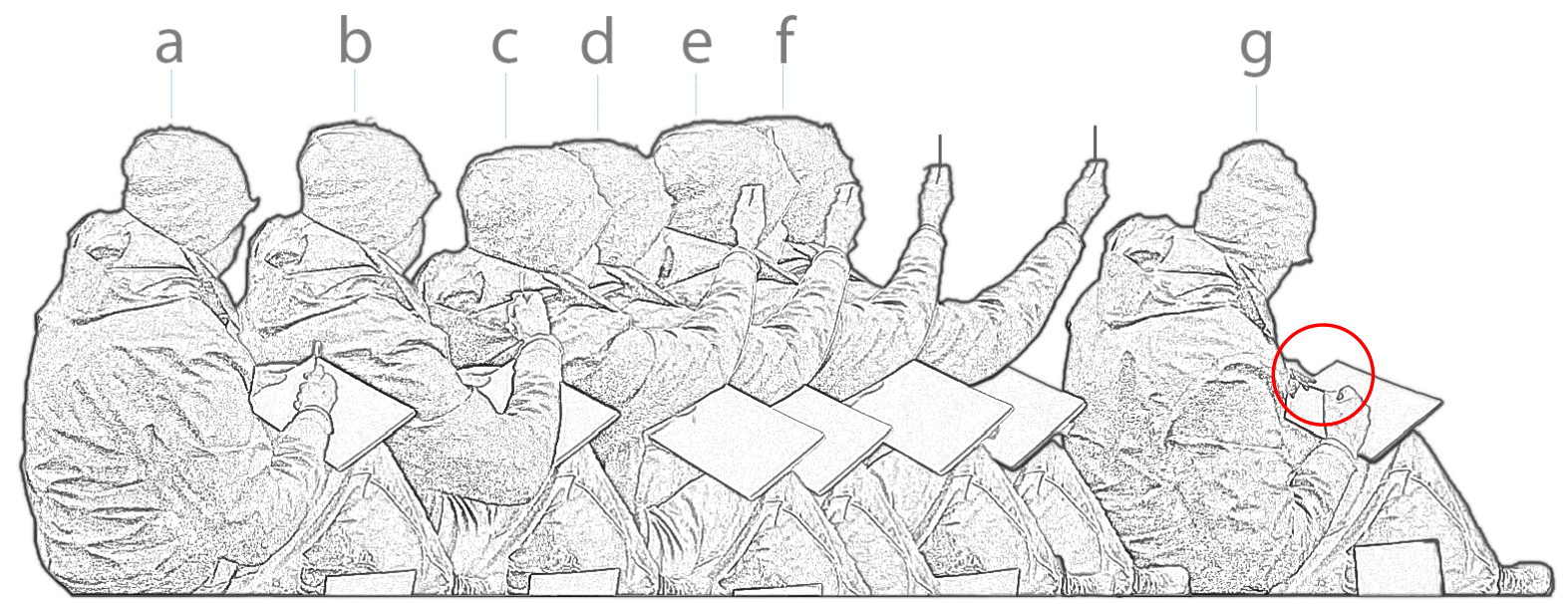

Figure 4

In Figure 5 below we see in the left panel how the distance between the tip of the pencil and the thumb is made to match that of the height of the chosen object in the visual field (the left lamppost). The right panel demonstrates how the location of the measuring device was trained onto another object within the same visual field, the right lamppost.
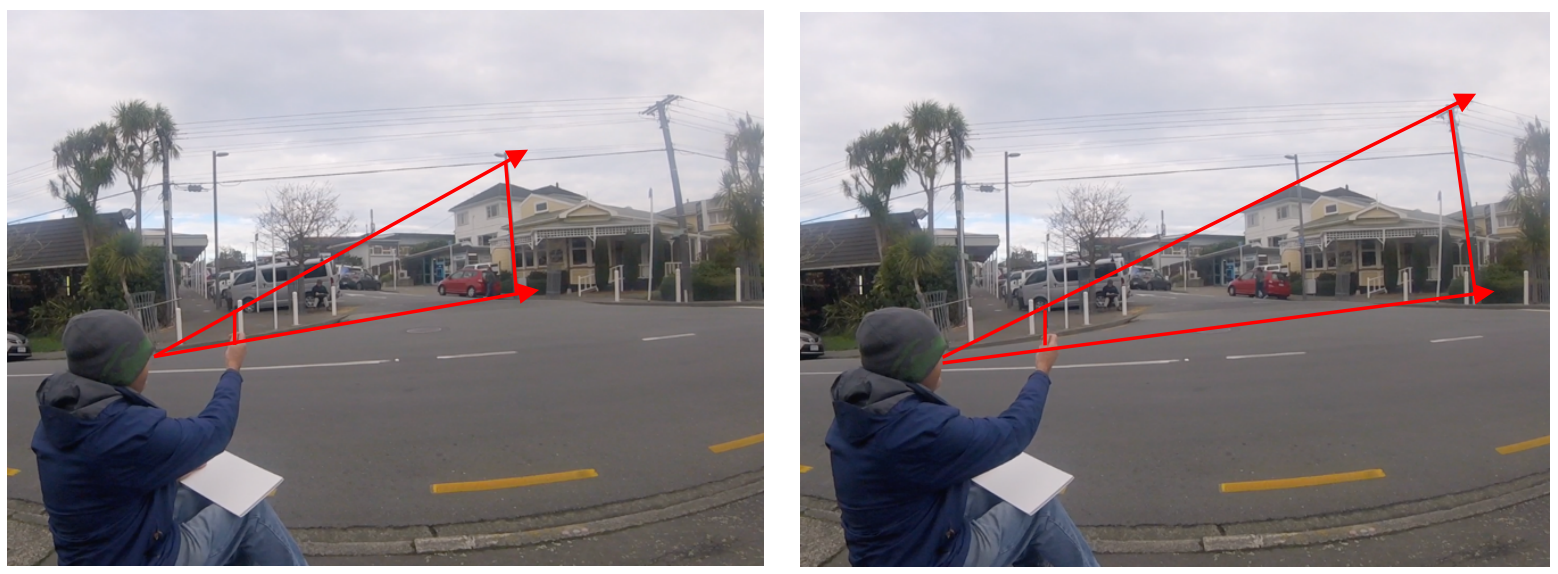

Figure 5

This excerpt displays how the artist nominated an object from the environment, tested it by nominating another, and then returned to the initial nomination as to select it as the unit of measure. The artist found this unit of measure in the here and now. Moreover, this property was not natural in an everyday sense, and thus it may be considered an object of professional 
vision (Goodwin, 1994): The artist spent considerable time during this third read, and by doing measuring he was organising the visual field into readable, objective properties to be translated as representational. The production of a unit of measure transformed the visual environment into a stable artistic model.

\section{Comparative method in situ}

The constitutive acts of locating a unit of measure, of raising a pencil to meet the eye an arm's length away, checking that unit against another candidate, and selecting the initial object as the unit of measure, all contributed towards the configuration of the ongoing drawing context. Yet, selecting a unit of measure from the visual field was done to compare that unit with others in the field. That is, having obtained the vertical measurement, and thus the unit of measure, the horizontal measurement soon followed.

Observe how the artist confirmed the position of the thumb (Figure 6a). By briefly rechecking the vertical position (Figure 6b), the artist immediately tilted his pencil from the vertical to horizontal position and momentary held it in place (Figure $6 \mathrm{c}$ ). The pencil moved slightly to the right (Figure 6d) before it quickly lowered (Figure 6e). The artist orientated his

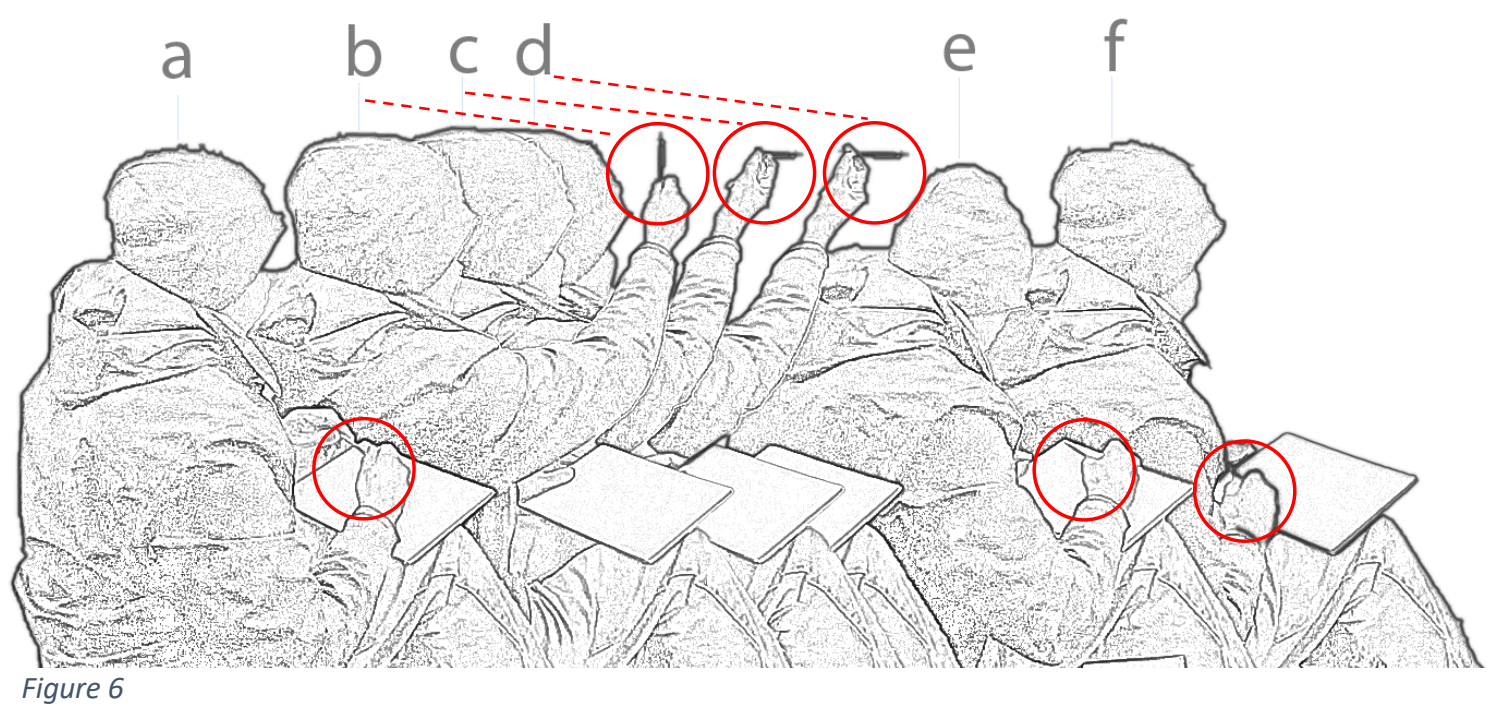


pencil to rest upon the sketching pad's bottom left side while he looked toward the building ahead (Figure 6f).

By placing the tip of the pencil at the top of the left lamppost, the artist checked that earlier unit, where the distance between the top and the bottom of the object corresponded with the distance between the tip of the pencil and the thumb (Figure 7: left panel). The artist then pivoted the pencil on its side so that the pencil's tip rested against the lamppost, while his thumb rested in space (Figure 7: right panel). This produced a squared unit of measure; a comparative unit was thus defined.
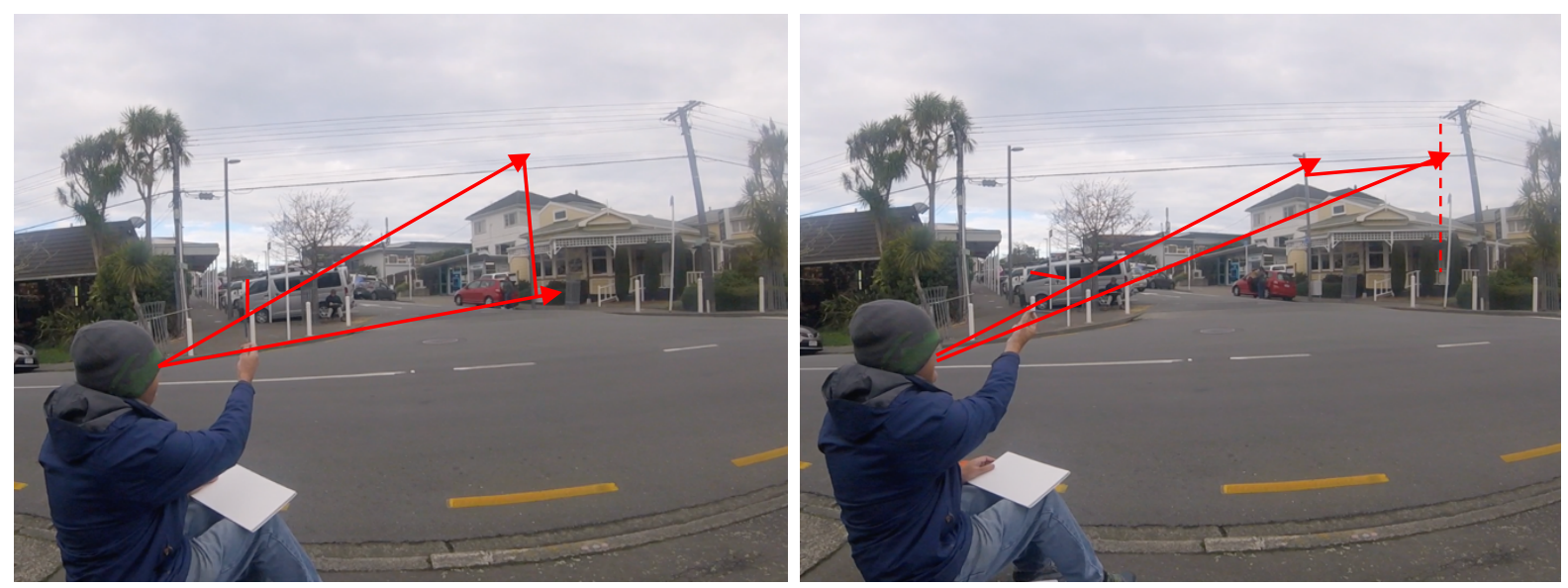

Figure 7

The knowledge gained from this basic measuring exercise could be phrased as "The height of the lamppost when turned on its side (one) is (one and one half) the width between the two" 36 . These actions, of measuring and finding, checking, and producing candidate objects from the visual field, enables the artist to see the visual field, in this case, as a grid-like system. Moreover, this substitution of the visual proportions ${ }^{37}$ caused the drawing to obtain objective characteristics standing on behalf of the object as a local record. Consequently, this

\footnotetext{
${ }^{36}$ The positionality of the researcher's camera skews the perspective: from the position of where the artist is sitting, this relationship is found to be closer rather than what is evident in the figure itself.

${ }^{37}$ The one unit is roughly 'made to fit' the height of the lamppost with objective, quantifiable properties from the setting; 'that lamppost' from 'that' position in space will always be 'that' height and 'that' width, for example. This point is falsified by the fact, the distance between the lamppost is not exactly 'one and one half'. Here is when 'artistic licence' features, itself an interesting use of accounting in its own right.
} 
measurement (the distance between the thumb and the tip of the pencil) is read as a real correspondence between the sketching pad and the artist's visual field.

\section{Translating the modified landscape to the domain of rendering field}

The excerpts above displayed how an artist used a measuring technique to organise and read a unit of measure from the visual field. This exercise produced a unit of measure to compare visual objects with. The artist, for example, learned of the height of the left lamppost. He too learned of the distance between the two lampposts was one and one-half. Thus, the bounding dimensions of his lines drawn in (Figures 1 and 2 above) were adjusted to match this working unit of measurement. Whether the unit of measure between the two lampposts is exactly one by one and one half became irrelevant. Consequently, the artist measured this one by one half as a forced approximation of the distance between two boundary objects within the visual field. Although up to this point we have learned how the artist organised his sketch and established the boundary-objects and the approximate distance between them, the next few excerpts illustrate how the artist transformed this approximation to the sketching pad.

\section{Losing the unit of measure}

As the artist continued to organise the proportional relationships between what he saw and read within the visual field, the unit of measure was somewhat forgotten, before it was translated onto the sketching pad. This is a curious sequence of activity, and they are seen in (Figure 8) below. I attempt to demonstrate how he accomplished losing his earlier measurement and altering in for another: 

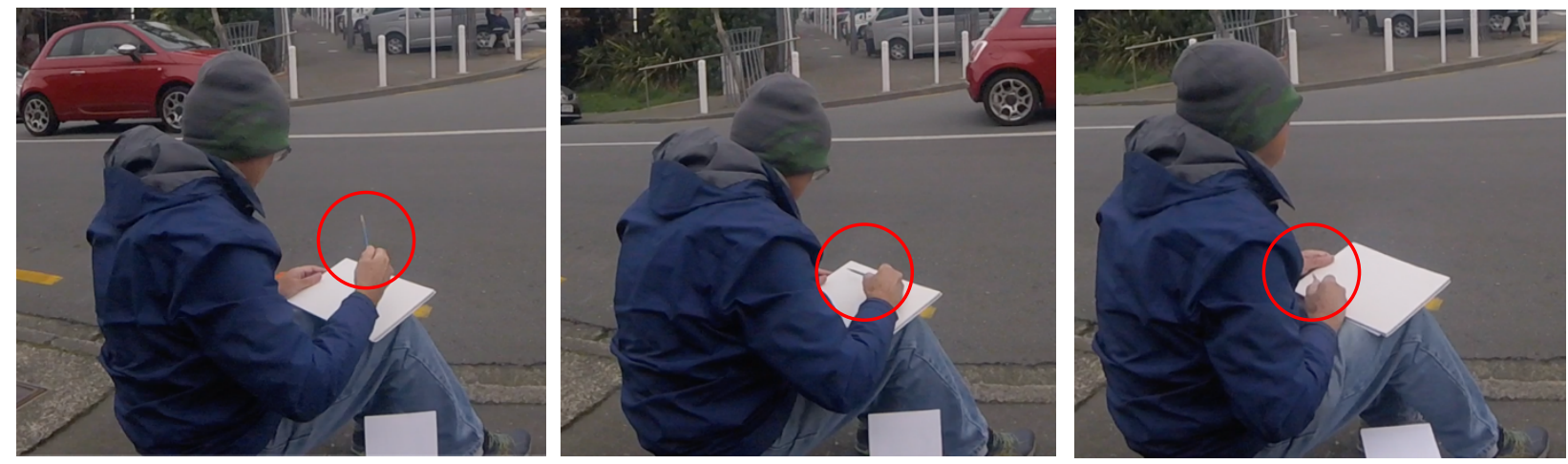

Figure 8

The artist lowered his arm after comparing the unit of measure to objects in the environment as he orientated to the pad. Observable in Figure 8 (left panel), the artist's thumb clearly marked the unit of measure. Moreover, as displayed in Figure 8 (middle panel), the artist placed the tip of the pencil upon the drawn 'left lamppost' line. He then rapidly raised his head and abruptly readjusted the pencil from a measuring to drawing grip (Figure 8: right panel).

Focusing on what happened to the unit of measure is relevant for two reasons. First, the artist demonstrated he had in fact found and recorded a unit to use in his sketch, and second, perhaps more importantly, the success of recording this unit calls to question why the action sequence above occurred. Subsequently, what could be gained from measuring and approximating, but not recording that measurement onto the page?

\section{Haphazard measuring}


We see a very subtle act in the artist's work as it unfolds in real time and as the artist continues to draw upon his earlier established lines. Consider the action sequence within (Figure 9) below, for example:

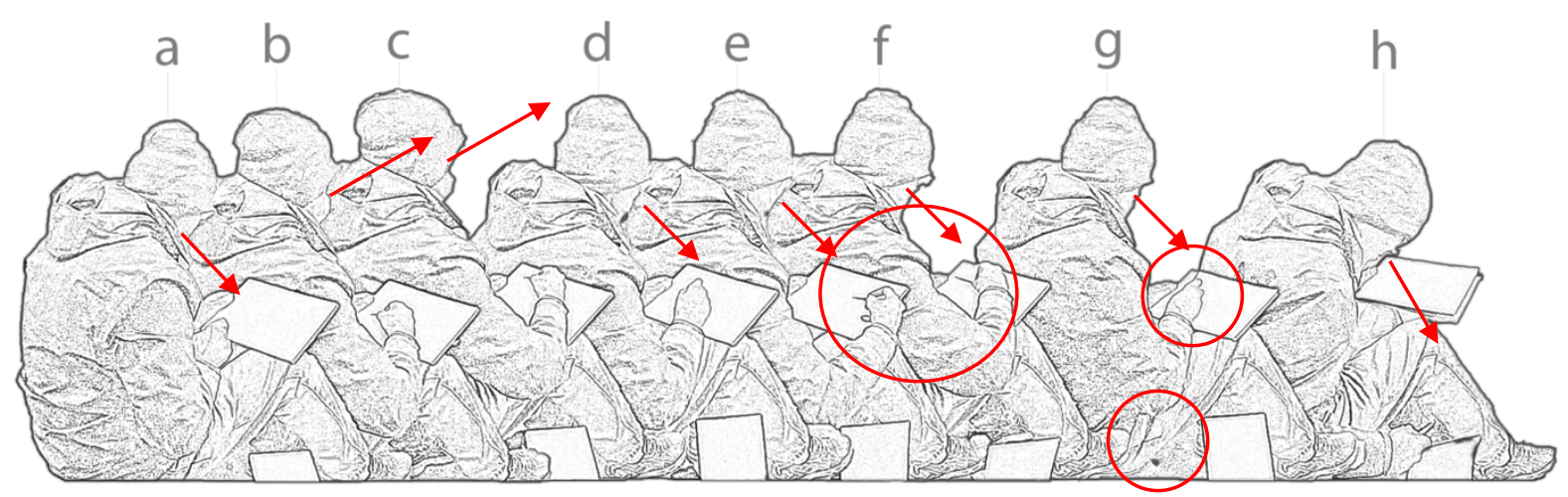

Figure 9

After a slight reposition of the pad upon his knee, the artist pushed the pencil into the pad, as to leave a deliberate record of placement (Figure 9a). He then positioned the pencil half-way up the page, lifted his head, looked at the sketching subject and drew a line (Figure 9b). The artist repeatedly looked between the object and this line (Figures 9c) to then raise his wrist slightly so the tip of the pencil rested on the right-hand side of the sketching pad (Figures 9de ). At this point, the artist focused upon the pad and sketched a vertical line. The 'unit of measure', however, had yet to make an appearance.

Notice how the artist raised the pencil from the right to the left of the pad (Figure 9f). The tip of the pencil touched the left-most line. The artist then rapidly pivoted the pencil from this vertical placement to a horizontal alignment (Figure 9g). Unexpectedly, as he pivoted the pencil, his hand could no longer keep hold of the eraser held underneath the palm; it dropped onto the street's pavement below. He paused to retrieve it (Figure 9g). His sketching flow was disrupted as a result (Figure 9h).

This pencil grip change between Figure 9e and Figure 9f above is a highly significant feature. In this move, the artist had haphazardly reproduced a unit of measure by arbitrarily 
placing his thumb onto the pencil. We see the artist approximate a unit of measure from the sketching pad. Subsequently, the initial unit of measure adopted and worked out from the artist's previous work was effaced, and this 'new' unit of measure made to take its place, for all practical purposes.

\section{Approximation as proxy for the real unit of measure}

The excerpts above showed the artist search, find, and compare a unit of measure within the visual field. This unit was translated onto the sketching pad as accurately as possible. The artist mundanely abandoned the placement of his thumb on the pencil. Remarkably, not only did these slight adjustments efface the earlier unit of measure with a new one, the recovery of the dropped eraser caused a complex disruption to the ongoing work of sketching.

The artist gazed to the sketching subject (Figure 10a) and with the pencil positioned to the right of the page (Figure 10b), looked to the building (Figure 10c). The artist loosely sketched a line on the right of the sketching pad without measurement. He then adjusted the pencil's position slightly down the pad whilst simultaneously looking at the drawn line on the left of the sketching pad (Figure 10d). He then pivoted the pencil from its current drawing position into a vertical configuration as it rested upon that left line (Figure 10e). He then carefully aligned the tip of the pencil to the top of this line, and then, with his thumb he took a vertical measurement. The artist re-pivoted the pencil into a horizontal position and placed the tip onto the left line (Figure 11f). With his thumb still in this rendering field unit's position, he focused his gaze upon the sketching pad and took a reading. Evidently, rather than using the pencil to measure, he had visually estimated where one and one half of the initial unit would rest upon the page. Successful, he touched the pencil down on the paper, and then lifted it from this point to reposition the tip of the pencil onto the previous unmarked 
line. The artist finally drew in a line, up and down the pad (Figure 10g). He then lifted his head and orientated to the sketching subject (Figure 10h).

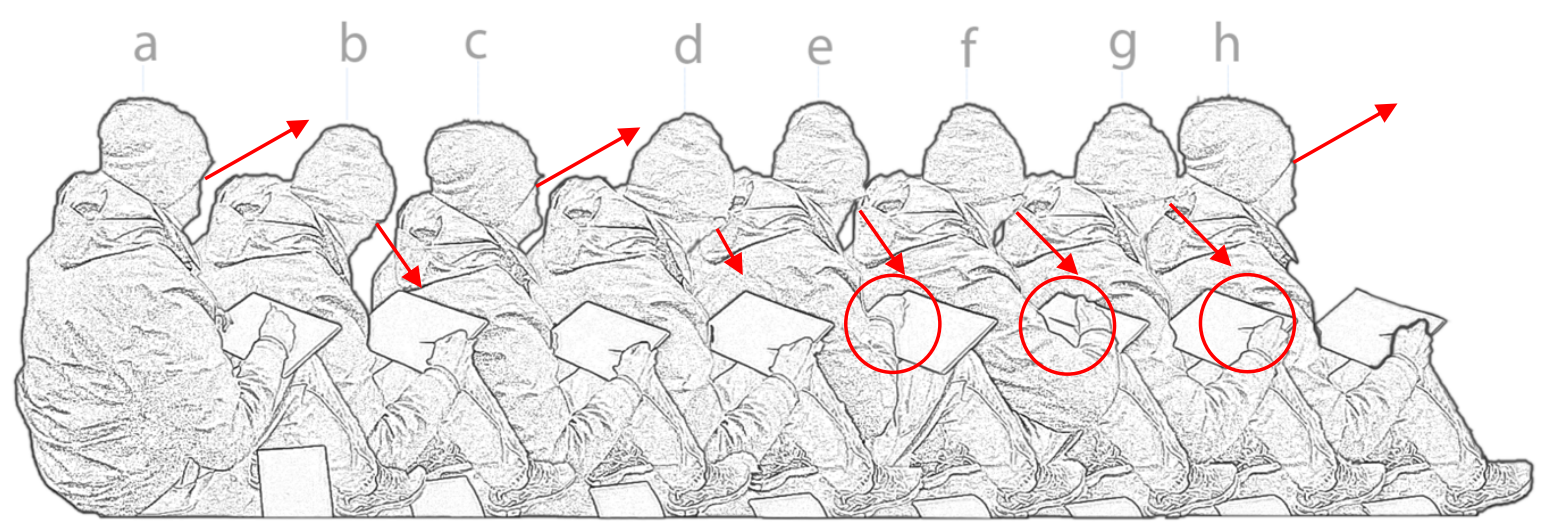

Figure 10

This measuring using the rendering field (Figure 9e) approximates the earlier unit of measure read from the visual field. The initial visual field measurements and their movements were disregarded entirely or substituted in favour of this newfound rendering unit (Figure 9f). It is my conviction that the sketch was successfully transformed into an artist's working object in this moment, the making of which was accomplished by using the rendered line as proxy.

The fact the artist had accomplished drawing two humble parallel lines one and one half of a distance apart on a sketching pad is far from unremarkable. It is unknown whether the artist had planned to draw two containing lines which represent the overall left and right of his drawing before he arrived on the scene, yet during the sketch he artfully worked to match the visual field and the sketching pad by using two lampposts as spatial aid. The consequence of drawing the two lampposts as roughly one and one half apart provided other art objects in the scene a related proportional relationship within the ongoing constitution of the artwork in production for the remainder of this sketching work.

\section{Summary}


The thumb placement seen in figures in $8 \mathrm{~b}$ and $10 \mathrm{f}$ should correspond with one another. Found in the ebb and flow of everyday life, the assemblage of local artistic work challenges this ideal version of events to explain how an artwork was formed. The artist lost his measure and unremarkably produced a new one, albeit approximative of the visual proportions of the building from his real time position. The above descriptions attempted to remain focused on the constitutive actions of drawing. Giving no special status to outside concepts, we can conclude that the artist displayed how the artful cover up of practical reasoning produced a contexture to which subsequent drawing work effortlessly flowed. This moment of effacing one measurement with another, has been shown as part of this drawing, without which the formation of this artwork would not be possible in and as ordinary sketching practice.

\section{Discussion}

Found in the corners of both every day and professional life, persons doing measurement is a fundamental social objectivating practice. Ethnomethodologists may search for and observe this activity in naturally occurring settings and respecify its methodological significance for studies on the production of social order:

The point of studying haecceities is to disclose an order of local contingencies of the day's work: Unique assemblages of equipment for recording and framing data, improvised methods for getting experiments to work, uncanny procedures for selecting 'good data' and cleaning the data of artefacts, expedient ways of getting results and getting them again, situated rhetoric's for instructing colleagues how to see the results etc. and etc. Assemblages of haecceities gloss the embodied and interactional work of doing experiments and demonstrating results (Lynch, 1991, p. 79). 
Relatedly, members producing objective measurements is constitutive in the day's work of urban sketching. An artist orienting to the visual field, erasing marks on the page, finding a candidate unit of vertical measurement, losing the unit of measure, simulating that unit of measure, and enabling the rendering field as proxy for the visual field's unit of measure, all for example, enclose the constitutive order of that produced sketch. Subsequently, respecifying measurement from topic of theoretical study to empirical observation, 'doing measurement' resulted in how 'the formation of approximation as a social resource' produced stable social order.

To answer the research question, how are artworks organised in and as practical social action? I relied on the respecification of measurement from topic to ordinary demonstration. The first section of figures presented in the case study above displayed how the artist's work of producing a unit of measure was unintentionally ineffective due to the haphazard act of readjusting his thumb's position on the pencil. The lack of a translated unit of measure effected the subsequent sketching action. The artist, for example, relied on direct observation to sketch both the left and right lamppost. He altered his drawing grip amid this sketching work and rotated the pencil so that its tip rested upon the left lamppost in a horizontal configuration. This 'manoeuvre' is curious. It questions not why the artist approximated the unit of measure, rather how. By respecifying the research question from measurement to formation of artwork in and as measurement management, approximation as social resource re-constituted the artist's contextual sketching work and enabled the activity to remain orderly for the moment's work.

What is sociologically significant about an artist approximating a distance only just measured? The artist's recovery of the dropped eraser caused a subsequent replacement manoeuvre functionally significant to the current place of order. For example, rather than continue from where he was interrupted, the artist started sketching the right lamppost to then 
take a vertical measurement from the sketching pad. This fundamentally altered the drawing and its representational accuracy. The previous manoeuvre (of approximating a horizontal unit of measure) was in this moment, completely effaced from the ongoing real-time activity.

One remarkable feature of this work is that the artist, during the entirety of the comparative measuring method, had not translated that unit onto the sketching pad directly. This second manoeuvre's reading and creation of the vertical measuring unit was completely contextual, momentary, local, arbitrary, ad hoc, contingent, haphazard and approximate; irrespective of sociological explanation, evaluation, prediction, criticism and the rest.

The current state of the sociology of art provides awkward space for ethnomethodological findings to occupy. This is due to three main reasons. First, classical ethnomethodological topics on the artful cover up of practical action and reasoning is devoid of observations into artistic workplace settings (Garfinkel, 1967). Second, ethnomethodology's respecification of Durkheim's aphorism challenges the shape of most mainstay art sociological literature to which ethnomethodology is incommensurable (Garfinkel, 2002). And last, my recommendation that ethnomethodologically respecified studies of artistic workplace settings are suited to the new sociology of art (Chapter Two) contradicts this incommensurable notion, thus providing the standing literatures with an opportunity to deflect ethnomethodological studies from integration. Ethnomethodological studies could still be suited to art sociology if the adoption of the ethnomethodological respecification occurred.

Take the comparative measuring method for example. Institutional pedagogy on the measuring technique exists in universities, schools, and in written and verbal and visual records. Both novice and expert artists may rely on this institutionally learned technique when drawing in real time. The artist thus brings this independent formal knowledge to bear 
upon his local sketching work. Abstractly, I understand this in what Goodwin called "a historically structured architecture for perception" (Goodwin, 2018):

It [the Munsell colour chart] was created by others, but it can be suddenly slotted into this immediate local action. In these ways, even in the midst of our local action, we are building upon the resources that we have inherited from our predecessors (p. 2).

Like the archaeologist's appropriation of the Munsell colour chart for identifying and classifying the tonal ranges of dirt samples (see Goodwin, 2000), the comparative measuring method was invented by artistic predecessors. Respecifying doing the comparative measuring method uniquely altered how the relationship between social structures (architectures for perception) and lived, local action was produced. The artist's use of the technique however, was not so much 'slotted into this immediate local action', as if the artist was following orderly instructions. The artist's organisational operations from taking a measured unit from the lived order and a social fact thus became the key focus of my descriptive analysis.

This analysis showed the duration of an individual artistic act was related to a retrospective-prospective act in that self-same gestalt assemblage. This was evident when the artist's sequential actions are traced between the assembly of the two measuring manoeuvres. Abandoning a measurement to then approximate it was not planned. The contingent acts are thus not related to outside entities, but rather are built from and within the sequentially unfolding contextures of simply doing sketching: Disruptions occur, such as dropping erasers, measurements are lost, such as approximation attempts to recover, and short-term memories are replaced with renewed attempts at organising the task at hand without attention to prior difficulty. 
In an ethnomethodological view, commonplace moments in life powerfully conceal the most extraordinary of things. The thoroughly lived taken for granted aspects of daily life constantly radiate the "seen but unnoticed" (Garfinkel, 1967, p. 35-75) conduct of commonsense activity. Considering learning how to notice naturally occurring common sense actions is an analytical enterprise. Understanding how one goes about noticing ordinary practices is a highly intellectual reflexive affair recommended by Garfinkel for ethnomethodologists.

Garfinkel (1967), however, created tension between the sociological-observer and the member-doer when he stated:

The seen but unnoticed backgrounds of everyday activities are made visible and are described from a perspective in which persons live out the lives they do, have the children they do, feel the feelings, think the thoughts, enter the relationships they do, all in order to permit the sociologist to solve his theoretical problems (p. 37).

Garfinkel suggests unveiling member's ordinary action through formally defined theories (ones external to their own living activities) may be irrelevant to the members who do the actual the living. Although Garfinkel's response is sharply positioned as an irony and directed to formal sociological reasoning, ethnomethodology is seemingly caught in an apparent contradiction: The act of noticing common sense conduct from an ethnomethodological perspective itself may be viewed as formal analysis (ethnomethodological recommendations are themselves formal sociological reasoning) ${ }^{38}$. Students of social life may face difficulty in accepting this proposition unless they first bracket the notion of ethnomethodology itself being formal, and second, not to take Garfinkel's word as representative of this primordial social order. As Livingston reminds us:

\footnotetext{
${ }^{38}$ Furthermore, the notion of formal in this sense could also mean to suggest a social calculus.
} 
"The only way that I understand Garfinkel's work is by finding in the world that which Garfinkel could be talking about" (Livingston, 2003, p. 483). It is in this sense Garfinkel (1967: 37) foregrounded his remark with: "When we ask him about them, he has little or nothing to say". The phenomenon in pursuit not only unproblematically exists in the often unexposed living mundane social world, but as Heritage once commented: "Ordinary people are apparently no more interested in the indexical properties of descriptions than they are in the reflective properties of action... all without strain or difficulty" (1984, p. 157). Rather than take the seen but unnoticed or essentially uninteresting as grounds for establishing concrete sociological representation, these features of daily life ought to become a topic of study in their own right ${ }^{39}$.

My role as analyst provided the task of video-analysing naturally occurring conduct and piecing together the real-time assembly into an analytical product of datum. By slowingdown the action I could discover how the artist, for example, produced an ineffective unit of measurement, but built from that ineffectiveness to approximate a new measurement, deal to a natural disruption to his workflow, and then returned to replace that earlier approximation within an entirely new pattern of activity which made use of approximation as resource to eventuate a one and one half distance between two lampposts represented as lines on a sketching pad. The analytical discovery Tanner could be talking about, may challenge the fact members themselves may not know exactly, or not pay attention to the mundane details of social order. Indeed, here lies a tension. If members naturally see but provide no notice to mundane phenomena, then how are those phenomena researchable without academic motivation to go about noticing? With the analyst paying such scholarly attention to member's activity, a certain style of descriptive product does emerge, and thus an

\footnotetext{
${ }^{39}$ I read Garfinkel had, in this way, proposed sense-making to be comprised in and of these features of human and social actions relating to each other within intersubjective action formations.
} 
ethnomethodological discovery into the mundane facts of social life is ultimately representational of living conduct.

Garfinkel dealt with this tension by accepting it. Ethnomethodological studies are undoubtedly analytical ones. The epistemological status of these findings however illustrates the deep intellectual debt owed to his theory. Commensurability, in my view, characterises the epistemics of ethnomethodological findings: They are subject to change, and are themselves living products of sociological work. For example, the fact that the artist used the artful cover up of approximation as a social resource does not tell us an objective fact about the social world. It tells us how that artist, on that day, in that moment -the artist's assemblage of haecceities - formed that art object. Part of that artwork formation was due to the artist's messy organisational ad hoc work of relating one action with another in a naturally occurring and ordinary way. Consequently, if the sociology of art is willing, then accepting these claims may provide a foundation for future studies inspired by the ethnomethodological style of sociology.

\section{Conclusion}

I focused on an urban sketcher measuring an object with his pencil and thumb. To think about this ordinary activity, I attempted to focus on the living effacements that ethnomethodological respecification may bring into view. Owen's reliance of approximation is an artistic resource, one which enables the orderly production of an artwork. 'Doing approximation' was dependent upon highly contingent, context producing, and context renewing constituents - actions that were managed by the artist in messy ways.

The way the member managed this work as part of a natural course of affairs ought to raise further curiosity towards a program of art research where more examples of artwork as practical social action could be influential to the social formation of artworks. These 
implications may relax how epistemological claims are made by art sociology: Sociological descriptions of such practical actions are corrigible, and are treated as representational of living orders, not living orders themselves. That is, to see the epistemic status of sociological facts as corrigible.

How persons organise themselves intersubjectively to produce meaningful context for artworks to form in conversation is the topic of the next empirical case. I continue with the trend with gestalt contextures and ethnomethodological respecification of Durkheim's social fact (Garfinkel, 2002). By visiting sites of artistic action with camera in hand, the analyst can collect, analyse, and present studies of a range of other social practices contingent upon each individual case. More studies of this nature may be used to build a large enough corpus for theoretical exposition. Until DeNora's (2002) call for explicating art in action is satisfactorily answered, only then may we consider the future of the new sociology of art as hospitable for studies of practical social action. 


\section{Chapter Seven: Artwork-A Talking Group's Practical Situated Accomplishment}

Why not go directly into the everyday details of social interaction and delineate the temporal development of social action in which people make each other understandable? (Kim, 1999).

\section{Introduction}

Unlike the two prevailing studies of artistic praxis, the following Chapter looks exclusively at how a group of people interact with one another to produce and manage a multi-party conversation involving material art objects as its defining topic. This chapter reengages with another style of analysis which raised a major question about how (or what) the social could be reasonably conceived in sociological studies. In this case study, the interpersonal social relationships and activities amongst the intersubjective group members is at once apparent. This is made most relevant in discussion with Garfinkel's "respecification of social order" (Garfinkel, 1991), where, all human action is treated as social, therefore providing not only co-present interaction, but observational studies of any human practice as explicatory of the social.

Indeed when two or more people interact with one another, social relationships between their actions are accountable as co-produced social objects. In this Chapter I aim to show how these co-products may be thought both socially independent from action whilst remaining situated in the settings. Two key ideas, namely, Gurwitsch's "thoroughgoing interdependent relationships between constitutive parts" (Gurwitsch, 1964), and Garfinkel's social order of the "gestalt properties of social facts" (Garfinkel, 2007) guide the following 
analysis. I describe how a group of artists naturally talk amongst themselves after a sketching session during a routine show and tell session situated within a quite public café.

\section{Roadmap}

Three main sections structure this chapter:

The first section discusses the data and methods where I use and select from the data corpus of materials that were gathered on site during the urban sketching research project. This site is the Wellington Rose Gardens, and the data shows a conversation happening between sketching group members that took place after they individually arrived at a nearby café to discuss their recently completed drawings. I myself had arrived in the day's café having just spent two hours sketching, to find three artists seated and talking amongst themselves.

In analysing these tapes, the natural discussions surrounding the member's talk of their artworks became "the phenomenon of concern" (see Luff \& Heath, 2012) as this collected data remained useful for transcription.

The second section presents the case study where I show detailed graphic and written transcriptions detailing how several artists interact with one another in real time. The group's natural conversational activities used to organise how artworks gained social meaning in a group talk setting are the key focus of the study.

The third and last section discusses the findings. I demonstrate here how artist's talk could be examined in real-world settings to describe those intersubjective practices as contributing factors for an artwork's social existence. Additionally, if art sociologists were truly interested in how social practices were influential to the objective formation of artworks, then visual transcription processes ought to increase, and ethnomethodological studies occur more frequently. 


\section{Research Background}

\section{Research Participant}

Members of the Lower Hutt Urban Sketching Group congregate each Wednesday afternoon, travel to a specific drawing location situated around the greater Wellington region, then find, and sketch in real time, urban objects: buildings, playgrounds, graveyards, churches, yachts, bridges, cottages, city and sea scapes, etcetera. As the art group members reach the end of their allocated afternoon two-hour time slot, they individually rendezvous to a nearby café and discuss their recently completed drawings.

Six participants make up the members in this study, one of whom is the researcher, and another is heard but not seen on film. Of the six participants, four are visible in the following graphic transcripts. Two members of the group, Amber and Steve are conversing with one another; Owen enters the scene; and then Geoff is handed a sketching book. Amber, Steve, Owen and Geoff are core members of the urban sketching group and have frequently featured in the larger corpus of video-ethnographic materials.

\section{Case Rationale}

The footage used in the following case study was collected after shadowing two artists in the field, Geoff and Amber. At the end of the urban sketching session, the group congregated at a nearby café to discuss their recently completed drawings. At this point of the research I had collected many ethnographic materials yet the discussions around the café setting had not been recorded. Having the artists talk about their artworks with one another provided an opportunity to analyse an alternative setting to artistic praxis, one that involves many artists talking about their work with one another in a relaxed and more social environment. In sum, 
the discussion of artworks after having just produced them is an important part of the group's social activity, and these discussions help constitute the meanings of the artworks as they become cultural products.

\section{Analytic Mentality}

I orientated toward an ethnomethodological approach of video data methodology (see Cekaite, 2020) and engaged with a multimodal-like analysis of the naturalistic studies of everyday activities (see Mondada, 2007). The group member's discussions, which are natural discussions of how the group talked of their artworks became the "phenomenon of concern" (see Heath \& Luff, 2007) when looking at the video data during analysis.

Now consistent across the case studies, this case study too draws upon both the writings of Aron Gurwitsch and his theory of functional significance (see Chapter Three), and Garfinkel's development of these ideas. Garfinkel's development - to turn attention from the gestalt coherence of things, to the coherence of orderliness of practical action - sets up the analytic mentality for the following case. My explicit concern was to describe how two actions immediately relate to one another in context, and to think about how the artists do that relating work. This is because functional significance 'misinterpreted' into a project of sociological enquiry may further explicate the social order constituted by persons relating to one another in real time (see Chapter Three). What may lay beyond these descriptions is left to the analysis.

\section{Ethnographic Context}

I had arrived in the café having just spent two hours shadowing Amber and Geoff in the field to find three artists seated and talking amongst themselves. To avoid interrupting their natural 
conduct, I positioned a small action goPro camera upon the café tabletop during the immediacy of the interaction. The remaining sketching group members joined the table one by one as discussion of the day's works developed into an hour-long public group conversation. We join the action below.

\section{The Case Study}

We begin with an example of Amber freeing her hands (Figure 1:1). This required an unforeseen obstacle, the sunglasses, to be relocated so that her sketching pad had enough room to comfortably fit upon the tabletop. Steve (on the right) made numerous utterances during this mundane manoeuvre which served as a technique to momentarily delay the conversation so Amber could finish her task.

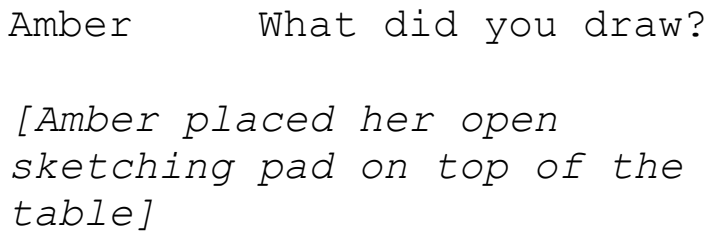

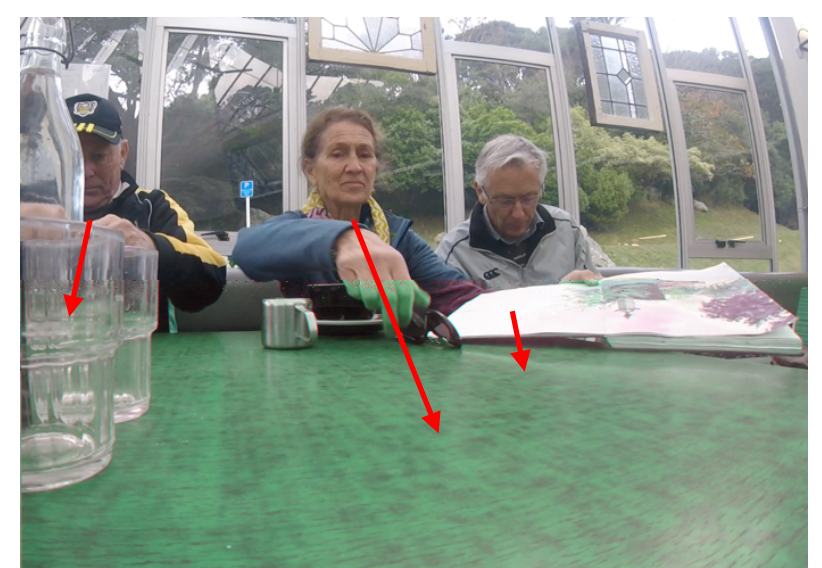

Figure 1:1

Steve aided Amber in her settling as he may have understood the functional role of Amber having moved the sunglasses to place her pad was to free her hands. This is evident within his last utterance "there you go" as he offered his pad to Amber (Figure 1:2). 
Steve

I picked a random / It's a weird little /

\section{There we go}

[Steve handed his sketching pad to Amber]

[Geoff, Steve and Amber looked to the sketching pad (Fig $1: 3)$ ]

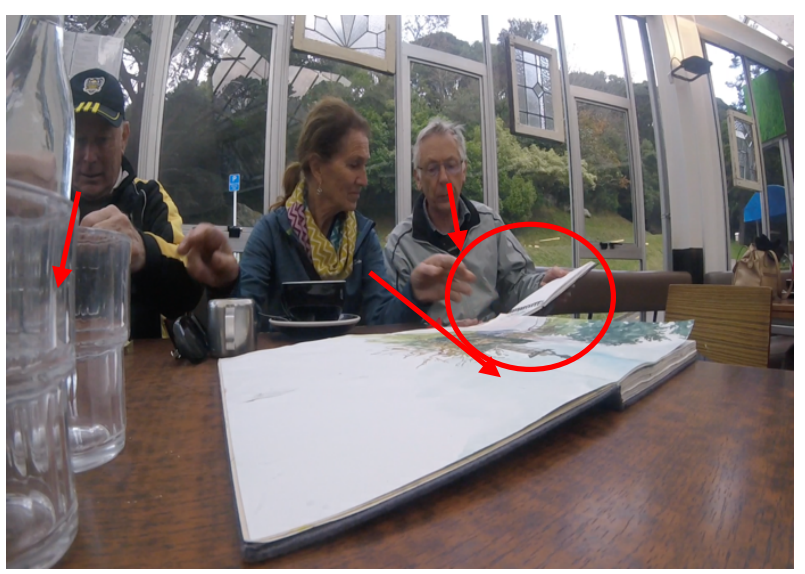

Figure 1:2

Amber's receiving of Steve's sketching pad provided her a first glance, and she immediately responded with “oh, nice!”. This excitement caused Geoff (on the left), to include himself as he orientated his gaze upon Steve's sketch (Figure 1:3).

Amber Oh, nice!
[Geoff laughed: heh, heh, heh]
[Steve leaned back in his chair]

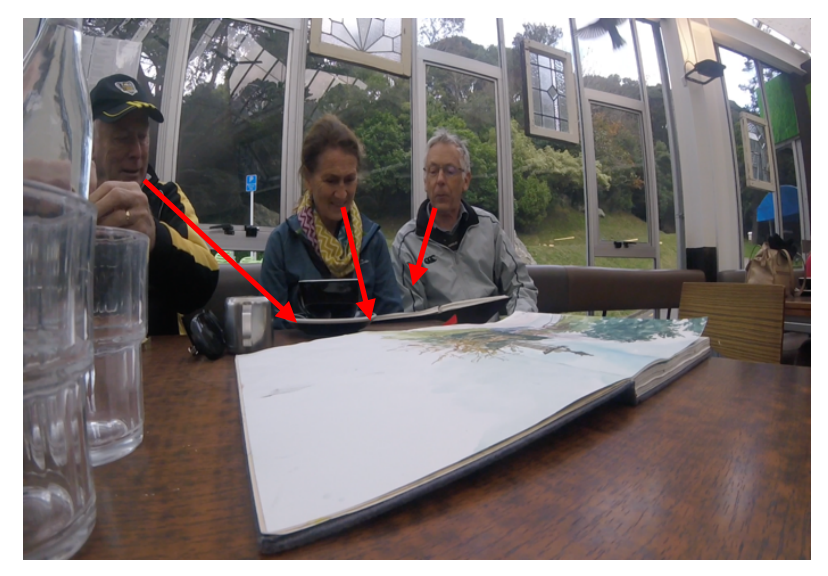

Figure 1:3

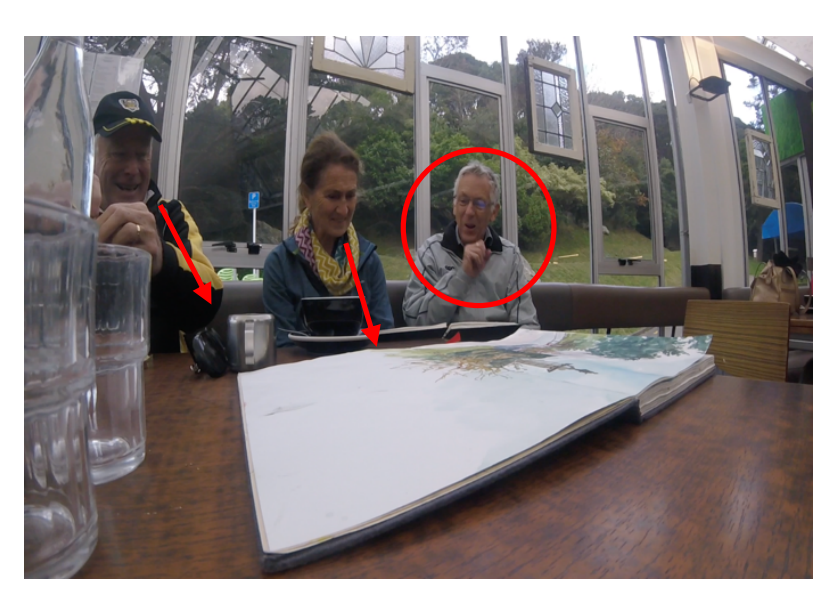

Figure 1:4

$\begin{array}{ll}\text { Amber } & \begin{array}{l}\text { Oh I like that in the } \\ \text { foreground }\end{array} \\ \text { backgr/ } & \text { And that in the } \\ & \text { That's - that's really } \\ \text { nice } & \\ \text { Geoff } & \begin{array}{l}\text { I thought }- \text { I thought } \\ \text { you might like that }\end{array}\end{array}$

Amber you might like that 
Whilst both Geoff and Amber were oriented to the drawing, Steve abruptly leaned back into his chair, and poked his tongue into the side of his cheek (Figure 1:4). He then immediately leaned forward and glimpsed at Geoff and gauged his reaction (Figure 1:5). Geoff remained focused on the table in-front of him (Figure 1:5). After Amber had given her first complete turn of talk, Geoff commented with "I thought you might like that" (Figure 1:4). Amber responded with "I do, and I like the colours just put on like that" and turned to Geoff, still focused upon the table in-front of him (Figure 1:6). Amber then turned from Geoff and returned to Steve's sketching pad.

[Steve glimpsed at Geoff]

Amber

I do - and I like the colours just put on like that

[Amber glimpsed at Geoff]

Amber Yeah, yeah, I really like that

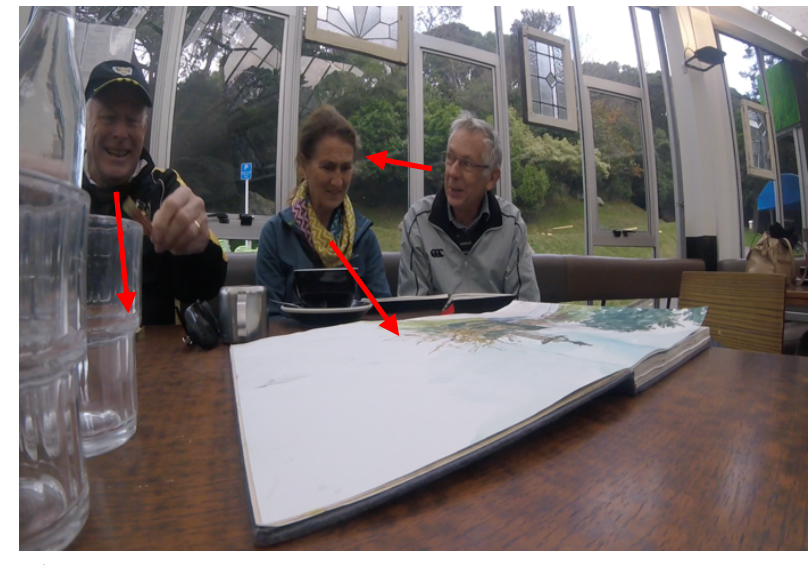

Figure 1:5

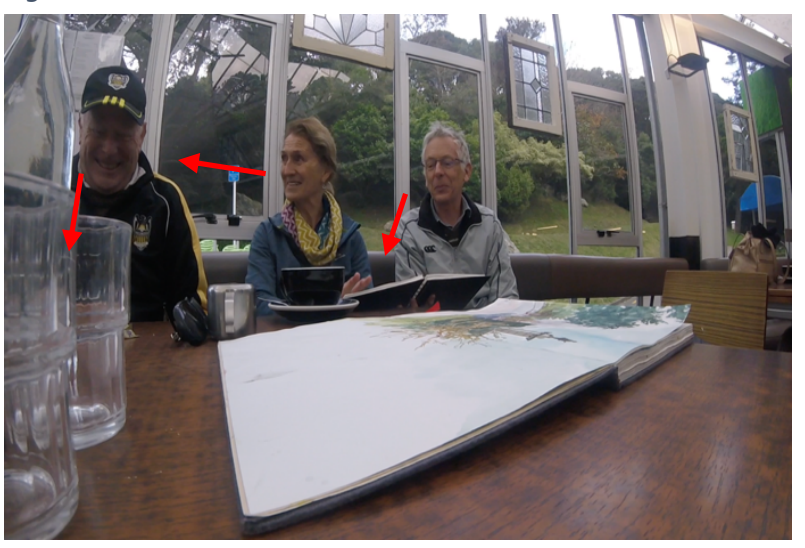

Figure 1:6

Amber, unsuccessful in her attempt to obtain eye contact with Geoff, focused her attention back to Steve's work beyond the connection of her own influence, and by vocalising her interests, features of Steve's work were now provided to the group for further comment. Take her next utterance for example, "and you even got the little house at the back!" (Figure 1:7). 
This speech was accompanied by a single-finger point, which Steve and Geoff followed to the sketching page; Owen entered the scene (Figure 1:7). Steve provided amber with a short answer, yet before this topic elaborated, an interruption occurred.

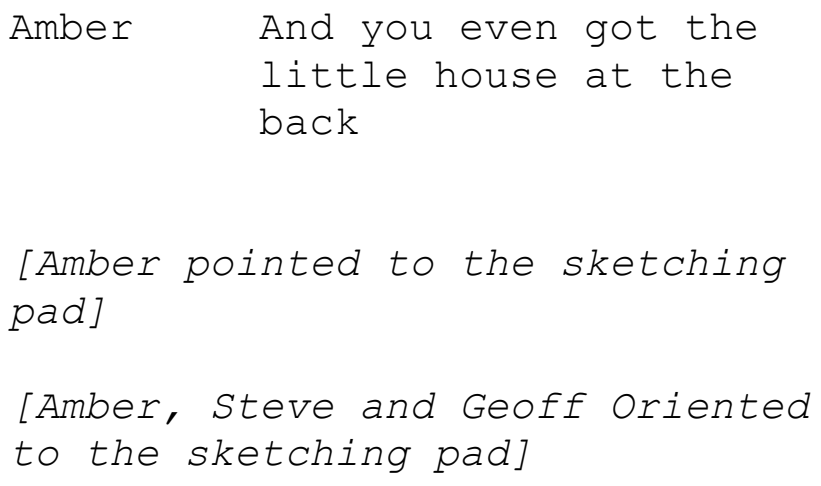

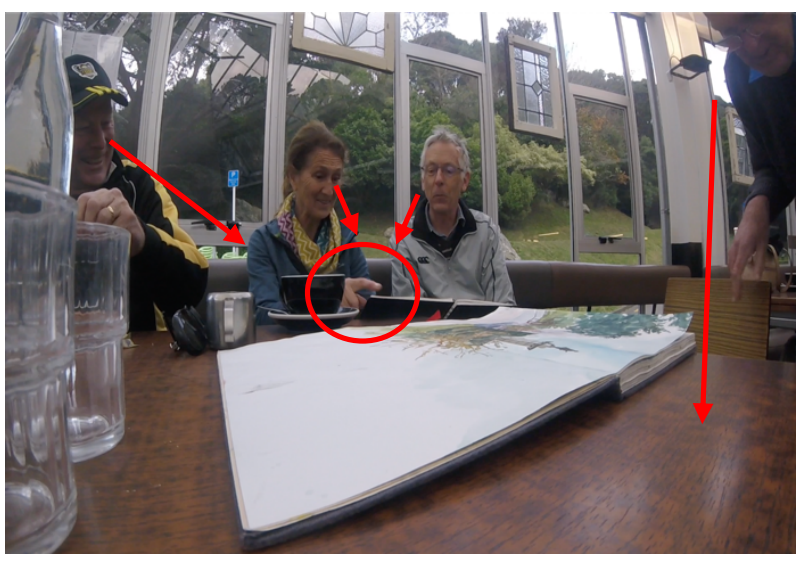

Figure 1:7

Due to the café setting having provided a relaxed environment for the sketchers, public interruptions were inevitable. These interruptions were just as much a part of the organisational work as the conversational work itself. The café server disturbed the ongoing reviewing work of the group, which may have provided a natural opportunity for the conversation to find an end, however, Amber continued to talk over the café server's disruption: “don't you — don't you love those ferny things —isn't it beautiful?" (Figure 1:9).
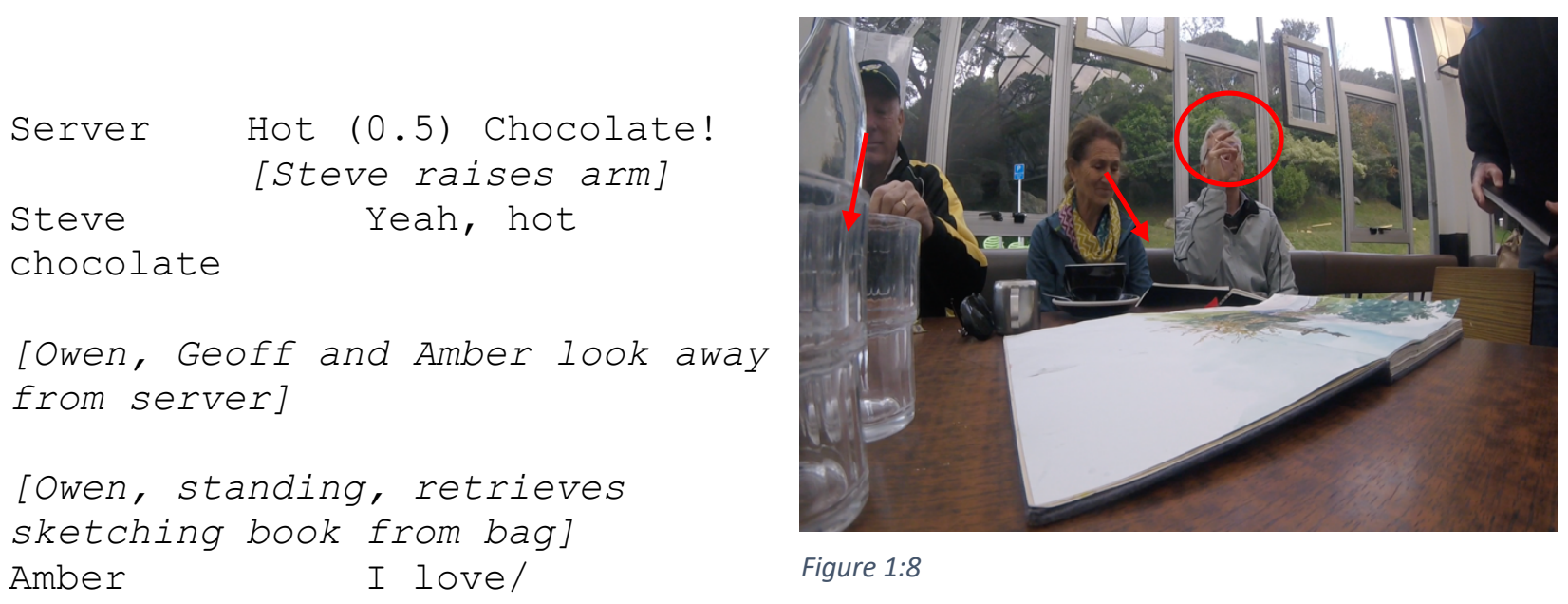

Figure 1:8 
[Café server places hot chocolate in front of Steve]

Steve

Thank you

[Geoff gazes between stirring his coffee and the pad]

Amber

don't you love the fountain - those ferny things?

[Owen leans in]

$\begin{aligned} & \text { Steve } \\ & \text { Amber } \\ & \text { Isn't it } \\ & \text { beautiful? }\end{aligned}$
Amber
Oh well done!
look at the pad]
Amber
that's really
nice

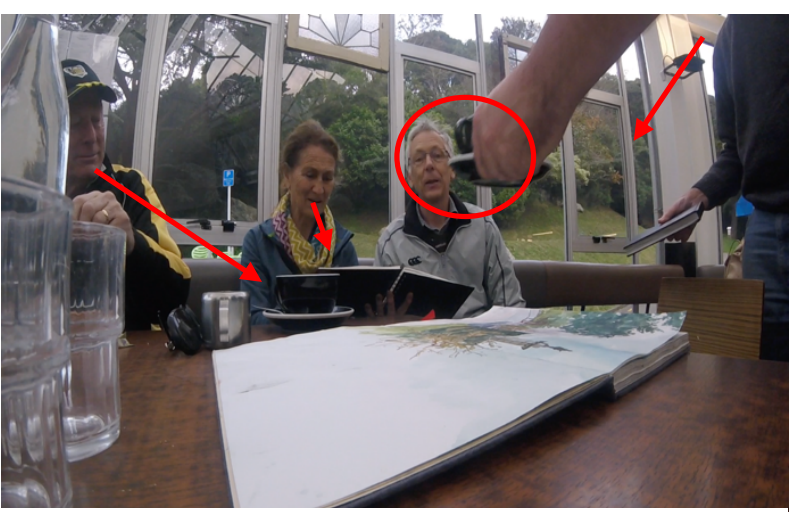

Figure 1:9

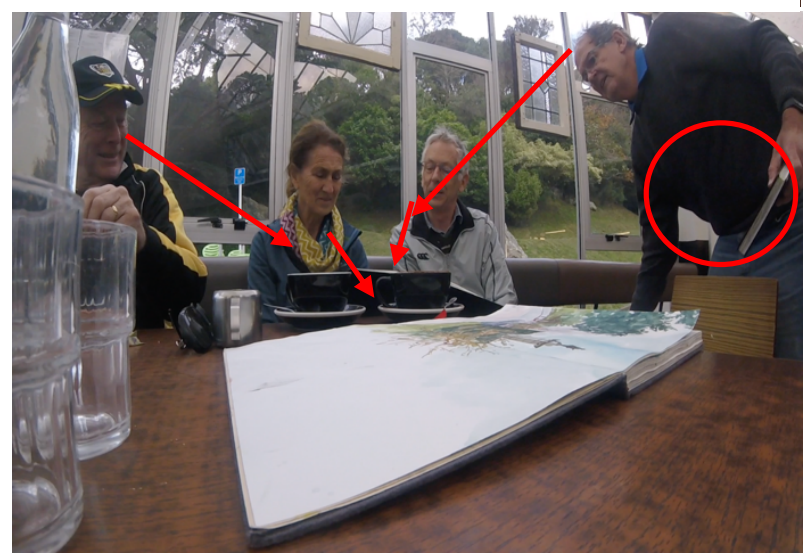

Figure 1:10

The café server attempted friendly chatter, yet Amber intruded upon this work - the group received a focal point for Steve's sketch as Amber loudly stated, “Oh, well done!". This praise drew the attention of all members of the group (Figure 1:10) — Owen responded, "that's great" and Geoff added, "nice Steve”- Amber handed Steve back his sketching pad, which signalled a natural end to reviewing Steve's work (Figure 1:11).
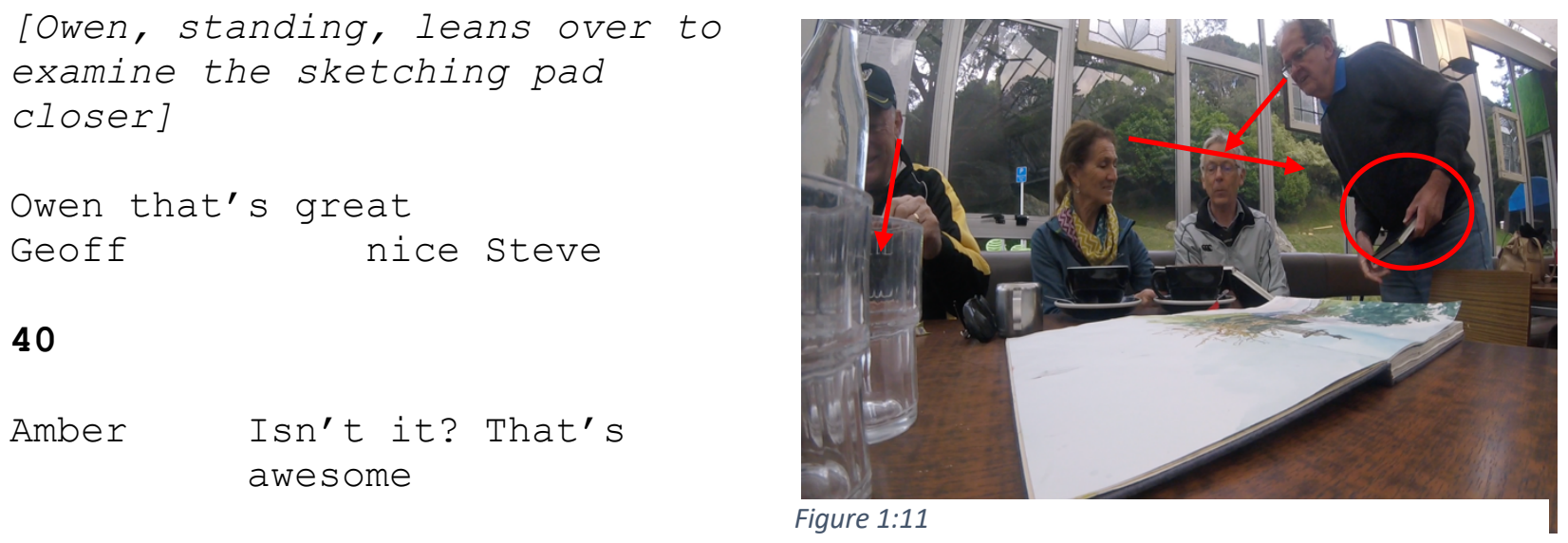
Within the above transcripts, several key intersubjective actions show Steve's waiting for Amber to place her pad down on the table, an example of 'doing politeness'. This action is not a singular instance, it is found within the other immediately surrounding actions, both previous and anticipated. 'Doing politeness' for this setting, in this specific time, was a publicly worked out temporal achievement between Amber and Steve. For example, the eye gaze work that occurred from Figures 1:1 and 1:2 show how they oriented and attended to each other. Steve's display of patience was a response to Amber engaged with reviewing his sketch, a shared goal.

As they organised their activity, Geoff's gaze remained downward until he looked over once Amber received the sketch (Figure 1:3). In response to Geoff's laugh, both Steve and Amber were unable to connect their gaze with his, effectively propelling the opportunity for the topic of conversation to shift. Moreover, this sequence of eye-gazing demonstrates an additional gloss, where 'doing avoidance' involved both Amber, then Steve, to unsuccessfully make eye contact with Geoff's artful avoidance.

The relationships between these intersubjective gazing actions may further demonstrate how locally contingent, and sequentially unfolding events, is not determined by an agreement between the members. Instead, at every observable action, a possibility of a shift in contexture may occur, as the three member's inability to make eye contact with one another suggests. Steve's drawing remained subject to the socially significant features of 'being polite' and 'avoiding' as an intersubjectively achieved object. Furthermore, it is unavailable as a singular object without removing it from the unknown direction of the ongoing contexture.

As this discussion came to an end, Amber noticed Owen standing with his sketching pad in hand and asked, "Wat'cha do?" (Figure 2.1). Owen replied by stating the name of the 
statue followed by a modified verbalisation responding to Amber's query: "where was that" — “Just a bit further down". Owen, still standing, oriented his sketching pad for Steve and Amber to inspect (Figure 2.2). He then formed an index-fingered point and 'pushed it' toward a certain direction beyond his sitting interlocutors. Amber read this with an over spoken response: "down the track—of the cemetery".

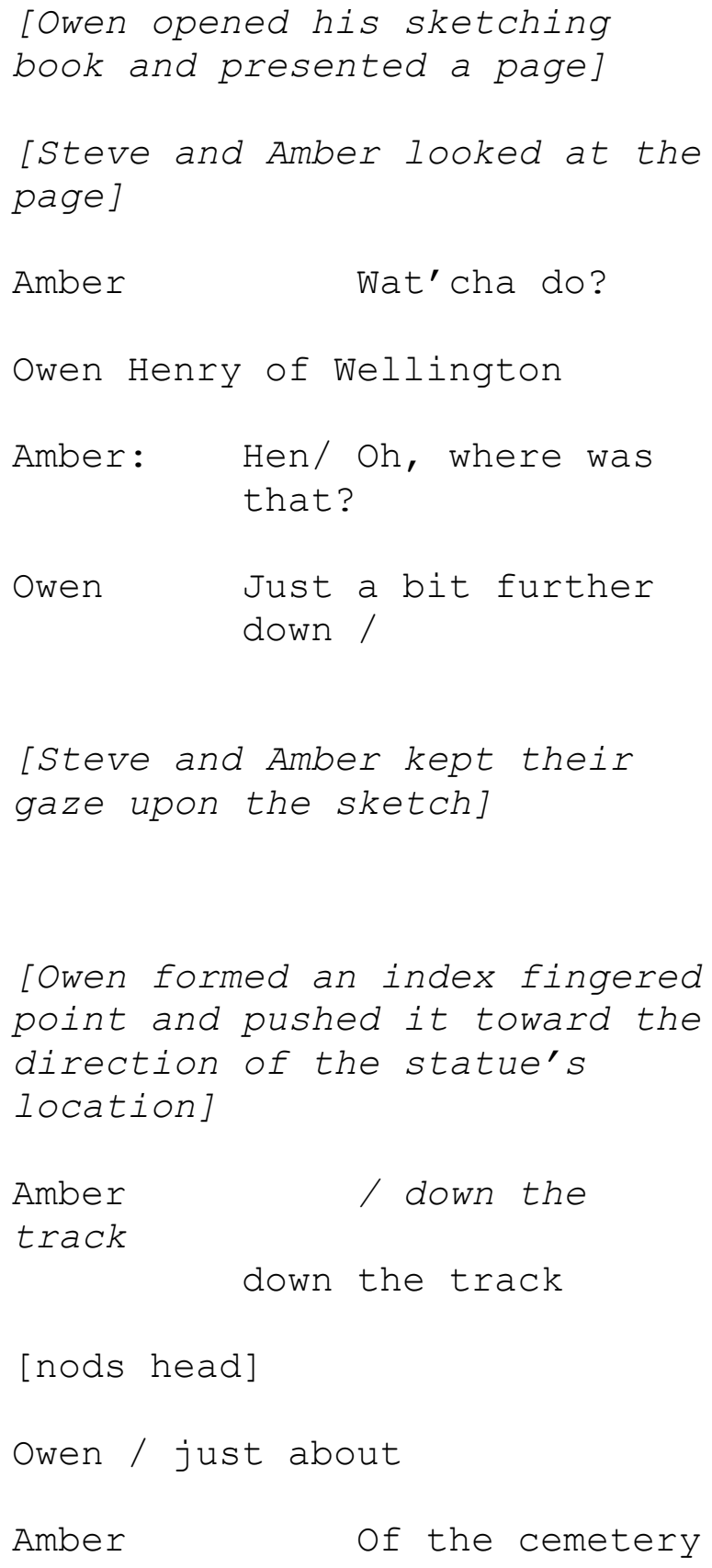

[Owen formed an index fingered point and pushed it toward the direction of the statue's location]

Amber
track

[nods head]

Owen / just about

Amber of the cemetery

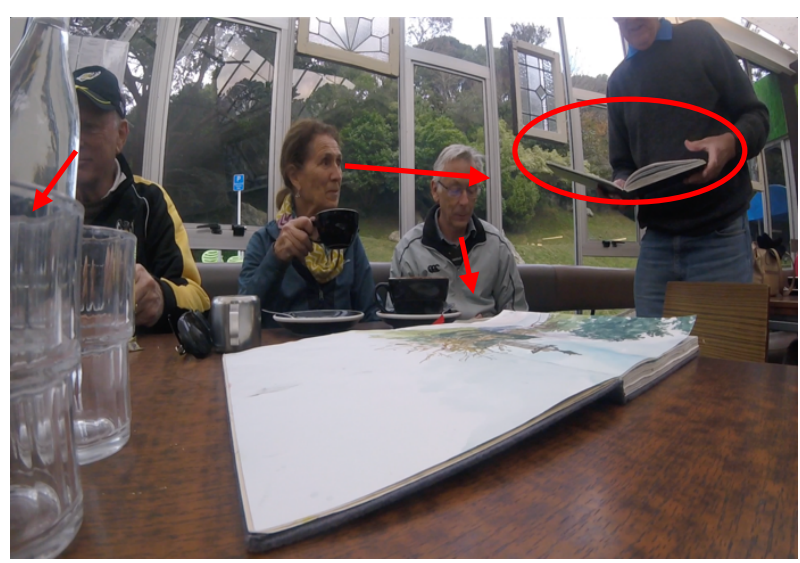

Figure 10:1
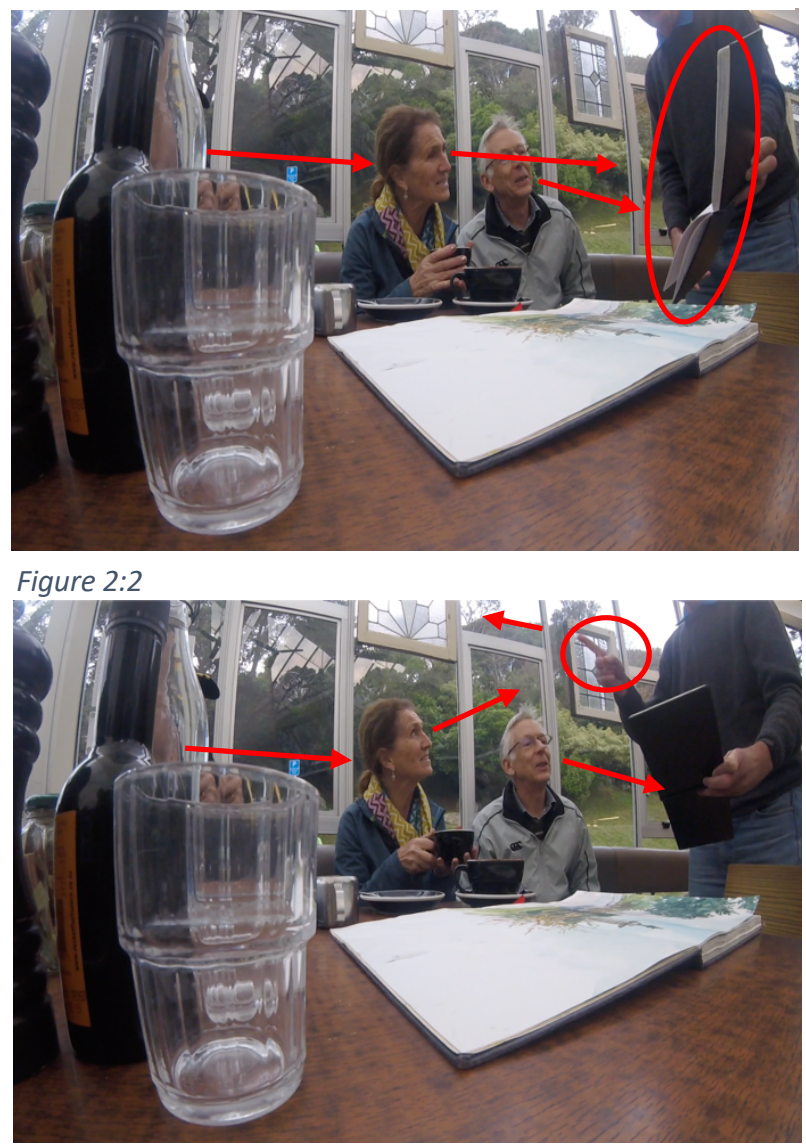

Figure 2:3 
Owen / just about
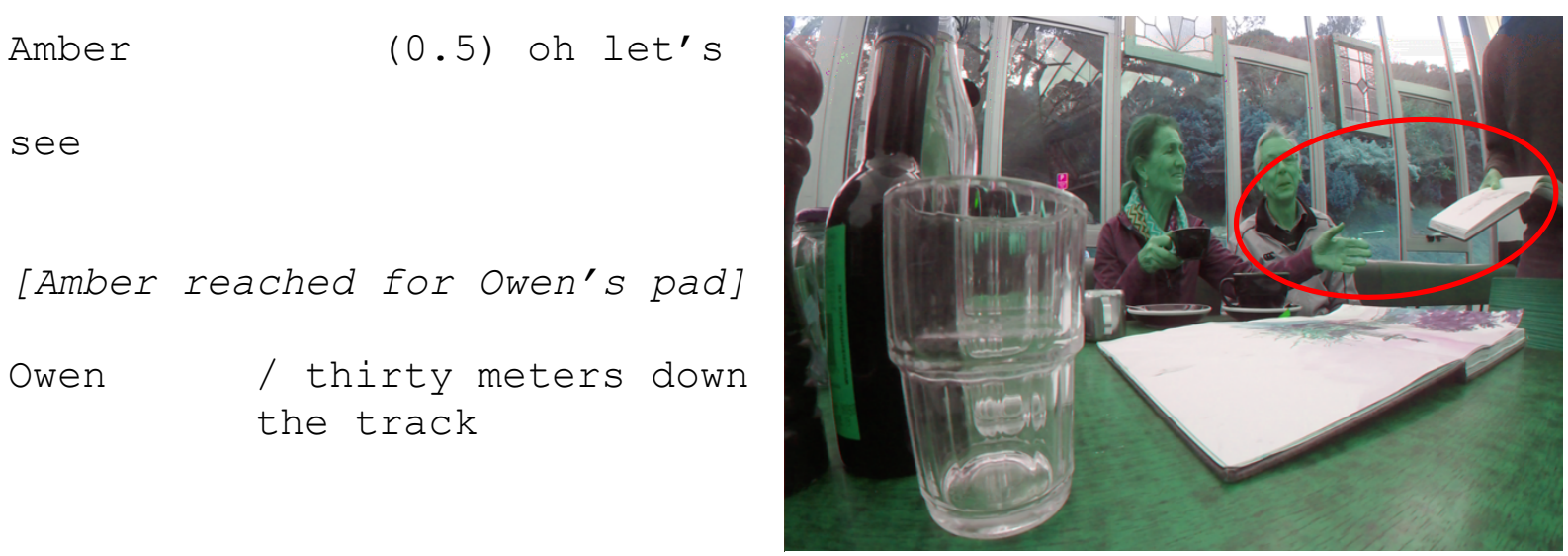

Amber was unaware that Owen knew of her drawing position. She had to work to obtain this information whereas Owen had to work to understand she was unaware of him knowing this. In this instance, notice how Owen provided a partial answer to Amber's request "where is that"? with "just a bit further down" (Figure 2:1 above). Once Amber verbalised the location as "down the track", she inferred 'in the cemetery?', and thus the relationship of the drawing subject was publicly narrowing. It no longer mattered whether Amber was aware of Owen's knowing of her drawing location because once the location of Owen's sketch was understood to be in the Cemetery, the group members were 'on the same page'. Accountable, Amber asked: "oh let's see" and held out her hand to receive the pad (Figure 2:4 above).

As Owen handed the pad to Amber, he presented it to the group before she managed to take it in her hands (Figure 2.5). During this manoeuvre, Geoff took notice of the sketch of the statue and uttered "I didn't think that was Seddon", and Thom immediately interrupted by stating "That's Seddon" and pointed to Amber's picture resting upon the tabletop (Figure 2.6). Amber mimicked Thom's action and pointed to her sketch and repeated, "That's Seddon". Geoff replied: "Is that Seddon?" and the group collectively said "Yeah". Geoff's question could imply a value judgement upon the quality of Owen's sketch as representing a statue of Seddon. For example, by stating “I didn't think that was Seddon”, I infer that 
Amber's earlier utterance of 'Cemetery' provided enough detail for Geoff to organise an earlier act of his: Gazing at Owen's sketch (Figures 2:2, 2:3). During this earlier episode, whilst Geoff orientated to how Owen discussed the location of the sketch with Amber, he assumed the statue to be 'Seddon'. When the sketch was passed to Amber, Geoff looked closer and understood, along with the location only just verbally given, that the sketch was in fact not 'Seddon', as Seddon does not rest in the Cemetery.

[Amber, Steve and Geoff gazed at the pad held by Owen whilst Amber grabs hold]

Geoff

I didn't think that was Seddon Seddon's got a bit of a/

Thom

That's Seddon

[points to Amber's sketch

lying open on the café tabletop]

Amber

That's Seddon

[points to her sketch]

Geoff

Is that Seddon?

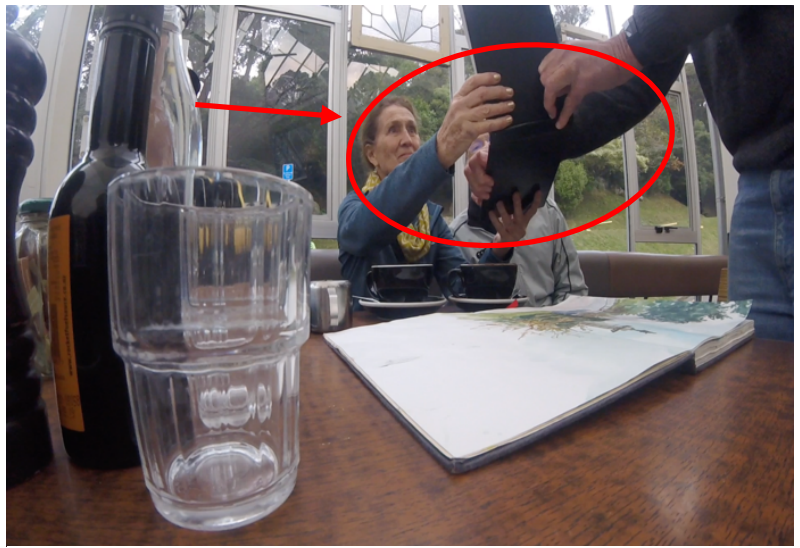

Figure 2:5

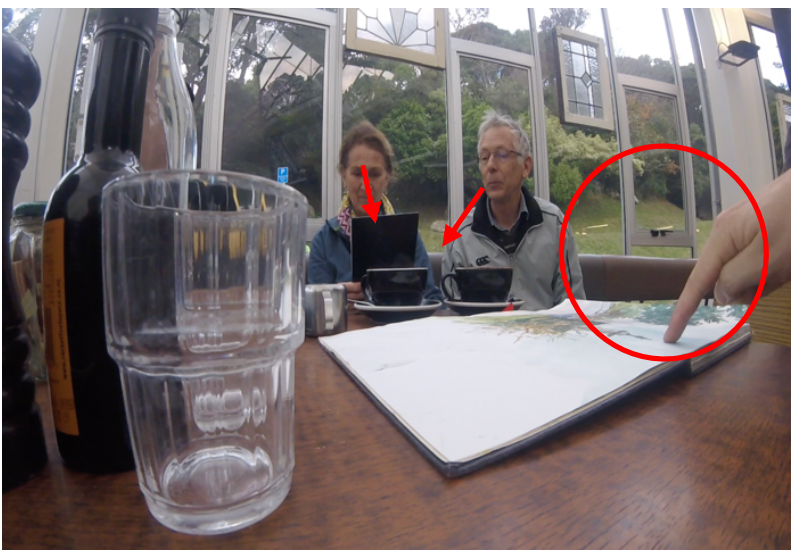

[collectively say] yeah

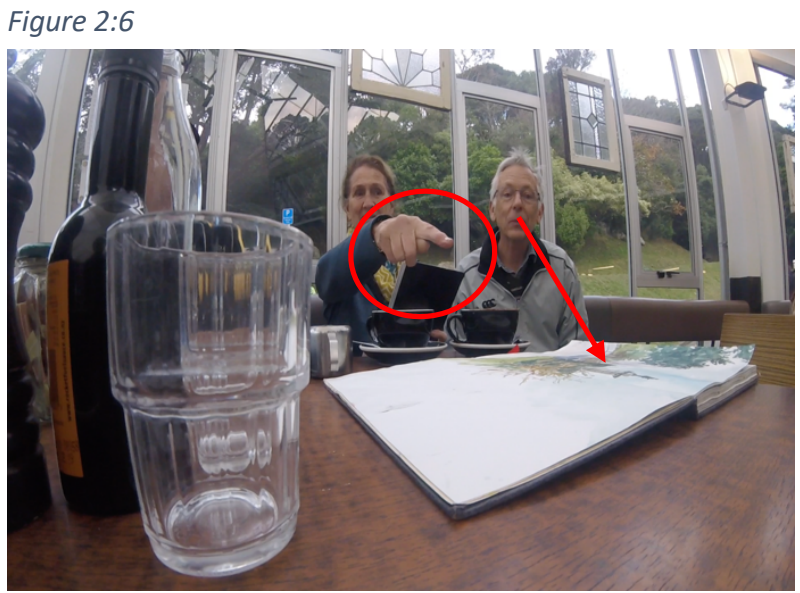

Figure 2:7 
Retrospectively, Thom artfully interjected when he stated, 'That's Seddon' and pointed to Amber's sketch. This interpolation may be an 'objectivation attempt' (Liberman, 2017); a way for the conversation to continue by way of reducing ambiguities. The members of the group ordinarily produced the facts of the situation, and collectively, they worked together to produce a local method of comparison to further evaluate the sketch. For example, the difference between Seddon and Owen's sketch was made from the group's previous working out of the cemetery location; whether Geoff initially judged Owen's sketch as inaccurate is unknown. Given his response, and what is shown in the case, however, the possibility of the sketch being judged on representing Seddon was removed from the context by the group's interaction. The importance of how ambiguities were tamed reveal that members oriented together to the contexture's theme of judging the quality of drawing of being representative of the statue, William of Wellington. They were now ready to judge.

Amber read to the group details from Owen's drawing: "Nineteen thirty-two" to which Owen clarified. During this exchange, Steve stood and looked across the table. This action incorporated a new art object into the unfolding gestalt organisation. As Steve continued to nominate a potential sketching book into an opportunity to shift the topic, Amber turned Owen's page within her hand to the group, specifically Clare (Figure 3.3), and stated "that's the strangest thing”. Clare responded with "it is isn't it?".

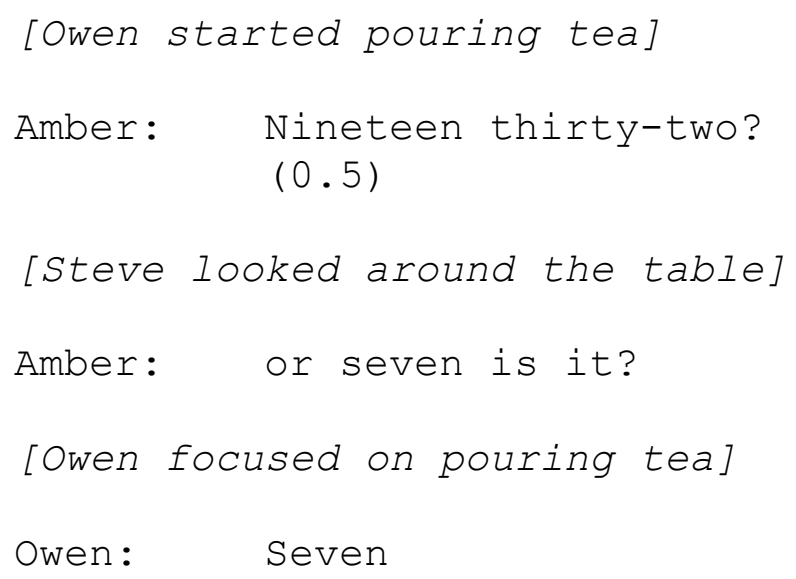

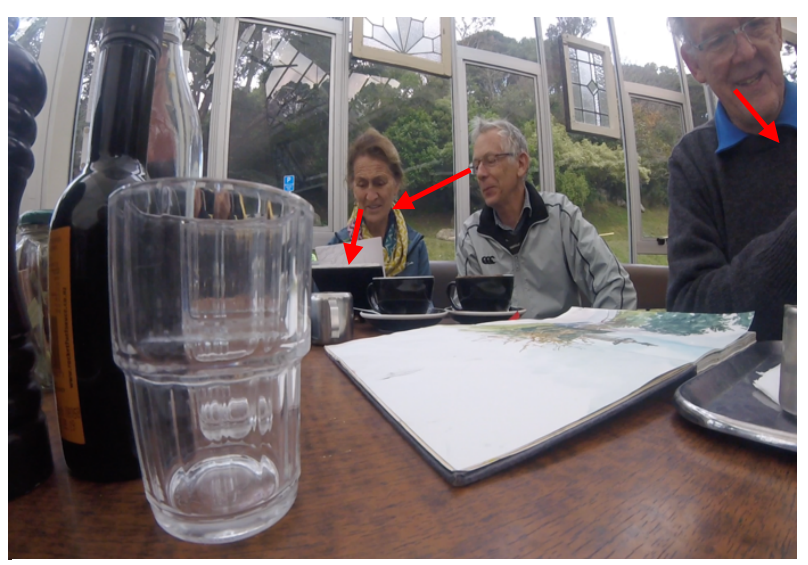

Figure 11:1 
[Steve stood and looked across the table]
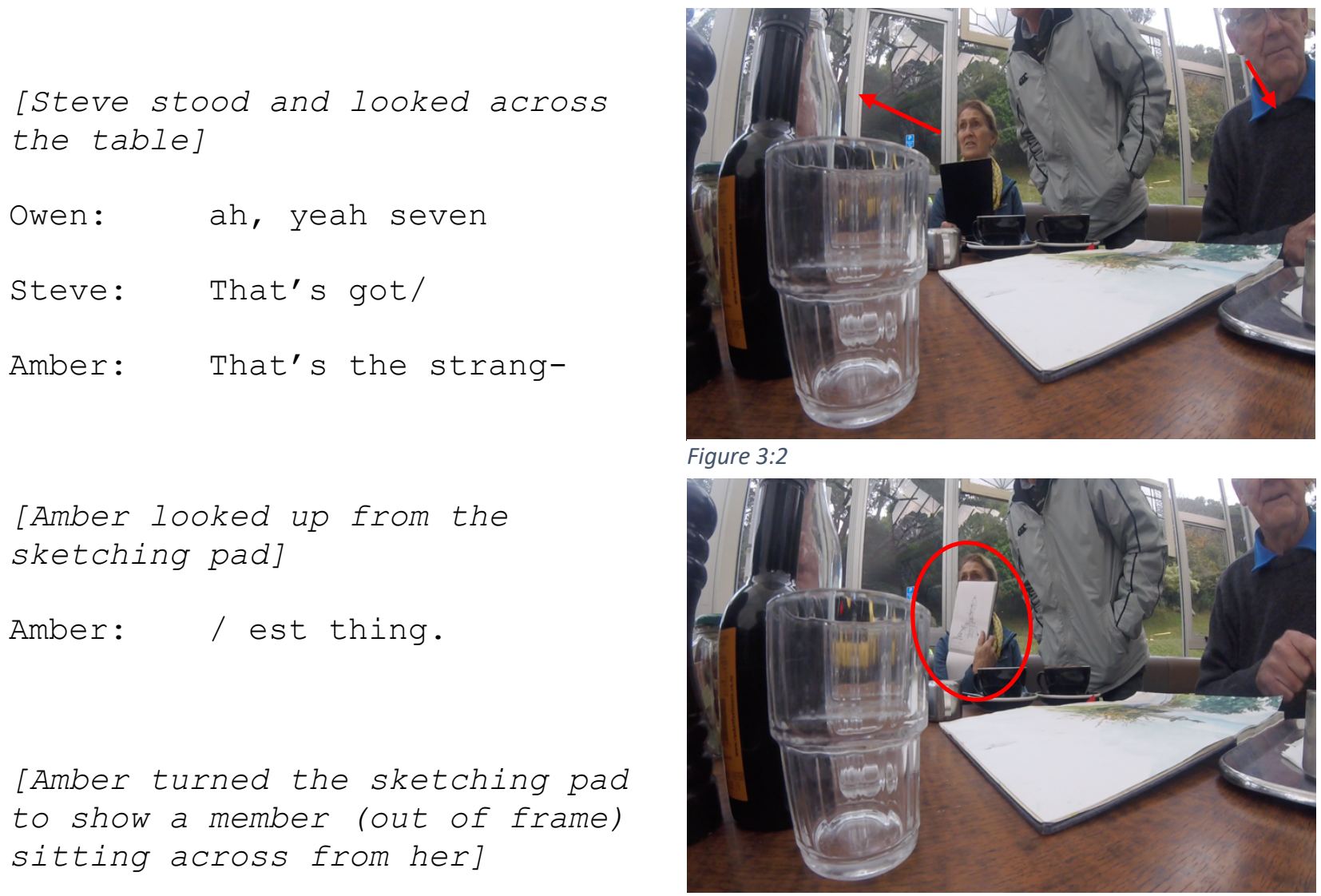

Figure $3: 3$

Clare: It is isn't it?

As this exchange took place, a simultaneous flurry of actions occurred in a chaotic-like order: As Owen raised Amber's sketching pad from the tabletop (Figure 3.4) Geoff handed Steve his drawing pad (Figure 3.5). Owen offered Amber's sketch to the group and held it in the air for someone to take. Thom eventually noticed others were occupied and took the pad from Owen's hands (Figure 3.6). We see in this short exchange that sketching books were used to organise the structure of the activity: 
Amber:

A big statue of a man in the nude

[Owen slid Amber's sketching pad toward himself]

[Owen picked the pad up with both hands from the table]

Clare: A big statue of a man what?

[Geoff held his sketching pad with one arm toward Steve]

[Steve grabbed the sketching pad from Geoff]

Amber: in the nude

[Steve sat down and looked at the sketch]

Clare: I think that was

Clare: / that was just past where I was

[Owen offered Amber's sketching pad to Geoff]

[Geoff turned his head and body from Owen]

[Owen continued to hold Amber's pad]

Amber: Henry Holland Memorial.

Amber: That's really

$$
\text { (0.5) [nods head] }
$$

Amber: Bizarre!

[unknown voice cuts in]
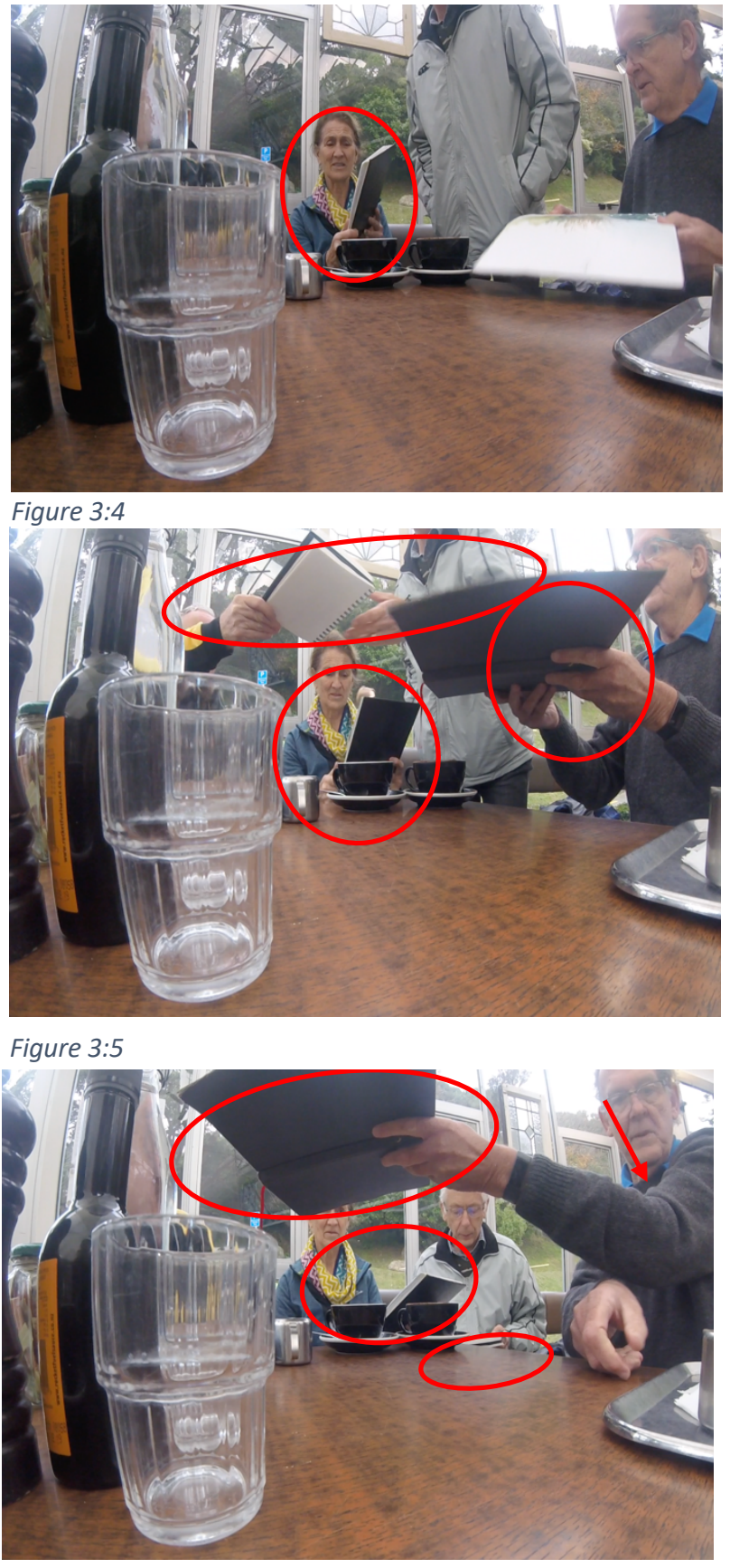

Figure 3:6

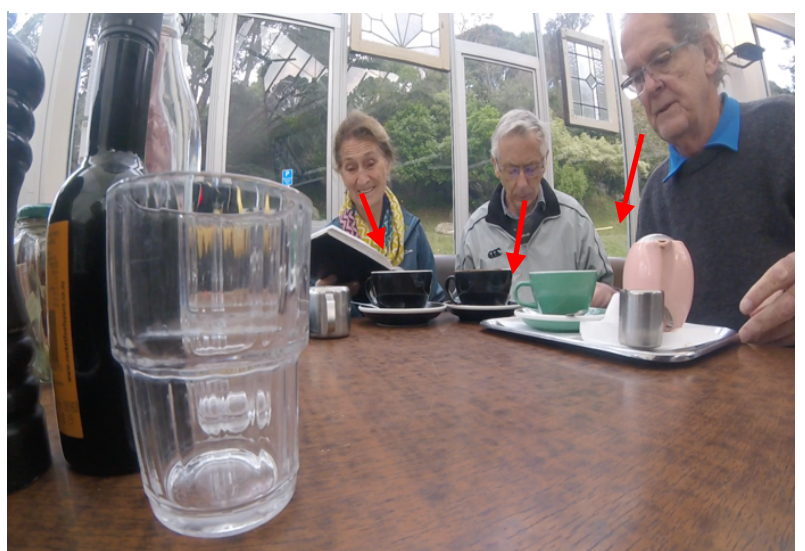

Figure 3:7 
At this mid-point of the discussion, the group members continued to talk amongst one another where two conversations occurred simultaneously. Focusing on the concurrent conversations through analysis would be unnatural to the members doing the talking, yet multiple conversations were video-recorded. Amber retained her examination of Owen's sketch of William of Wellington, alongside her conversation with Clare during this chaotic moment by declaring how strange a naked picture of a man in the nude is as a sketching subject. Hearable but not witnessable on the tape is Thom starting a conversation with Geoff. Moreover, Steve stood up and approached Clare (off camera) to ask, "how did you get on?". The group conversation thus has organised from orienting toward a single topic: Steve's or Owen's sketching pad, and produced three concurrent, and separate conversations. The group's ability and success at socialising in this manner (branching off conversations) provided new contextual arrangements to which art objects were able to find new character. We join the action as Amber and Owen embark down one of these conversational paths.

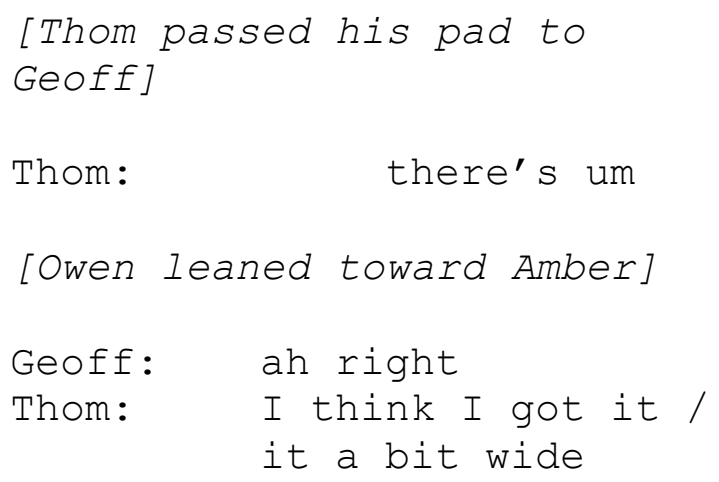

[Owen directed Amber toward his sketching pad with an index fingered point]

Owen:
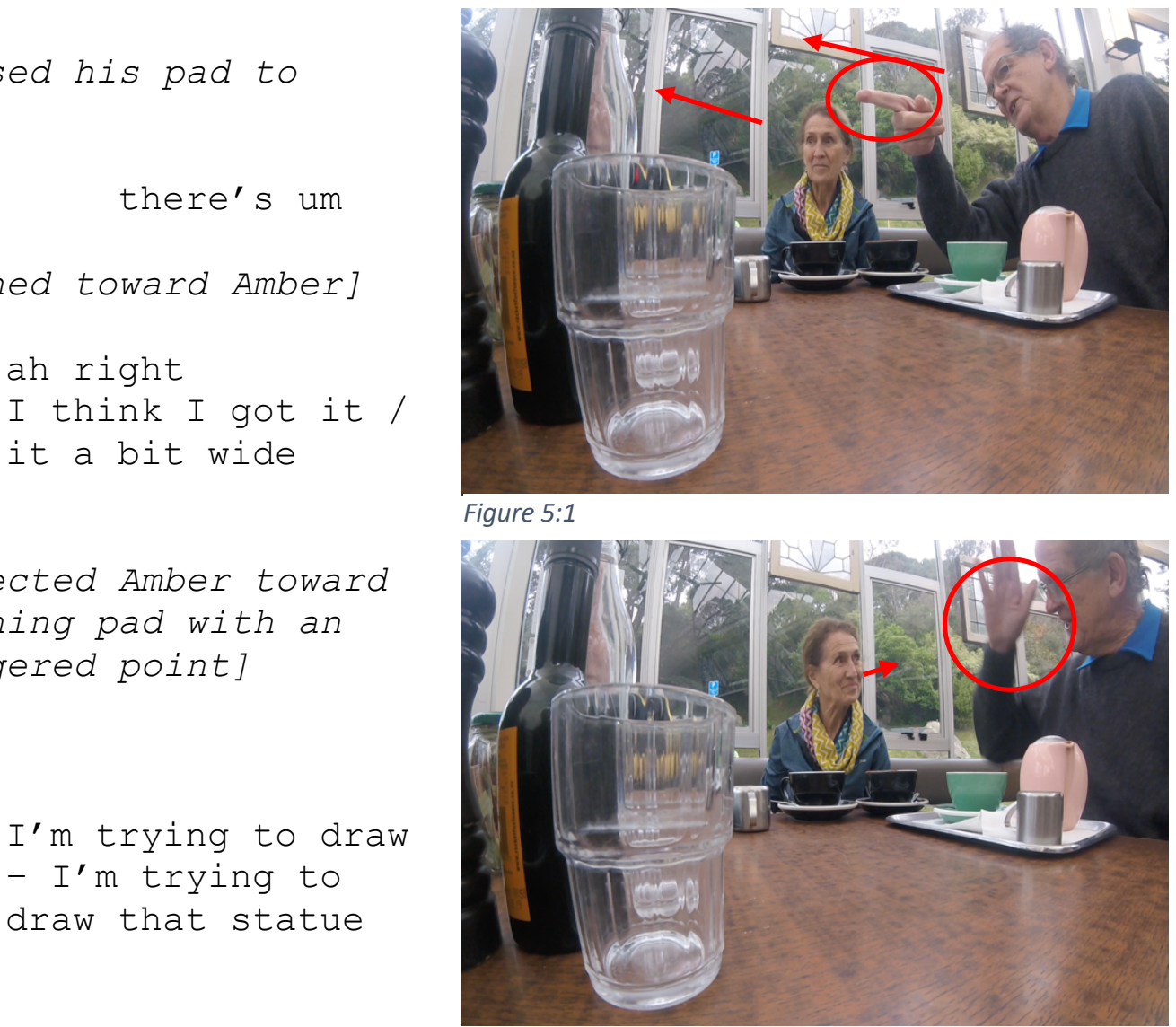


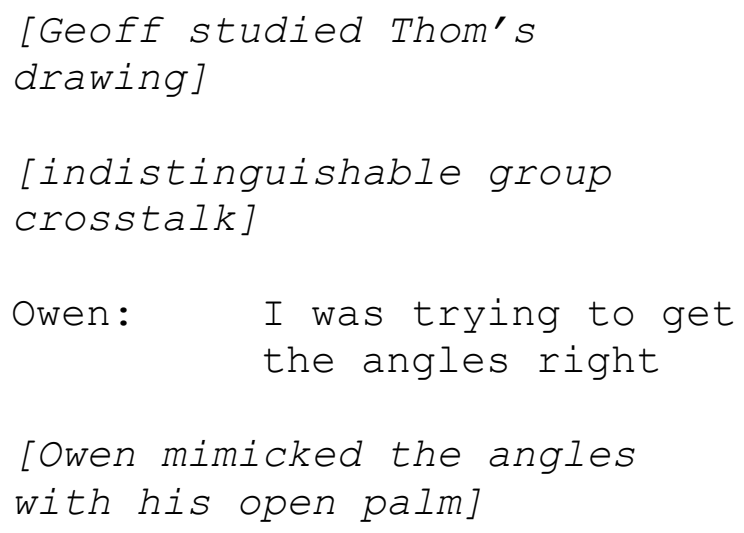

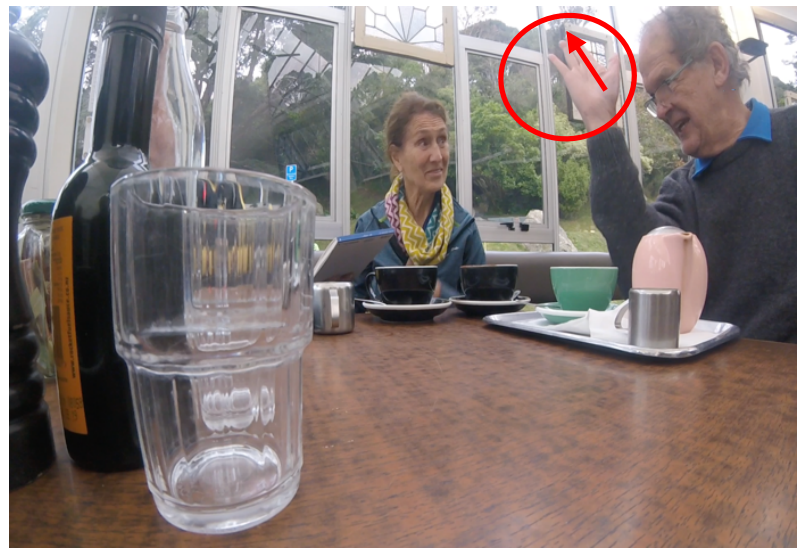

Figure 5:3

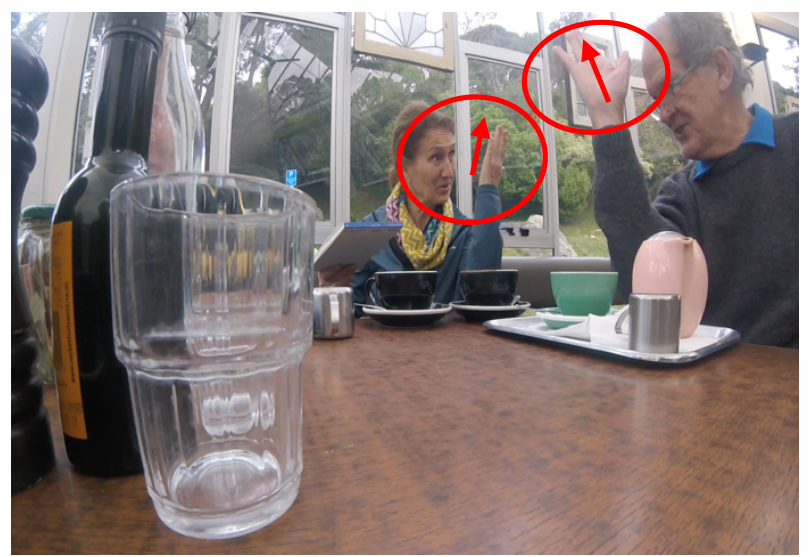

Figure 5:4

The discussion demonstrated above is on the surface, unremarkable. Two artists discussed the difficulty in drawing statues by providing for each other relevant expressions of experience found in that process. How did the two artists actively express that difficulty though their embodied and spoken conduct? Consider how Owen received Amber's attention through his pointing gesture (Figure 5:1) as he then uttered "I'm trying to draw that statue; I was trying to get the angles right. He then raised his arm to produce a vertical-like angle, whilst Amber listened and observed his gesturing (Figure 5:2). Amber encouraged Owen's statement: “yes, when you're looking up at it" as Owen altered his gesture to produce a flatter angle (Figure 5:3). She then mimicked Owen's gestures with her own (Figure 5:4). Owen continued: "So I was drawing it, sort of extending the lines so I made sure I could have it all lined up, you know?” Amber replied with "Yes" (Figure 5.5 below). 


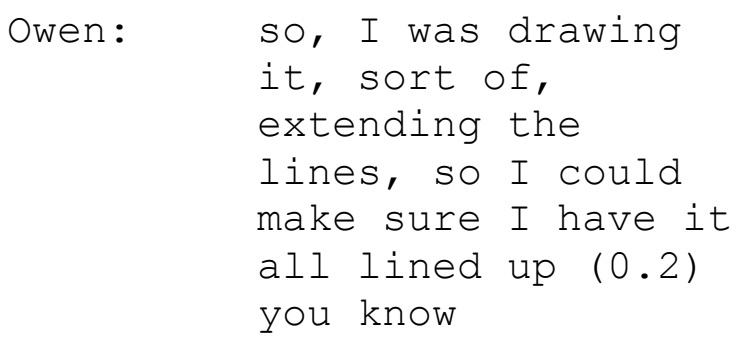

Amber: $\quad$ yes

\{cross talk\}

Thom: you know it quite well because you've / you've just done it, so you know it quite well

Amber: I've done - you have to be very careful because

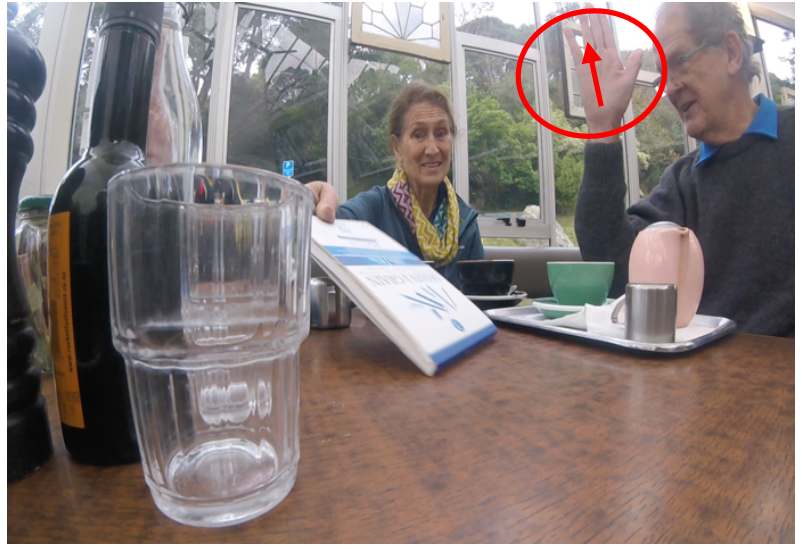

Figure 5:5

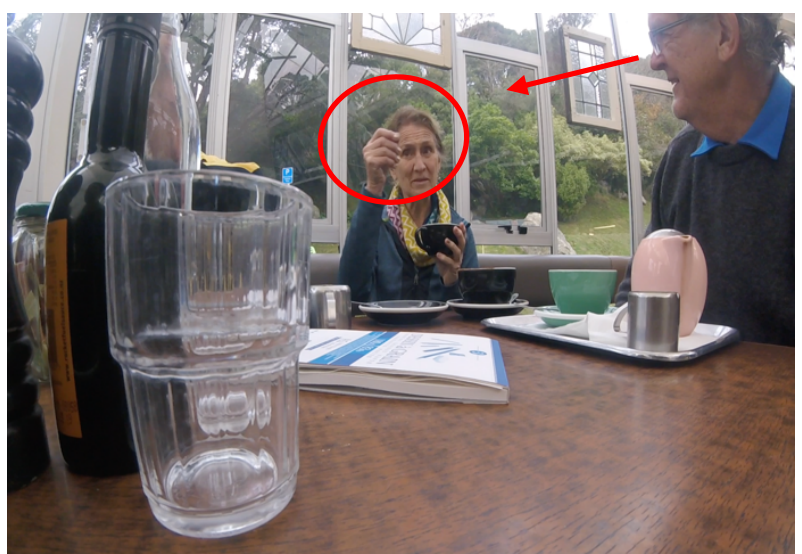

Figure 5:6

[Amber raised her arm to mimic drawing gestures]

Owen's work of orienting Amber to the sketch is to, introduce the topic of angles. Amber's mimicking work, and expressions of experience found in the process of extending lines, provided an alternative point of view Amber may have overlooked in her earlier analysis. After this brief footing, Amber continued the conversation and raised her arm and mimicked a drawing action whilst stating: "You have to be very careful because, one little jerk, and it looks weird" (Figure 5:7). Here, we see a relationship between this performed method of getting lines and angles accurate with Owen's earlier expressions of gesturing angles with his palm. Amber continued: "You know, the bumps have to be in the right place”, Owen replied "yeah" (Figure 5:8). 


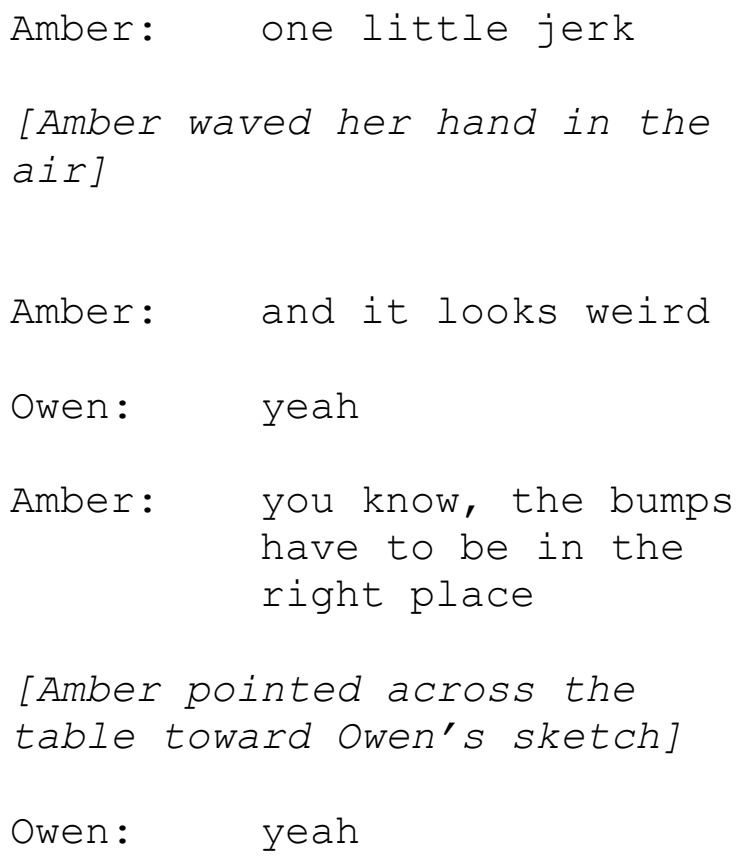
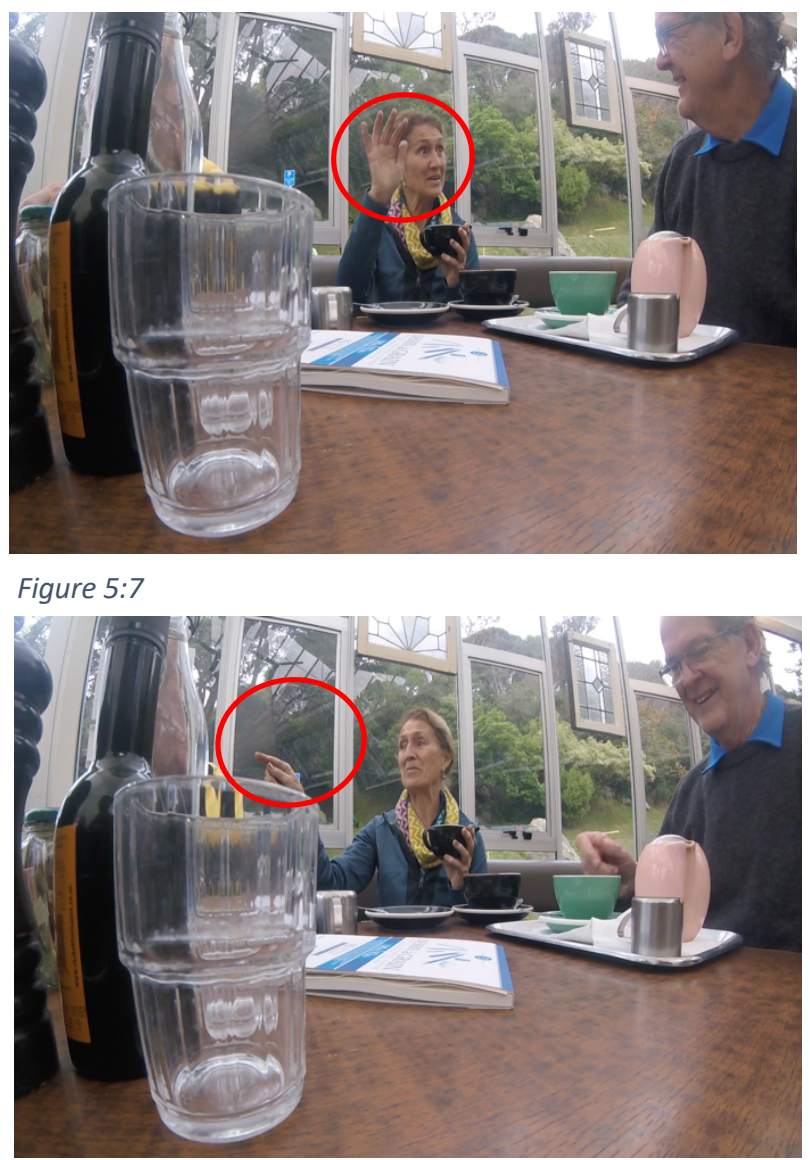

Figure 5:8

Owen then contributed to the progression of the topic whilst raising his hands to either side of his head: "And that shape of the head, you have to look up at it like this" (Figure 5:9). Amber replied, "yeah I know!” to which Owen declared: "It's quite a challenge really”. Amber ended with "I'd like to go into that graveyard" (Figure 5:10 below).

Owen:

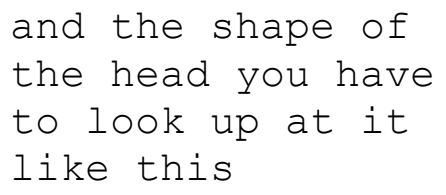

[Owen turned his head and raised his arms to either side]

Amber: yeah, I know!

[Thom passed his pencil to Geoff]

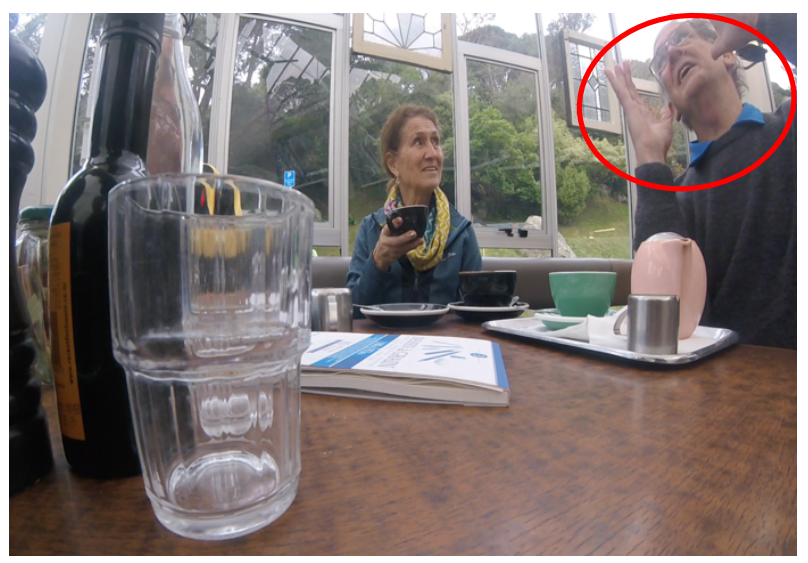

Figure 5:9 
Owen: yeah, it's quite a challenge really

Thom:

$$
\text { oh, it's a }
$$

mechanical

Amber: yes, it is

challenging, it's good

Owen:

it's great

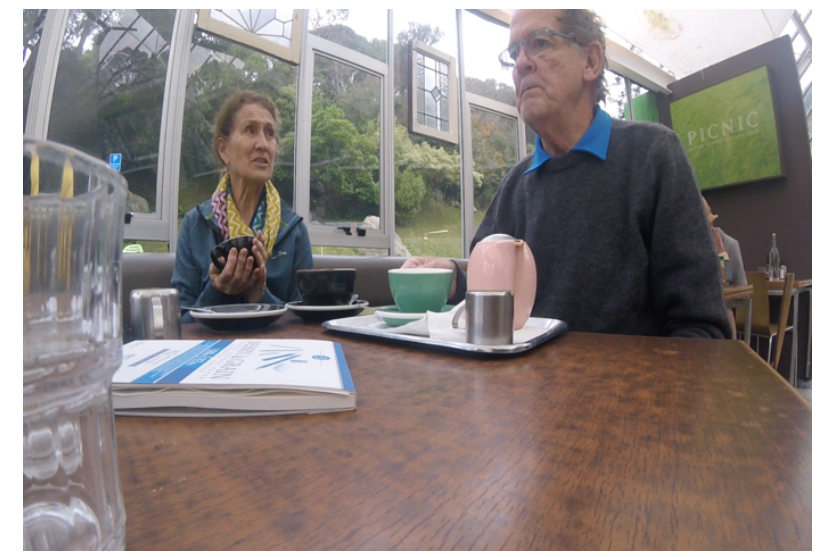

Figure 5:10

Amber: I'd like to go into that graveyard

This last phrase raises curiosity. The earlier confusion of the subject location had been realised (the cemetery), but Owen's choice of the sketching subject may not have been that “Bizarre” after all (as Amber earlier implied) . Owen's expression here, one of difficulty, may provide these actions of mimicking, gesturing, and the verbally mutual empathizing of the challenge of drawing the subject, with renewed meaning. He chose the subject not for its topic, but for its interest and challenge from a skill-development point of view. Each part of this conversational work thus aided the overall relational system of how Owen's art object came into an accountable form as being agreed to be difficult. Due to the complexity of angles and purpose of its selection as drawing practice, the statue adopted an alternative meaning in their conversational action as it primarily revolved around the appreciation of what concentrated looking in the field entails. Amber thus worked with Owen to find community in their artistic style by mimicking each other's motions of what it was like drawing in action, emphasising the role of measuring angles with the naked eye, a significant feature of the sketch which may had been left previously unnoticed within Amber's earlier review. For Owen, not only was the sketch and subject selection skilful, but it was recognised by him as not being appreciated, spurring his return to the topic. 
During Owen and Amber's discussion, Thom had branched off and initiated a conversation with Geoff and stated: "you know it quite well because you've just done it”".

Although the audio is indistinguishable, we could infer, alongside the knowledge that Thom had shadowed Geoff in the field to both arrive at the same drawing subject, Thom had asked Geoff for advice and handed over his sketch and waited for Geoff's review. The camera followed the action to Geoff, who had Thom's sketching pad open in his right hand. With the mechanical pencil in his left, he demonstrated the drawing technique of convergence to the novice sketcher, as the last segments below demonstrate:

Along with the pencil in one hand and the sketching book in the other, Geoff's verbal doings were oriented to instructing Thom. Geoff began: "You should be-that" (Figure 6:1). This style of answer pivoted from explanatory to demonstrative: "One line through here" (Figure 6:3). Rather than offer a theory of what Thom ought to have done, Geoff offered a visual lesson through a series of sequentially unfolding deictic references made to the sketch. Geoff's gestures of moving the pencil from one point to another prompted Thom's reply: "yeah right; yeah, it's not equal is it?" Geoff uttered "See, that's got to go back to, uh here" (Figure 6:3) whilst he moved the pencil between another series of points.

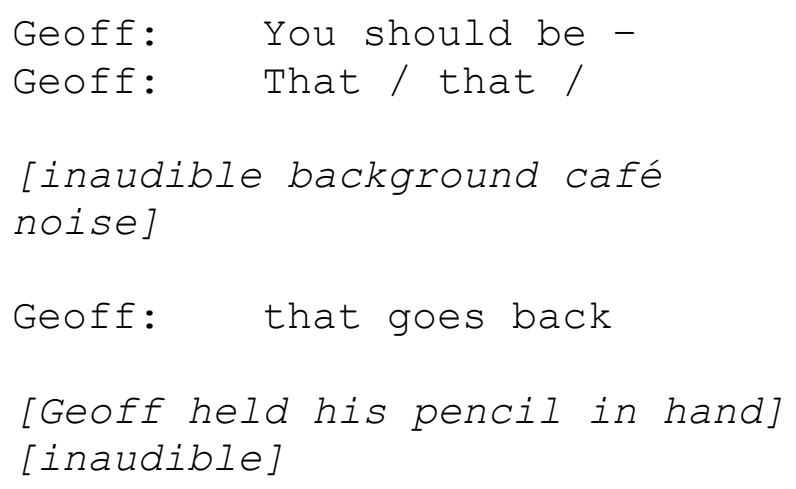

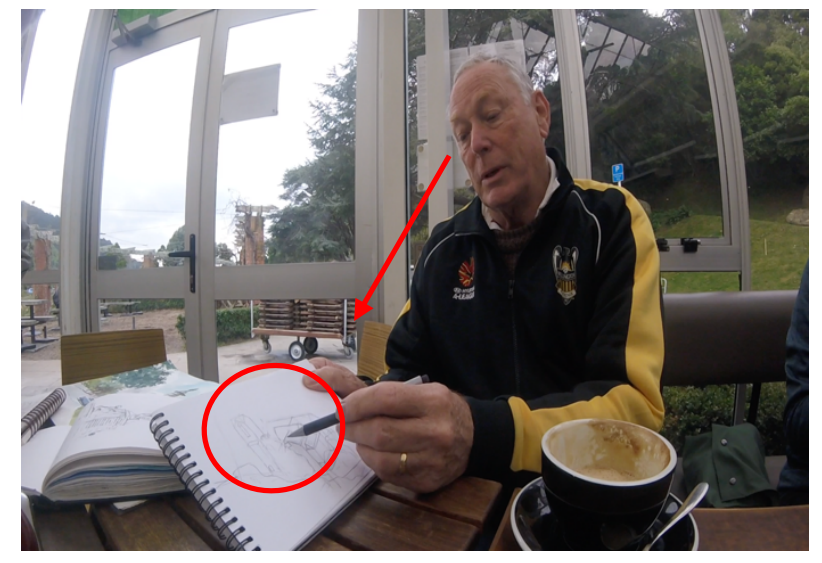

Figure 6:1 
Geoff: one line

Geoff: through there

Thom: $\quad$ yeah right

Thom: $\quad$ yeah, it's not equal is it?

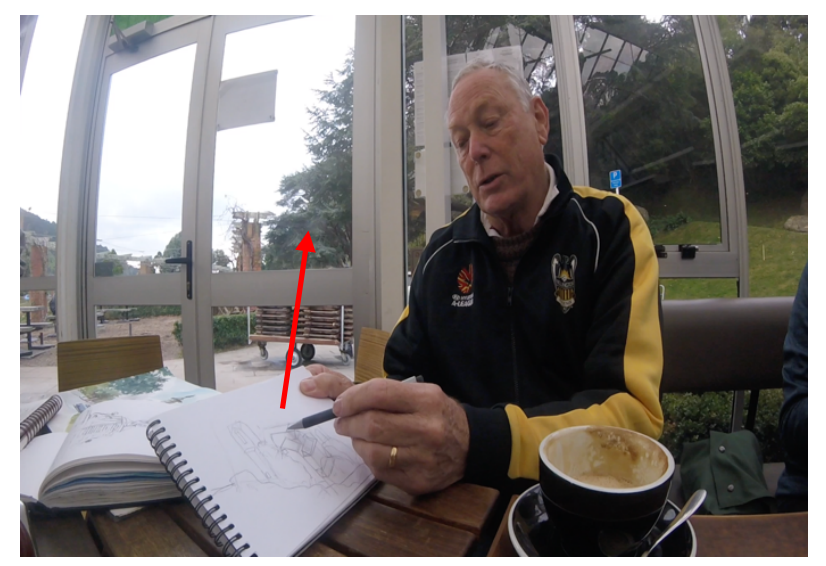

Figure 6:2

By super imposing the pencil over the line-to-be-corrected, Geoff and Thom produced a local interactional pattern that lasted until Geoff's demonstration ended. For example, we hear Thom state: "To match it?". Geoff replied with "yeah". The notion of 'matching' is one constituted by the previous action of taking one point (Figure 6:1, 6:2) and drawing a line to another (Figure 6:3). 'Matching' is thus taking the line shown in Figure 6:4 to Figure 6:5.

Correspondingly, the location of (Figure 6:3) is thus 'the same' as that shown in (Figure 6:5).

Geoff: $\quad$ see that's got to go back to, uh, here

Geoff:

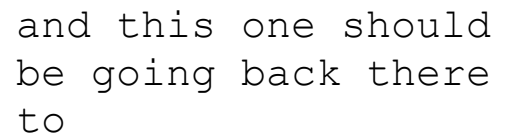

Thom:

to match it?

[Amber slowly starts to stand]

Geoff: $\quad$ yeah

[inaudible]

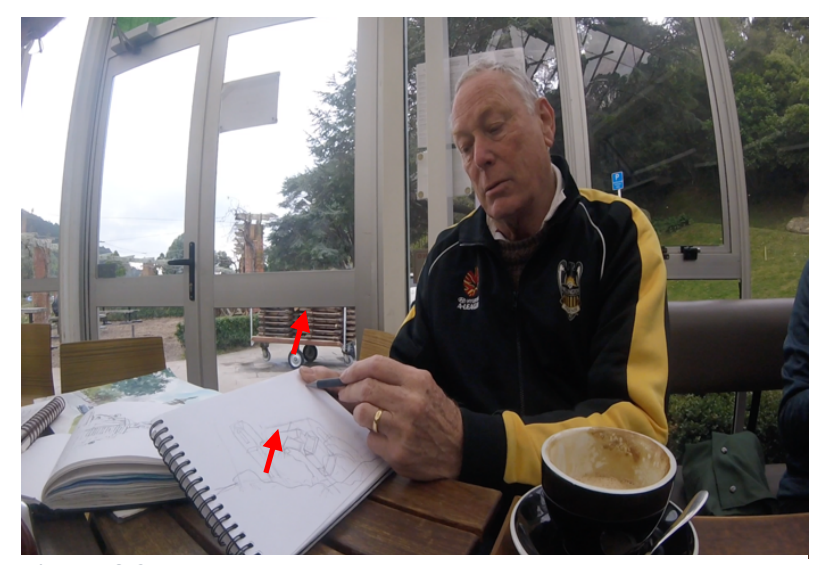

Figure 6:3

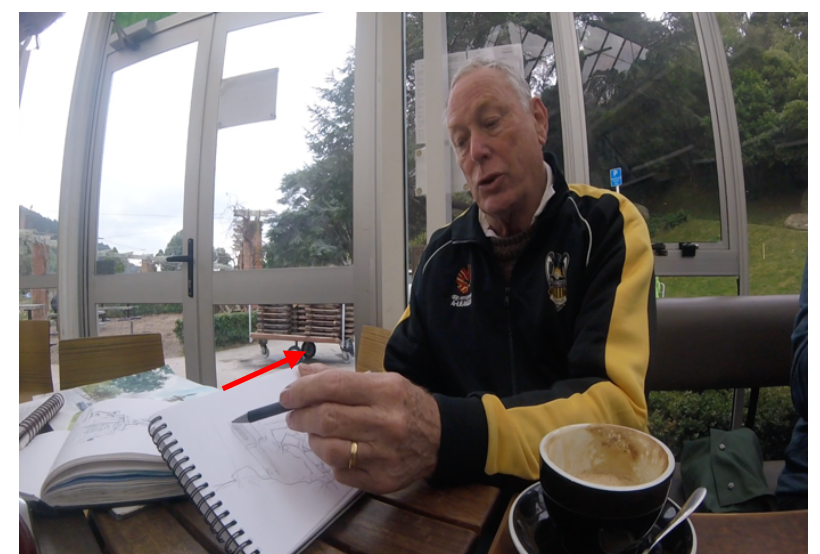

Figure 6:4 


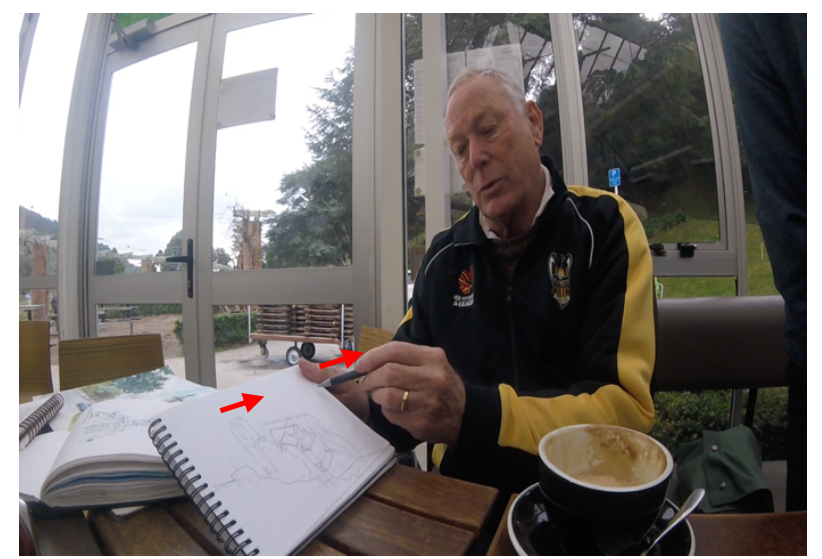

Figure 6:5

Geoff continued: "This one should be coming back this way a wee bit" (Figure 6:6 below) just a wee bit”, as Thom replied: “yeah right” (Figure 6:7). The point found at Figure 6:7 also 'matched' the same point found in Figures 6:3 and 6:5. Thom did not inquire into the meaning behind the demonstration. Thom may have known the principle but had failed to execute it in the field. Subsequently, under the artist's model of 'convergence', Thom's drawing did not adhere to strict linear perspective principles to which Geoff was correcting.

Geoff: this one should be coming back this way a wee bit

Geoff: just a wee bit

Thom: $\quad$ yeah right

Geoff: and um, yeah and the other

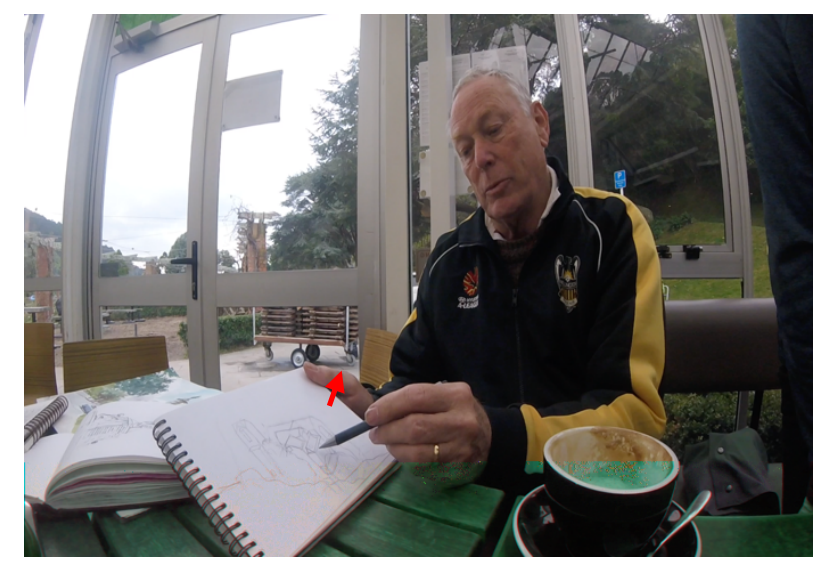

Figure 6:6

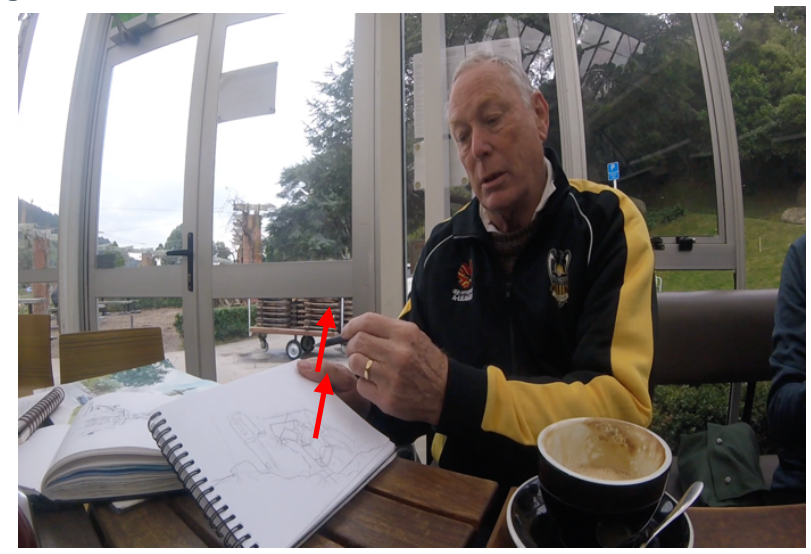

Figure 6:7 
[Amber leaned over Geoff to retrieve a sketching pad]

Amber: can I just get this one? [inaudible]

Geoff: will be over in this other direction

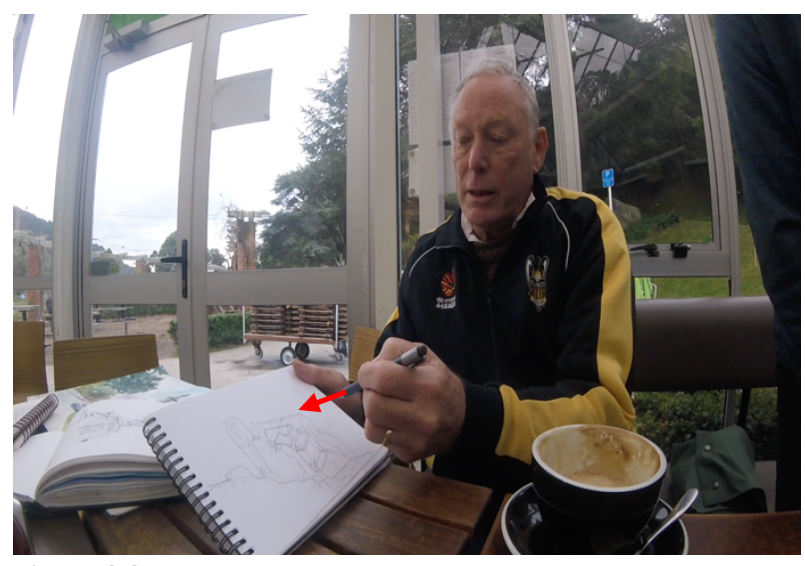

Thom: yeah right

Geoff: so

Amber: oh yeah that's in the graveyard

[inaudible cross talk]

Geoff: so yeah, yeah, yeah that's great, its good

[inaudible cross talk]

Amber: that's lovely.

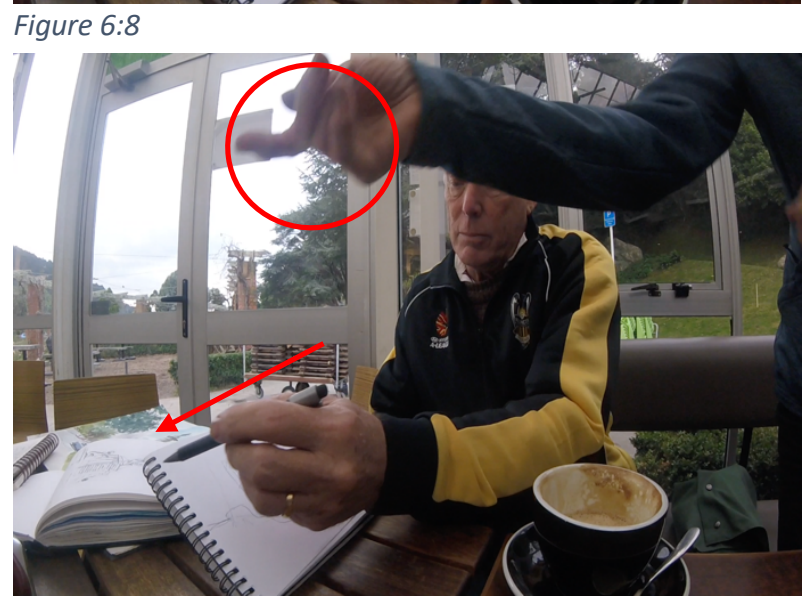

Figure 6:9

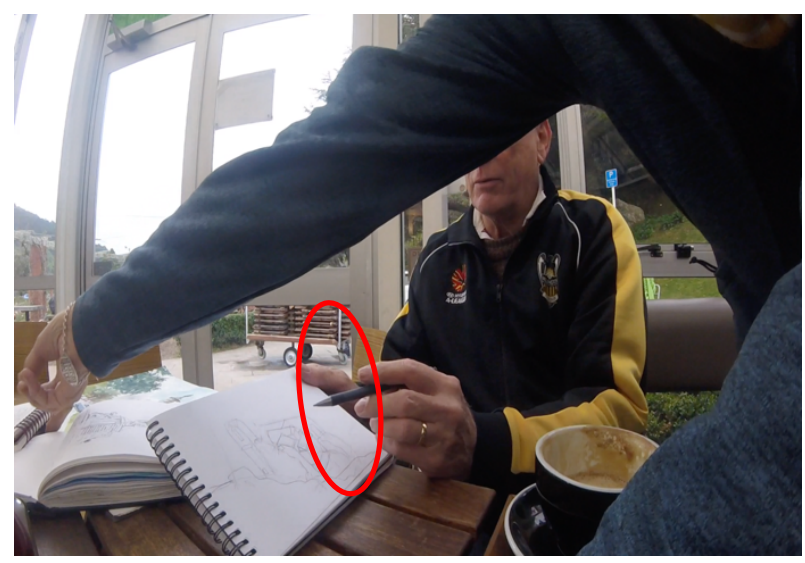

Figure 6:10

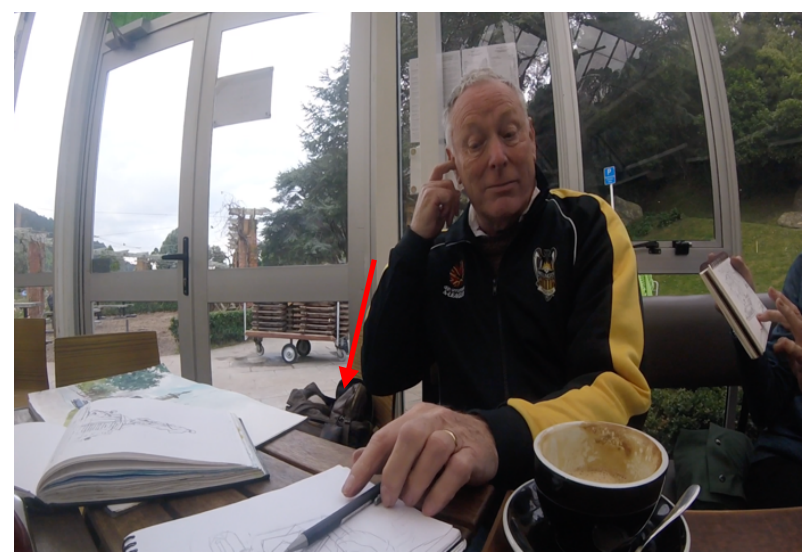

Figure 6:11 
As Geoff continued to locate other vanishing points within the image (from Figure 6:8 to 6:9) with Thom repeatedly responding with "yeah right”, Amber leaned over Geoff and retrieved Clare's sketching pad (Figures 6:9 and 6:10). This natural interruption caused Geoff to place both the sketching pad and the pencil down onto the tabletop and utter: "so yeah, that's great, it's good" (Figure 6:11). Geoff had provided Thom with an ad hoc analysis of how the lines ought to have been placed under the guidance of the principle of convergence without ever using the term to do so. Subsequently, when Amber provided a natural way to end the lesson, Geoff took the opportunity to do so (Figures 6:10, 6:11 above).
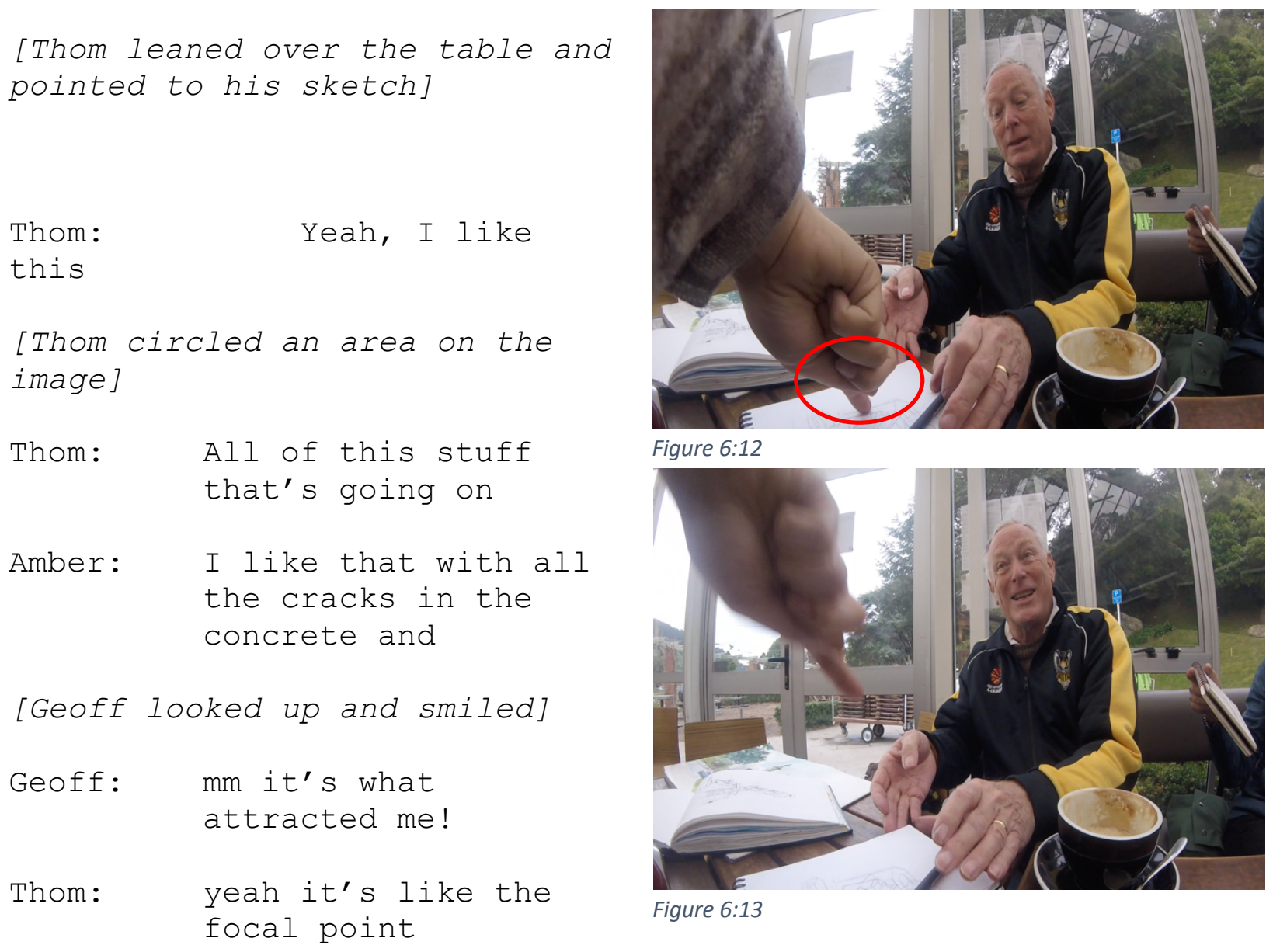

Figure 6:12

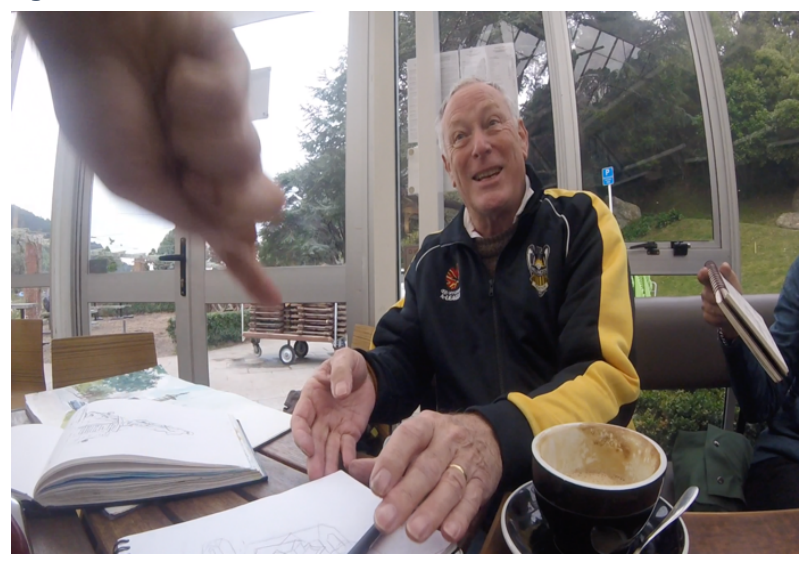

Figure 6:13

Geoff: yeah 


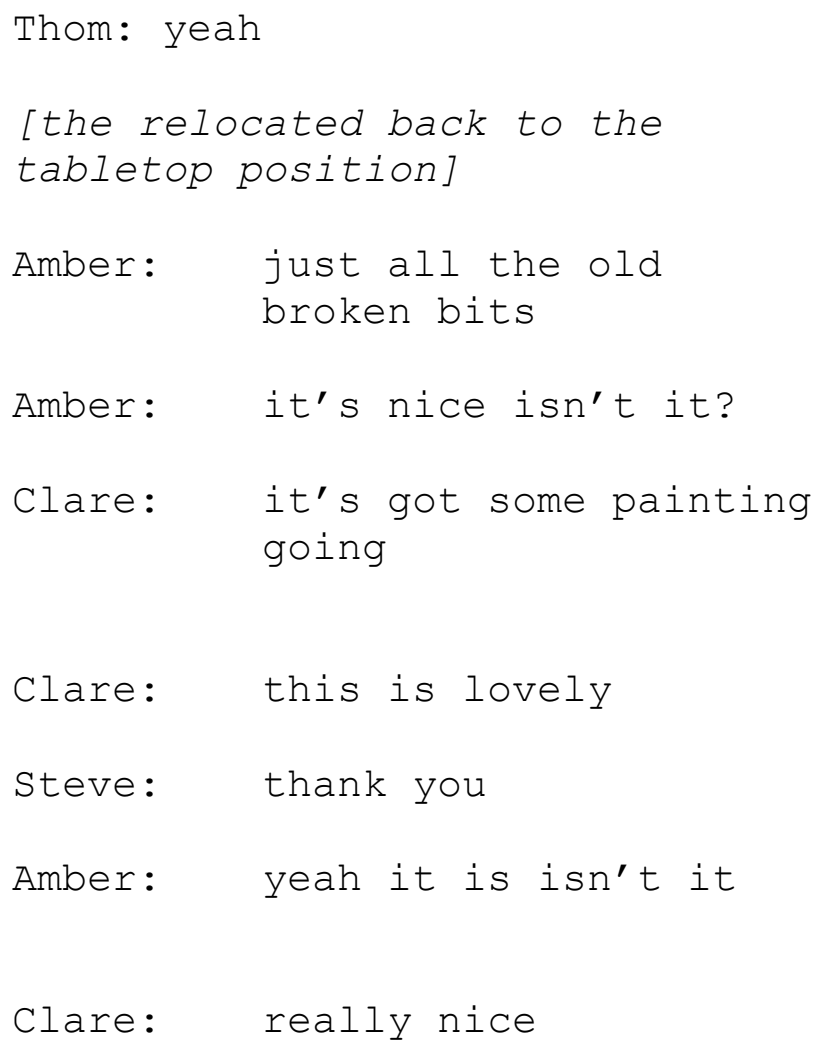

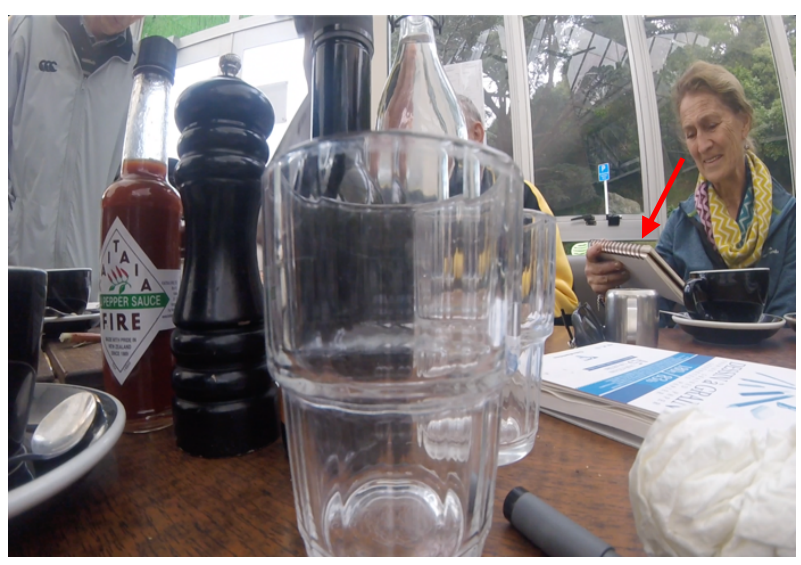

Figure 6:14

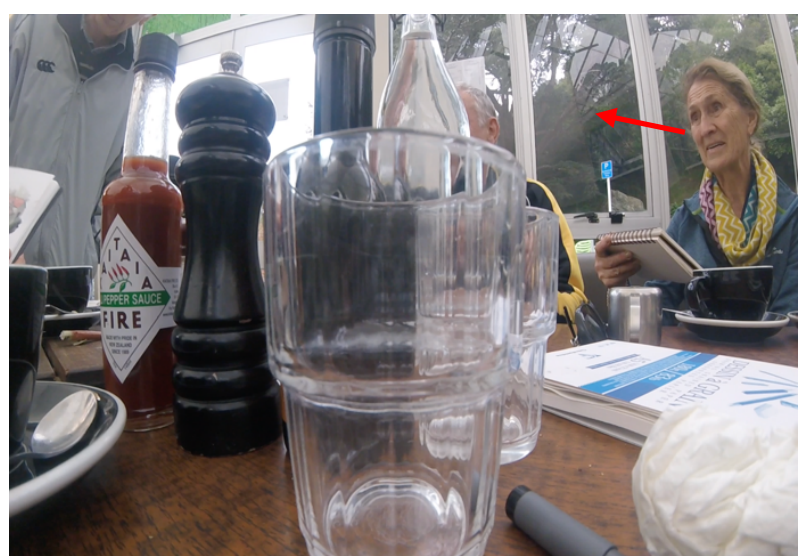

Figure 6:15

Geoff's attempt to end the conversation was rejected by Thom as he took this opportunity and introduced a new theme. He stood up to circle at a certain section of the drawing, stating: "yeah I like all this—all of this stuff that's going on" (Figure 6:12 above). Geoff looked up and smiled at Thom (Figure 6:13 above) and stated: "mm it's what attracted me!". Thom continued: "yeah it's like the focal point". Geoff then replied with "yeah", mirrored by Thom. This short sequence may have given the interlocutors another topic to discuss: the focal point of the image. However, the topic found a natural end as the conversation faded into Amber analysing Clare's sketch book (Figures 6:14 and 6:15 above). The videotape ends.

Geoff did not once utter the words linear perspective, convergence, or terms of other formal art principles. The formation of the above art object, Thom's sketch, was unique to the social situation, however. Geoff demonstrated how some of Thom's lines could be 
'corrected' under one of these non-spoken fundamental principles of art, convergence. I suggest the artfulness of this sequence rests in the ability for Geoff to work with Thom in producing an encouraging mode of review: part of being a member of the group is to enjoy the art of urban sketching. Consequently, Geoff's encouragement was a way for him to offer his skilled experience to a more inexperienced sketcher without providing a formal lesson.

\section{Discussion}

This chapter asked: How do practical actions form an artwork? And within the above case analyses, I described how the configuration of member's actions formed the public meaning of the sketching books as artworks. For example, I suggest there is artfulness within a series of moments during the aforementioned case study: Steve's waiting (Figure 1); Amber's intrusions upon the café server's interruption (Figure 1); the group's clarification of Seddon's location as getting on the same page (Figure 2); member's publicly displaying corrections to initial guesses (Figure 3); group members selectively orienting to each other's drawings, in and amongst other synchronous conversations (Figure 4); members branching off into cointeractive groups; modifying previously discussed topics, such as when Owen returned to the talk of subject selection, and Amber's newfound appreciation of Owen's artistic style by way of his emphasis of measuring angles (Figure 5); one novice and skilled sketcher providing ad hoc analysis of how the lines ought to have been placed under principles of convergence without providing a formal lesson to so do (Figure 6). In short, this group's natural conversational activities were used to organise how artworks gained social meaning in a group talk setting.

Abstractly, these commonplace activities however facilitate something more-social phenomena. Within doing group talk, the constitutive nature of each individual social act as it responded to, and related with, previous, current, and projected acts was amplified in the 
act's timings: the relationship between one member's action and another caused the intersubjective contexture to produce a public social object, one that exists independently of each action, but not of the situation those actions reflexively contextualise. There is something beyond each social action.

Theoretically, to my understanding this argument is seemingly matched by that of Garfinkel and Sack's (1970) formal structures thesis. For example, they state:

(a) In that they exhibit upon analysis the properties of uniformity, reproducibility, repetitiveness, standardization, typicality, and so on; (b) in that these properties are independent of particular production cohorts; (c) in that particular-cohort independence is a phenomenon for member's recognition; and (d) in that the phenomena (a), (b), and (c) are every cohort's practical, situated accomplishment (p. 346).

They argue whereby properties being independent of a production cohort, is that cohort's practical, situated accomplishment. In this way, something beyond social action remains situated and produced or accomplished by the interacting members. Interpreting these abstract theoretical notions in observable naturally occurring data is possible, however. Choosing any of the above case analyses may provide adequate example, yet the situation where Geoff produced a lesson on convergence for Thom is a pertinent example.

Abstracting Garfinkel and Sack's quote, we ask: how are the social properties of an artwork independent of the persons who do the talking? Reinterpreting their answer may indicate that 'independent social properties of an artwork' are accomplished in situated social activities: the group's ordinary urban sketching group café talk. Whether Geoff's talk is 
doing that of convergence (an independent concept not featured in his talk) may therefore be somewhat misguided.

Understandably the artistic principle may not be familiar to sociological readers. I was fortunate to acquire an intermediate sketching ability during my doctoral research. Initially this was done under the guide of the unique adequacy requirement of methods (see Morriss, 2019 for a methodological definition). The suggestion is for analysts to develop a deep practical competence in the work that members do to experience the lived haecceities of everyday life. Engaging with the activity may reveal the specific characteristics of those activities that would otherwise be unavailable and simply not discoverable through observation alone. As a participating member of the sketching group, I often drew alongside the artists in the field. When the group members thus discuss technical specifics of their drawings, I can comment from my own lived experiences of learning how to draw with and like them.

Convergence in this instance is the principle found within linear perspective models of drawing. The concept enables a sense of three-dimensional realism on the two-dimensional surface of a piece of paper. Here, all lines that are parallel to one another in space eventually converge to a single point. Thus, parallel lines in space, appear unparallel to the naked eye. This is best illustrated in an image of a railway track. We know that the track is equal distance from either side, and we also know that the tracks never narrow to a single point, for if they did the train would cease to function. Yet if we stood in the middle of a railroad track and looked upon the horizon, we would eventually see how the two tracks meet at a single point. If we walked along the track to meet that point, it would appear the point had not in fact converged, and upon raising our head and looking further down the track, we would perceive the tracks would further meet at another single point upon the horizon. This 
perspective phenomenon is termed convergence and it is essential to follow if realist drawing is the artist's objective.

Taking this concept and applying it to the sketcher's drawings would not aid the analysis of sociological phenomenon. Mistakenly pursued in that it would be an analyst's comparison of what Geoff was really doing with Thom in his interaction (rather the analysis ought to focus on explicating their talk). By turning to Geoff's local talk and conduct, we observe Geoff provide the novice artist Thom with an ad hoc visual demonstration, a direct correction of his linework. Thom thus learns that one-line ought to be one way and not another, that the lines and angles may need to be re-drawn for accuracy. Crucially, Geoff's superimposing over the lines in this way, shows us properties that are normative. Convergence is thus seen but not talked about in Geoff's answer, yet his public display of superimposition relied on an independent property to feature in the situation (his knowledge of linear perspective). Consequently, we see how an independent property is independent of the cohort, whilst also, the independent property is situated in the contexture and raised in witnessable social actions. We literally see the independency in the interdependent relationships between Geoff's action and the artful ways he demonstrated an objective lesson in a local way. In this way are the formal structures of practical action structured and organised in local settings in and through member's talk and conduct.

The sociology of art moves art around the topic of ethnomethods due to its nondeclarative aim of studying social order. Art sociologists are interested in local social practices but not because they fail to practice ethnomethodology. My hope here is to exaggerate the showing of how action-by-action sequences of mundane detail was done to influence the immediate retrospective and prospective details of how a setting may gain its distinct, yet temporary character, sustained by the members just long enough, for their relevancies to harden and objectivate (Liberman, 2019). This is what it means to do 
ethnomethodology. To provide such descriptions for the sociology of art, would be thus to 'fill a gap' in that missing literature whilst also providing descriptions of social order respecified.

\section{Conclusion}

As this dissertation has been exploring, Gurwitsch played a major role within Garfinkel's development of context which has been until recently, often underutilised. An examination into these primary ideas may not only reveal functional significance is a concept surrounding the constitutive parts of a gestalt contexture (Chapter Three) but observing how these parts are 'thoroughgoing and interdependent' may characterise the gestalt-contexture under analytical observation. This theory was not enough, however.

Garfinkel's relevant move was to utilise Gurwitsch's original thinking by misreading the contribution to gestalt psychology to expand it beyond gestalt abstractions. Consequently, the parts of a gestalt-contexture may become acts of a social setting, and thus the relationship between the acts within any given social setting are to be described in such a way as to remain faithful to the naturally produced functionally significant character of that setting. Garfinkel, having taken his initiative from Gurwitsch's great achievement (Garfinkel, 2002) could now move closer to the empirical investigation of context in both domains of reason (Livingston, 2016) and intersubjective social interaction.

This chapter demonstrated how artists' talk could be examined in real world settings to describe those intersubjective practices as contributing factors for an artwork's social existence. Enshrouded in such social phenomenon, an artwork may feature. Consequently, the sociology of art may benefit from conducting studies that remain faithful to how people act in naturally occurring ways as they produce artwork. 
Additionally, if art sociologists were truly interested in how social practices were influential to the objective formation of artworks, then visual transcription processes ought to increase. Make no mistake: the aim is to study the social practices surrounding artwork, less so of studying the artwork itself (see Becker et al, 2007) and more of the social interactive work itself. At this point, a version of art sociology is thus one of intersubjective social interaction research, describing how the very local member's actions are organized in a Gurwitschian gestalt configuration, where the object is in part influenced by the artful social practices of everyday normal life.

In the discussion chapter to follow, I make a clear distinction between intersubjective social action and action within domains of practical reasoning to open up the issue of studies of workplace actions being social. Indeed, when two or more people interact with one another, social relationships between their actions are accountable as co-produced social objects. Above, I made the brief suggestion these co-products are socially independent from each other action but are still situated in the setting. I drew from Garfinkel and Sack's thesis whereby independent social properties are produced in situated social practices. I believe the above case and its analytical details show this to be true. In this way, the sociology of art benefits from an ethnomethodological alternate description of practical action. It can demonstrate how objective social properties are properties of the situated practical social actions of persons naturally acting in the work; of these we can continually investigate. 


\section{Chapter Eight: Discussion}

The reason why there is 'no work' for the concepts of 'social actor' and 'social structure' to do is that they are to be viewed, as suggested above, relative to a problematic, and these notions have a role in the traditional conception of the problem of social order. It is just this problem which ethnomethodology respecified to get its own enterprise off the ground. The classic conception of the problem requires its solution by means (stable arrangements of social relations or stable arrangements of the characteristics of persons) which are external to the orderliness observable in the sites of everyday activity. Ethnomethodology's respecification is, however, to treat the solution to 'the problem of social order' as completely internal to those sites. It conceives social settings as self-organising and for just that reason has no further need for the received concepts of 'social actor' and 'social structure' (Sharrock \& Anderson, 1991, p. 141).

\section{Introduction}

Recently published literature in the sociology of art connects with some of my dissertation's earlier defined goals. As found within an earlier position paper indicative of the sociology of artworlds, Eyerman and Ring (1998) argued, for example, meaning had been lost from view. They ask, "how are meanings involved in this production of objects, and how are these meanings related to wider social processes and structures?" (Eyerman \& Ring, 1998, p. 280). ${ }^{40}$ So, they are suggesting that art sociology ought to study both context and

\footnotetext{
${ }^{40}$ These enquiries, although appropriate at the time, may seem currently outdated given their claims were indirectly responded to by the artworlds sociologists, where they themselves later asked 'what about the meaning of the artwork itself? (Becker et al., 2007; see also Chapter 2).
} 
meaning whilst expanding beyond the study of artwork production subsisting as a societalwide accomplishment.

McCormick (2019) has recently published on Eyerman's significant contributions to art sociology. Reminding us that pre-millennial sociology of art had "deliberately bracketed out meaning", McCormick argues Eyerman, almost a decade later, has reissued his call for sociologists to take meaning more seriously (McCormick, 2019, p. 254-255). She further discusses Eyerman's outline of what a meaningful sociology of the arts would entail by restating his four-step roadmap': (1) a shift from a paradigm of production (artworlds) to one that is centred on creation and imagination and that treats meaning as an emergent property in the interaction between subject and object; (2) a non-instrumental conception of culture, as culture is autonomous; (3) bring the artist and artwork back into view; and last, (4) a shift to a perspective that includes collective as well as individual actors (see Eyerman, 2006, p. 32). Under these steps we may realise a suitable direction for art sociology; one that focuses on the meaning of artwork as discoverable social phenomena.

In relation to my thesis question, specifically of the 'emergent conditions' from this thesis's research process, comparisons between Eyerman's and my own outline are possible. For example, his 'roadmap' and my independent findings are focused upon treating meaning as an emergent property between people's actions and objects. Furthermore, both bring a "non-instrumental conception of culture" (Eyerman, 2006, p., 33) as I found people freely form artworks through a series of ordinary everyday social and practical actions. Further still, both bring the artist and artwork back into view; and lastly, both adopt a perspective that includes collective as well as individual actors. Given both road maps are compatible, however, does not suggest both are commensurable.

In the following discussion I advocate for a cultural sociology of everyday life (Hurdley, 2016) to direct modern art sociology toward producing descriptions of the 
constitution of meaningful human relations, both social and praxeological, that witnessably surround an artworks formation. The thesis question was addressed once these research conditions were met - answering how artworks were formed by practical social actions was therefore and in part accomplished through the analytical descriptions of artwork formation.

What Eyerman's call may thus have been late on providing, is an appreciation of the wide range of sociological studies that have surpassed his aging suggestion. In the literature review of this thesis (Chapter Two) for example, I showed how an art sociologist's a priori epistemological approaches towards studying an artwork's meaning were unsatisfactory, and thus contested. This resulted in my following of developments on epistemological woes based upon the pioneering work of one particular text, "Art from Start to Finish" (Becker et al., 2007). This text further provided materials for scholarly debate outside of this initial authors' circle, and expanded, perhaps amalgamated, under two foundational papers: Art in Action (Acord and DeNora's, 2008) and towards a new sociology of art (De La Fuente, 2007). ${ }^{41}$ Consequently, contemporary art sociology has strongly incorporated meaning into its post-millennial, empirical social investigations.

Before discussing how the empirical studies of this thesis specifically connect with this literature, I turn to discuss something which although related, is indirectly involved-a socio-material analysis of culture. This is important to recognise because it opens up the possibility that ethnomethodological studies are incommensurable with the sociology of art.

Strandvad (2012) offers an example of a competing externalist socio-material direction in the sociology of art. Here, she pursues the development of a cultural sociological approach which includes both sociality and materiality by way of studying the social relationships between a team of Danish film makers. She argues that the success of the art

\footnotetext{
${ }^{41}$ McCormick cites De La Fuente's paper amongst a series of 'thematic' others regarding materiality and mediation, yet claims these works are unable to progress Eyerman's roadmap to step two due to their inspiration of Actor Network Theory because it fails to provide culture as a 'relatively autonomous realm' (see McCormick, 2019: 256).
} 
object is irrelevant if the collective process of its making is then ignored. Pertinent to Strandvad's case is how she adopts Latour's writings as they call attention to the fact that the social should be seen as constituted by, and dependent upon, materialities, rather than as an autonomous domain in and of itself (see Latour, 2005). Nevertheless, inspired by "DeNora's studies, Latour's propositions about seeing objects as actants, and Hennion's suggestions for how art-works may be addressed sociologically" (Strandvad, 2012, p. 165), she focuses on the filmmaker's social relations that surrounded the film-object over an extended ethnographic period of qualitative observation and interview.

As mentioned, McCormick viewed Eyerman's roadmap as a barrier to cases such as Strandvad's because culture was argued as non-instrumental: culture is autonomous. Although this view aligns with my own in so far that the free formation of constitutive social actions may provide an artwork with its meaning (forthcoming discussion), it would be unfair at this stage to dismiss Strandvad's study for simply being Latourian due to the way her study unfolded. Strandvad's earlier presumption was initially based on Bourdieu. Yet as she engaged with her fieldwork, she realised something was at odds with her earlier a priori assumptions:

Likewise, inspired by Bourdieu, I assumed that the structure of the field of cultural production 'causes' works of art (Bourdieu, 1993). However, for the filmmakers, the film appeared to be as important as the social relations which surrounded it. To my surprise, the film itself did not simply seem to be the outcome of the filmmaker's work. Moreover, conflicting with my sociological presumptions, the evolving product also seemed to exert an influence on the social processes during production (Strandvad, 2012, p. 164). 
Given the details of Strandvad's case, she learned from engaging with the filmmakers that the collective social work they do together may often result in the non-production of artworks, and in this instance no film was created as a result. This does at first connect with an artworld's approach, where the societal-wide network of persons involved in a large project such as those borne of the film production industry may appear as influenced by external social forces, networks and structures (Becker, 1987). Yet, by shifting focus upon the meaningful socio-material developments of the artwork itself, she came to ultimately discover "paying attention to the role of the object may help progress understanding of the unfolding social processes around it” (Strandvad, 2012, p. 174). In this way, Strandvad developed her initial presumptions and provided a suggestion whereby art sociologists could learn to pay more attention to both the material objects and the social processes that surround the work of artwork formation, which became her resulting analytical focus and suggestion for further research.

Strandvad's case is not an outlier in the cultural studies of materiality (see Fox, 2013; Griswold, Mangione \& McDonnell, 2013; Rubio, 2012; Rubio; 2016; Rubio \& Silva, 2013). Yet these studies, and others associated with them, assimilate too much focus upon either the social, the object, or both, the social-material and less of the real time observational social actions that comprise that work: Where are the studies of embodied social talk (conduct, in and as material engagements) as the primary focus of analysis?

Connecting to the opening quote of this chapter, this dissertation's main analytical attitude was one that adhered to a strong version of ethnomethodological respecification (see Garfinkel, 1991, 2002). This attitude, I believe, provided me with a way to orient towards any setting where human persons are seen to be acting, with themselves, the world, others, and turn that setting into a domain of ethnomethodological research. In attempting to explicate the endogenous organisation of that setting's local action, of how a person's actions may be 
organised in such a way as to meaningfully structure their environment in concrete ways, it was only after having produced descriptions that I realised an inherent tension with the approach taken: The respecification may relax the focus upon the social as it may no longer be necessary to chase a definition of what happens in those settings as social, but, rather, to explicate how those settings produce what happens ${ }^{42}$.

Accepting ethnomethodological discoveries of social order in non-socially interactive social situations raises whether ethnomethodological studies of work are suitable for the new sociology of art, a point of discussion the following chapter continues.

\section{Roadmap}

Six main sections structure this chapter:

The missing studies of real-time social action: I continue to argue here that an art sociology which enables the social researcher the freedom to visit social settings where artworks are obvious features and observe and record how people interact with those objects or interact with themselves whilst art objects feature in their intersubjective talk and conduct would provide us with adequate conditions to gain access to social phenomena in the making.

Connections with ethnomethodology: This section moves to discuss how Gurwitsch's gestalt theories are ultimately a throwaway; they show how one action cannot be removed from its setting without altering that setting's formation. This is important because the phenomena of meaning is not seen as an individual unit or singular act which stands alone, rather meaning is produced as a constitutive relationship between an entire temporal

\footnotetext{
${ }^{42}$ Little concern may be found in this by ethnomethodologists. It is of my view after the adoption of such a respecification attitude, all action remains social, and thus ethnomethodologists are free to study the endogenous orders of both the social and non-social activities as a result, i.e., any sense of any action is organised socially.
} 
assembly of practical actions; to discover the meaning of an artwork is then to describe how these practical social actions organise a setting to be meaningful.

Toward relational sociology?: This section briefly connects with Crossley's position by suggesting relational sociology "must endeavour to tackle the problem of individualism" (Crossley, 2010). Moreover, it must endeavour to capture the action in interaction. Here, Crossley suggests relational sociology must endeavour to capture and analyse the social world in interaction, analysing what happens between social actions. As we will see, Crossley however removes the possibility of single-case analyses.

The findings: Artworks are meaningfully formed by a person's situated endogenous actions in a myriad of co-present and individual settings. This thesis argued the relations between two actions are meaningful when they are interdependent in both person-to-person and person-to-object interaction, as described as an assembly and organisation in and as practical social action. This attitude not only directs scholars to social order as a member's observable accomplishment but also provides access and an attitude to its further study.

Answering the research question: This section raises the notion that little of the art sociology literature demonstrates how constitutive actions are freely formed by the members involved in their creation without first corresponding that formation to a sociological theory, principle, model or concept external to the member's local work itself. Additionally, there is compatibility between ethnomethodological approaches to social studies of social practice in the sociology of art. This thesis argues the relations between two actions are social when they are interdependent in both person-to-person and person-to-object interaction. We now turn to address the missing studies of real time social action. 


\section{The missing studies of real time social action}

It is not news that art sociologists at the turn of the twenty-first century debated the issue of how a sociologist could represent "contextually indeterminate social action" (see Becker et al., 2006) prior to persons acting in the world. Hence, a new program of research was developed to understand how artworks could be made meaningful (see Chapter Two). De La Fuente coined this issue as paradigmatic to the new sociology of art, where subsequently, the contextual status of cultural products ought to move scholars toward investigating the site-specific meaning-making action of artwork production (De La Fuente, 2007; 2011). De La Fuente, at present, recommends art sociologists' turn from these former concerns toward theorising the textual (De La Fuente, 2019). I disagree. Although the first generational studies connected to this earlier notion (Acord and DeNora, 2007; Rubio, 2012; Gerber \& Klett, 2014; Zembyalas, 2014), they predated DeNora's imperative call toward investigating artful social practices (see DeNora, 2014). Consequently, this ethnomethodological turn is something which De La Fuente and new art scholarship have left unaddressed at the turn of the current decade.

My original suggestion in the literature review (Chapter Two) was that the new sociology of art is suited to ethnomethodological studies of everyday life and work. Moreover, I recognised Acord and DeNora (2008) advocated for art sociology to move towards the emergent local-interactional work that persons do in natural social settings as, for them, describing such interactional operation of the arts may become a significant scholarly accomplishment resulting from answering their question of "how specific features of artistic forms emerge as meaningful and consequential within interactions" (Acord \& DeNora, 2008, p. 226). Furthermore, by introducing the idea of DeNora's affordances (DeNora, 2002, 2003), persons are thus seen as embodied, creative agents, and therefore sociologists ought to resist correlating predefined categories to material engagements due to a desire to describe such 
interactional practices that surround artwork rather than artwork itself. This is an important idea because it suggests that the sociology is sound yet requires further studies to progress. I thus concluded the literature review by suggesting that due to this proposition for a new art sociology direction — an art in action approach—several motivating and collegial sentiments amongst scholars had surfaced: "Yet despite its vivid description of social life, applications thus far of this approach lack a practice-oriented method that would allow for grounded analysis unmediated through discourse (Klett \& Gerber, 2014, p. 277); “There has always been a blind spot in the sociology of art: any discussion of specific artworks" (Becker et al., 2006, p. 1); "culture is a much more contingent and site-specific phenomenon than sociologists have tended to concede" (Rubio, 2012, p. 156), "Practical aesthetics, the conduct, interaction and practice ... would seem worthy of a little analytical attention from the social sciences" (Heath and vom Lehn, 2004, p. 62). And lastly, "real time events may play a leading role in determining how, and even if, culture is integrated into action trajectories" (Acord \& DeNora, 2008, p. 234). Despite the wide range of human actions, what are the ones that relate to culture?

These studies often articulate suitable directions for social research and then provide little to no follow through. The very studies they claim to desire are left to be desired. It is not my argument here to suggest sociological researchers of art fail to engage with fieldwork nor analysis of what makes art meaningful, however. Little of the art sociology literature demonstrates how constitutive actions are freely formed by the members involved in their creation without first corresponding that formation to a sociological theory, principle, model or concept external to the member's local work itself. In this way, although Acord and DeNora (2007) may argue otherwise, pre-defined categories can only ever remain as a sociological correspondence. The sociologist seldom places the literature aside to turn to living domains, to see 'action trajectories' track a natural course. 
Further in this way, I ask: Why the disdain of simple descriptions of the constitutive relations between members' actions and their local organisational forms? Furthermore, what is negative about scholarship that seeks to show action-by-action sequences of how real art objects feature and are managed in and by person's talk and conduct? An art sociology which enables the social researcher the freedom to visit social settings where artworks are obvious features, and to observe and record how people interact with those objects, or interact with themselves whilst art objects feature in their intersubjective talk and conduct, would provide us with adequate conditions to gain access to the social phenomena of accounting (Garfinkel, 1967). This view is one that I have argued to be aligned with Eyerman's focus on meaning for 'new sociology of art'. However, unlike Eyerman's position (2006), I, like Acord and DeNora (2008), position a view against a priori correspondence between sociological theory and how persons manage to constitute an artwork as a meaningful object in real-time situated action in naturally occurring ways.

Perhaps less known to art sociology are the emergent publications of art ethnomethodologist, Yaël Kreplak (2015; 2017; 2018a; 2018b). Her studies are easily compatible with Acord and DeNora's new art sociology whilst they also contribute to an ethnomethodological analysis of everyday social interaction and practical reasoning that surround artwork (see Chapter Two).

Pertinent here is Kreplak's main argument within her latest text, “Art in and as Practice" (Kreplak, 2018b). She argues that ethnographies of artistic practice do not simply bridge the gap between artworlds and artworks, as more is needed. Kreplak incorporated the attitude of the ethnomethodological "missing interactional what" (see Lynch, 2015) into her close studies that observed how persons constituted artworks during social interaction. Her research intention was "to identify the constitutive practices, which are inevitably missing 
from versions found in the literature, and which are only to be discovered through a detailed study of the particular deeds that shape these practices" (Kreplak, 2018, p. 144).

Given this research aim, by investigating how people constitute the objectivity of artworks within situated social practices, Kreplak's findings suggest that one is undoubtedly engaged in a thoroughgoingly ethnomethodological enterprise (Kreplak, 2016, p. 159-161). Consequently, we find harmony between ethnomethodology and the new sociology of art's research aspirations.

Relatedly, the original thesis question, 'how are artworks organised in and as practical social action' was thus softly synthesised together in employing Kreplak's and DeNora's (2014) shared sentiment: Where are the studies which show the real time constitutive social actions that surround artwork? What are the artful ways persons assemble their actions into meaningful, accountable formations that influence further actions?

\section{Discussing Chapter Four}

Following a professional artist traverse river terrain, Chapter Four was the first chapter to experimentally address how artworks are organised in and as practical social action. During an initial phase of analysis, I utilised indexicality by explicitly describing how one action relates to another. As for example, a pronoun such as 'this' may relate to an object during utterances, gestures, and actions, as found in the case: "Where does this go?". The object is undefined, yet given more of the context, what 'this' may refer to becomes trivially understandable.

When the three artists were walking among the river stones, Freeman pointed to the island and said, "do you see it?"; The reference of the pronoun "it" as it related to the island, more specifically the cabbage tree, thus could be argued to be a situated social 
accomplishment; a stable account was intersubjectively assembled. This style of analysis may seem compelling at first, however as argued in Chapter Three, indexicality is ultimately a throwaway; all actions are situated, and thus all actions are demonstrably used to refer, not just pronouns and deictic action. The mistake was to originally analyse and search for referential action as topic.

In comparison, given the nature of the kaleidoscopic metaphor, the real time constitutive social actions that surround artwork were explosive. For example, understanding how the relationship between two actions are held to be related to one another, and then seemingly detached, or reified, or made concrete, or, ordered, became inherently interesting. As the artists navigated around the terrain, I understood their actions to form what I called small gestalt detachments. These are subject to change at any moment, for any contextually related reason. For instance, when the artists discovered the path to the river was overflowed and their expected route was thus compromised, the shift in re-routing that occurred was locally achieved. Freeman's body language (how he pointed back toward where we had headed from, took a strong voice, and led us back to where we had started) contributed to the meaning of the situation. In connection with artworks, then, the interconnected relationships between intersubjective social actions, terrain navigation, and the entire organisation was all done in the name of "painting"; it was part of the artistic activity of doing plein air painting. Placing myself in that setting exposed only some of the social ways artists produce their accounts during a natural course of painting — of doing artwork creation.

\section{Discussing Chapter Five}

I initially adopted a research attitude, "sociology of the witnessable order" (Livingston, 1987, 2016) during the preliminary analysis of data and as I moved toward producing studies of "the missing interactional what" (Lynch, 2015) in art sociology literature. I originally aimed 
to study how artworks were constituted in and as social actions_-including the worksite practical actions of artists. After conducting these studies, however, I was left with a confused version of what the "social" could mean.

What I had achieved in one case study for example, was a description of, and ethnography about, an artist at work behind closed studio doors. I described how this artist painted and how the sequential brushwork he performed over the course of that painting was consequential to the overall production of the artwork (Chapter Five). Yet the social remained hard to isolate from the description of that setting's details because the relations between one artistic action and another gained a material, not a social, response. I was leaning towards how an intersubjective model of sense-making produces social phenomena; I was lost from the original position taken. In this way I successfully adhered to Livingston's ethnographies of reason, but was it an ethnography of the social?

Initially, I claimed to have the primary objective of describing the constitution of an artwork in and as an ensemble of contextual social actions. What I accomplished was, in fact, a showcase of the reasoning praxis of how an artist constitutively organised his actions in a series of organised local details, and thus the phenomenon analysed was social.

One main example provided in this particular case study was the small-pot big-brush discrepancy. These actions of firstly putting the large brush down on the tabletop to then retrieve a smaller brush created an ad hoc environment; one that may or may not have been realised: The artist eventually picked up the big brush he had earlier discarded. Now, dual wielding two brushes, the way he was painting connected with the beat of the music, his feet lifted, and in turn, the energy supplied to the mark-making actions is speculatively different (what Laurier (2008, p. 2) once called a "counterfactual"). However, the videotape isolates a singular occurrence. In analysing this occurrence, we can see how the endogenous order from one action to another co-constituted the gestalt assembly of how this painting was done. 
Ultimately, I turned towards how members of living society organise their action through single-case empirical descriptions. This included the investigation of how gestalt-contextures could be included in the move from the study of art structures (Becker, 1979) towards artwork (Becker, 2006) formations.

Given the above claim in which the sociology of art is looking for the social (and not the human praxis) within art in action, I raise concerns whether the new sociology of art and their approach ought to continue studying praxis - of how artists organise their action during the production of artwork creation in non-social settings. Are ethnomethodological studies of worksite practices interesting to the new art sociologists? (Chapter Nine provides an answer).

\section{Discussing Chapter Six}

The study of the urban sketcher relying on approximation as a social resource (Chapter Six), was also made under the earlier appreciation of how all action is indexical. The way Owen managed his sketching action during a natural course of drawing raised further curiosity as it may contribute to the formation of artworks. I concluded this empirical chapter by stating "the constitution of the art object as being a corrigible social fact respecified" would enable scholars to further investigate such mundane social phenomena (found within the methodological tension of having to cope with describing action and capturing meaning without using variables to do so, is a corrigible fact of doing ethnomethodological research). Yet this is more of a methodological claim than an empirical finding. None of the analysed actions Owen performed in this case study were accomplished in an intersubjective social interaction setting, further raising the question of whether the sociology of art is interested in such studies.

One key moment within this study was how the artist ordinarily dropped his eraser during his measuring. The placement of his thumb on his pencil required replacing due to the 
new ad hoc task of retrieving the fallen eraser, yet no direct replacement occurred. What had occurred was a guess as to where that placement was, and thus, this small action may have affected subsequent sketching work. Moments like these (small, trivial, and mundane) are still constitutive in that setting. And again, as following Gurwitsch's theory, the meaning of a constitutive part is found in the relations between the parts and not in the part itself. When this idea is supplied with Garfinkel's recommendation to study social action rather than theorise, we can discover a newfound appreciation of what the artist was doing. The clarity of these findings in worksite settings has been strengthened as a result.

However, clarifying the relationship between two actions as being socially interactive or not does nothing to question whether artworks are independent objects external to living persons ${ }^{43}$, or whether an artwork's meaning may be constituted in part by human reasoning praxis. This is a nod toward a praxeological approach for art scholarship (see Kramer, 2017).

I appeared uneasy on the explicit focus or distinction between praxeological constitutive acts (like sketching, viewing the art objects, drawing lines, dropping erasers, and so on) and socially constitutive acts (like asking questions, responding, telling a joke to receive laughter, greeting others, and the other, endless constitutive social-interactive actions therein). Owen's sketching and Clive's' mark-making actions were practical, but were they oriented with, or constitutive of, another's social actions in that setting in that time?

\section{Discussing Chapter Seven}

Chapter Seven sought to explicate what was organisational about a group of artists discussing their work with one another. Analytically, I described how the configuration of conversational actions partly formed the public meaning of the sketching books. For

\footnotetext{
${ }^{43}$ As Kobyshcha (2018) has recently argued against due to her finding of art objects as perception-relevant performances between persons and their entanglements (p. 495).
} 
example, I suggested there was artfulness within a series of their moments: Steve's waiting; Amber's intrusions upon the café servers interruption; the group's clarification of Seddon's location as "getting on the same page"; members publicly displaying corrections to initial guesses; group members selectively orienting to each other's drawings, in and amongst other synchronous conversations; members branching off into co-interactive groups; modifying previously discussed topics, such as when Owen returned to the talk of subject selection, and Amber's newfound appreciation of Owen's artistic style. His emphasis of measuring the statues angles provided an ad hoc analysis of how the lines ought to have been placed under the artistic principle of convergence, all without providing a formal lesson to so do. The art group's natural conversational activities were used to organise how artworks gained social meaning, through these very local social interactions, as "talking events in art spaces" (see Adipa, 2019).

These commonplace interactional activities facilitated the social phenomena of accounts. Within doing group talk, the constitutive nature of each of the individual social acts as they responded to, and related with, previous, current, and projected acts, amplified during the act's timings: The relationship between one member's action and another caused the intersubjective relationships to produce a public social object; one that may have existed independently of each action but not of the situation in which those actions reflexively contextualised themselves.

This chapter became more theoretically stable due to its status as the last chapter. For example, I was no longer interested in how indexicality may feature in the members' actions as an analytical frame. In addition, the discovery of an unpublished yet transcribed lecture by Garfinkel (see Garfinkel, 1993), and its connection with a published lecture on similar materials (Garfinkel, 2007), confirmed an original but hard-to-place suspicion: Using functional significance as a single minimal analytical frame would produce descriptive 
studies that display the social organisation of meaning within any setting. This chapter was simply an arrival to what I had been attempting to produce throughout the dissertation:

Describing members action as endogenously organised without using formal variables to do so. ${ }^{44}$ Because to do so would substitute local order for something found elsewhere.

Garfinkel's theoretical insights on how the social world is organised is simply to continue to produce these studies of endogenous local orders, to learn and provide more examples of social order phenomena.

The following section returns to asking how new art sociology can pursue the social. I realised, now at the end of the dissertation, that ethnomethodological respecification is a theory on the social, and that as all actions are social, studies of human praxis, regardless of whether the relationship between two actions are socially interactive, is itself constitutive of social reality. Because of the attitude of remaining indifferent to whether co-presence features in a person's situated activity, the topic of investigation shifted. How is situated activity organised endogenously?

Subsequently, after briefly discussing how Gurwitsch's studies were relevant in producing descriptions of constitutive actions in organisational structures, I turn to address how such descriptions may contribute to the new sociology of art literature, or indeed, whether that is possible at all.

\section{Connections with ethnomethodological theory}

This section moves to discuss how Gurwitsch's gestalt theories show how one action cannot be removed from its setting without altering that settings formation. This is important

\footnotetext{
${ }^{44}$ As argued in Chapter Three, 'the correspondence theory of truth' was treated by Garfinkel as a how/what problem. That is, rather than attempt to explain what members are doing in any setting, by asking how they do the what, the problem of correspondence is re-specified. What is of interest now, is to describe how the members organise their action in a situation to stabilise the sense and meaning of those self-same actions.
} 
because meaning is not seen as an individual unit or singular act which stands alone, rather meaning is produced as a constitutive relationship between an entire temporal assembly of practical actions; to discover the meaning of an artwork is then to describe how these practical social actions organise a setting to be meaningful and accountable.

One consequence of engaging with this ethnomethodological style of analysis, particularly in domains of practical and technical reasoning (see Livingston, 2016), was the surprising strength of Garfinkel's use of Gurwitsch's gestalt phenomena due to its general ability to notice an alternate for both social and non-social orders in ordinary life. As I alluded to earlier, I argued that studies of social-interactional relationships are suited to the sociology of art, not studies of artistic praxeology. This does not open a direct criticism upon ethnomethodological approaches, however.

Gurwitsch played a major role within Garfinkel's development of context, which, until recently, has been overlooked. An examination into these primary ideas may reveal functional significance is a concept surrounding the constitutive parts of a gestalt contexture. Observing how these parts are thoroughgoing and interdependent may characterise the gestalt-contexture under analytical observation (with or without the social).

Garfinkel's relevant move was to utilise Gurwitsch's original thinking by expanding it beyond concepts, reducing the gestalt abstractions to people's observable real time activities. Consequently, the parts of a gestalt-contexture may become acts of a structure, and thus the relationship between the acts within any given structure of action are to be described in such a way as to remain faithful to the naturally produced character of that structure (see Livingston, 2016). Garfinkel, having taken his initiative from Gurwitsch's great achievement (Garfinkel, 2002), could now move closer to the empirical investigation of the members production of accounts. 
Concerning Watson's argument whereby gestalt contextures may enable a renovation of methods (see Watson, 2017, p. 15). Methodologically, I encountered no required notion of indexicality nor reflexivity during the analytical phases within this dissertation. I did however retain a notion of accountability (Garfinkel, 1967). Additionally, I recognised a need for corrigibility. I did not find myself revisiting theoretical explications, partly because I recognised Gurwitsch had done that work and I was convinced by his arguments of functional significance, and partly because Garfinkel (and Wieder) had "taken Gurwitsch to the world and came back educated" (Liberman, 2008, p. 253). Consequently, this ethnomethodological dissertation was not designed to develop and progress Gurwitsch's theories. Rather, somewhere along the way an example of findable instances of gestalt coherence within the data was discovered, signaling a useful analytical frame for simplifying theoretical concerns towards data, and Garfinkel provided a microscopic focus on two constitutive actions and the immediate relationship between them in social settings.

Notwithstanding the important Gurwitschian theoretical notion that no act stands alone, practical social action is contextual action, bound to the local occasion, and it is only practical for and in that self-same situation. It achieves something functionally relevant to the local social structures. The management of which is for the members to decide. Discussing the constitutive social actions is thus a discussion of how the setting was socially organised; something which a relational theory may help develop further.

\section{Toward Relational Sociology?}

As previously argued, ethnomethodology remains indifferent to co-present settings as exclusive to the study of social order. However, that does not facilitate ignorance of other emerging sociology. Relational sociology (see Prandini, 2015; see also Cook, 2012; Rimmer, 2020 on relational sociology in art and music) thus has a place in this discussion due to its 
project-finding similarities towards new directions for sociological analysis. For example, Crossley has recently written extensively on relational sociology (Crossley, 2011; 2015a; $2015 b)$. He does not suggest another revolution or turn in sociology is required, but rather it is rather a reminder, or at least a self-proclaimed revisiting of fundamental sociological ideas featured in the classics, of social relations. He does so by introducing the dichotomy between holism (the whole is greater than the sum of its parts) and individualism (the parts explain the whole $)^{45}$ (Crossley, 2011, p. 40). Crossley argues both relations are context-dependent, and emergent - properties exist between individual actions through their relations which may give rise to wholes. Crossley solidifies his position by suggesting relational sociology "must endeavour to tackle the problem of individualism" (Crossley, 2011, p., 41) moreover it must endeavour to capture the "action in interaction" (ibid). Subsequently, Crossley suggests relational sociology must endeavour to capture and analyse the social world in interaction, analysing what happens between social actions.

I do not seek here to evaluate Crossley's position (to suggest an alternative), however I can find preliminary connections between his relational version of sociology and a version of ethnomethodology I have discussed herein. First, Gurwitsch's relational theory on functional significance is the most pressing issue to address due to his thesis that to remove one part from the whole would alter the distinct interconnected relationship that help constitutive the overall gestalt whole, i.e., part-wholes (Gurwitsch, 1964). Second, Garfinkel's misreading of Gurwitsch's text provides a project of observing how persons in ordinary settings organise their actions subsequently structuring and managing the situated setting, endogenously.

\footnotetext{
${ }^{45}$ Crossley's view of that of the latter, that social structures constitute a higher order of being, where he suggests although context-dependent, parts are unable to be abstracted from their wholes.
} 
By further investigating the relationship between Gurwitsch and Garfinkel in his later writings, I argued that the "thoroughgoing interdetermination and interdependence of constitutive actions", i.e., the relationships and relations between two constitutive acts, are part of the fundamental unit of social meaning, intelligibility, order, and organisation.

In Crossley's relational sociology, specifically his definition that "a social relationship, to reiterate, is the lived trajectory of iterated bouts of interaction between actions" (Crossley, 2011, p. 48), I find common ground. However, as Crossley (2011) continues to suggest, "interaction and individual dyadic relations are important but we need to be able to look beyond such dyads to the structure, indeed, "social structure"' (p. 53). I find this problematic.

The ethnomethodological attitude of relations I have been advocating in this dissertation implies that actions are constitutive of the whole. The relations between one action and the next co-constitute the whole. Functional significance is observable in a person's interactive actions. Under this notion, analysing the asocial may not require looking beyond two parts. As Crossley suggests, "because [relations] entails interdependence between actions and properties which only emerge as it unfolds, as a function of that unfolding, properties which belong to the interaction between the actors rather than to any of them in isolation" (Crossley, 2011, p. 45).

What Crossley is missing in this above description is, like Gurwitsch, not an abstract notion of a relational theory, rather, an empirical project to explicate how members of society organise their conduct in real world contextual settings. In many ways, this project of the observational explication of social relations in interaction is inherently ethnomethodological. The prize are rich descriptions of member's practical actions that organise a setting into a stable order as phenomena to be investigated: How is that done? 


\section{Findings and the 'missing interactional what'}

Considering the notion that the new sociology of art paradigm seeks out socially interactive settings which feature artworks, the thesis question may only be partially answered in using ethnomethodological approaches. I concluded the literature review (Chapter Two) with the suggestion that due to this proposition for a new direction in art sociology—an "art in action" approach — several motivating and collegial sentiments amongst scholars surfaced regarding how more studies of real-time action were needed. I further suggested that what is problematic in these contemporary studies, however, were the ways in which they articulated suitable directions for social research and then often provided little to no follow through of engaging with such empirical work.

The issue with this suggestion is one of this compatibility: Ethnomethodological studies are incommensurable, asymmetric and alternate with formal sociological reasoning (Garfinkel and Wieder, 1992; Garfinkel, 2002). However, by retaining an attitude of ethnomethodological respecification, art sociologists may better appreciate how these studies contribute to social studies of how practical social action organise artwork's local meanings.

I have found from this dissertation's empirical descriptions that artworks are formed by person's situated endogenous actions. Language is inescapable, and language use in action is social. As such, human action is accountable, and therefore organising. Due to these factors, this thesis argued the relations between two actions are meaningful when they are interdependent in both person-to-person and person-to-object interaction, as described as an assembly, and organisation in and as practical social action. In both settings, a person's interdependent actions relate to another and therefore configure a meaningful relevant organisation; a structure of social action which may feature the co-constitution of artworks as practical social action. 
I found specifically, in the two case studies where an artistic action was described, a noticing where ad hoc methods of artist-object interaction were produced and relied on as resource during the production of artwork. For example, Clive Kelly (Chapter Five) managed to solve a local issue by utilising an ad hoc tool exchange. This provided further opportunity for actions to arise in his studio setting that otherwise would not have been consequently available. The local management of these ad hoc actions and their causation fuelled the final creation of the artwork and thus became the focus of the analytical description. Likewise, in Owen's case (Chapter Six), an ineffective measurement was made and subsequently used to approximate another next measurement. This approximated next measurement was used to directly correspond his linework to the building within his field of vision. This subsequently caused slight and unintended inaccuracies between what is seen and what is drawn. These were organised in and as the practical social actions structuring the activity of doing urban sketching.

Of the two case studies that feature explicit intersubjective interactive settings, where constitutive actions were related to other persons as, for example, in the case study of plein air artists navigating river terrain to select something to paint, the investigative descriptions of context may raise concern with how the sociology of art treats a priori explanations of meaningful social action beyond the members' local work. This study upheld the analytic mentality of "kaleidoscopic detail" (Watson, 2008, p. 244) and attributed each of the constitutive elements observable from the recorded materials as worthy of value. Each of the party's individual actions contributed to the contextual field of our party and to the way the action gained meaning in relation to that contextual field. How a group made up of two artists and a social researcher engaged in the subject selection of plein air painting through a series of activities (observing subject matter for the first time, realising the river's water level was too high for crossing, re-routing their journey, serendipitously re-viewing the subject from an 
unplanned viewing point, and lastly, becoming aware of the sun's relationship with the artist's position on foot all comprised the features of a specific day's work of painting.

The case study of the commonplace activities of café talk an urban sketching group used to discuss their artworks, facilitated the task and production of artworks as social phenomena.

For example, within doing group talk, the constitutive nature of each of individual social act as it responded to, and related with, previous, current, and projected acts was amplified in the act's timings: The relationship between one member's action and another caused the intersubjective contexture to produce a public social object; one that exists independently of each action but not of the situation those actions reflexively contextualise.

Such interactional descriptions of artistic activity are missing from the sociology of art literature. How the constitutive parts are organised in and as a contextual field, and how members orient themselves to that field is a descriptive product of this dissertation. Given the property of "corrigibility of descriptions" (see Chapter Three) how they can be used to create knowledge may be best left to the reader's interpretation of the cases; of how the actions displayed therein produce the order of the social setting; and, how recognising these ethnomethods discoverable in the natural settings, people find themselves simply acting with their bodies and language use.

Art?

This dissertation has attempted to get close to the natural ways people organise their activities, whether alone or together. By adding "artist" to the people, and "artistic practice" to the activities, a theme was born.

Art, however, is far more complicated and nuanced than what these studies could contribute as a definition. Traditionally speaking, observational sketching and painting, the 
act of capturing a visual three-dimensional representation on a two-dimensional plane is only one, albeit common, view of what art is. I cannot offer a definition of the arts, nor was one required in this dissertation to produce sociology. Instead, how persons translate what they see and feel into concrete art objects was inherently interesting due to the involvement of both context and embodiment. Least not because of the situated nature of sitting and looking; of the relationship between the hand and eye and the body; of the type Freeman and Owen display when situated in the field; and of the rhythmic dance of gestural marks Clive feels with his hands and feet — the real time displays of artistic practice show us the orderliness of artwork production. These studies may tell us nothing about what 'art' is. I would rather leave that task to the artists, and in turn do as they often do, leave that for the world to decide.

What these studies have attempted to demonstrate is the ordinary way persons act in the world in settings where some type of artwork is involved. How their actions ordinarily comprise and constitute, through their very activity, the meaningful organisation of an artwork. Gurwitsch was truly onto something when he argued it is not the constitutive part, nor the whole, rather the whole-part, and the relations between which ultimately provide the identity of the gestalt. Garfinkel however took that idea and searched for it within people's observable actions. What he claimed to have discovered was a phenomenon previously gone unnoticed: social order as a member's local achievement. When people act in the world in ways that feature artworks, they are producing social order. These studies are attempts at explicating those actions guided by Gurwitsch's and Garfinkel's academic research.

\section{Conclusion}

This chapter began by introducing the relevant and current sociology of art literature to provide background context for the dissertation's findings. I connected with McCormick's suggestion that Eyerman provided a road map for art scholars to utilise in their own studies. 
Under these steps, scholars may realise a suitable direction for art sociology; one that focuses on the meaning of artwork as discoverable social phenomena. However, in relation to my thesis question, specifically of the emergent conditions from this thesis's research process, comparisons between Eyerman's and my own outline are possible. I advocated for a cultural sociology of everyday life (Hurdley, 2016) to direct modern art sociology toward producing descriptions of the constitution of meaningful human relations, both social and praxeological, that witnessably surround an artworks formation. The thesis question addressed these research conditions - answering how artworks were formed by practical social actions was therefore and in part shown to be accomplished through the analytical descriptions of artwork formation. I suggested that the sociology of art already had established its own road map through the writings of Sophia Acord and Tia DeNora (2007) and further suggested this programme sought to find the missing international what in art studies (Kreplak, 2018b).

Notwithstanding the important Gurwitschian theoretical notion that no act stands alone, ethnomethodology's practical social action is contextual action, bound to the local occasion, and it is only practical for and in that self-same situation. It achieves something functionally relevant to the local social structures, the management of which is for the members to decide (and for scholars to further investigate).

Accepting ethnomethodological discoveries of social order in non-socially interactive social situations raised whether ethnomethodological studies of work were suitable for the new sociology of art. I argued that they are. This is because there is compatibility between ethnomethodological approaches to social studies of social practice in the sociology of art. This thesis argues the relations between two actions are social when they are interdependent in both person-to-person and person-to-object interaction. In both settings, a person's interdependent actions relate to another and therefore configure a socially relevant and 
meaningful organisation; a structure of social action which may feature the co-constitution of artworks as meaningful social objects. 


\section{Chapter Nine: Conclusion}

While Gurwitsch set social science on the right path when he wrote, "In this sense the object may be said to derive its existence and the meaning of its existence from intersubjectively concatenated and interlocking experiences," there remained to provide this theoretical version with its local details. (Liberman, 2011, p. 76)

\section{Answering the Research Question}

Within the dissertation's four empirical case studies — situating myself in the living conduct of what it was like putting on hiking boots and traversing river terrain with art equipment, conducting an interview with an artist at work behind his closed studio doors, sitting next to an urban sketcher measuring and drawing an urban building, and of attending a sketching group discussion where sketching books were passed around the table and evaluated, appreciated, and talked of - $-\mathrm{I}$ attempted to describe how persons in their course of actions organised their work to produce artworks.

I take ownership of the descriptions found within these empirical chapters as I suggest they do contribute to the new sociology of art literature. First, they demonstrate how the observable actions caught on film are analysable as social phenomena, constitutive of social order, and therefore, are really and truly how persons assemble the local meaning of artworks as social action. For example, actions such as pointing towards a cabbage tree on top of an island (Chapter 4) organised not only the current orientation of the walking group but also the previous utterances such as "it's over there over that fence line" and of the subsequent actions. For when the artists continued forward they encountered the river as an obstacle. These mundane features of navigation are part of the context of how the landscape was ordered; these frustrations were worked out as achievements, as practices involved in the real 
time pursuits of finding something to paint. There was no guarantee that we would make it over that fence line. All we knew was that we were heading in a direction and upon attempting to arrive at it, we were doing something organised.

The organisation of artworks in and as practical social action was clearly demonstrated as a socially relevant one, as it was full of local trouble and their artful solutions. The descriptions of which provide clear graphic representations of how artists really walk around natural terrain and orient themselves as artists for the purposes of painting. With the use of the video camera, we saw how artist's interactions unfolded on visual record to aid further study of the component actions that constitute an artwork's assembly.

By turning the topic of mundane social order into an explicit object of empirical inquiry, I pursued these empirical case studies under the explicit influence of ethnomethodological theory and its approaches (Chapter 3). The analytical task was not only one of understanding component actions but also understanding how these actions were organised, taken for granted, and yet constitutive of the orderly structure of any given activity. We could say that structure is determinate, or objective, but it is not until we get close to where the action is actually organised where we see troubles with such strong claims surface as a result.

Key among the analytical approaches taken within this thesis is the idea of endogenous orders; a term found in the writings of Aron Gurwitsch, and one further related to his key concept of functional significance. When I attended studio sessions and interviews with a local artist over the course of two years, of key interest was how that artist organised his studio work, his mark-making activity. This empirical study described how the artist used, alongside skilled action, technique, knowledge, and experience, mundane encounters, ambiguous and ad hoc solutions, episodes of practical reasoning to organise his artwork in 
real time. For example, when the artist was unable to dip his large brush into his small pot of paint, he placed that large brush onto his workbench, retrieved another smaller brush in its place, and continued with his mark-making activity. These actions are both practical and social. Social because they require reliance on both verbal and nonverbal human language.

The following actions are social acts: understanding that large things do not fit into small containers, understanding that trivial matters like these are inconsequential to professional work, and understanding that during painting these events do occur and yet they too require effacing for getting back to the main task of adding and removing light to convey spectacular imagery on two-dimensional surfaces. These are social acts, not in the sense that they involve people gathered together, but social in the sense that to do these acts requires membership of a society to meaningfully produce them. This study showed that it is not just the practical social action of painting that produced an artwork, but how the actions relate to one another in real time, and how two relationships are not observable in isolation: The assembly of interconnectedness between two actions is what constitutes the social glue used to provide concreteness of an artwork.

When sitting next to an urban sketcher and observing him sketch an object in real time it became of interest when he dropped his eraser, yet the dropping of the eraser was not itself inherently interesting. Rather, it was how the measurement can be shown to be lost. This provokes analytical interest. For example, the sketcher in using the comparative measuring technique (placing the thumb at a certain point on a pencil as it is held at a right angle upon any line within the visual field), and then translating that measurement onto his sketching pad (by keeping his thumb on the pencil and marking the distance between the two points), constituted a precise measurement. One that can be used for subsequent measuring work due to analysis of the proportions. It is not this skilled and technical manoeuvre that 
was of partial interest. Rather, it was how a gust of wind blew the eraser off the sketcher's knee, interrupting the sketch.

Because the artist had to retrieve his eraser, he lost his precision measurement (he removed his thumb from the pencil). In proceeding his sketching work, however, the artist did not return to re-measure his earlier, and now lost, thumb placement. Instead, he produced an estimate.

This new estimated measurement was subsequently and concretely marked on the page, and thus the analysis of proportions became at risk of being less precise than the earlier mark measured. Answering the thesis question, then, the sketcher's practical actions, whether professional (measuring techniques) or mundane and trivial (retrieving an eraser and approximation), organised how the artwork gained its intelligibility as a sketcher's object. Using approximation as a resource was a key finding, and the ad hoc nature of how an approximation was a contingent part of an ordinary sketching session provides information of how sketchers actually do sketching. This itself is inherently interesting as it orients the analyst around the organisational conduct that an artist may routinely perform on any given sketch work. We can relax claims that his action was determinate and instead reframe the setting as accomplished through mundane actions.

Descriptions of how artworks were formed in and as constitutive social practices are something art sociology has seldom produced. Contributing descriptive studies of the work persons do to organise the mundane social orders which may surround an artwork is something the last empirical chapter accomplished. For example, when attending a postsketching group session, several artists congregated to provide each other with their sketching books as conversational objects. Analysing the activities of how these artists talked to one another, passed these books around, and drew from language to supply the situation with words and ideas shared, subsequently demonstrated how artworks were organised, whilst 
emphasising the intersubjective. Many of the observable practical actions seen within this chapter demonstrate the interrelatedness of how one person's actions connect with another person's next action. The urban sketcher's social activities such as doing waiting and doing being polite (Chapter 7), facilitated a locally achieved yet socially organised structure of doing group talk. As the conversation seemingly had no direction, the constitutive parts to this group conversation were amplified by timings.

By observing and analysing the relationship between one member's action and another's, I came to conclude that the intersubjective episode produced a public social object (talk of artworks); and this object may exist independently of each of these actions, but not of the situation those same actions reflexively contextualise. I suggested there may be something beyond each social action (cognition, motivation, inner-speak, intention, for example), but one cannot deny the public work member's do to make this object publicly concrete. I am entirely interested in public display of action to see how that itself contributes to the assemblages of other public forces (like next actions, interruptions, facial expressions). Subsequently, this chapter was one of the clearest examples of how an artwork is organised in and as practical social actions. It touched on how the very objectivity of an artwork was rendered and maintained in the group's public seeable-hearable talking, and of doing talking about artworks.

Of the above answers to the thesis question, I claim the answers will always relate to the observability of the situation. It is not as simple as defining here the answer which may only be found in the detailed looking of the particular case. Artworks are organised in and as practical social action due to the constitutive work members do to relate one action to the next. This involves the incorporation of prior actions back into the current context or projecting possible trajectories of further actions. In all cases however, the members do the action, and the connection of these actions, whether ordinary or professional, builds up the 
constitutive details that assemble how an artwork is organised as a social object, a concrete and objective one, used to stabilise that setting's structure. Consequently, members may take these actions for granted, even dismiss them as trivial. Analytically they are possible to see, and a close inspection of these connections between actions may reveal more than what is seen in real time. These notions themselves are features of the social phenomena Garfinkel sought to explicate in both his theoretical and empirical investigations, and one that requires further exploration today.

\section{Addressing the Aims and Objectives}

The theoretical branch of this research aimed to identify how to approach the abstract attitude of Gurwitsch's ideas and apply them to empirical situations (Chapter 3). As Liberman has expressed:

While Gurwitsch (Gurwitsch (1966: 433) set social science on the right path when he wrote, "In this sense the object may be said to derive its existence and the meaning of its existence with intersubjectively concatenated and interlocking experiences," there remained to provide this theoretical version with its local details. This "intersubjective concatenation" turned out to be a gloss for worldly complexities that were imponderable for many theorists, especially on those occasions where the parties being studied have little idea themselves of what they are thinking. (Liberman, 2011, p. 76).

In this way, I hopefully can show how this study is a soft approach toward these intersubjective concatenations - not in theoretical ways but in their very empirical demonstrations. This dissertation's research focus thus remained less on the artwork, or art 
object, and more on the embodied person situated in the living world from an ethnomethodological perspective and contribution.

How members conducted their actions to organise how an artwork (or an art object) is relevant (or not) to their practical activities at hand was the primary interest of empirical inquiry. Examples include how Clive Kelly, the artist, used brushes to make marks; how Owen, the sketcher, used his pencil and thumb to make a measurement; how Freeman and Buck, the plein air artists, pointed, directed, and re-directed themselves around a natural river terrain in pursuit of something to paint; and lastly, how a group of urban sketchers passed around their sketching pads and talked about them with each other. Analytically describing the relations between one observable practical action and the next is where this thesis gained its subject matter within these case studies. How those relations observable within are made accountable as action was considered here as an accomplishment of social order.

However, it is important to further understand why art sociology should care about these descriptions. The main aim of the literature review was to identify where these descriptions could contribute to ongoing discussion and claim the relevance of the findings. When I traced the epistemological development within the new sociology of art movement, I realised the suitability of ethnomethodology's program (Garfinkel, 2002). It always seeks to provide richly described empirical studies and is compatible with the art in action approach that Acord and DeNora (2008) advocate. The aim then was to provide studies of how art is organised in action for this gap within the literature. This dissertation aimed to explicate how practical social actions organised the local meanings of artworks. It contributes several descriptive studies of the work people do to organise the mundane social orders that surround an artwork.

\section{The Significance and Implications of the Findings}


For the benefit of progressing this investigation it was necessary to consider how ordinary, public and practical actions interconnected with each other to produce accountable sense, and how descriptions of the practical actions that surround the organisation of an artwork are, significant for the new sociology of art.

Experimenting with an analytical mentality designed to explicate how the endogenous order of any social setting is organised by the people in that setting, is significant on its own merit. Yet by attaching this sentiment to the sociology of art, the implications grew due to the nature of how that literature deals with endogenous order itself. For example, I suggested in the discussion chapter (Chapter 8) the missing interactional descriptions of artistic activity are missing from the sociology of art literature. How the constitutive parts of persons' actions are organised in and as a phenomenal field, and how members orient themselves to that field is a descriptive product of this dissertation's empirical cases. These descriptions move beyond Gurwitsch — they move beyond Garfinkel's specifications of Gurwitsch's writings too. What these descriptions do is keep us orientated to how persons in the settings organise their actions to make their settings accountable for themselves and for each other.

The implications of this remark may therefore provide opportunity for art sociologists to return to the sites of where artistic work is conducted and simply describe the interconnected and thoroughgoing interdependent relations between one action and the next; to understand how these relations are made significant, or not, to the unfolding contexture of that person's activity. Against their claims that artworks are objective, our efforts may result in a rich detailed understanding of how an artwork was organised in and as a series of practical actions. These descriptions may then sit alongside other-incommensurablestudies in the new sociology of art; they may then be called for when art sociologists require understanding of how an artwork is organised by artists, not as an artistic feat, but as a sociological one, full of the mundane, ambiguous, vague, contextual, non-representable, tacit, 
and other ordinary social resources used in account productions. As my studies have attempted to show, they are only preliminary in their experimentation. I had to deal with major epistemological issues where perhaps none were needed. The design of studies for the sociology of art may take the art practice and object over and above the sociological one I have kept in main focus throughout this dissertation's empirical work.

Theoretically, I argue the findings also strengthen ethnomethodology's own stance toward the correspondence theory of truth because the artful ways members organise their action are far from representable in formal terms. This positive finding continues to challenge any epistemological stance that seeks to explain how artworks gain their meaning a priori and independent of the member's action itself. For to do so, would suggest that sociology could define the meaning of an artwork before the members produce the social meaning for the situations they are involved with producing: 'the missing interactional what' is a symptom of formal sociology, not a critique of it. An alternate is possible: one that ethnomethodology argues it can provide; one that I have attempted to show in this dissertation is possible to create by utilising this analytical mentality that Gurwitsch's theories and Garfinkel's use of them has provided.

Subsequently, the research clearly illustrates the possibility of doing such alternative descriptive work, but it also raises the question of whether these alternatives are in fact what the new sociology of art is looking for. I would suggest that any scholar working within such an ethnomethodological frame can produce these studies, including art sociologists. These descriptions may then find use within art sociology's theoretical discussions. Perhaps, as Garfinkel has always recommended, the distinction between a theoretical discussion about artwork and an ethnomethodological description of how people organise an artwork are incommensurable with one another, which I believe is a positive finding to launch enquiries from. 


\section{The Contribution}

Modern sociological literature is open for ethnomethodological-based descriptions of artwork production. As I had suggested in the discussion chapter, the topic of meaning remains just as pertinent since Becker et al first opened the theme up for empirical investigation (from an indeterminate perspective). What this thesis uniquely adds from then till now, however, is the notion of Gurwitschian theory applied to observable practical actions (as fuelled by Garfinkel's lifelong theoretical work). If nothing more was to result from this dissertation than connect the new sociology art with this notion then I would consider it a success.

The primary aim of my dissertation is perhaps the objective to expand upon ethnomethodological attitudes and apply them to settings where artworks are produced, and then offer those descriptions to the new sociology of art as interesting perspectives of how an artwork may be considered a socially accomplished one. The contribution may be considered successful if art sociologists themselves would turn, if only briefly, from formal sociological explanation, to how the ambiguities of a situation are resolved, or not, by real people, in real time, to organise their affairs in concrete, stable ways. If these descriptions are produced, then perhaps these findings would have contributed enough. This would be motivation to go out into the world and look for the ways people organise their ordinary affairs (and report back their findings for others to see and then discuss). As one opening quote of this dissertation suggested, if there is anything axiomatic to ethnomethodology, it is that social order is witnessable in any living real time situated action. Sociologists need to master this domain and increase the discussions of the social phenomena that are constitutive stable senses of social reality. Taking seriously the study of social order can only contribute further to one of sociology's original and foundational subject matters. 


\section{The Limitations of the Study}

Several major challenges of this study were encountered throughout the process. For example, the role of the researcher during fieldwork was problematic due to the way naturally occurring data ought to be collected. Why would a researcher need to be involved in the data collection process when there is readily available data found in the form of online video sharing websites such as YouTube, or even in some cases, directly from the cell phones and other video recording devices from the people themselves? Obtaining ethics approval, repetitively returning to the field to collect data and then analysing it was difficult and time consuming work.

Another major challenge was found in the analytical process itself: the tension between writing about what was happening in real time and attributing the idea that these writings were equal to the actions being described. This is a major limitation of ethnomethodological research, however, one way to solve this issue is to accept it. Written accounts can never stand on behalf of living action; the next best solution is to recognise this, and then treat written descriptions as subject to change. The result is to provide the most accurate descriptions of observable conduct possible and supply access to that data so others can see for themselves how well the descriptions hold.

These two challenges aside, the findings (that artworks are endogenously organised in and as member's practical social actions) are limited when placed in contrast to what that may say of how artworks are produced as external, independent, or theoretically defined objects. Sociologists looking for these themes will not find them in ethnomethodological based studies.

Another limitation of the study is the issue of selecting what is pertinent, perspicuous, or important to study itself. For example, although the activities I have described in this 
dissertation are significant due to their involvement in the members' own practical work, they are nonetheless of mundane subject matter. This is a limitation because, due to the amount of intellectual labour required to produce such studies, the question remains: Why study something so difficult yet mundane when one could easily study something explicitly newsworthy and find the mundane in that? This criticism is well received. However, in defence of this dissertation, I had never aimed to study such things. The aim of the dissertation was to understand how an ethnomethodological description of artwork production could be recognised in and through the theoretical writings of Aron Gurwitsch as misread by Harold Garfinkel and adapted as an empirical project for the new sociology of art to use in later subsequent studies. Epistemically it is a refresher on the accuracy that an 'ethnomethodological respecification' may bring to any analysis of social life.

\section{Further Research}

To best understand what the future of art sociology research may look like, I asked the following: What did I do, Where did I go, What did I learn? And, What would I do next? One aspect omitted from this dissertation was a first-person perspective account of how the meaning of an art object was rendered as an artistic process, of discussing how, for example, a still life, was sketched, and painted, procedurally, and in real time. In retrospect, this hybrid study of work may not have as much of a place in contemporary art literature than what I had once imagined due to it being more of an ethnomethodological study for explicating social order in workplace settings. I would therefore attempt to provide a way for studies of artistic practices to continue with studying the interconnected relationships between members' actions in artistic settings instead.

However not just in this rich descriptive way, but rather, as a fully-fledged distinction between formal counterparts, the aim of this dissertation is to challenge directly the way 
formal art sociology accounts for the meaning of an artwork. The idea that it is impossible for a general theory of meaning to explain how the social world gains its meaning is not taken further enough. I am unconvinced that ethnomethodology is completely suited to this task; for at times, ethnomethodological writers often recognise the incommensurability between formal sociology and its alternatives, whether done though the notion of lebenswelt pairs ${ }^{46}$ or any other of its related concepts (see Garfinkel, 2002).

There is a major issue between what ordinary members of society project on the possibility of formal sociological reasoning. Nowhere more pressing is in the case of in the quest for a general artificial intelligence (i.e., the possibility of fully autonomous self-driving cars; and of pronoun disambiguation technologies). I would suggest in this deeper line of the philosophy of meaning and representation, art sociologists could very well be the people who germinate a major future sociological critique against the possibility of a general theory of meaning.

A thesis of how artworks can teach us about the human ambiguities, the interconnected relationships between parts, of how persons organise their conduct for themselves and for each other in real situations to produce the stable sense of that setting, are all directions of which future research can continue to develop. Artist's know more than most about the way a body and its senses is situated in the world, and how that visual framing creates a worldview to be used in a very formal praxis (linear perspective, for example). At times we forget we have eyes that are limited to see, or bodies that sense only what we experience that which lays directly in front of us. Language is a powerful social resource-in fact, sometimes it takes us away from what is practically possible in the world itself.

\footnotetext{
${ }^{46}$ A term used to help describe any distinction between an action and a formal rule that describes that action. In the field of mathematics for example, an equation and the work of working out a formula using an equation make up a pair. Lebenswelt means "lifeworld" in the sense that life found within the world or stream of everyday life. Lebenswelt pairs are examples of formal rules on one hand, whilst informal and practical work on the other - the two are seen as belonging together.
} 
I am convinced of both Gurwitsch's and Garfinkel's solutions to the correspondence theory (as expressed in Chapter 3), but there is much left to do within this space. There is something to be said of what is not possible. Getting involved beyond the descriptions of social order, claiming that the way social order is primary to meaning, and the way that social order is unavailable to formal sociological means is not enough: arguments need to be created to suggest that because of this, certain claims are dismissible (like meaning being explained as an independent and objective entity rather than a local and related one). I am unconvinced that ethnomethodology has not taken it far enough — that there is a consequence of doing this research that undermines what members know; that the ethnomethodologist may at times know better (i.e., the horrors surrounding the representation of meaning), and therefore that persons may be taught the techniques of ethnomethodological respecification to see for themselves how accomplished they are in their organising of social order.

Ethnomethodology does have claims to have discovered this domain of social investigation (social order as a practical worked out accomplishment), but the reality is (and ethnomethodologists would agree) people live their lives without needing to know how this is accomplished in ordinary terms alone.

Future studies may therefore organise themselves around issues of where formal approaches claim they are able to predict, explain, and understand social behaviour. Of levelling a direct critique upon the work of these others, there is no reason to take an ethnomethodological position and then allow formal representation to dominate social life. This leaves the question open of what would come out of such a critique? What would the studies involve one to do? Understandably, they would seek to correct the misunderstandings and contribute to the reorientation of the possibilities of formal reasoning, reintroducing how it is in fact the situated reasonings that contribute just as much to the way the world is made orderly and accountable than it is the representations of such a formal world. 
What is more likely to happen, however, is that ethnomethodologically alternative studies are produced to remind us of how rich our social lives are when we start to look at the local contingencies that ethnomethods rely on when producing stable social orders. A collection of studies that look at these ethnomethods, and continue to learn from them ought to remain a central task. This dissertation therefore contributes to providing such alternative studies for the sociology of art. They show us that, indeed, it is possible to discover how important these local contingencies are to how ethnomethods operate in situ, of how orderly settings are made orderly. Any other expectations would be misplaced entirely, disappointingly yet deliberately so. 


\section{Bibliography}

Acord, S. (2010). Beyond the Head: The Practical Work of Curating Contemporary Art. Qualitative Sociology, 33, 447-467.

Acord, S., \& DeNora, T. (2008). Culture and the Arts: From Art Worlds to Art in Action. Annuals of the American Academy of Political and Social Science, 19(6), 223-237.

Adipa, P. (2019). Talking events: How social interaction and discourse shape cultural participation, aesthetic evaluation, and meaning-making. Poetics, 77, 101381.

Alexander, J. (2004). Cultural pragmatics: Social performance between ritual and strategy. Sociological Theory, 22(4), 527-573.

Anderson, R. J., Sharrock, W. W. (2017). Ethnomethodology: A first sociology? Retrieved from https://www.sharrockandanderson.co.uk/the-archive/ethnomethodology-2/

Arminen, I. (2008). Scientific and "Radical" Ethnomethodology: From Incompatible Paradigms to Ethnomethodological Sociology. Philosophy of the Social Sciences, 38(2), 167-191.

Armour, L. (2000). Socio-Logic and the 'Use of Colour'. In S. Hester \& D. Francis (Eds.), Local Educational Order: ethnomethodological studies of knowledge in action. Amsterdam: John Benjamin's Publishing.

Atkinson, M., \& Heritage, J. (1984). Structures of social action: studies in conversation analysis. Cambridge: Cambridge University Press.

Atkinson, P. (2006). Everyday Arias: An Operatic Ethnography. New York: Rowman \& Littlefield.

Austin, J. L. (1955). How to do things with words. Oxford: The Clarendon Press.

Bagnolo, V. (2018). Urban Sketching. Drawing on Location as a Tool for Reading Architectural and Urban Contexts, Cham.

Bar-Hillel, Y. (1954). Indexical expressions. Mind, 63(251), 359-379.

Bassetti, C. (2014). The knowing body-in-action in performing arts. Embodiment, experimental transformation, and intersubjectivity. In T. Zembylas (Ed.), Artistic Practices: Social Interactions and Cultural Dynamics. London: Routledge.

Baxandall, M. (1974). Painting and Experience in Fifteenth Century Italy: A Primer in the Social History of Pictorial Style. Oxford: Oxford University Press.

Becker, H. (1978). Art Worlds. California: University of California Press.

Becker, H., Faulkner, R., \& Kirshenblatt-Gimblett, B. (2006). Art from Start to Finish: jazz, painting, writing, and other improvisations. Chicago: The University of Chicago Press.

Bourdieu, P. (1984). Distinction: A social critique of the Judgement of Taste. London: Routledge

Button, G. (1991). Ethnomethodology and the Human Sciences. Cambridge: Cambridge University Press.

Cicourel, A. V. (1964). Method and measurement in sociology. Glencoe: Free Press of Glencoe.

Coulter, J. (1991). Logic: ethnomethodology and the logic of language. Cambridge: Cambridge University Press.

Crossley, N. (2011). Towards Relational Sociology. New York: Routledge.

Crossley, N. (2015). Relational sociology and culture: a preliminary framework. International Review of Sociology, 25(1), 65-85.

Crossley, N. (2015). Music Worlds and Body Techniques: On the Embodiment of Musicking. Cultural Sociology, 9(4), 471-492.

David, M. (2008). The correspondence theory of truth. In Stanford Encyclopaedia of Philosophy.

De La Fuente, E. (2007). The 'New Sociology of Art': Putting Art Back into Social Science Approaches to the Arts. Cultural Sociology, 1(3), 409-425. 
De La Fuente, E. (2010). The Artwork Made Me Do It: Introduction to the New Sociology of Art. Thesis Eleven, 103(1), 3-9.

De La Fuente, E. (2019). After the cultural turn: For a textural sociology. The Sociological Review, $67(3), 552-567$.

DeNora, T. (2000). Music in Everyday Life. Cambridge: Cambridge University Press.

DeNora, T. (2014). Making Sense of Reality: culture and perception in everyday life London: Sage.

Dominguez Rubio, F., \& Silva, E. B. (2013). Materials in the Field: Object-trajectories and Objectpositions in the Field of Contemporary Art. Cultural Sociology, 7(2), 161-178.

Douglas, J. (1970). Understanding Everyday Life: Toward the Reconstruction of Sociological Knowledge. Chicago: Aldine Publishing Company.

Eyerman, R. (2006). Toward a meaningful sociology of the arts. Myth, meaning, and performance: Toward a new cultural sociology of the arts, 13-34.

Eyerman, R., \& Magnus, R. (1998). Towards a New Sociology of Art Worlds: Bringing Meaning Back In. Acta Sociological, 41(3), 277-283. Retrieved from http://www.jstor.org/stable/4201087

Fele, G. (2008). The phenomenal field: ethnomethodological perspectives on collective phenomena. Human Studies, 31, 299-322.

Fitzgerald, R., \& Housley, W. (2016). Introduction to Membership Categorisation Analysis. London: Sage.

Fox, N. (2013). Creativity, anti-humanism and 'the new sociology of art'. Journal of Sociology, $51(3), 522-536$.

Garfinkel, H. (1952). The perception of the Other: A study in Social Order. (PhD). Harvard, Cambridge, Mass.

Garfinkel, H. (1967). Studies in Ethnomethodology. New Jersey: Prentice Hall.

Garfinkel, H. (1988). Evidence for Locally Produced, Naturally Accountable Phenomena of Order, Logic, Reason, Meaning, Method, etc. In and as of the Essential Quiddity of Immortal Ordinary Society, (I of IV): An Announcement of Studies. Sociological Theory, 6(1), 103109.

Garfinkel, H. (1991). Respecification: evidence for locally produced, naturally accountable phenomena of order*, logic, reason, meaning, method, etc. in and as of the essential haecceity of immortal ordinary society, (I) - an announcement of studies. (G. Button Ed.). Cambridge: Cambridge University Press.

Garfinkel, H. (1993). Ethnomethodology Misreading of Gurwitsch--Phenomenal Field Tape 1 of 2, Side 1.

Garfinkel, H. (2002). Ethnomethodology's Program: Working out Durkheim's Aphorism. Oxford: Rowman \& Littlefield.

Garfinkel, H. (2007). Four Relations between Literatures of the Social Scientific Movement and their Specific Ethnomethodological Alternates. In S. Hester \& D. Francis (Eds.), Orders of Ordinary Action: Respecifying Sociological Knowledge. Aldershot: Ashgate.

Garfinkel, H., \& Liberman, K. (2007). Introduction: The Lebenswelt origins of the sciences. Human Studies, 30(1), 3-7.

Garfinkel, H., Lynch, M., \& Livingston, E. (1981). I.1 The Work of a Discovering Science Construed with Materials from the Optically Discovered Pulsar. Philosophy of the Social Sciences, 11(2), 131-158.

Garfinkel, H., \& Sacks, H. (Eds.). (1970). On formal structures of practical actions. New York: Appleton Century-Crofts.

Garfinkel, H., \& Wieder, L. (1992). Two incommensurable, asymmetrically alternate technologies of social analysis. In G. Watson \& R. Seiler (Eds.), Text in context: studies in ethnomethodology (pp. 175-206). Newbury Park: Sage. 
Gerber, A., \& Klett, J. (2014). The Meaning of Indeterminacy: Noise Music as Performance. Cultural Sociology, 8(3), 275-290.

Goffman, E. (1983). The Interaction Order: American Sociological Association, 1982 Presidential Address. American Sociological Review, 48(1), 1-17.

Gomart, E., \& Hennion, A. (1999). A Sociology of Attachment: Music Amateurs, Drug Users. The Sociological Review, 47(1_suppl), 220-247.

Goode, D. (1994). A world without words: The social construction of children born deaf-blind. Philadelphia: Temple University Press.

Goode, D. (2007). Playing with my Dog Katie. An Ethnomethodological Study of Dog-Human Interaction. West Lafayette, Indiana: Purdue University Press.

Goodwin, C. (1994). Professional Vision. American Anthropologist, 96(3), 606-633.

Goodwin, C. (2000). Practices of color classification. Mind, culture, and activity, 7(1-2), 19-36.

Goodwin, C. (2013). The co-operative, transformative organization of human action and knowledge. Journal of Pragmatics, 46(1), 8-23.

Goodwin, C. (2018). Why Multimodality? Why Co-Operative Action? Social Interaction. VideoBased Studies of Human Sociality, 1(2).

Goodwin, M. H., Cekaite, A. (2018). Embodied Family Choreography. London: Routledge.

Griswold, W., Mangione, G., \& McDonnell, T. E. (2013). Objects, Words, and Bodies in Space: Bringing Materiality into Cultural Analysis. Qualitative Sociology, 36(4), 343-364.

Gurwitsch, A. (1964). The Field of Consciousness. Pittsburgh: Duquesne University Press.

Gurwitsch, A. (2010). The Collected Works of Aron Gurwitsch (1901-1973) (Vol. III: The Field of Consciousness: Theme, Thematic Field, and Margin).

Hanks, W. F. (1992). The indexical ground of deictic reference (pp. 43-76). Cambridge: Cambridge University Press.

Hauser, A. (1982). The Sociology of Art. Chicago: University of Chicago.

Heath, C., Hindmarsh, J., \& Luff, P. (2010). Video in Qualitative Research. Analysing Social Interaction in Everyday Life. London: Sage.

Heath, C., \& Luff, P. (2007). Ordering competition: the interactional accomplishment of the sale of art and antiques at auction. The British Journal of Sociology, 58, 63-85.

Heath, C., \& vom Lehn, D. (2004). Configuring Reception: (Dis)-Regarding the "spectator" in Museums and Galleries. Theory, Culture and Society, 21(6), 43-65.

Hennion, A. (2004). Pragmatics of tase. In M. Jacobs \& N. Hanrahan (Eds.), The Blackwell Companion to the Sociology of Culture (pp. 131-144). New York: Blackwell Publishing.

Hennion, A. (2007). Those Things That Hold Us Together: Taste and Sociology. Cultural Sociology, $1(1)$.

Hennion, A. (2019). Objects, Belief, and the Sociologist: The Sociology of Art as a Work-To-BeDone. In A. Smuditis (Ed.), Roads to Music Sociology. Musik und Gesellschaft: Springer.

Hennion, A., \& Grennier, L. (1999). Chapter 16: Sociology of Art: New Stakes in. Post-Critical Time. In S. R. Quah \& A. Sales (Eds.), The International Handbook of Sociology (pp. 341355). London: SAGE Publications.

Heritage, J. (1984). Garfinkel and Ethnomethodology. Cambridge: Polity.

Hester, S., \& Francis, D. (2007). Analysing orders of ordinary action. Aldershot: Ashgate.

Hilbert, R. (2007). Ethnomethodology and social theory. In The New Blackwell Companion to Social Theory. Edited by Bryan S. Turner. Oxford. Blackwell Publishing Ltd.

Hurdley, R. (2016). Everyday life. London: Sage.

Husserl, E. (1990). Logical Investigations (J. N. Findlay, Trans.). London: Routledge. Inglis, D., \& Hughson, J. (2005). The Sociology of Art: Ways of Seeing. UK: Macmillan Education. Kim, K.-M. (1999). The Management of Temporality: Ethnomethodology as Historical Reconstruction of Practical Action. The Sociological Quarterly, 40(3), 505-523. Retrieved from http://www.jstor.org/stable/4121339 
Kobyshcha, V. (2018). How Does an Aesthetic Object Happen? Emergence, Disappearance, Multiplicity. Cultural Sociology, 12(4), 478-498.

Kreplak, Y. (2015). Discovering $a<<$ perspicuous setting $>>$ : describing artworks as praxeological objects. Paper presented at the International Institute for Ethnomethodology and Conversation Analysis, Kolding (Denmark).

Kreplak, Y. (2017). Docile Documents. Propositions for a reading of the documentation of collections. In E. Bullot \& S. Grassi (Eds.), Document bilingue (201-204). Marseille: Mucem/Manuella Editions.

Kreplak, Y. (2018). Artworks in and as practices. The relevance of particulars. In P. Sormani, G. Carbone, \& G. Priska (Eds.), Practicing Art/Science: Experiments in an Emerging Field. London: Routledge.

Kreplak, Y. (2018). On Thick Records and Complex Artworks: A study of Record-Keeping Practices at the Museum. Human Studies, 41(4), 697-717.

Latour, B. (2005). Reassembling the Social: An Introduction to Actor-Network-Theory. Oxford: Oxford University Press.

Laurier, E. (2009). Ethnomethodology/Ethnomethodological Geography. In R. Kitchin \& N. Thrift (Eds.), International Encyclopaedia of Human Geography (pp. 632-637). Oxford: Elsevier.

Laurier, E. (2014). The Graphic Transcript: Poaching Comic Book Grammar for Inscribing the Visual, Spatial and Temporal Aspects of Action. Geography Compass, 8(4), 235-248.

Levinson, S. C. (1983). Pragmatics. Cambridge: Cambridge University Press.

Lewis, D. (1972). We, the Navigators. The Ancient Art of the Landfinding in the Pacific. University of Hawaii Press.

Liberman, K. (2007). Husserl's Criticism of Reason: with Ethnomethodological Specifications. New York: Lexicon Books.

Liberman, K. (2011). The reflexive intelligibility of affairs: Ethnomethodological perspectives. Cahiers Ferdinand de Saussure Revue suisse de linguistique générale, 64, 73-99.

Liberman, K. (2013). More Studies in Ethnomethodology. New York: Lexicon Books.

Liberman, K. (2018). Objectivation practices. Social Interaction. Video-Based Studies of Human Sociality, 1(2).

Lindwall, O., \& Lymer, G. (2005). Vulgar competence, ethnomethodological indifference and curricular design. Mahwah, NJ: Lawrence Erlbaum Associates.

Livingston, E. (1987). Making Sense of Ethnomethodology. London: Routledge and Kegan Paul.

Livingston, E. (2003). Reading Ethnomethodology's Program. Research on Language and Social Interaction, 36(4), 481-486.

Livingston, E. (2016). Ethnographies of Reason. Aldershot: Ashgate.

Lynch, M. (1985). Art and Artifact in Laboratory Science: A Study of Shop Work and Shop Talk. London: Routledge \& Kegan Paul.

Lynch, M. (1988). The externalized retina: Selection and mathematization in the visual documentation of objects in the life sciences. Human Studies, 11(2), 201-234.

Lynch, M. (1991). Method: measurement - ordinary and scientific measurement as ethnomethodological phenomena. (G. Button Ed.). Cambridge: Cambridge University Press.

Lynch, M. (2011). The Origins of Ethnomethodology: Elsevier Science \& Technology.

Lynch, M. (2012). Revisiting the Cultural Dope. Human Studies, 35(2), 223-233.

Lynch, M. (2015). Garfinkel's Studies of Work. Oxford: Oxford University Press.

Lynch, M. (2019). Garfinkel, Sacks and Formal Structures: Collaborative Origins, Divergences and the History of Ethnomethodology and Conversation Analysis. Human Studies, 42(2), 183 198. 
Lynch, M., \& Bjelic, D. (1992). The work of a (scientific) demonstration: respecifying Newton's and Goethe's theories of prismatic color. London: Sage.

Macbeth, D. (1999). Glances, trances and their relevance for a visual sociology. In Media Studies" Ethnomethodological Approaches, edited by P. L. Jalbert. Lanham MD: University Presses of America.

Mair, M., \& Sharrock, W. (2019). Harold Garfinkel: SAGE.

Maynard, D., \& Clayman, S. (1991). The Diversity of Ethnomethodology. Annual review of Sociology, 17, 385-420.

Maynard, D. W. (2014). Social Actions, Gestalt Coherence, and Designations of Disability: Lessons from and about Autism. Social Problems, 52(4), 499-524.

McCormick, L. (2019). Moving beyond production: Ron Eyerman and the cultural sociology of the arts. American Journal of Cultural Sociology, 7(2), 247-259

Mcllvenny, P. (2020). The future of 'video' in video-based qualitative research is not 'dumb' flat pixels! Exploring volumetric performance capture and immersive performative replay.. Qualitative Research.

Mondada, L. (2006). Video recording as the reflexive preservation and configuration of phenomenal features for analysis. In Knoblauch, Hubert, Schnettler, Bernt, Raab, Jürgen, Soeffner, \& G. Hans (Eds.), Video analysis: methodology and methods: qualitative audiovisual data analysis in sociology (pp. 51-68): Lang.

Parsons, T. (1937). The structure of social action. New York: McGraw-Hill.

Peirce, C. S. (1958). The Collected Papers of Charles Sanders Peirce (A. W. Burks Ed.Vol. VII: Science and Philosophy). Cambridge: Harvard University Press.

Pollner, M. (2012). The End(s) of Ethnomethodology. The American Sociologist, 43(1), 7-20. doi:10.1007/s12108-011-9144-z

Prandini, R. (2015). Relational sociology: a well-defined sociological paradigm or a challenging 'relational turn' in sociology? International Review of Sociology, 25(1), 1-14. doi:10.1080/03906701.2014.997969

Rawls, A. W. (2008). Harold Garfinkel, Ethnomethodology and Workplace Studies. Organization Studies, 29(5), 701-732. doi:10.1177/0170840608088768

Rawls, A. W. (2011). Wittgenstein, Durkheim, Garfinkel and Winch: Constitutive Orders of Sensemaking. Journal for the Theory of Social Behaviour, 41(4), 396-418.

Rimmer, M. (2020). Trans-Actions in Music. In C. Morgner (Ed.), John Dewey and the Notion of Trans-action: A Sociological Reply on Rethinking Relations and Social Processes (pp. 111141). Cham: Springer International Publishing.

Rooke, J., \& Seymour, D. (2005). Studies of Work: Achieving Hybrid Disciplines in IT Design and Management Studies. Human Studies, 28(2), 205-221.

Rubio, D. F. (2012). The material production of the Spiral Jetty: a study of culture in the making. Cultural Sociology, 6(2), 143-161.

Ruggerone, L., \& Jenkins, N. (2015). Talking about Beauty: A Study of Everyday Aesthetics among Low-Income Citizens of Milan. Symbolic Interaction, 38(3), 393-412.

Sacks, H. (1995). Winter 1967. In Lectures on Conversation (pp. 513-546).

Schegloff, E. (1984). On some questions and ambiguities in conversation. Cambridge: Cambridge University Press.

Schegloff, E. A., \& Sacks, H. (1973). Opening up Closings. Semiotica, 8(4).

Schutz, A. (1967). The Phenomenology of the Social World. Evanston, IL. Northwestern University Press.

Sharrock, W. W., \& Anderson, B. (1991). Epistemology and Professional Scepticism. Cambridge: Cambridge University Press.

Sharrock, W. W., \& Anderson, R. J. (1986). The Ethnomethodologists. London: Routledge. 
Silverstein, M. (1976). Shifters, linguistic categories, and cultural description. Meaning in anthropology, 11-55.

Strandvad, S. M. (2012). Attached by the Product: A Socio-Material Direction in the Sociology of Art. Cultural Sociology, 6(2).

Suchman, L. (1987). Plans and situated actions: the problem of human-machine communication. New York: Cambridge University Press.

Sudnow, D. (1978). Ways of the Hand. Cambridge: Polity Press.

Tanner, J. (2010). Michael Baxandall and the Sociological Interpretation of Art. Cultural Sociology, 4(2), 231-256.

Tolmie, P., Benford, S., \& Rouncefield, M. (2013). Playing in Irish music sessions. London: Routledge.

Vom Lehn, D. (2014). Harold Garfinkel: The Creation and Development of Ethnomethodology. London: Routledge.

Watson, R. (2008). Comparative Sociology, Laic and Analytic: Some Critical Remarks on Comparison in Conversation Analysis. Cahiers de praxematique, 50, 203-244.

Watson, R. (2016a). De-Reifying Categories.. In R. Fitzgerald \& W. Housley (Eds.), Advances in Membership Categorisation Analysis. London: Sage.

Watson, R. (2016b). Harold Garfinkel and Pragmatics. In J. Östman \& V. Jef (Eds.), Handbook of Pragmatics (Vol. 20). Online: John Benjamin's Publishing Company.

Wilson, T. (1970). Normative and Interpretive Paradigms in Sociology. Chicago: Aldine Publishing Company.

Wowk, M. T., \& Carlin, A. P. (2004). Depicting a Liminal Position in Ethnomethodology, Conversation Analysis and Membership Categorization Analysis: The Work of Rod Watson. Human Studies, 27(1), 69-89.

Zembylas, T. (Ed.) (2014). Artistic Practices: Social Interactions and Cultural Dynamics. New York: Routledge.

Zolberg, V. (1990). Constructing a Sociology of the Arts. New York: Cambridge University Press.

Zolberg, V. (2015). A Cultural Sociology of the Arts. Current Sociology, 63(3), 896-915. 


\section{Appendix}

\section{General Ethics: Signed Consent, Anonymisation, and Data Management}

This dissertation has two separate approved ethics applications asking for consent to film and research members of the public. The first ethics application gained signed consent from two individual artists, whilst the second ethics application gained signed consent from the urban sketching group members.

I applied for the first round of ethics on the $6^{\text {th }}$ August 2017. The university approved the ethics application eleven months later, $19^{\text {th }}$ of July 2018. I had conducted interviews prior to gaining ethical approval, as there were delays with the ethics, however none of these interviews were recorded nor was any data obtained. Only once the ethics was approved and signed did filming occur.

The approved research information sheets and the participant consent forms were sent from me to the Artist-participants via email (see Appendix, document 1). The information sheet asks whether the artist accepts being involved with a video-recorded interview about their artistic process in their studio for one hour.

The second round of ethics was approved by the University ethics committee on $1^{\text {st }}$ of May 2019. These approved research information sheets and the participant consent forms were provided to members of the sketching group via forwarded email from me to the group's acting secretary (see Appendix 2).

These consent forms are made of two parts, the first form asks members of the group for consent to be researched in general, while the second form asks whether members of the group are interested in being involved in the research on that specific day of recording. This two-step consent procedure was put in place due to the public and self-organising nature of the group: some members may want to participant in their weekly sketching activities without 
the pressure of being involved in research. On these cases, I would avoid filming nonconsenting members by either turning the camera off or covering both the camera's lens and microphone. Any data that identified non-consenting members was disregarded if obtained.

As some of the artist members were reluctant to sign new forms on each filming session, they offered joint consensus on being freely filmed in subsequent sessions. At this point in the research, all the members had offered signed consent in earlier studies and as the rapport was strong enough, each member felt comfortable being video recorded around the café table. I had also advised the group I was recording and asked verbal consent to film, and to state if they would not like to be filmed as I could avoid using data that featured them; in addition, moving the camera around the table was in no way covert.

Obtaining signed consent forms and securely managing data enabled me to render raw materials into presentations to discuss. I transformed video data into images presented in the following cases in accordance with the signed ethics agreement. The participants did not request pseudonym and/or pixilation anonymisation on any written materials. This caused no concern to remove the name of the participants from the documents, including no requirement to avoid any imagery detailing participants faces within transcripts. In short, all participants granted full consent to be filmed without anonymity.

The Victoria University of Wellington stipulates data captured from doctoral fieldwork remain stored on a secure H-drive. I transferred the data from the GoPro's memory card to the university's server after the completion of each field session. I downloaded these video files to a university computer when analysis was required. I deleted any materials from the university computer once the written materials had begun to form during the drafting stage of this research. All remaining records were uploaded securely back to the H-drive. The handling of data was conducted behind closed university office doors and video materials were never left unattended. 


\title{
Ethics Consent Information Sheets (Artists).
}

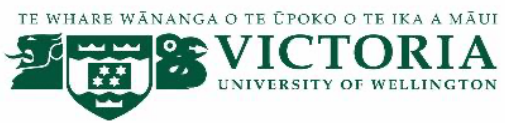 \\ Doing Art behind closed studio doors \\ INFORMATION SHEET FOR PARTICIPANTS
}

\begin{abstract}
Who am I?
My name is Max Baddeley and I am PhD student in Sociology at Victoria University of Wellington and this research is part of my doctoral thesis. You are invited to take part in this research. Please read this information before deciding whether or not to take part. If you decide to participate, thank you. If you decide not to participate, thank you for considering this request. This research has been approved by the Victoria University of Wellington Human Ethics Committee; Application ID: 0000025231.
\end{abstract}

\section{What do I aim to do?}

If an artist were to watch themselves at work, how would they describe their own activity? Understanding how embodied artistic action is translated into words is a major topic and challenge for contemporary research within the sociology of art. The aim of my project is to observe and describe the working process of how an artist accounts for their own activity after producing a work of art. In order to address this goal, I wish to work with artists who are interested in recording themselves for roughly forty minutes once a week while they work. I wish to meet regularly for follow-up video-recorded interviews where the tapes will be watched and talked about in the artist's studio for one hour once a week over six weeks.

\section{How can you help?}

You have been invited to participate because you are an artist who works consistently throughout the year in your own studio space. It is anticipated that you work alone and are willing to video-record yourself for at least forty minutes a week as you work on current creative projects. If you agree to take part in this research I will ask three things of you:

1. To extend an invitation to visit your place of work in order to conduct an hour long video-recorded 'studio tour' and discuss the creative process in current projects with the researcher present.

2. To naturally record yourself working for roughly forty minutes on an art object as you work throughout your normal working schedule without the researcher present.

3. To organise six weekly one hour follow up meetings to discuss what the 'work tapes' consist of. These meetings will be recorded with the researcher present.

These sessions would ideally continue over the duration of a complete work of art, series or project. To limit the burden on your end, the scheduling details are flexible and will be worked to suit your availability and personal needs.

You can choose to not answer any question or stop the session at any time, without giving a reason. You can withdraw from the study by contacting me at any time from the beginning of the research. If you withdraw during the research, the information you provided will kept and any copies will be returned to you. The research is not confidential, and you will be named in the final report. 


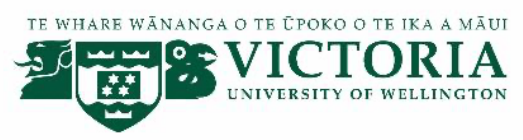

\section{Doing art in and beyond closed studio doors \\ CONSENT TO INTERVIEW}

This consent form will be held for three years.

Researcher: Max Baddeley, Sociology, Victoria University of Wellington.

- I have read the Information Sheet and the project has been explained to me. My questions have been answered to my satisfaction. I understand that I can ask further questions at any time.

- I agree to take part in a video and audio recorded interview in my studio

- I agree to take part in the study by recording myself at work once a week for forty minutes

- I agree to take part in the study by meeting once a week for six weeks to discuss my recorded tapes. These meetings will be video recorded.

I understand that:

- I may withdraw from this study at any point during the research and any information that I have provided will be returned to me or destroyed.

- $\quad$ Any information I provide will not be kept confidential to the researcher and their supervisors

- I understand that the results will be used for a PhD dissertation, academic publications and conferences

- I would like a copy of the recording of my interview: Yes $\square$ No $\square$

- I would like a copy of the transcript of my interview: $\quad$ Yes $\square$ No $\square$

- I would like to receive a copy of the final report and have added my email address Yes $\square$ No $\square$ below.

Signature of participant:

Name of participant:

Date:

Contact details: 


\title{
Ethics Consent Information Sheets (Sketchers).
}

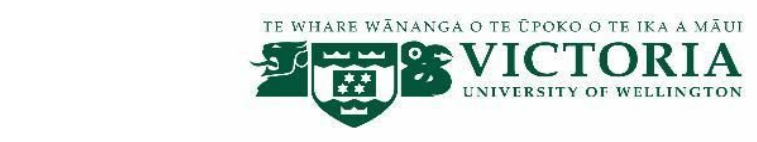

\section{Doing observational sketching in urban settings}

INFORMATION SHEET FOR PARTICIPANTS

\begin{abstract}
Who am I?
My name is Max Baddeley and I am PhD student in Sociology at Victoria University of Wellington and this research is part of my doctoral thesis. You are invited to take part in this research. Please read this information before deciding whether or not to take part. If you decide to participate, thank you. If you decide not to participate, thank you for considering this request. This research has been approved by the Victoria University of Wellington Human Ethics Committee; Application ID: 0000027180.
\end{abstract}

\section{The aim of the project}

I wish to work with an urban sketching group who have members that are interested in being recorded for eight meetups while they sketch in urban settings around the greater Wellington region. For an urban sketcher, the mundane work that surrounds drawing is familiar, but it is strange for an outsider. How do artists turn socially available resources into skilled domains of expertise? The aim of this project is to video-record a group of artists drawing directly from observation in public settings. The goal of the research is to observe, describe and understand how a group of urban sketchers organise public settings to produce work, and how they can use that order to record commonly experienced everyday settings in artistic ways.

\section{How can you help?}

You have been invited to participate because you are an urban sketcher who regularly participates in urban sketching. It is anticipated that you will sketch in a group for this project. Your participation is voluntary. If you do not wish to participate, you can still attend the session and will not be recorded. If you agree to take part in this research I will ask two things of you:

1. Turn up to your normal group drawing sessions whilst being open to the possibility of being video recorded with a small hand-held GoPro camera. You can choose on the day whether you wish to be filmed or not.

2. If you choose not to be recorded, to allow the presence of a researcher with a camera to film other group members.

Although this project is not an interview-based research project, some contextual questions may be asked during filming. I will to the best of my ability be undisruptive to the group by not interrupting members interacting with one another. Avoiding the distraction of non-participants is a priority. This will be helped by speaking and moving quietly with care. Participants can choose to not answer any question or ask for the filming to stop without giving a reason. If you choose to be filmed on the day, and then change your mind, I will continue to film other consenting members of the group, however I will stop filming you for 


\section{Doing observational sketching in urban settings}

CONSENT TO RESEARCH

This consent form will be held for three years.

Researcher: Max Baddeley, Sociology, Victoria University of Wellington.

- I have read the Information Sheet and the project has been explained to me. My questions have been answered to my satisfaction. I understand that I can ask further questions at any time.

- In principle, I agree to be video and audio recorded during future drawing sessions.

I understand that:

- On the day of drawing, I will be provided with a form asking if I am willing to be recorded for that particular day.

- Participation is voluntary, and If I do not want to participate I can still attend the sessions and will not be recorded. The researcher will be as non disruptive as possible, speaking and moving quietly.

- I may withdraw from this study upto any point until July 1st. Any information that I have provided via videorecording will be edited out of the tapes and destroyed.

- $\quad$ Any information I provide will be kept confidentially through the use of pseudonyms and pixelation in all the written and visual materials produced from the recordings.

- I understand that the results will be used for a PhD dissertation, academic publications and conferences.

- I would like a copy of the my materials being used in publication:

Yes $\square \quad$ No $\square$

- I would like to receive a copy of the final report. I have added my email address

Yes $\square \quad$ No $\square$ below.

Signature of participant:

Name of participant:

Date:

Contact details: 